ALINE DURRER PATELLI JULIANI

\title{
Projeto e Construção de um Motor Elétrico Linear Aplicado à Bioengenharia
}





\section{ALINE DURRER PATELLI JULIANI}

\section{Projeto e Construção de um Motor Elétrico Linear Aplicado à Bioengenharia}

Tese apresentada à Escola de Engenharia de São Carlos, da Universidade de São Paulo, como parte dos requisitos para a obtenção do Título de Doutora em Ciências, Programa de Engenharia Elétrica.

Área de Concentração: Sistemas Dinâmicos

Orientador: Prof. Dr. Diógenes Pereira Gonzaga 


\section{AUTORIZO A REPRODUÇÃO E DIVULGAÇÃO TOTAL OU PARCIAL DESTE TRABALHO, POR QUALQUER MEIO CONVENCIONAL OU ELETRÔNICO, PARA FINS DE ESTUDO E PESQUISA, DESDE QUE CITADA A FONTE.}

Ficha catalográfica preparada pela Seção de Tratamento da Informação do Serviço de Biblioteca - EESC/USP

$\mathrm{J} 94 \mathrm{p}$

Juliani, Aline Durrer Patelli

$9 \mathrm{p}$

Projeto e construção de um motor elétrico linear aplicado à bioengenharia / Aline Durrer Patelli Juliani ; orientador Diógenes Pereira Gonzaga. -- São Carlos, 2011.

Tese (Doutorado-Programa de Pós-Graduação em Engenharia Elétrica e Área de Concentração em Sistemas Dinâmicos) -- Escola de Engenharia de São Carlos da Universidade de São Paulo, 2011.

1. Máquinas elétricas. 2. Método dos elementos finitos. 3. Motores elétricos - controle.

4. Bioengenharia. 5. Membros artificiais. I. Título. 
FOLHA DE JULGAMENTO

Candidato(a): Engenheiro Eletricista ALINE DURRER PATELLI JULIANI.

Tese defendida e julgada em 14/01/2011 perante a Comissão Julgadora:

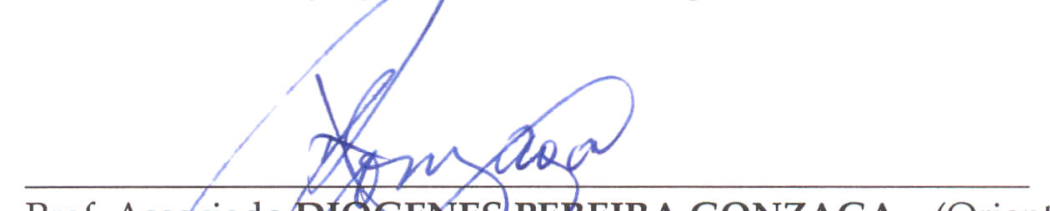

Prof. Assøciado/DIOGENES) PEREIRA GONZAGA - (Orientador)

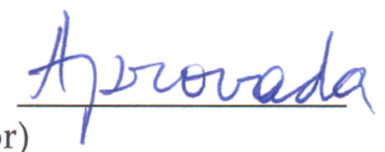

(Escola de Engerthario de Săo Carlos/USP)

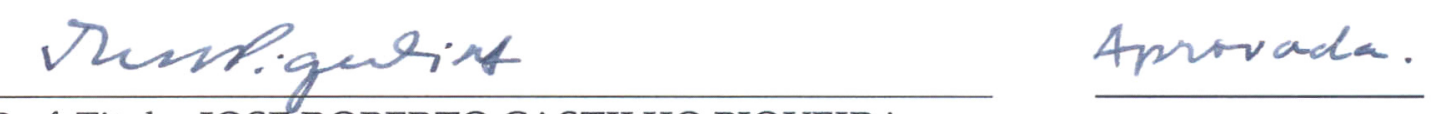

Prof. Titular JOSE ROBERTO CASTILHO PIQUEIRA

(Escola Politécnida/USP)

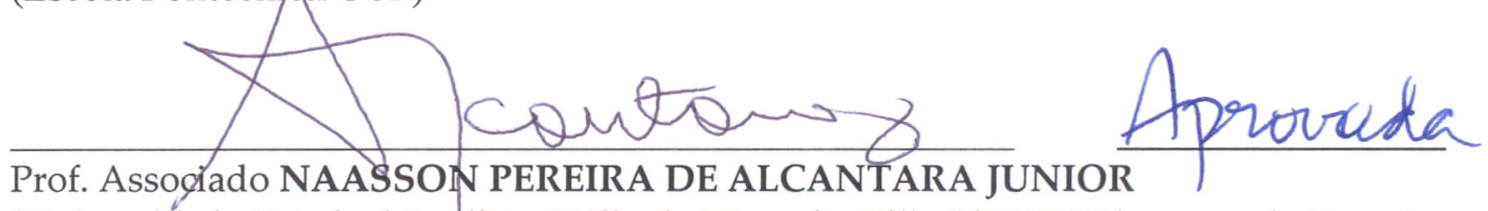

(Universidade Estadual Paulista "Júlio de Mesquita Filho"/UNESP/campus de Bauru)

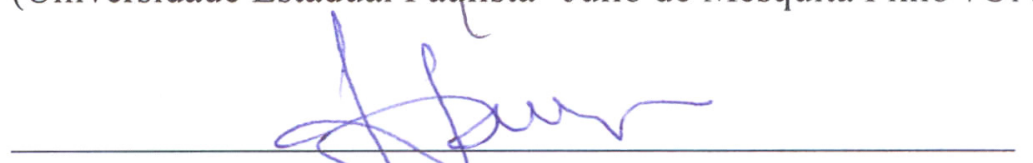

Prof. Dr. MANOEL LUIS DE AGUIAR

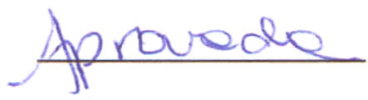

(Escola de Engenharia de São Carlos/USP)

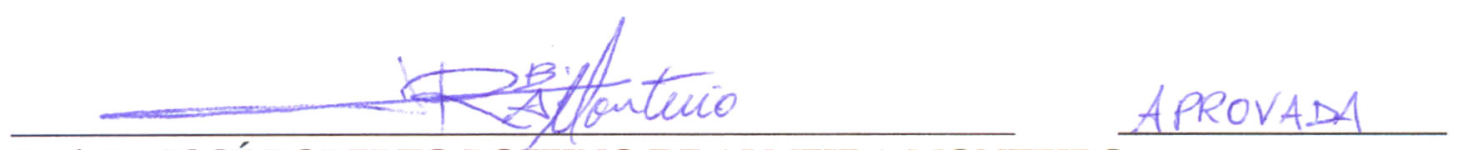

Prof. Dr. JOSÉ ROBERTO BOFFINO DE ALMEIDA MONTEIRO

(Escola de Engenharia de São Carlos/USP)
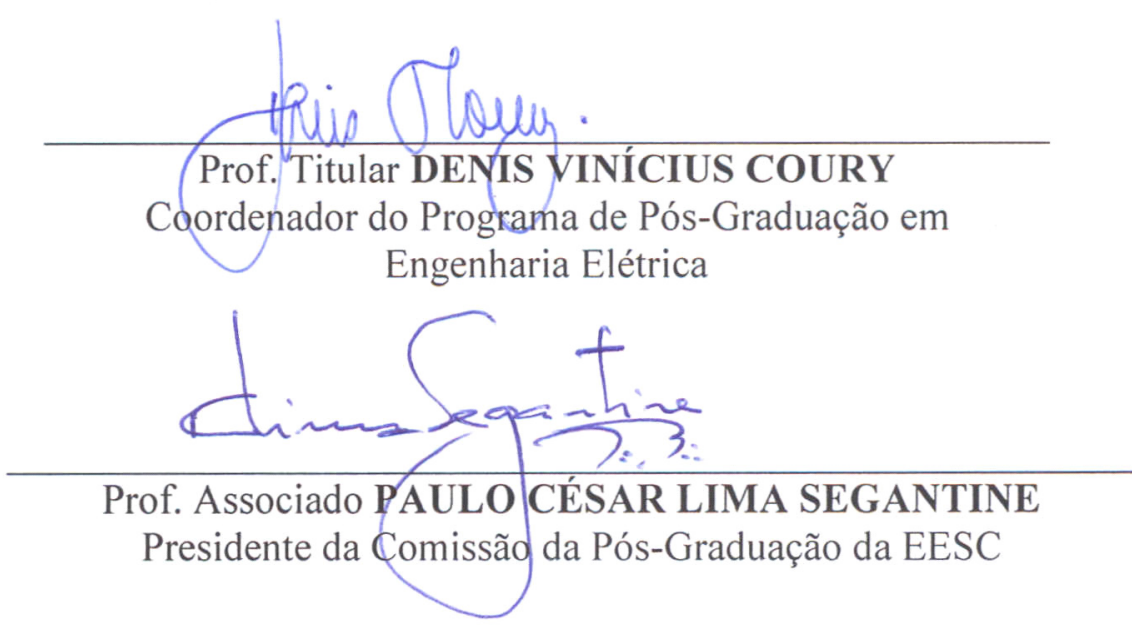

Dedico este trabalho a minha mãe Fátima, ao meu noivo Alex e ao meu irmão Allan, pela dedicação e compreensão. 


\section{AGRADECIMENTOS}

À Fundação de Amparo à Pesquisa do Estado de São Paulo, pela concessão da bolsa de doutorado e pelo apoio financeiro para a realização desta pesquisa.

Ao Prof. Dr. Diógenes P. Gonzaga pela excelente orientação e por optar pelo adiamento de sua aposentadoria para a realização deste trabalho.

Ao Rui Bertho pelo auxílio e pelas ideias na execução da parte prática do projeto, que foram essenciais para a sua completa realização.

Ao Prof. Dr. Manoel L. de Aguiar pelas sugestões e pelos ensinamentos na área de acionamento e controle de máquinas elétricas.

Ao Prof. Dr. José Roberto B. de A. Monteiro pelo auxílio no acionamento do motor linear e pela concessão do uso do laboratório.

Ao Prof. Dr. Geraldo R. M. da Costa por ceder um espaço no Laboratório de Análise de Sistemas de Energia Elétrica para a realização deste projeto.

Ao Prof. Dr. Alberto Cliquet Jr. pela ajuda nos assuntos relacionados à área de Bioengenharia e pelo uso do laboratório.

As minhas amigas Cristiane L. Zeferino e Scheila V. Biehl pelo apoio.

À Prof. Angela C. P. Giampedro por revisar os textos na língua Inglesa.

Ao Prof. Dr. Maurício B. de C. Salles por viabilizar o intercâmbio com a universidade RWTH Aachen.

Ao Prof. Dr. Kay Hameyer pelo convite para visitar o Institut für Elektrische Maschinen.

Ao Eng. Marc Lessmann pela ajuda no uso do software iMOOSE e pelas sugestões.

Ao Eng. Ronald J. Z. Dangel pelo auxílio na área de bioengenharia. 


\section{RESUMO}

JUliAni, A. D. P. Projeto e Construção de um Motor Elétrico Linear Aplicado à Bioengenharia. 2011. 147 f. Tese - Escola de Engenharia de São Carlos, Universidade de São Paulo, São Carlos, 2011.

Considerando-se o atual estágio de desenvolvimento das máquinas elétricas, tanto em termos de ferramentas computacionais auxiliares nas simulações e nos projetos, quanto de materiais e sistemas eletrônicos de acionamento e controle, propõe-se neste trabalho a construção de um dispositivo eletromecânico, na classe dos motores elétricos lineares, que atenda às necessidades e se aplique à bioengenharia, mais propriamente às próteses de membro superior, na forma de acionador translacional. Este dispositivo deve substituir os sistemas que utilizam motores elétricos rotativos com mecanismos de adaptação mecânica (roldanas, vários fios, redutores), que convertem o movimento rotacional em linear. Também, os dispositivos híbridos, como atuadores eletro-hidráulicos e eletropneumáticos, que necessitam de fontes de energia de naturezas diferentes da eletroeletrônica, podem ser substituídos pelas máquinas elétricas lineares. Uma revisão dos conceitos relacionados à área de bioengenharia é feita, destacando-se os mecanismos de transmissão existentes. É apresentada uma análise comparativa entre os principais motores lineares, enfatizando-se as características construtivas, as vantagens e as desvantagens de cada um, relacionados à aplicação. A escolha da máquina a ser projetada e construída recaiu no motor linear síncrono, com ímãs permanentes na superfície da parte móvel, em uma estrutura tubular. Para esta máquina, é exposta uma metodologia de projeto, baseando-se nos seguintes tópicos: equacionamento do circuito magnético, cálculos de parâmetros utilizando-se o método dos elementos finitos e modelagem matemática por meio das equações por fase. Após a etapa teórica, a construção da máquina é apresentada juntamente com os ensaios experimentais, possibilitando a comparação das características reais em relação ao projeto inicial. Por fim, o motor é aplicado ao dedo artificial, verificando-se a sua capacidade de substituição do motor rotativo.

Palavras-chave: Máquinas Elétricas; Motores Lineares; Método dos Elementos Finitos; Acionamento e Controle; Bioengenharia; Próteses de Membro Superior. 


\begin{abstract}
JULIANI, A. D. P. Design and Construction of a Linear Electric Motor Applied to Bioengineering. 2011. 147 p. Thesis - São Carlos School of Engineering, São Paulo University, São Carlos, 2011.

By means of the latest technological advances of the electrical machines, both in terms of computational aids in simulations and designs, materials and electronic systems of drive and control, this work put forward the construction of an electromechanical device, in the class of the linear motors. It will be applied to bioengineering area, in particular in upper limb prostheses, in the form of a translational actuator. This linear motor must substitute the systems that use electric rotational motors with planetary gears and lead screw transmission, to convert the rotational movement into linear. The hybrid mechanisms, like electro pneumatic/hydraulic actuators, which need energy sources different from electronics, can be changed for the linear electric machines too. A review about bioengineering topics is done, where the existent mechanical mechanisms are highlighted. According to the application necessities, the advantages and disadvantages of different topologies of electric linear machines are compared and the constructive characteristics are emphasized. The tubular linear synchronous motor, with permanent magnets on the surface of the mobile part, was chosen to be applied to hand prostheses. To this machine, a design methodology is presented for calculating the motor dimensions, based on the following subjects: magnetic circuit equating, finite element analyses to evaluate parameters and machine dynamic modeling. After the theorethical stage, the construction of the machine is presented with the experimental results, allowing comparisons between the real characteristics and the initial design features of the motor. Finally, the machine is applied to an artificial finger to verify its capability to replace the rotational motor.
\end{abstract}

Keywords: Electrical Machines; Linear Motors; Finite Element Method; Motor Drives and Motion Control; Bioengineering; Upper Limb Prostheses. 


\section{LISTA DE FIGURAS}

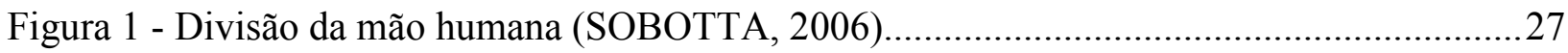

Figura 2 - A mão humana: 1) Falange distal; 2) Falange média; 3) Falange Proximal................28

Figura 3 - Taxinomia estática da mão. Adaptado de (DOLLAR, 2008). ..................................29

Figura 4 - Atuadores tradicionais e suas consequências (CARROZZA et al., 2002)...................31

Figura 5 - Atuadores menores e suas consequências (CARROZZA et al., 2002).......................31

Figura 6 - Prótese mioelétrica comercial (CHAPPELL; KYBERD, 1991). ................................32

Figura 7 - Slider crank. Adaptado por (CUNHA, 2002) de (CARROZZA et al., 2000)..............32

Figura 8 - Mecanismo de acomodação. Adaptado por (CUNHA, 2002) de (PORFÍRIO, 1992)..33

Figura 9 - a) CTArm1; b) CTArm2. Adaptado de (MA; HIROSE;YOSHINADA, 1993)........... 33

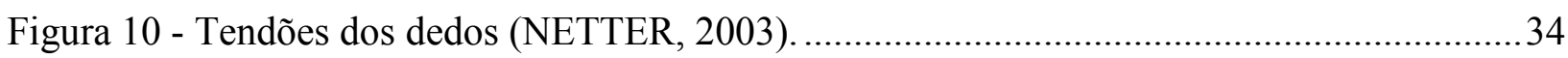

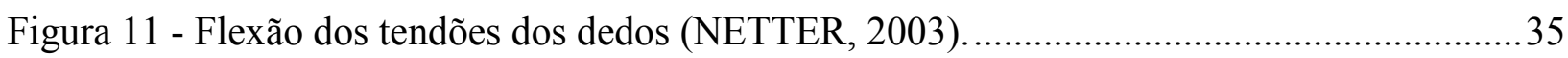

Figura 12 - Representação esquemática do dedo indicador conectado ao motor elétrico linear... 35

Figura 13 - Comportamento das juntas em função do tempo para o movimento 1 .......................36

Figura 14 - Deslocamento da parte móvel do motor para a realização do movimento 1..............37

Figura 15 - Comportamento das juntas em função do tempo para o movimento 2 ...................... 37

Figura 16 - Deslocamento da parte móvel do motor para a realização do movimento 2.............. 38

Figura 17 - Mecanismo soft gripper com molas. Adaptado de (ZOLLO et al., 2007).................39

Figura 18 - Dimensões do membro superior direito: a) Vista frontal da mão; b) Vista lateral da mão e c) Vista frontal do antebraço e da mão...............................................................40

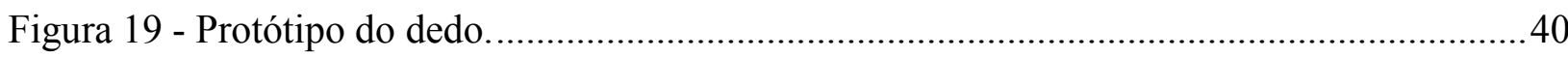

Figura 20 - Vista frontal do protótipo do dedo...................................................................... 41

Figura 21 - Protótipo do dedo com o fio de nylon. .................................................................41

Figura 22 - Interesse pelos motores lineares em função dos anos. Adaptado de

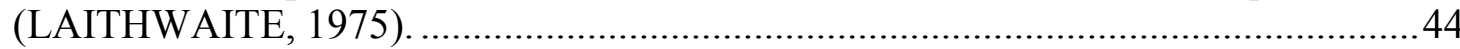

Figura 23 - Processo imaginário da obtenção do motor linear a partir do rotativo (OLIVEIRA,

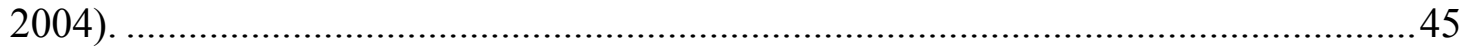

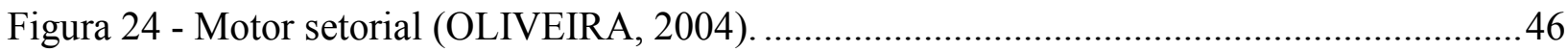

Figura 25 - Obtenção do motor linear tubular, com seção transversal em forma circular, a partir do motor linear plano (JULIANI, 2010) .......................................................4

Figura 26 - a) Motor linear de indução e as correntes parasitas nas extremidades; b) Comportamento das correntes parasitas; c) Variação do fluxo magnético (SUNG; NAM, 1999)......

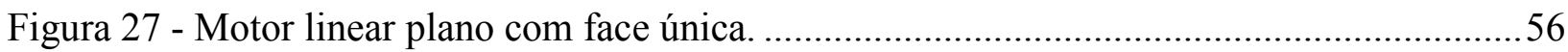

Figura 28 - Motor linear plano com dupla face....................................................................56 
Figura 29 - Motor tubular: a) com ímãs no interior; b) com ímãs na superfície (BIANCHI et al., 2003)......

Figura 30 - Taxa de força por volume comparando-se motores tubulares com e sem ranhuras e ímãs no interior do linor. Adaptado de (BIANCHI et al., 2003) .

Figura 31 - Taxa de força por volume comparando-se motores tubulares com e sem ranhuras e ímãs na superfície do linor. Adaptado de (BIANCHI et al., 2003).

Figura 32 - Taxa de força por volume comparando-se motores tubulares com e sem ranhuras, e ímãs no interior do linor, para diferentes tamanhos de raio externo. Adaptado de (BIANCHI; BOLOGNANI; TONEL, 2001).

Figura 33 - Linor com ímãs no interior. Adaptado de (ZYL et al., 1999).

Figura 34 - Linor com ímãs na superfície. Adaptado (ZYL et al., 1999).

Figura 35 - Linhas de fluxo magnético de um motor tubular .

Figura 36 - Linor com enrolamento.

Figura 37 - Linor de enrolamento (BASAK, 1996).

Figura 38 - Dimensões que devem ser especificadas para o projeto do motor linear sem ranhuras.

Figura 39 - Dimensões que devem ser especificadas para o projeto do motor linear com ranhuras.

Figura 40 - a) Fluxo magnético em um par de pólo; b) Circuito magnético análogo (JULIANI et al., 2010).

Figura 41 - Força eletromagnética por pólo versus $R_{m} / R_{s}$ (JULIANI et al., 2010).

Figura 42 - Dimensões do dente.

Figura 43 - Diagrama de blocos do acionamento do motor linear. 75

Figura 44 - Circuito de acionamento do MLSIP (JULIANI, 2007).

Figura 45 - Sinais de comando dos transistores do circuito de acionamento do MLSIP (JULIANI, 2007).

Figura 46 - Tensão de saída do inversor trifásico do MLSIP (JULIANI, 2007).

Figura 47 - Modelo do MLST.

Figura 48 - Controle do MLST.

Figura 49 - Localização dos dois primeiros pares de pólo do motor.

Figura 50 - Comparação dos fluxos magnéticos da fase $A$ referentes aos motores com e sem ranhuras.

Figura 51 - Comparação das tensões induzidas da fase $A$ referentes aos motores com e sem ranhuras.

Figura 52 - Comparação das forças eletromagnéticas referentes aos motores com e sem ranhuras.

Figura 53 - Densidade de fluxo magnético do motor com ranhuras e chanfros. ......................... 86

Figura 54 - Densidade de fluxo magnético do motor sem ranhuras. ........................................... 86

Figura 55 - Densidade de fluxo magnético normal no entreferro do primeiro projeto. 
Figura 56 - Densidade de fluxo magnético normal no entreferro do segundo projeto. .88

Figura 57 - Densidade de fluxo magnético normal no entreferro do terceiro projeto. .88

Figura 58 - Densidade de fluxo magnético normal no entreferro do quarto projeto. .88

Figura 59 - Força eletromagnética do primeiro projeto. .89

Figura 60 - Força eletromagnética do segundo projeto. .89

Figura 61 - Força eletromagnética do terceiro projeto. .89

Figura 62 - Força eletromagnética do quarto projeto. .90

Figura 63 - Densidade de fluxo magnético do primeiro projeto. .90

Figura 64 - Densidade de fluxo magnético do segundo projeto. 91

Figura 65 - Densidade de fluxo magnético do terceiro projeto. .91

Figura 66 - Densidade de fluxo magnético do quarto projeto. .91

Figura 67 - Fluxo magnético da fase $A$ do motor selecionado para ser construído. .93

Figura 68 - Tensão induzida da fase $A$ do motor selecionado para ser construído .93

Figura 69 - Desenho do motor linear tubular no software Ansys ${ }^{\circledR}$ : a) Vista em duas dimensões, b) Vista de uma parte do motor tubular $\left(10^{\circ}\right)$.

Figura 70 - Densidade de fluxo magnético obtida no programa iMOOSE. .95

Figura 71 - Vetores da densidade de fluxo magnético na região abrangida pelo retângulo vermelho da figura 70 .

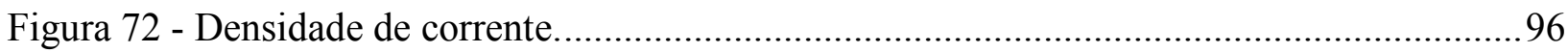

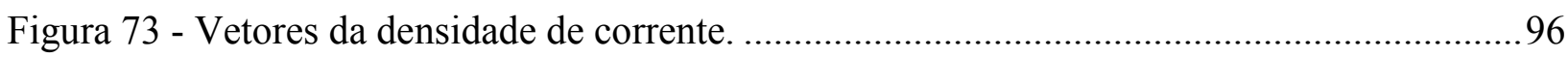

Figura 74 - Comparação da força eletromagnética obtida por meio do software FEMM com o iMOOSE.

Figura 75 - Ímãs sem o efeito da inclinação: a) Vista dimetric; b) Vista frontal (JULIANI et al., 2010).

Figura 76 - Ímãs com o efeito da inclinação: a) Vista dimetric; b) Vista frontal (JULIANI et al., 2010).

Figura 77 - Ímãs com o efeito da inclinação plana: a) Vista dimetric; b) Vista frontal (JULIANI et al., 2010).....

Figura 78 - Comparação da força eletromagnética do motor considerando-se os ímãs com e sem o efeito da inclinação (JULIANI et al., 2010). .98

Figura 79 - Diagrama de blocos da simulação dinâmica. .99

Figura 80 - Deslocamento da parte móvel do motor com controle de tensão por PWM.

Figura 81 - Velocidade mecânica e referência com controle de tensão por PWM.

Figura 82 - Força eletromagnética com controle de tensão. 100

Figura 83 - Corrente elétrica e tensão induzida por fase com controle de tensão. 101

Figura 84 - Força eletromagnética com a ausência e a presença de anéis feitos de aço entre os ímãs.

Figura 85 - Fluxo magnético com a ausência e a presença de anéis feitos de aço entre os ímãs.104 
Figura 86 - Ampliação da área abrangida pelo retângulo cinza da figura 85 .

Figura 87 - Tensão induzida com a ausência e a presença de anéis feitos de aço entre os ímãs. 105

Figura 88 - Ímãs de NdFeB no formato de arco e magnetização radial..... 106

Figura 89 - Construção do linor. 107

Figura 90 - Linor construído com os rolamentos. 107

Figura 91 - Chapa com furo central e raio igual a $R_{s}$ 108

Figura 92 - Os dois tipos de chapas que compõem o estator. 108

Figura 93 - Carretéis para enrolar as bobinas. 109

Figura 94 - Dispositivo para auxiliar o enrolamento das bobinas. 109

Figura 95 - Bobinas feitas e separadas por fase. 110

Figura 96 - Componentes do estator. 110

Figura 97 - Montagem do estator. 111

Figura 98 - Motor construído. 112

Figura 99 - Sensores de detecção da posição.

Figura 100 - Sinais lógicos das chaves optoeletrônicas.

Figura 101 - Circuito de medição da indutância mútua. 115

Figura 102 - Medição da tensão induzida por fase.. 116

Figura 103 - Comparação da tensão induzida experimental e calculada no programa FEMM. 116 Figura 104 - Sensor piezorresistivo FlexiForce ${ }^{\circledR}$......

Figura 105 - Medição da força eletromagnética. 118

Figura 106 - Força eletromagnética experimental comparada com a calculada no programa FEMM......

Figura 107 - Força eletromagnética exigida pela aplicação. 119

Figura 108 - Posição do atuador: a) inicial; b) intermediária; c) final. 120 


\section{LISTA DE TABELAS}

Tabela 1 - Categorias dos instrumentos de apoio (ENDERLE; BLANCHARD;

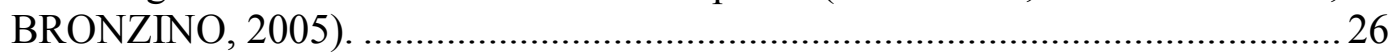

Tabela 2 - Características do motor utilizado em (ZOLLO et al., 2007)...............................42

Tabela 3 - Características do motor com o redutor utilizado em (ZOLLO et al., 2007)........42

Tabela 4 - Características do motor com redutor e sistema de transmissão utilizado em (CARROZZA et al., 2002) .............................................................................. 43

Tabela 5 - Características do motor elétrico linear deste trabalho..........................................54

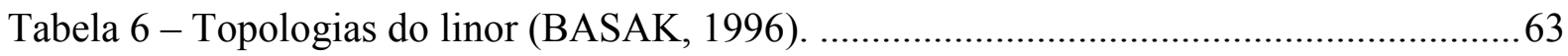

Tabela 7 - Categorias de aço elétrico e algumas aplicações (AKsteel, 2008). .......................71

Tabela 8 - Categorias de aço elétrico utilizadas nos Estados Unidos (HENDERSHOT; MILLER, 1994).

Tabela 9 - Categorias de aço elétrico utilizadas na Europa (HENDERSHOT; MILLER,

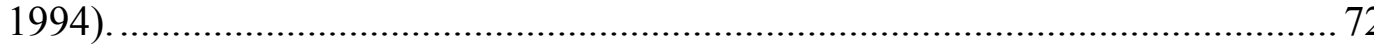

Tabela 10 - Características das principais baterias (ABVE, 2009) …...................................78

Tabela 11 - Características construtivas dos motores projetados com e sem ranhuras. ...........83

Tabela 12 - Parâmetros dos motores projetados com e sem ranhuras..................................... 85

Tabela 13 - Características construtivas dos motores projetados........................................87

Tabela 14 - Parâmetros dos motores projetados......................................................................92

Tabela 15 - Dimensões do projeto inicial do motor...............................................................93

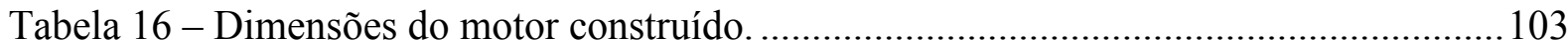

Tabela 17 - Parâmetros do motor construído........................................................................... 103

Tabela 18 - Detecção dos sensores de acordo com a posição angular................................... 113

Tabela 19 - Características elétricas por fase do protótipo................................................. 114

Tabela 20 - Fator de distribuição para motores sem ranhuras. ............................................. 137 


\section{LISTA DE SÍMBOLOS}

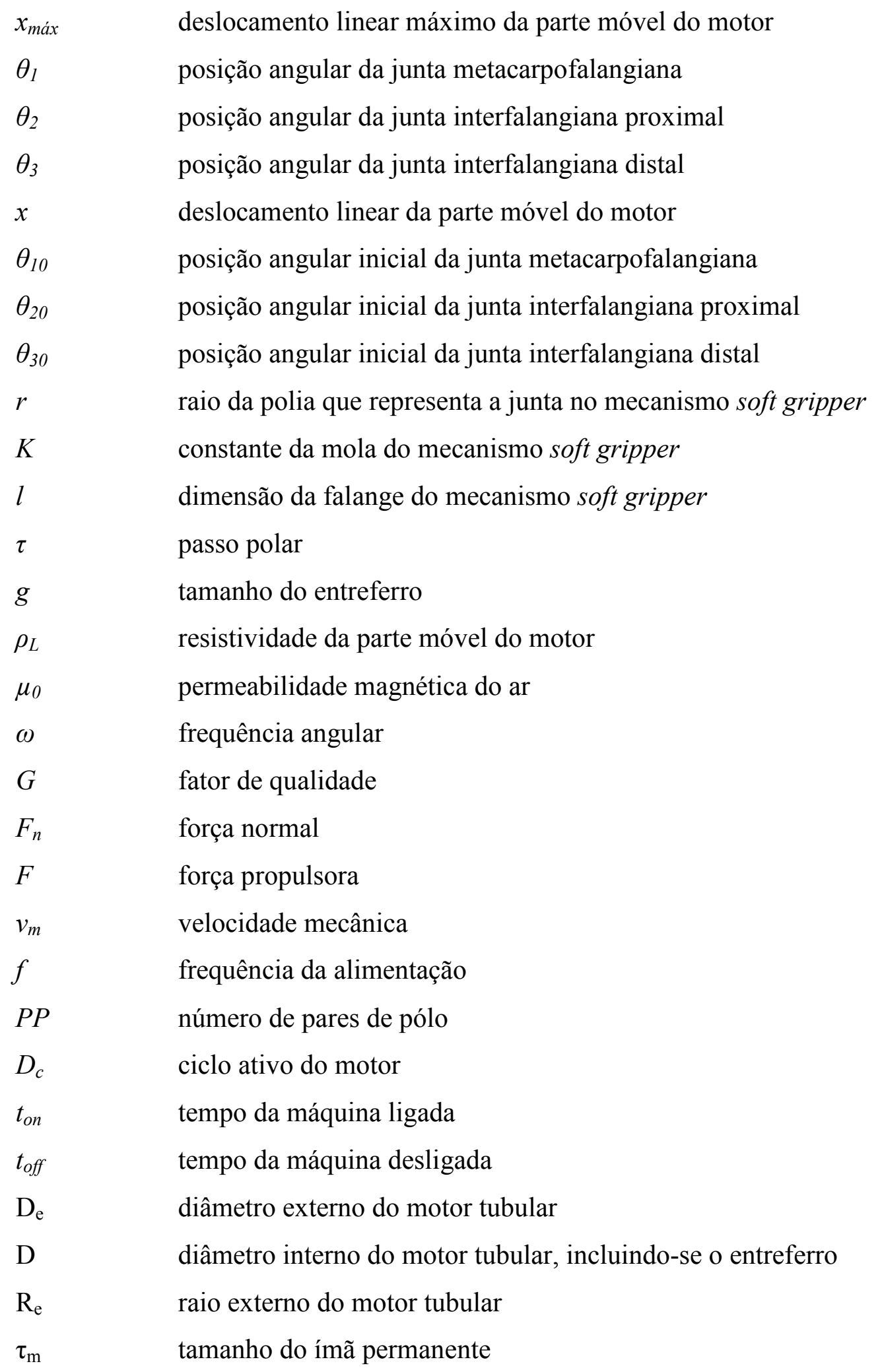




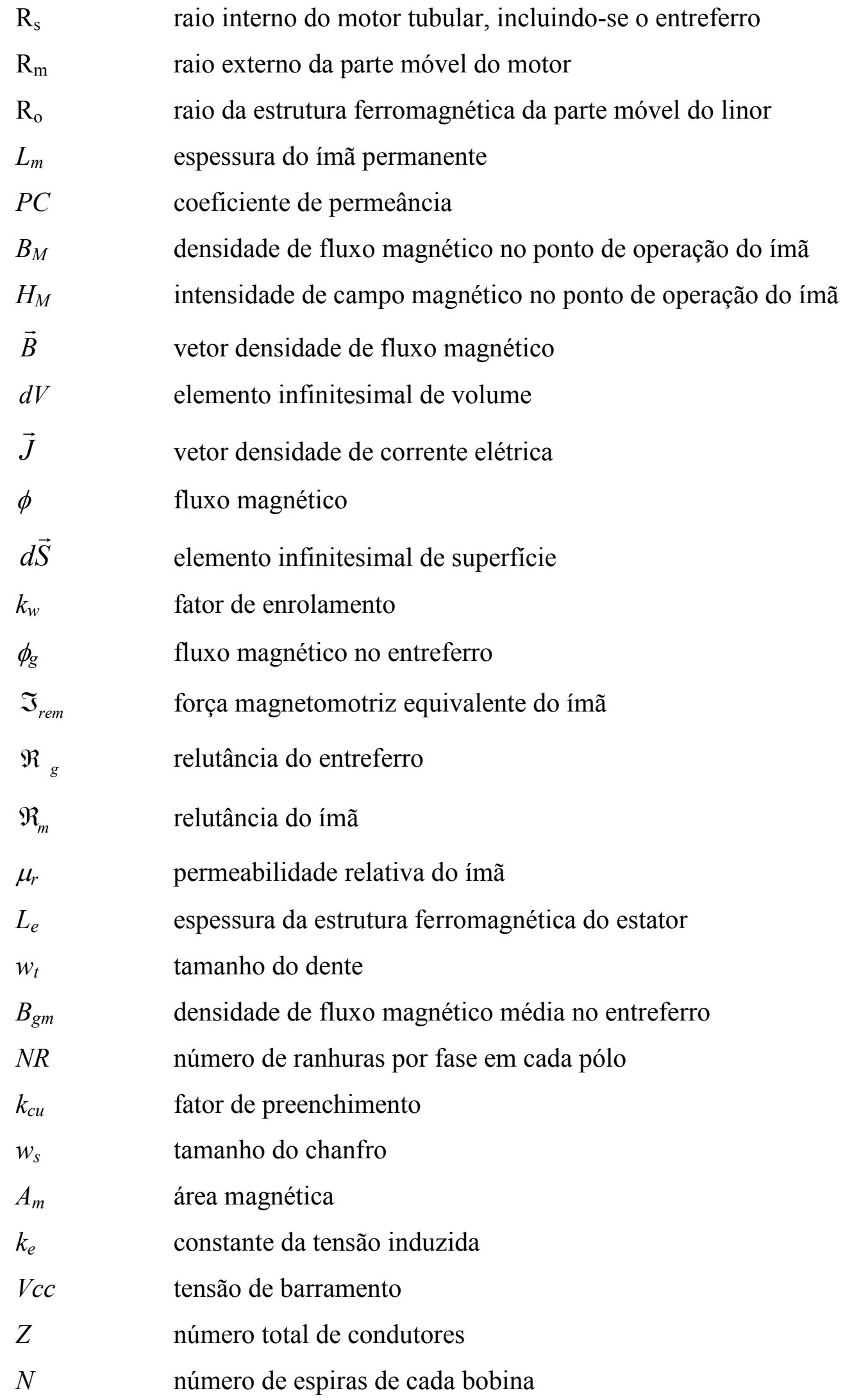




\begin{tabular}{|c|c|}
\hline$N_{\text {BobinasFase }}$ & número de bobinas por fase \\
\hline$d_{c u}$ & diâmetro do fio de cobre \\
\hline$A_{\text {ranhura }}$ & área da ranhura \\
\hline$v_{a}$ & tensão de alimentação da fase $\mathrm{A}$ \\
\hline$v_{b}$ & tensão de alimentação da fase B \\
\hline$v_{c}$ & tensão de alimentação da fase $\mathrm{C}$ \\
\hline$R$ & resistência elétrica \\
\hline$L$ & indutância \\
\hline$e$ & tensão induzida \\
\hline$M$ & indutância mútua \\
\hline$i$ & corrente elétrica \\
\hline$f_{f}(x)$ & função normalizada \\
\hline$\omega_{e}$ & velocidade angular elétrica \\
\hline$\omega_{m}$ & velocidade angular mecânica \\
\hline$D$ & coeficiente de atrito viscoso \\
\hline$F_{c}$ & força de carga \\
\hline$F_{e l}$ & força eletromagnética \\
\hline$M_{L}$ & massa do linor \\
\hline$N_{p}$ & número de pólos \\
\hline$T_{L}$ & tamanho do linor \\
\hline$T_{E}$ & tamanho do estator \\
\hline$B_{e}$ & bitola do enrolamento \\
\hline$F_{e f}$ & valor eficaz da força eletromagnética \\
\hline$P_{r}$ & perda resistiva por fase \\
\hline$M_{e}$ & massa do estator \\
\hline$M_{T}$ & massa total \\
\hline$V_{o l}$ & volume total \\
\hline$D_{F}$ & densidade de força \\
\hline$m$ & número de fases \\
\hline$N_{s}$ & número total de ranhuras \\
\hline
\end{tabular}


v

$k_{s}$

${ }^{v} k_{z}$

${ }^{v} k_{s k}$

$h_{b o b}$

$v_{e l}$

$\gamma$

$\alpha$

$d$

$G_{x}$

$G_{v}$

$H_{c}$ número de harmônicas da série de Fourier

fator de passo

fator de distribuição

fator de inclinação

tamanho da bobina

velocidade

distância entre duas bobinas consecutivas

ângulo de inclinação dos dentes ou dos ímãs

ciclo ativo do dispositivo de potência

bloco de controle de posição

bloco de controle de velocidade

ganho do sensor de corrente 


\section{SUMÁRIO}

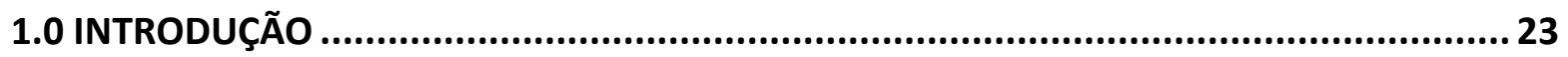

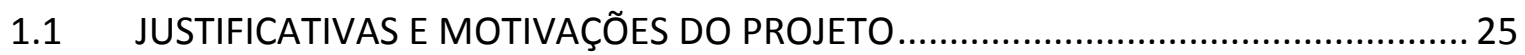

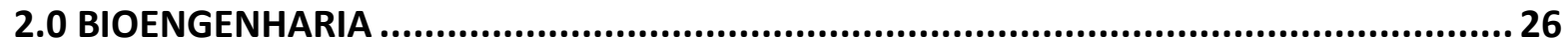

2.1 A MÃO HUMANA E OS SEUS PRINCIPAIS MOVIMENTOS ….................................. 27

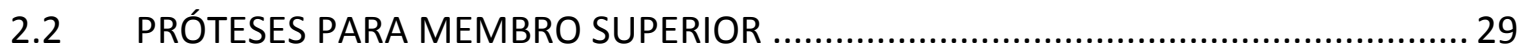

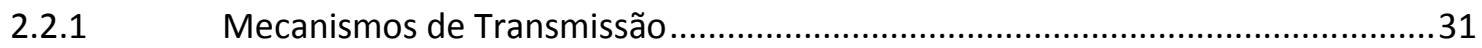

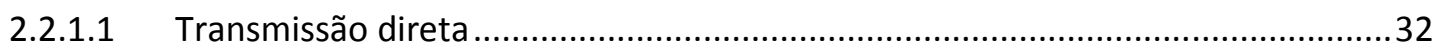

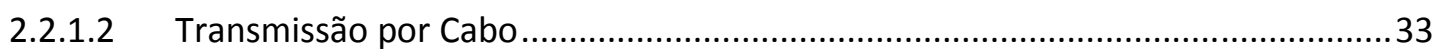

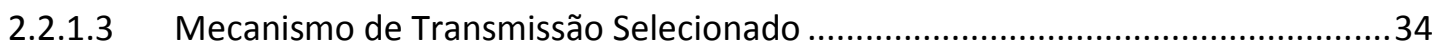

2.2.2 Acoplamento Cinemático Interfalangiano e Interdigital .......................................34

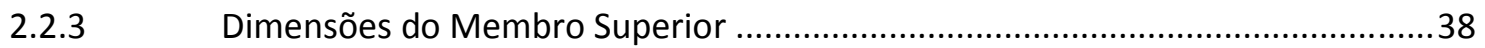

2.3 MOTORES COMUMENTE UTILIZADOS EM PRÓTESES DE MEMBRO SUPERIOR .... 41

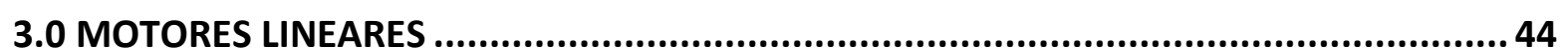

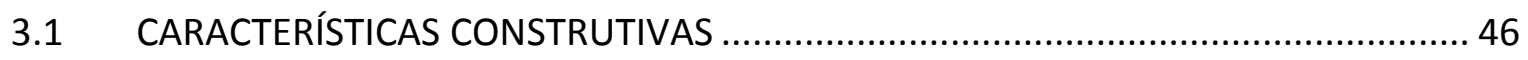

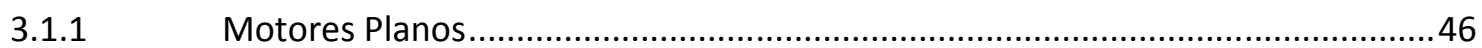

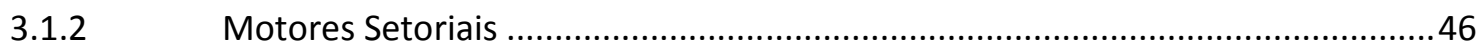

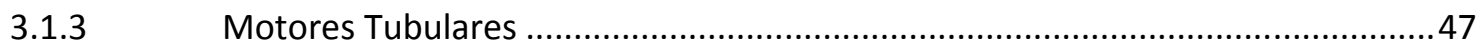

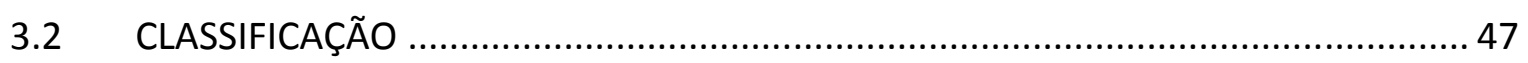

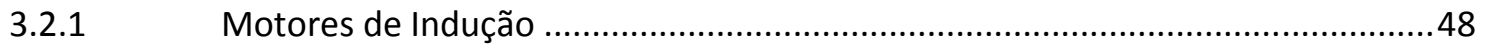

3.2.2 Motores de Corrente Contínua ................................................................................ 48

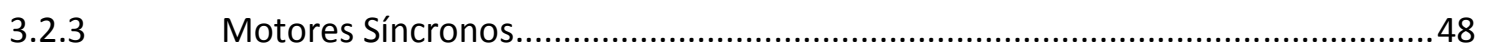

3.2.3.1 Motores com Ímãs Permanentes.........................................................................49

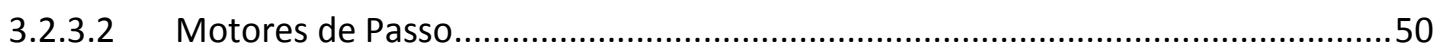

3.2.3.3 Motores de Relutância Chaveada ........................................................................50

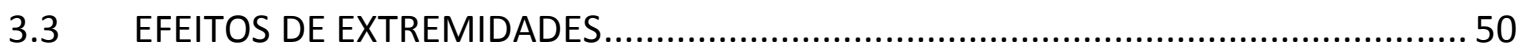

3.3.1 Efeito Longitudinal de Extremidade ............................................................. 51

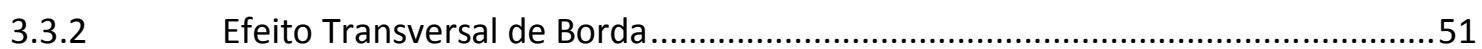

3.4 COMPARAÇÕES ENTRE OS PRINCIPAIS MOTORES LINEARES ................................ 52

4.0 METODOLOGIA DE PROJETO DO MOTOR LINEAR ................................................ 53

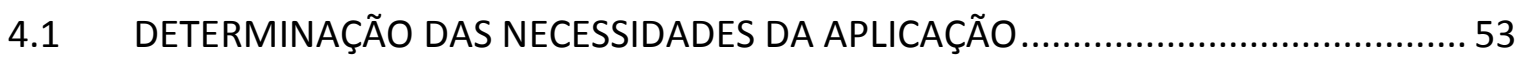

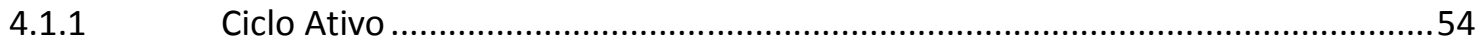

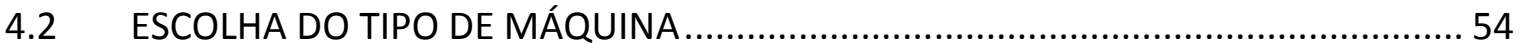

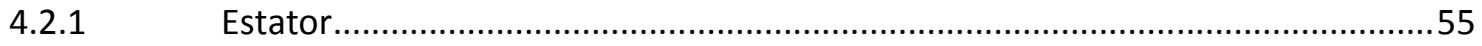




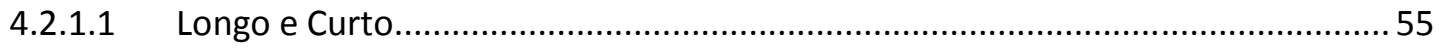

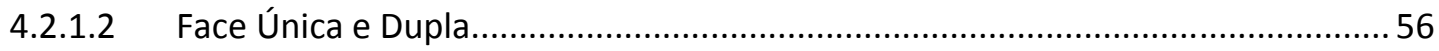

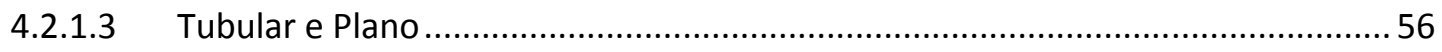

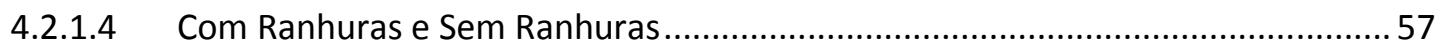

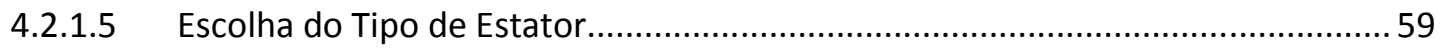

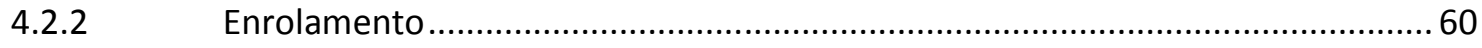

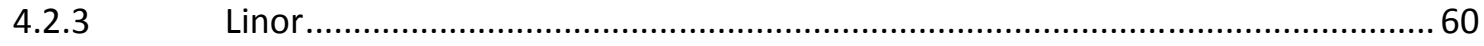

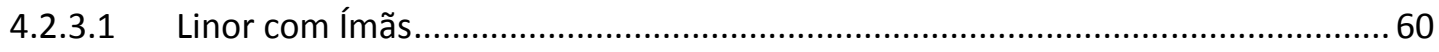

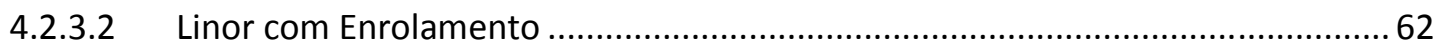

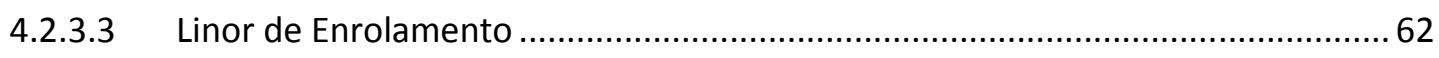

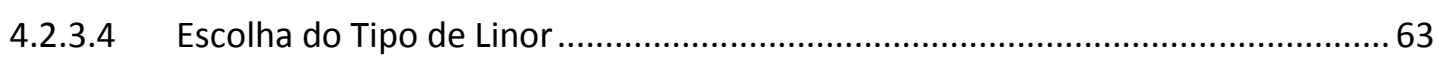

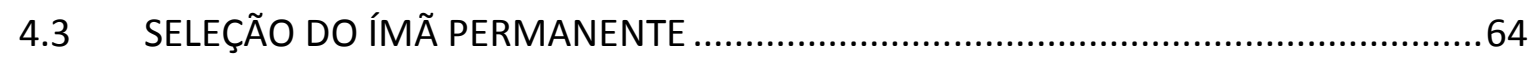

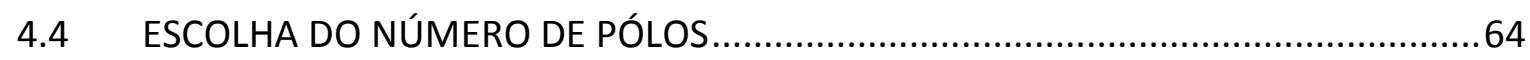

4.5 DETERMINAÇÃO DO NÚMERO DE FASES DO ESTATOR .......................................64

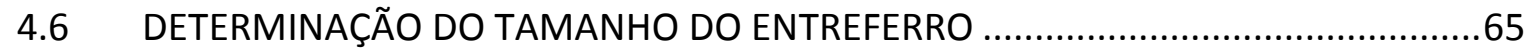

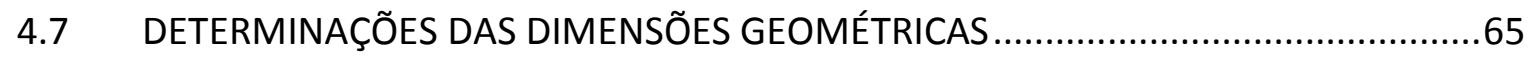

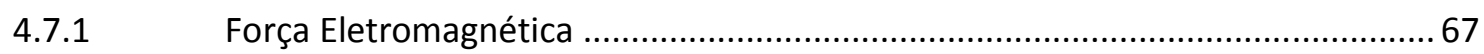

4.7.1.1 Força Eletromagnética Ótima do Motor Sem Ranhuras........................................68

4.7.1.2 Força Eletromagnética Ótima do Motor Com Ranhuras ...................................... 70

4.7.2 Cálculo das Estruturas Ferromagnéticas ............................................................. 70

4.7.2.1 Material Ferromagnético .................................................................................... 71

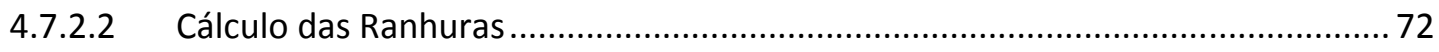

4.8 CÁLCULO DO FLUXO MAGNÉTICO POR PÓLO .......................................................73

4.9 CÁlCULO DO NÚMERO DE CONDUTORES, DE ESPIRAS E DO DIÂMETRO DO

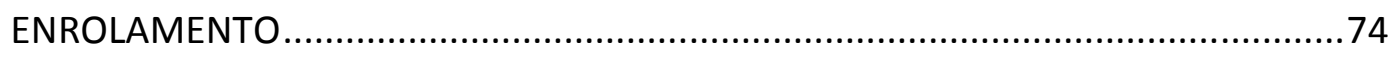

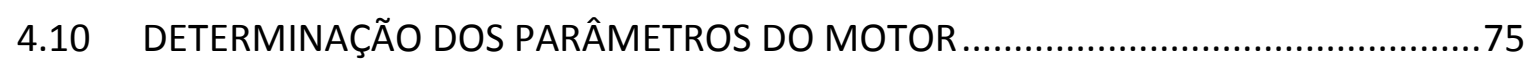

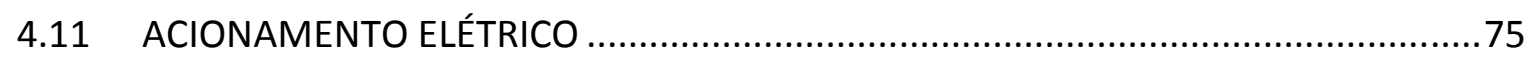

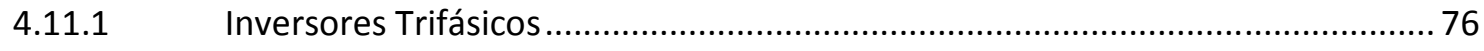

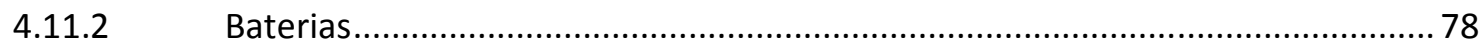

4.12 MODELAGEM MATEMÁTICA DO MOTOR LINEAR SÍNCRONO TUBULAR COM

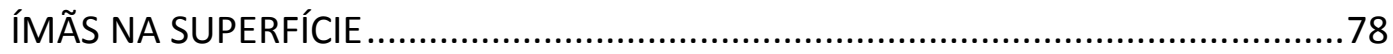

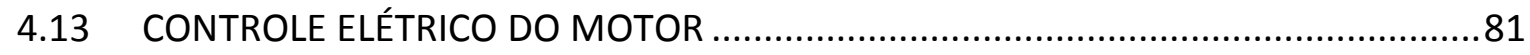

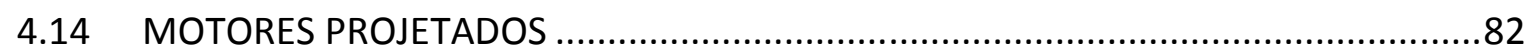

4.14.1 Comparação do Estator Com e Sem Ranhuras..................................................... 83

4.14.2 Análise da Influência da Geometria e dos Ímãs ..................................................... 87

4.14.3 Seleção do Motor a Ser Construído....................................................................... 92 
4.14.3.1 Comparação dos Resultados Obtidos por Meio do Software FEMM com o Software iMOOSE

4.14.3.2 Otimização do Projeto do Motor Tubular Considerando-se Dois Métodos do Efeito da Inclinação (Skew) dos Ímãs.....................................................97

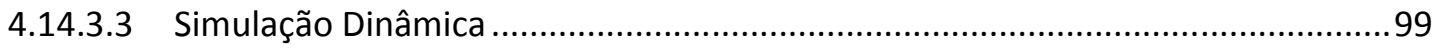

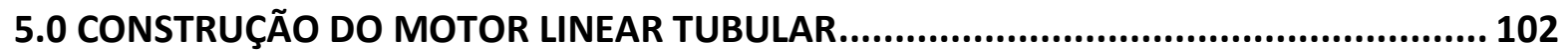

5.1 ESTUDO DA VIABILIDADE DA CONSTRUÇÃO DO MOTOR.................................... 102

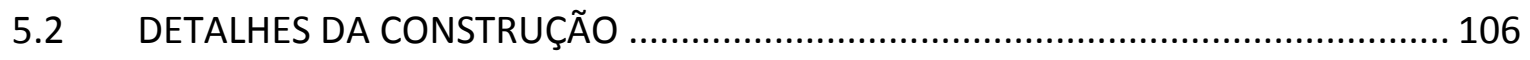

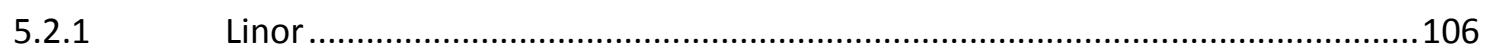

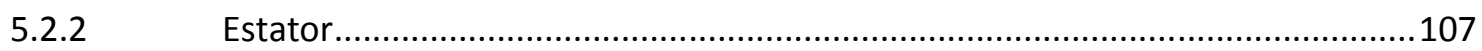

5.2.3 Acionamento Elétrico ……………………………………………………....112

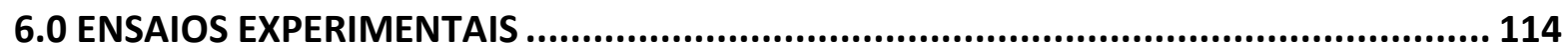

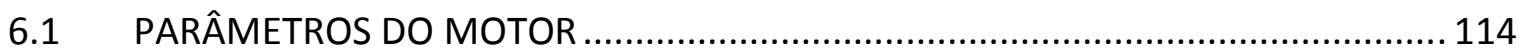

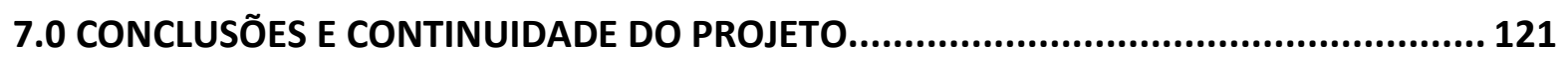

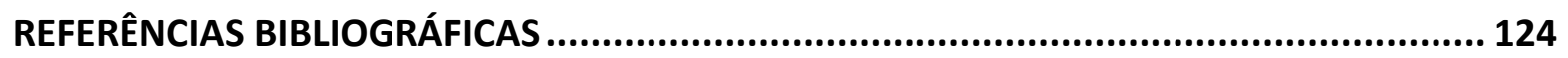

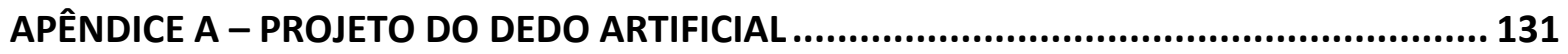

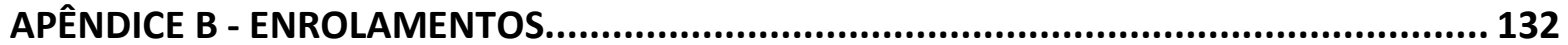

APÊNDICE C - OBTENÇÃO DO FLUXO MAGNÉTICO NO ENTREFERRO DO MOTOR SEM

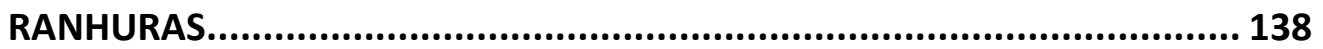

APÊNDICE D - FUNÇÕES DE TRANSFERÊNCIA DO CONTROLE ELÉTRICO ……………….... 138

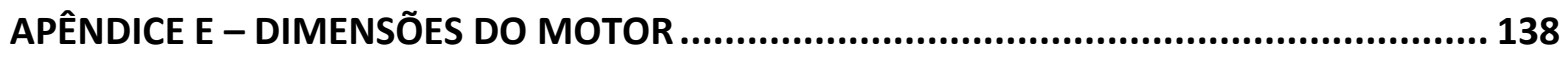




\section{Introdução}

As máquinas elétricas são utilizadas em várias aplicações e estão inseridas em diversos ambientes. Tornaram-se elementos primordiais ao cotidiano do ser humano, o que foi possibilitado pelo desenvolvimento da tecnologia dos semicondutores de potência e dos microprocessadores, que viabilizaram a implementação de técnicas de controle mais sofisticadas, melhoraram as capacidades nominais e a velocidade de chaveamento dos dispositivos de potência.

Outros fatores que contribuíram para o avanço tecnológico das máquinas elétricas foram o desenvolvimento de materiais, como os ímãs de ferrita e os de terras raras, e o aumento constante da capacidade de processamento dos computadores que facilitou a realização de simulações e de projetos de motores, como por exemplo, a utilização do Método dos Elementos Finitos para a análise do campo magnético.

Estes progressos interferem diretamente na área de bioengenharia, gerando alguns benefícios, como: redução do tamanho e da massa dos motores, maior eficiência, torque eletromagnético de acordo com as necessidades da aplicação e controle de posição e de velocidade das máquinas.

Em (CUNHA, 2002) e em (DEL CURA et al., 2003) são detalhados os motores convencionais e não convencionais para o uso em uma prótese de membro superior. Um estudo é realizado especificando as vantagens e as desvantagens de cada um, possibilitando a escolha do que apresentasse as maiores vantagens para a implementação da prótese. Apenas são comparados, entre as máquinas convencionais, os motores de corrente contínua (CC) com as máquinas síncronas com ímãs permanentes. Este último apresenta significativas vantagens em relação ao primeiro, mas possui características que podem ser melhoradas pela substituição por outro tipo de máquina, que é detalhada a seguir. 
Uma vantagem importante de um grupo especial de motores é o movimento de translação, proporcionado pela conversão da energia elétrica em mecânica, sem os dispositivos de adaptação de movimento. Estas máquinas são denominadas de motores elétricos lineares, que podem ser classificadas de acordo com o seu funcionamento: motores de corrente contínua, motores de indução e motores síncronos, incluindo-se os motores de passo e de relutância (GIERAS, 1994).

Cada uma destas máquinas é descrita resumidamente em (McLean, 1988), destacando-se as suas principais características e aplicações. Além disso, são apresentadas técnicas para a análise do desempenho das máquinas, entre elas o método dos elementos finitos. Também são feitas algumas considerações em relação aos aspectos construtivos.

Em (EASTHAM, 1990) são comparadas as máquinas lineares síncronas e assíncronas.

Em (GIERAS, 1994) são descritos detalhadamente o acionamento elétrico, as características e as aplicações do motor de indução linear.

As máquinas síncronas lineares são apresentadas em (DENG et al., 1986; DENG et al., 1987), especificamente na determinação do campo magnético e em (PROFUMO et al., 2001) e (LEE et al., 2000) são mostradas as características geométricas, sendo que a segunda referência trata dos motores de relutância.

Em (SHAFFER, 1994) é mostrado um método para a determinação dos parâmetros do circuito equivalente da máquina linear síncrona e em (MILLER, 2002) é apresentada a modelagem matemática, sendo que simulações computacionais são feitas para o cálculo dos parâmetros do motor.

Em (LIN et al., 2002) o acionamento e o controle do motor linear são tratados.

Cada tipo de máquina possui as suas vantagens e desvantagens, devendo ser utilizada de acordo com as necessidades da aplicação.

Os motores lineares são comumente utilizados em indústrias e na tração elétrica de transportes coletivos, (McLean, 1988). 


\subsection{Justificativas e Motivações do Projeto}

Normalmente, as máquinas aplicadas na área de bioengenharia são motores de corrente contínua, como em (CHAPPELL; KYBERD, 1991) e (WEIR; GRAHN, 2000), que são utilizados para movimentar os dedos de uma prótese de membro superior.

Este tipo de máquina possui movimentos rotacionais no eixo que são convertidos em movimentos lineares, para esse tipo de aplicação, utilizando-se engrenagens.

Já o motor elétrico linear, como a própria nomenclatura sugere, possui movimento linear em sua parte móvel. Esta característica dispensa adaptações mecânicas para a conversão do movimento rotacional em translacional, evita as manutenções ocasionadas por desgastes ou problemas e elimina o barulho produzido por elas, que é a principal reclamação dos usuários de próteses.

A literatura relacionada ao projeto, construção e aplicação de máquinas elétricas em bioengenharia é escassa. Geralmente, são citados apenas o tipo de motor utilizado e as características elétricas, não havendo um detalhamento da máquina elétrica.

Portanto, este trabalho propõe a substituição dos motores rotativos com as adaptações mecânicas pelo motor linear. Os conceitos básicos na área de bioengenharia e das máquinas lineares são apresentados para auxiliar e justificar a escolha do tipo e da operação da máquina, de acordo com as necessidades da aplicação. 


\section{Bioengenharia}

Nos Estados Unidos, o Instituto Nacional de Saúde (National Institutes of Health) define a bioengenharia como a integração de princípios da engenharia e das ciências física, química e matemática, para estudos da biologia e da medicina. Ela permite o avanço de conceitos fundamentais, cria conhecimentos de níveis moleculares a órgãos, desenvolve novos materiais biológicos, processos, implantes, dispositivos e utiliza a informática para a prevenção, diagnóstico, tratamento de doença, reabilitação de pacientes e melhoria da saúde.

As principais áreas abordadas pelas instituições, como John Hopkins University, Massachusetts Institute of Technology, Duke University, University of Denver e outras, são: engenharia celular e de tecidos, sistemas cardiovasculares, ciência em imagens biomédicas, neurociência, fisiologia da engenharia molecular e celular, biologia computacional e bioinformática, biomecânica, engenharia de reabilitação e engenharia em nanotecnologia de ciências biológicas (SHOURESHI, 2005).

Dentro do universo da bioengenharia, este trabalho situa-se na área de engenharia de reabilitação, que poder ser caracterizada na forma mais simples apresentada na tabela 1 . $\mathrm{O}$ desenvolvimento desses produtos tecnológicos requer a contribuição de engenheiros mecânicos, de materiais, e eletricistas, cirurgiões ortopédicos, protéticos, ortéticos, profissionais da saúde e da computação (ENDERLE; BLANCHARD; BRONZINO, 2005).

Tabela 1 - Categorias dos instrumentos de apoio (ENDERLE; BLANCHARD; BRONZINO, 2005).

Próteses e órteses

Instrumentos de apoio para pessoas com problemas visuais severos

Instrumentos de apoio para pessoas com problemas auditivos severos

Instrumentos de apoio para problemas táteis

Dispositivos de Comunicação aumentativos e alternativos

Auxiliares de mobilidade e manipulação

Instrumentos de apoio para recreação 
A contribuição deste projeto é na categoria de próteses de membro superior. Este capítulo apresenta subseções relacionadas a este assunto, incluindo-se os motores comumente utilizados e à mão humana.

\subsection{A Mão Humana e os Seus Principais Movimentos}

A mão humana, além de ser o principal órgão do sistema motor capaz de executar tarefas complexas (estáticas e dinâmicas), possui um importante papel na comunicação nãoverbal, e também tem a função de órgão tátil e de pressão (CUNHA, 2002).

Em relação à constituição óssea, a mão divide-se em carpo, metacarpo e falanges (figura 1).

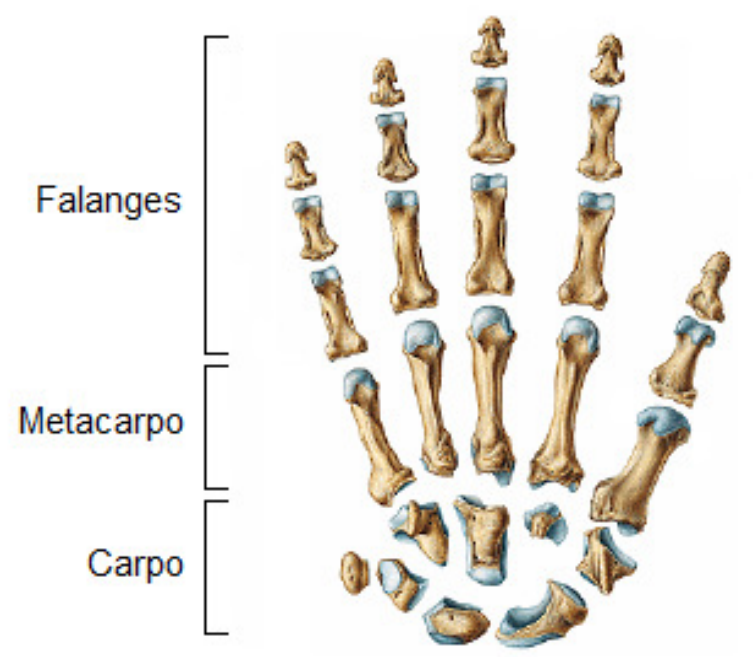

Figura 1 - Divisão da mão humana (SOBOTTA, 2006).

O carpo possui oito ossos, que constituem o punho, e o metacarpo tem cinco ossos que formam a palma da mão. Cada dedo possui três falanges, com exceção do polegar que tem apenas duas. Portanto, a mão humana é formada por 27 ossos (SOBOTTA, 2006). 


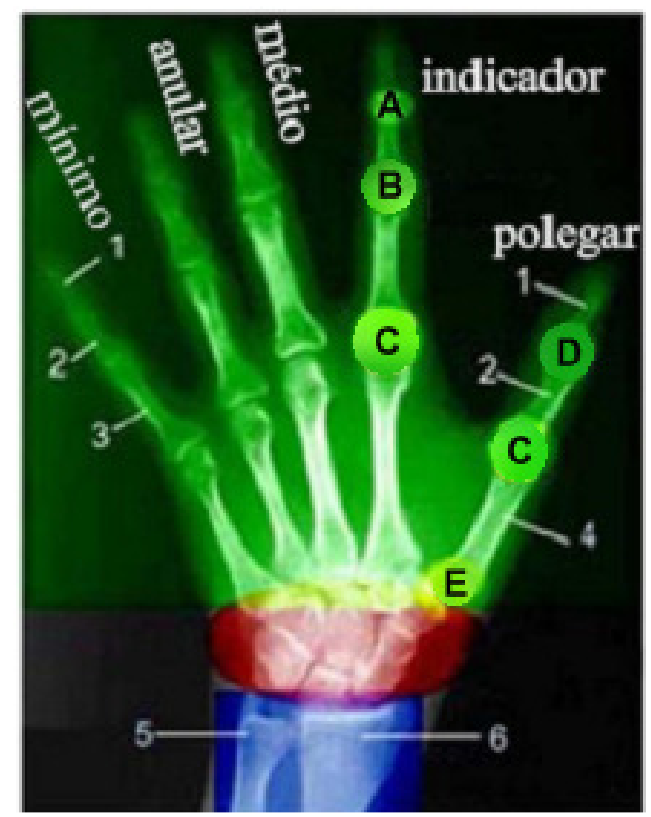

Figura 2 - A mão humana: 1) Falange distal; 2) Falange média; 3 ) Falange Proximal; 4) Osso do Metacarpo; 5) Ulna; 6) Rádio (DRAGULESCU; UNGUREANU, 2007).

A figura 2 mostra a nomeação dos dedos, das falanges e das juntas. Cada um dos quatros dedos centrais (indicador, médio, anular e mínimo) possui quatro graus de liberdade (GL), que é a flexibilidade de movimentação.

A junta metacarpofalangiana (MCP - Metacarpophalangeal) tem dois GL (letra C na figura 2). A junta interfalangiana proximal (PIP - Proximal Interphalangeal) e a distal (DIP Distal Interphalangeal) têm um grau de liberdade cada uma (letra B e A, respectivamente, na figura 2), (DRAGULESCU; UNGUREANU, 2007).

O polegar possui uma estrutura diferente e tem quatro GL, um pela junta interfalangiana (letra D na figura 2), um pela junta metacarpofalangiana (letra $C$ na figura 2) e dois pela junta trapeziometacarpal (letra E na figura 2), (DRAGULESCU; UNGUREANU, 2007).

Admitindo-se o sistema de coordenadas no pulso, a mão humana tem $23 \mathrm{GL}$, no total, que a possibilitam de assumir diversas formas para segurar objetos. A figura 3 apresenta a taxinomia do ato de agarrar, baseada em (DOLLAR, 2008). 


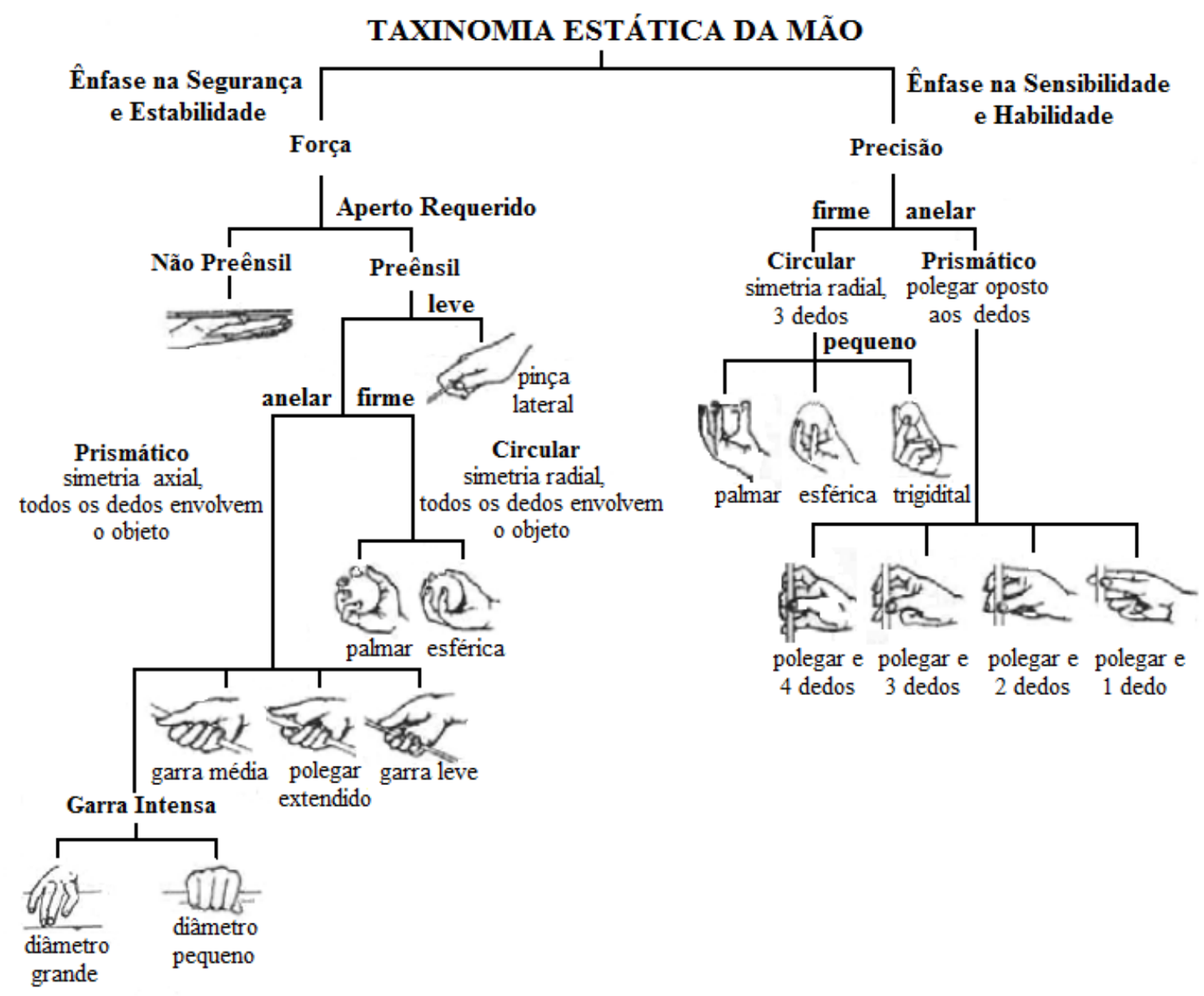

Figura 3 - Taxinomia estática da mão. Adaptado de (DOLLAR, 2008).

\subsection{Próteses para Membro Superior}

As próteses possuem a função de substituir um membro ausente, objetivando a melhoria da qualidade de vida do paciente.

Uma prótese ideal deveria ser semelhante a um membro natural do corpo humano e possuir as mesmas capacidades motoras. No entanto, este conceito ainda está distante da realidade: as próteses atuais são simples garras com um ou dois graus de liberdade (CARROZZA et al., 2002).

As próteses disponíveis comercialmente e os projetos de mãos multifuncionais são confiáveis e robustas, mas a capacidade de agarrar um objeto ainda deve ser melhorada. 
Tem-se demonstrado que as metodologias e os conhecimentos de mãos robóticas podem ser aplicados no domínio das próteses, para que o desempenho final seja melhorado (CARROZZA et al., 2002). Alguns exemplos são: Stanford/JPL Hand (SALISBURY; CRAIG, 1982) e UTAH/MIT (JACOBSON et al. 1983).

Estas mãos artificiais atingem excelentes desempenhos para reproduzir as capacidades humanas, mas necessitam de controladores enormes, possuindo tamanhos e massas não compatíveis para a aplicação em uma pessoa. Com isso, estes problemas forçam o desenvolvimento de próteses comerciais simples, que são amplamente utilizadas e apreciadas, como a Otto Bock SensorHand (OTTO BOCK, 2007), que possui apenas um grau de liberdade, movimenta os dedos em velocidade de $15-130 \mathrm{~mm} / \mathrm{s}$ e pode gerar uma força de aperto de até $100 \mathrm{~N}$ (CARROZZA et al., 2002).

Os principais problemas a serem resolvidos para o aumento do desempenho das próteses de membro superior, segundo (CARROZZA et al., 2002), são:

1) Falta de informação sensorial dada ao usuário;

2) Falta de comando "natural";

3) Capacidades limitadas de garra;

4) Movimentos não naturais durante o ato de agarrar.

O primeiro e o segundo problema podem ser resolvidos pelo desenvolvimento de um sistema que relacione o sistema nervoso periférico (SNP) com os dispositivos artificiais, reconhecendo e estimulando o SNP de modo seletivo (CARROZZA et al., 2002).

O terceiro e o quarto problemas podem ser solucionados aumentando-se o grau de liberdade da prótese. Para isso, mecanismos, sensores, atuadores e controles devem ser adaptados e/ou desenvolvidos, respeitando-se as seguintes limitações: consumo energético, ruído, aparência, tamanho e massa.

De acordo com (CARROZZA et al., 2002), o uso dos atuadores tradicionais, volumosos e pesados, limita o número de graus de liberdade, objetivando atingir uma garra estável por meio de uma alta força $(100 \mathrm{~N})$. Esta filosofia é representada pela figura 4. 


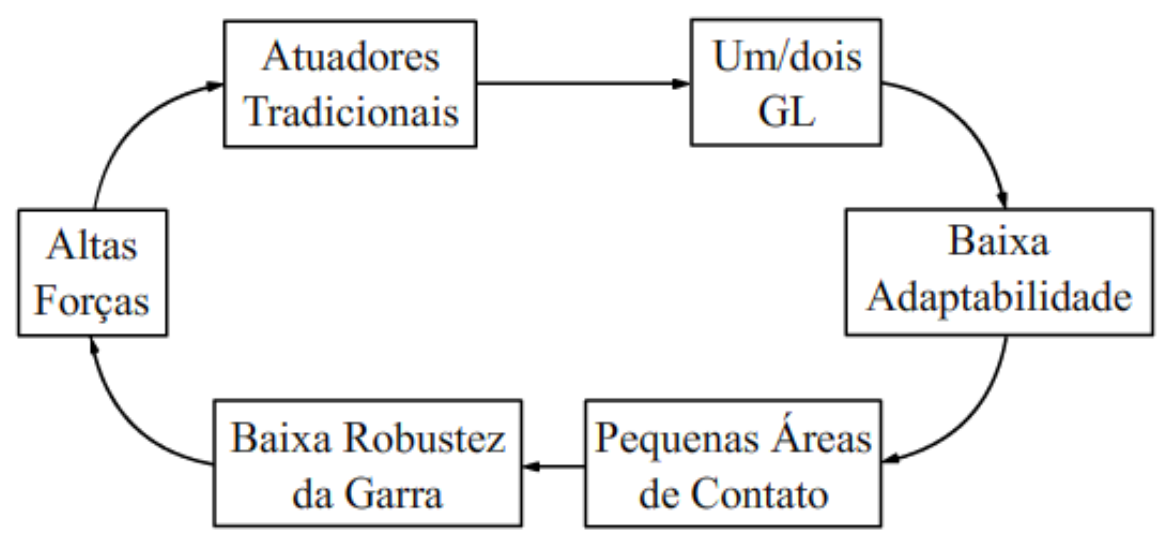

Figura 4 - Atuadores tradicionais e suas consequências (CARROZZA et al., 2002).

Substituindo-se os atuadores tradicionais por atuadores menores, obtém-se um aumento no número de graus de liberdade da mão. Isso proporciona uma maior área de contato entre o dedo e o objeto a ser segurado, garantindo uma melhor estabilidade no ato de agarrar. Esse ciclo pode ser observado na figura 5.

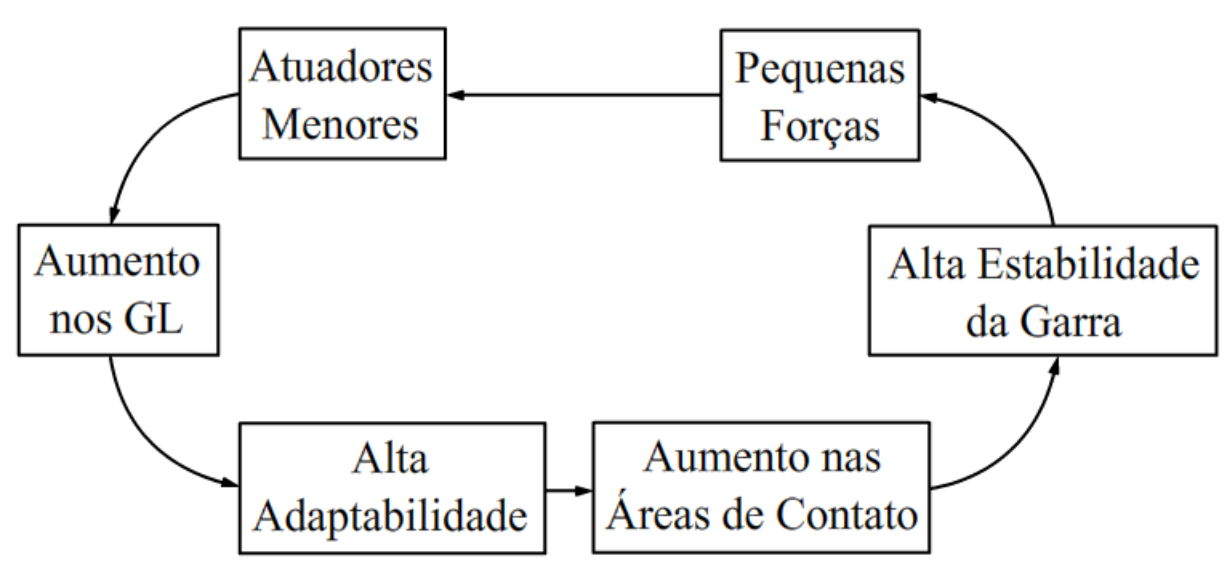

Figura 5 - Atuadores menores e suas consequências (CARROZZA et al., 2002).

\subsubsection{Mecanismos de Transmissão}

Os mecanismos de transmissão são componentes mecânicos que proporcionam os movimentos das próteses. São divididos em dois grupos: transmissão direta e transmissão por cabo. 


\subsubsection{Transmissão direta}

O atuador é conectado diretamente aos mecanismos. São alguns exemplos: pinça planar, manivela deslizante e mecanismo de acomodação.

As próteses mioelétricas comerciais são consideradas relativamente simples, pois possuem apenas um grau de liberdade, que consiste no ato de abrir e fechar uma pinça. A figura 6 mostra em malha aberta a superfície de eletrodos na pele que capta sinais, que são utilizados para controlar o atuador conectado diretamente na mão artificial (CHAPPELL; KYBERD, 1991).

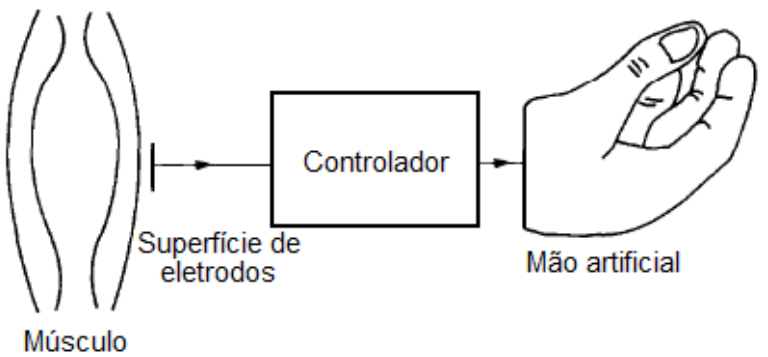

Figura 6 - Prótese mioelétrica comercial (CHAPPELL; KYBERD, 1991).

A manivela deslizante (slider crank) proporciona o movimento de flexão e extensão, sendo diretamente fixada no atuador linear (conjunto do motor rotativo e redutor) que é conectado na junta do dedo (CARROZZA et al., 2000), podendo ser observada na figura 7. O mecanismo possui uma haste ligando a transmissão parafuso-guia à falange, de modo a transmitir a força do atuador linear.

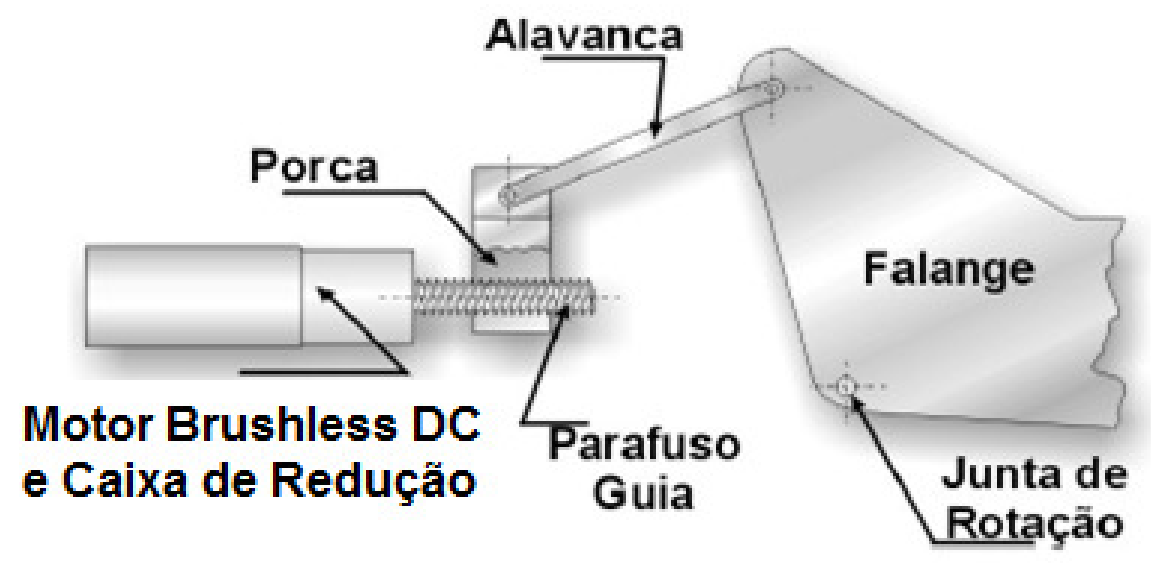

Figura 7 - Slider crank. Adaptado por (CUNHA, 2002) de (CARROZZA et al., 2000). 
O mecanismo de acomodação (MA) consiste em movimentar um dedo com três graus de liberdade com apenas um único atuador (conjunto do motor rotativo, redutor e um conversor do movimento rotativo em linear). As juntas são conectadas por duas hastes (figura 8), quando uma delas realiza o movimento de flexão, a outra apenas a acompanha. Quando o sentido do motor é invertido, ocorre o movimento de extensão ocasionado pela outra haste.

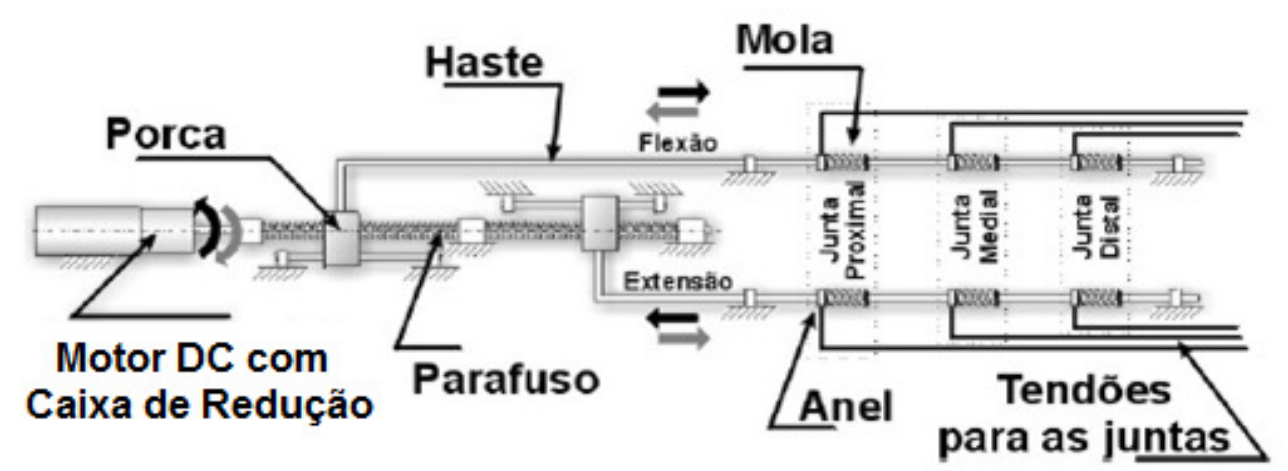

Figura 8 - Mecanismo de acomodação. Adaptado por (CUNHA, 2002) de (PORFÍRIO, 1992).

\subsubsection{Transmissão por Cabo}

Alguns mecanismos que utilizam a transmissão por cabo são: soft gripper, CTArm1 e CTArm2.

O CTArm1 (figura 9.a) e CTArm2 (figura 9.b) são compostos por polias e cabos, sendo que cada motor proporciona um grau de liberdade, reduzindo a quantidade de força na tração do cabo. São necessários $n$ cabos para $n$ graus de liberdade (MA; HIROSE; YOSHINADA, 1993).

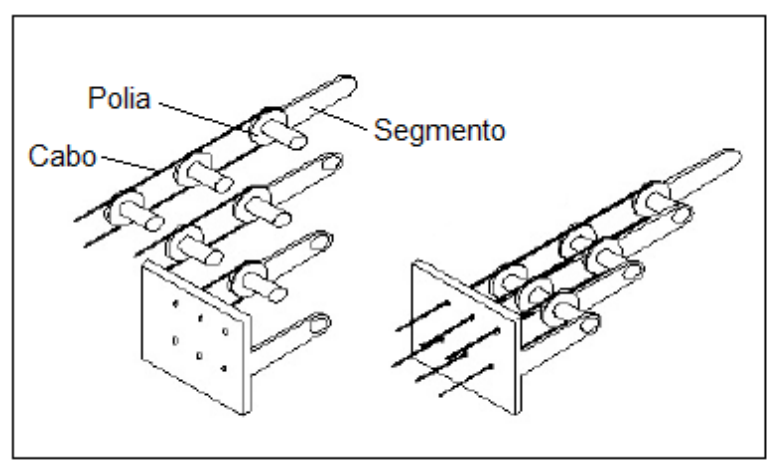

a)

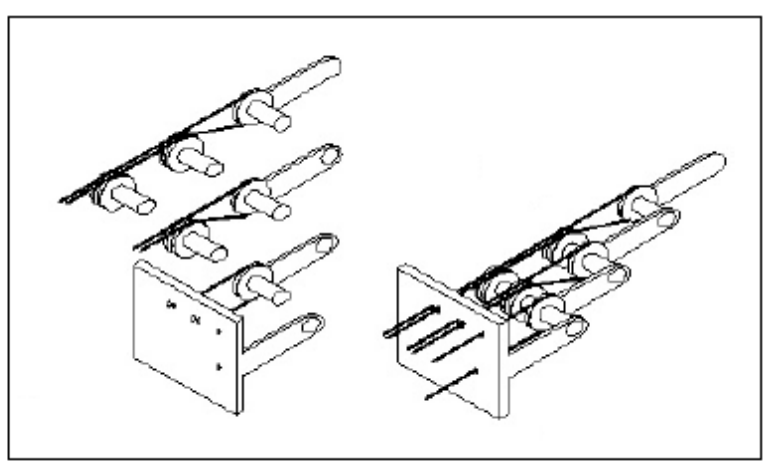

b)

Figura 9 - a) CTArm1; b) CTArm2. Adaptado de (MA; HIROSE;YOSHINADA, 1993). 
Em (ZOLLO et al., 2007) é utilizado o mecanismo soft gripper, desenvolvido por (HIROSE; UMETANI, 1978) para mãos de robôs, na prótese de membro superior. Este mecanismo foi adaptado com uma mola em cada junta, sendo sua torção a responsável pela extensão dos dedos.

Apenas um único atuador linear (conjunto do motor rotativo, com o redutor e com um conversor de movimento) é utilizado por dedo, sendo conectado a um cabo que realiza a flexão.

\subsubsection{Mecanismo de Transmissão Selecionado}

O mecanismo soft gripper foi selecionado para ser construído, para que testes do motor linear projetado possam ser feitos, com o objetivo da verificação se suas características estão de acordo com as necessidades da aplicação.

O mecanismo de transmissão por cabo é o que melhor se assemelha aos tendões da mão humana, sendo que o soft gripper necessita de apenas um atuador para o seu acionamento.

\subsubsection{Acoplamento Cinemático Interfalangiano e Interdigital}

Os acoplamentos cinemáticos interfalangiano e interdigital relacionam as falanges, os dedos e os seus limites angulares, quando realizam os seus movimentos. Eles dependem da distribuição e da fixação dos tendões nos dedos, de como estes passam através de “eletrodutos" naturais (bainhas sinoviais) e das trócleas ósseas nas articulações, que possuem a função de forçar o acoplamento dos movimentos, conforme figuras 10 e 11 (CUNHA, 1999).

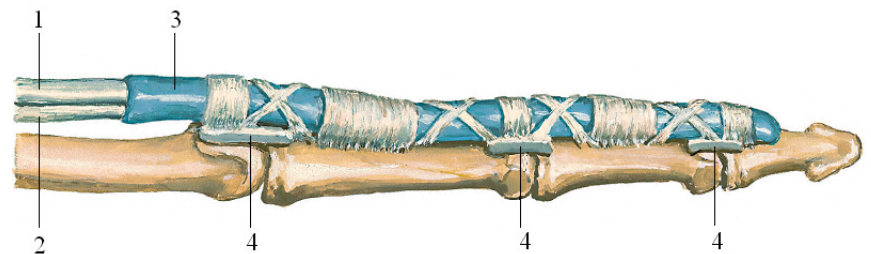

Figura 10 - Tendões dos dedos (NETTER, 2003).
1 Tendão flexor superficial

2 Tendão flexor profundo

3 Bainha sinovial

4 Ligamentos palmares 


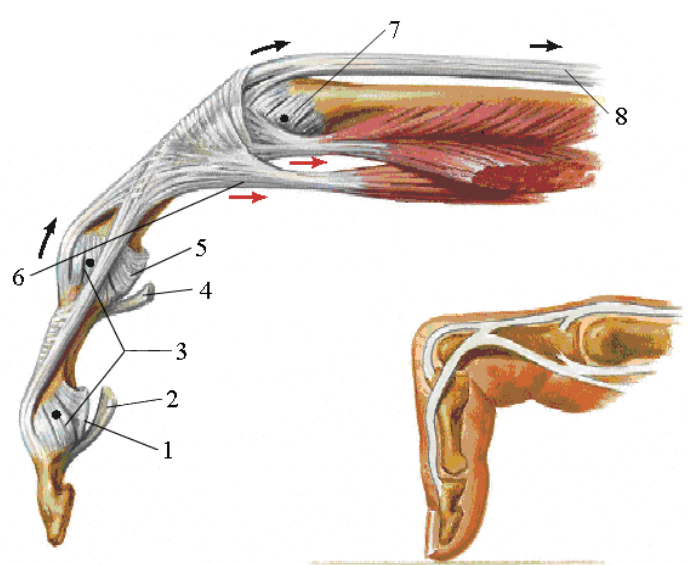

1 Ligamento palmar

2 Tendão flexor profundo

3 Ligamentos colaterais

4 Tendão flexor superficial

5 Ligamento palmar

6 Músculo lumbrical

7 Ligamento colateral

8 Tendão extensor

Figura 11 - Flexão dos tendões dos dedos (NETTER, 2003).

Para a obtenção das funções cinemáticas, que expressam a posição angular de cada junta em função do tempo, (CUNHA, 1999) desenvolveu o seguinte método: aquisição de uma sequência de imagens relativas a um movimento pré-determinado, relacionando simplesmente o dedo e as suas falanges, seguido de uma análise detalhada das imagens A referência e as posições angulares adotadas são mostradas na figura 12, sendo as juntas metacarpofalangiana, interfalangiana proximal e interfalangiana distal representadas pelos números 1,2 e 3, respectivamente.

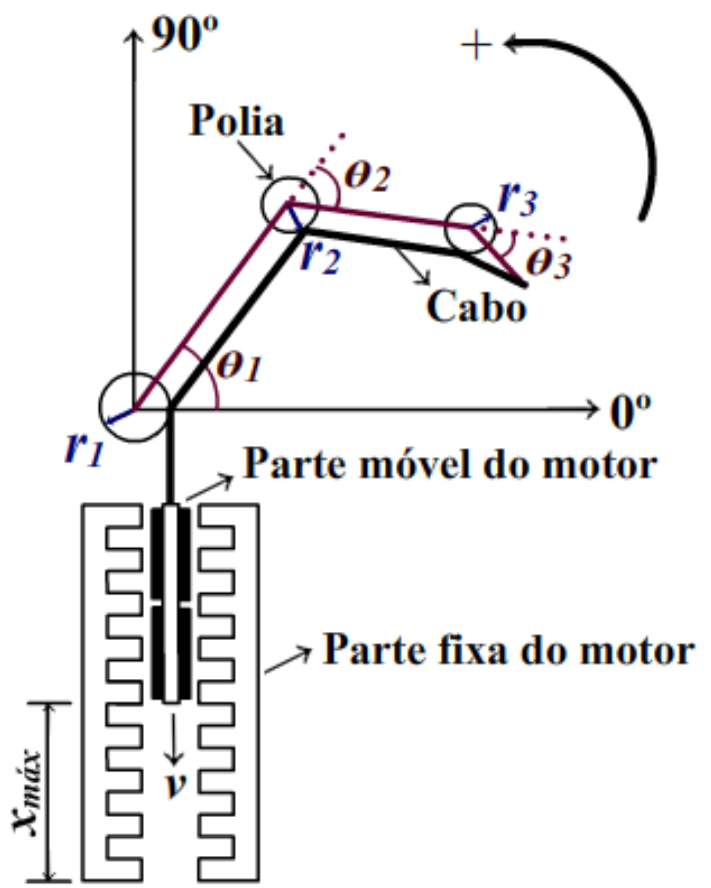

Figura 12 - Representação esquemática do dedo indicador conectado ao motor elétrico linear. 
A representação esquemática do mecanismo soft gripper é mostrada na figura 12 , sendo constituído por polias (desempenham a função das juntas) e por um cabo (tem a função do tendão) que é conectado na parte móvel do motor elétrico, que possui o deslocamento linear equacionado $(x)$ por (1) e tem o valor máximo igual a $x_{m a ́ x}$.

$$
x=r_{1} \cdot\left(\theta_{1}-\theta_{10}\right)+r_{2} \cdot\left(\theta_{2}-\theta_{20}\right)+r_{3} \cdot\left(\theta_{3}-\theta_{30}\right)
$$

Onde:

$\theta_{1}, \theta_{2}$ e $\theta_{3}$ são as posições angulares de cada junta;

$\theta_{10}, \theta_{20}$ e $\theta_{30}$ são as posições iniciais dos ângulos de cada junta;

$r_{1}, r_{2}$ e $r_{3}$ são os raios das polias [m].

As posições angulares de cada junta foram obtidas por (CUNHA, 1999), para alguns movimentos do dedo indicador, e são apresentadas a seguir.

Movimento 1: similar ao movimento do dedo indicador para executar uma garra em gancho (garra de força esférica da figura 3).

As equações do ângulo de cada junta em função do tempo são:

$$
\begin{aligned}
& \theta_{11}=-0,0589226 \cdot t^{3}+0,88557 \cdot t^{2}-4,37456 \cdot t+91,8317 \\
& \theta_{21}=0,162963 \cdot t^{3}-1,25581 \cdot t^{2}-13,2188 \cdot t+4,76111 \\
& \theta_{31}=0,350337 \cdot t^{3}-4,54477 \cdot t^{2}+6,33347 \cdot t-13,9532
\end{aligned}
$$

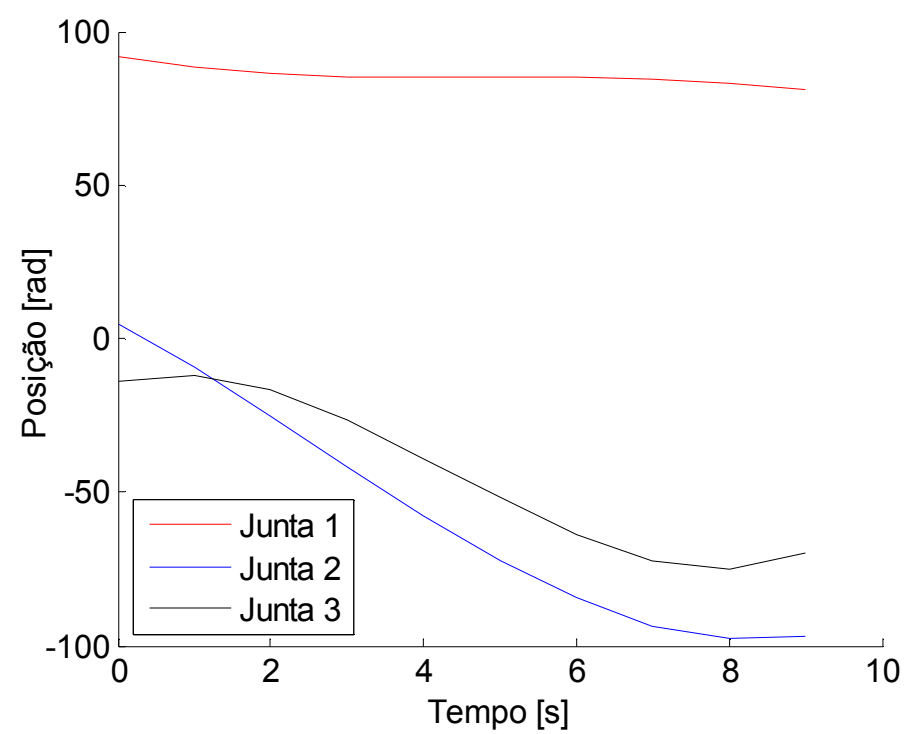

Figura 13 - Comportamento das juntas em função do tempo para o movimento 1. 
O deslocamento da parte móvel do motor para realizar o movimento é mostrado na figura 14 .

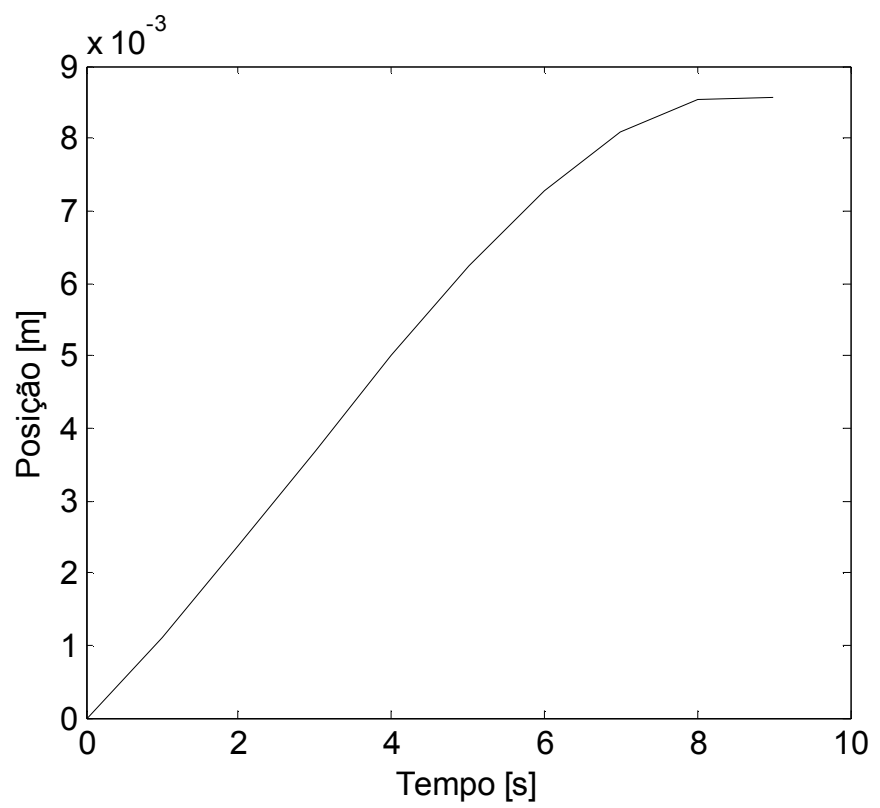

Figura 14 - Deslocamento da parte móvel do motor para a realização do movimento 1.

Movimento 2: garrra de força (garra de força anelar da figura 3).

As equações do ângulo de cada junta em função do tempo são:

$$
\begin{aligned}
& \theta_{12}=-0,0822196 \cdot t^{3}+0,975436 \cdot t^{2}-7,18733 \cdot t+95,6253 \\
& \theta_{22}=0,0744237 \cdot t^{3}-1,73091 \cdot t^{2}+1,38744 \cdot t-1,90202 \\
& \theta_{32}=0,00840456 \cdot t^{3}-0,519059 \cdot t^{2}-1,8545 \cdot t+1,85051
\end{aligned}
$$

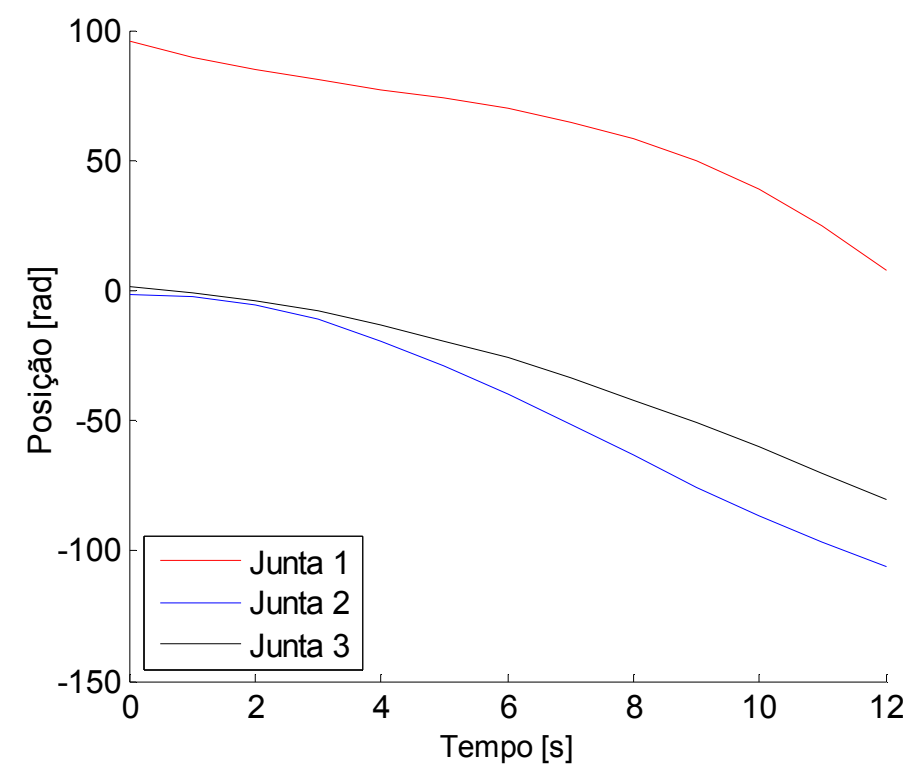

Figura 15 - Comportamento das juntas em função do tempo para o movimento 2. 
O deslocamento da parte móvel do motor para realizar o movimento é mostrado na figura 16.

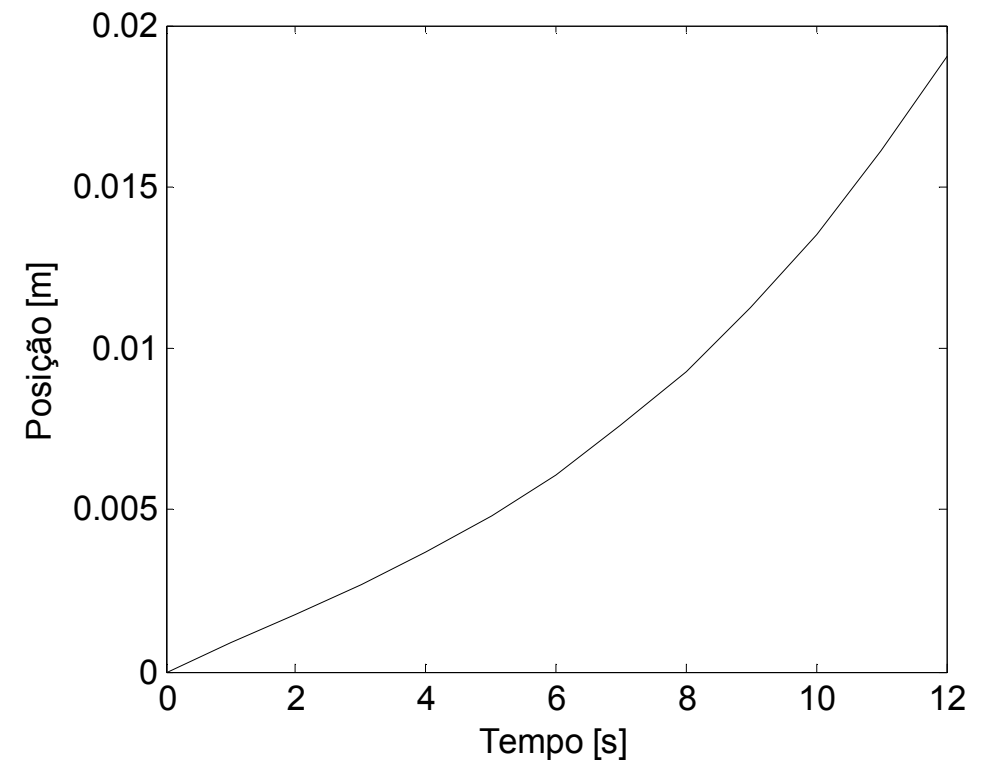

Figura 16 - Deslocamento da parte móvel do motor para a realização do movimento 2.

\subsubsection{Dimensões do Membro Superior}

Em (ZOLLO et al., 2007) são apresentados os parâmetros do dedo indicador para o mecanismo soft gripper (figura 17), de um adulto do sexo masculino, que foram obtidos por meio de simulações no 3D CAD. 


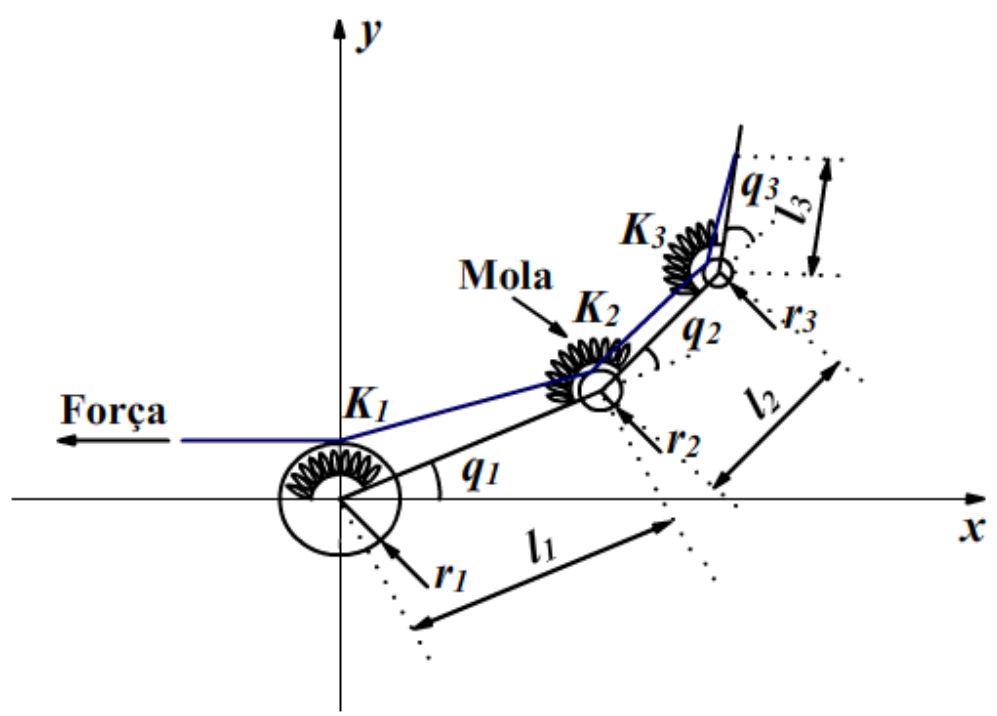

Figura 17 - Mecanismo soft gripper com molas. Adaptado de (ZOLLO et al., 2007).

Onde:

$K_{1}, K_{2}$ e $K_{3}$ são as constantes das molas [N m/rad];

$l_{1}, l_{2}$ e $l_{3}$ são as dimensões das falanges $[\mathrm{m}]$;

$q_{1}, q_{2}, q_{3}$ são os ângulos das juntas [rad];

Estes valores dependem das diferentes funcionalidades da mão a serem consideradas. Com o objetivo de atingir uma garra estável (sem o escorregamento do objeto) e da distribuição de uma força uniforme, (ZOLLO et al., 2007) obtiveram os seguintes parâmetros:

- $r_{l}=0,007 \mathrm{~m} ; r_{2}=0,003 \mathrm{~m} \mathrm{e} r_{3}=0,002 \mathrm{~m}$;

- $K_{l}=0.01093 \mathrm{~N} \mathrm{~m} / \mathrm{rad} ; K_{2}=0.00669 \mathrm{~N} \mathrm{~m} / \mathrm{rad}$ e $K_{3}=0.00503 \mathrm{~N} \mathrm{~m} / \mathrm{rad}$.

As dimensões da mão utilizadas por (ZOLLO et al., 2007) foram obtidas de (CHENG.; OBERGEFELL; RIZER, 1994), que é um banco de dados de medidas antropológicas baseadas em pesquisas realizadas por (McConville et al., 1980) e (GRUNHOFER, KROH, 1975).

A figura 18 mostra as dimensões apresentadas por 95\% das pessoas vivas em um grupo com 31 indivíduos, do sexo masculino, da força aérea americana, sendo as medidas obtidas em (McConville et al., 1980) e as ilustrações adaptadas de (Naval Biodynamics Laboratory, 1988). 
1) $11,13 \mathrm{~cm}$

2) $27,61 \mathrm{~cm}$

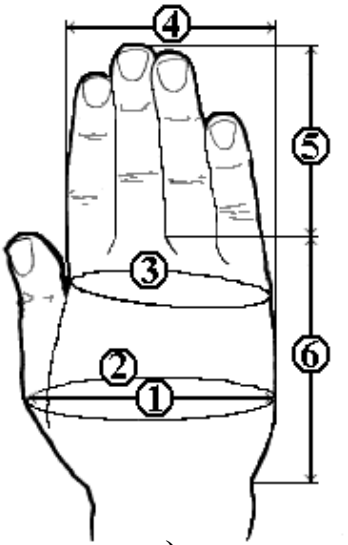

a)

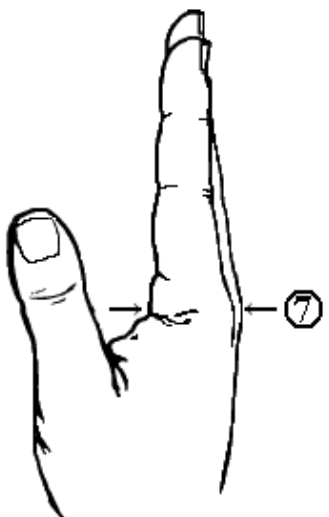

b)
3) $23,14 \mathrm{~cm}$

4) $9,41 \mathrm{~cm}$

5) $8,74 \mathrm{~cm}$

6) $11,75 \mathrm{~cm}$

7) $3,12 \mathrm{~cm}$

8) $26,83 \mathrm{~cm}$

9) $6,39 \mathrm{~cm}$

10) $9,63 \mathrm{~cm}$

Figura 18 - Dimensões do membro superior direito: a) Vista frontal da mão; b) Vista lateral da mão e c) Vista frontal do antebraço e da mão.

Na prótese, construída por (ZOLLO et al., 2007), os dedos indicador e médio são idênticos. Portanto, o tamanho do dedo indicador deve ser igual ao mostrado pela figura 18.a.

Baseando-se nas justificativas apresentadas na subseção 2.2.1.3, utilizou-se o mecanismo soft gripper, desenvolvido por (HIROSE; UMETANI, 1978), e as dimensões e os parâmetros do dedo indicador do projeto mecânico apresentado por (ZOLLO et al., 2007), tem-se o esquema do dedo que foi construído, apresentado no apêndice A.

O protótipo (figura 19 e 20) foi construído, na oficina mecânica do departamento de Engenharia Elétrica da Escola de Engenharia de São Carlos, com chapas de latão, que apresenta boa resistência mecânica e química e facilidade de soldagem, sendo as suas dimensões especificadas pelo tamanho das polias e das falanges.

É utilizado um fio de nylon (figura 21), acoplado ao eixo do motor linear, para realizar o movimento de flexão e as molas são as responsáveis por realizar o movimento de extensão.

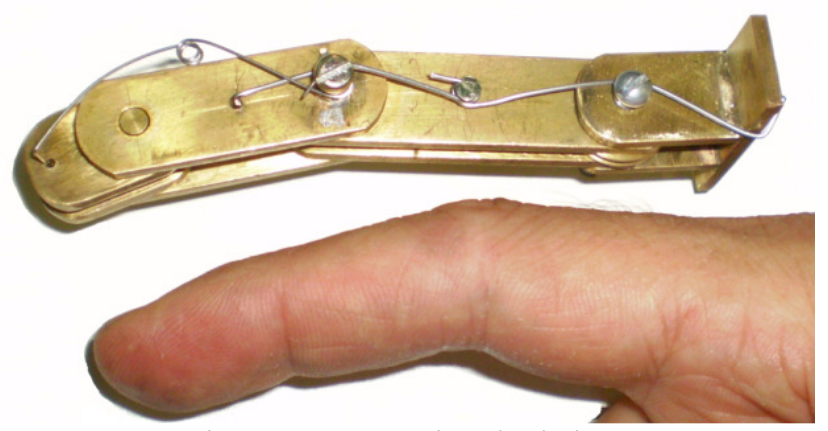

Figura 19 - Protótipo do dedo. 


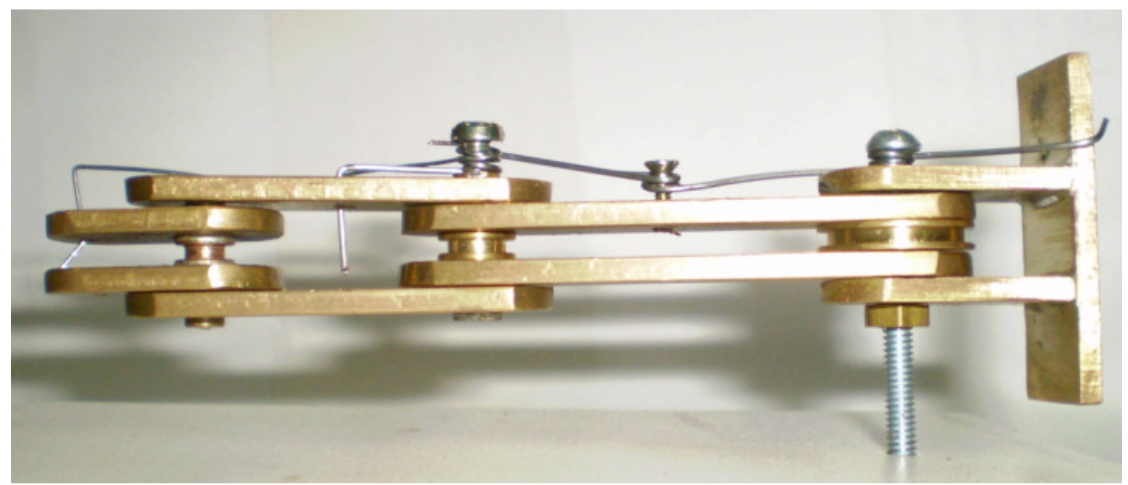

Figura 20 - Vista frontal do protótipo do dedo.

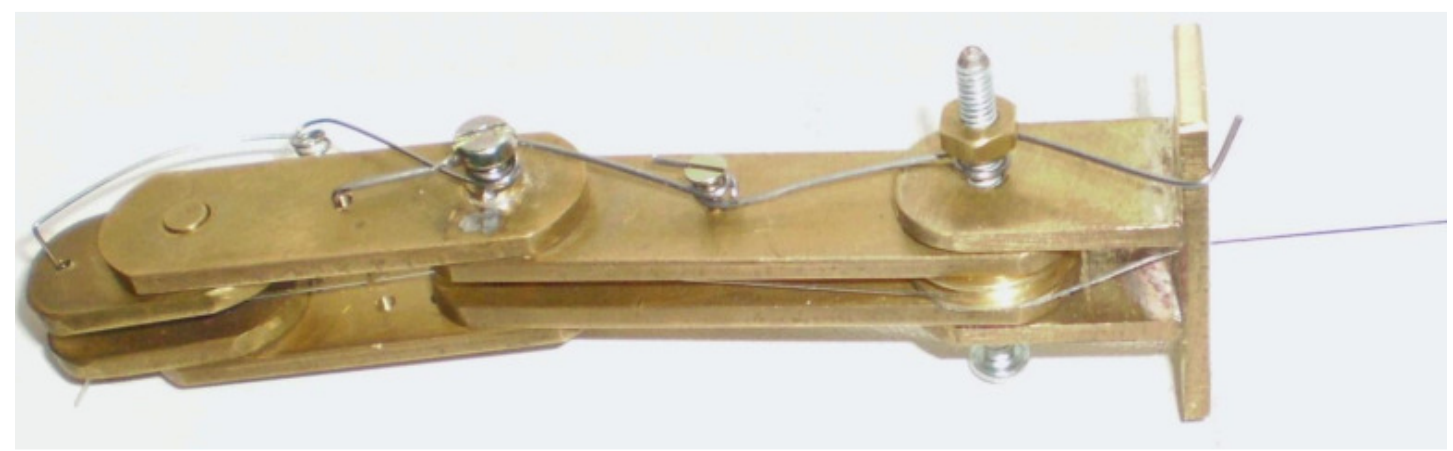

Figura 21 - Protótipo do dedo com o fio de nylon.

\subsection{Motores Comumente Utilizados em Próteses de Membro Superior}

Em (ZOLLO et al., 2007), cada dedo (com três graus de liberdade) é acionado por um único motor rotativo, sendo as suas principais características mostradas na tabela 2. Apenas os dedos polegar, o indicador e médio possuem movimentos. A massa da prótese é em torno de 1 $\mathrm{Kg}$. 
Tabela 2 - Características do motor utilizado em (ZOLLO et al., 2007).

Características do Motor Rotativo

\begin{tabular}{ll}
\hline Fabricante & Faulhaber - 1727 006 C \\
Tipo do Motor & Motor de corrente \\
& contínua \\
Tensão Nominal [V] & 6 \\
Torque Máximo [mNm] & 5 \\
Velocidade Máxima [rpm] & 7000 \\
Corrente Elétrica Máxima [A] & 0,9 \\
Massa [g] & 28 \\
Eficiência [\%] & 70 \\
Diâmetro do Motor [mm] & 17 \\
Diâmetro do Rotor [mm] & 6 \\
Largura do Motor [mm] & 38,1 \\
Força Translacional Máxima & 1,67 \\
Equivalente [N] & \\
Velocidade Linear Máxima & 2,2 \\
Equivalente [m/s] & \\
\hline Fonte: Faulhaber. &
\end{tabular}

Utilizando-se um redutor, têm-se os resultados apresentados na tabela 3.

Tabela 3 - Características do motor com o redutor utilizado em (ZOLLO et al., 2007).

\section{Características do Motor com o Redutor}

\begin{tabular}{ll}
\hline Taxa de Redução & $14: 1$ \\
Massa sem o Motor [g] & 23 \\
Velocidade Máxima [rpm] & 5000 \\
Tamanho sem o Motor [mm] & 21,2 \\
Torque Máximo em & 300 \\
Operação Contínua [mNm] & \\
Torque Máximo em & 450 \\
Operação Intermitente [mNm] & \\
\hline
\end{tabular}

Fonte: Faulhaber. 
Deve-se ressaltar que os dados apresentados na tabela 2 referem-se a um motor rotativo, já os da tabela 3 são do conjunto do motor com o redutor. Essas características não são exatamente as exigidas pela aplicação, pois é utilizado um sistema de transmissão de movimento por rosca, que tem a função de converter o movimento rotativo em linear e que possui uma vantagem mecânica.

O artigo não especifica esse sistema de transmissão e também não cita as características do conjunto do motor com o redutor e com a rosca.

Em (CARROZZA et al., 2002), a prótese projetada utiliza o sistema de transmissão da manivela deslizante. As principais exigências da aplicação supridas pelo conjunto, do motor com o redutor e com o sistema de transmissão, são mostradas na tabela 4.

\begin{tabular}{lc}
$\begin{array}{c}\text { Tabela } 4 \text { - Características do motor com redutor e sistema } \\
\text { de transmissão utilizado em (CARROZZA et al., 2002). }\end{array}$ \\
\hline $\begin{array}{c}\text { Características do Conjunto: } \\
\text { Motor com Redutor e com Sistema de Transmissão }\end{array}$ \\
\hline Força nominal [N] & 12 \\
Máxima velocidade [m/s] & 0,02 \\
Massa [g] & 3,2 \\
Taxa de transmissão & $1: 125$ \\
Número de estágios de engrenagens & 3 \\
\hline Fonte: Faulhaber.
\end{tabular}

Segundo (CARROZZA et al., 2002), o principal problema encontrado em sua aplicação, relacionado ao atuador, é o alto barulho ocasionado pela adaptação mecânica.

Foi constatado, também, que mesmo a força gerada pela mão sendo baixa, uma melhor distribuição das áreas de contato entre os três dedos e o objeto segurado foi obtida. Este resultado pode parcialmente compensar a redução da força do atuador, que permitiu uma estabilidade semelhante a uma prótese tradicional, quando o objetivo é agarrar um objeto que possui uma forma complexa (CARROZZA et al., 2002).

Nenhuma referência bibliográfica que propusesse a aplicação do motor elétrico linear em próteses de membro superior foi encontrada durante a execução deste trabalho. 


\section{Motores Lineares}

Os motores lineares pertencem ao grupo especial de máquinas elétricas, que convertem energia elétrica em energia mecânica na forma de movimento translacional (GIERAS, 1994). Surgiram em 1838, apenas sete anos após a descoberta da lei de Faraday, e começaram a ser essencialmente empregados em 1950 pelo Prof. E. R. Laithwaite (EASTHAM, 1990).

A figura 22 mostra o interesse pelos motores lineares com o passar do tempo. A escala vertical é logarítmica e é baseada numa estimativa do dinheiro investido na construção e nos testes dos motores lineares (LAITHWAITE, 1975).

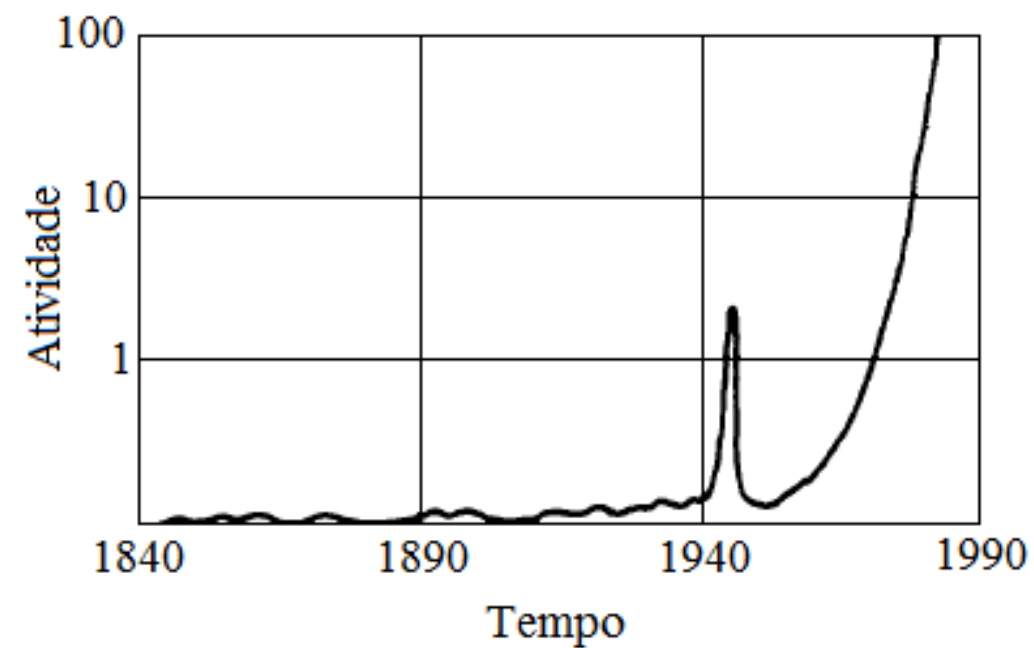

Figura 22 - Interesse pelos motores lineares em função dos anos. Adaptado de (LAITHWAITE, 1975).

Segundo (LAITHWAITE, 1973), o que atrasou em mais de sessenta anos a exploração comercial dos motores lineares foram: as dificuldades em se estabelecer as diferenças entre as máquinas rotativas e lineares e a ausência de definições em relação às características mecânicas do estator e da parte móvel do motor. Conforme as pesquisas foram sendo realizadas, conclui-se que a necessidade de um tamanho grande de entreferro iria prejudicar muito a eficiência da máquina, o que acarretou o desinteresse pelos motores lineares. 
Em 1965, Laithwaite conseguiu uma forma de caracterizar a qualidade do motor linear de indução por meio de uma única equação, na qual importantes variáveis da máquina são consideradas, como: passo polar $(\tau)$, tamanho do entreferro $(g)$ e resistividade da parte móvel $\left(\rho_{L}\right)$. As constantes são: permeabilidade magnética do vácuo $\left(\mu_{0}\right)$ e frequência angular $(\omega)$. A equação 8 foi a responsável por despertar novamente o interesse pelos motores lineares e foi nomeada de fator de qualidade $(G)$, (LAITHWAITE, 1973).

$$
G=\frac{\mu_{0} \cdot \tau^{2} \cdot \omega}{\pi^{2} \cdot \rho_{L} \cdot g}
$$

As máquinas lineares são obtidas de um processo imaginário de "corte" e de "desenrolamento" do motor rotativo, que é mostrado na figura 23 (BOLDEA; NASAR, 1985).
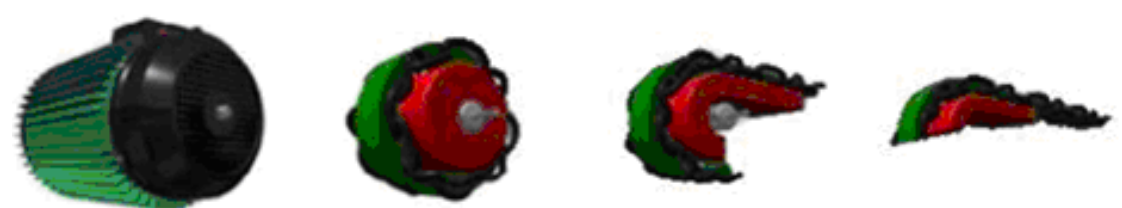

Figura 23 - Processo imaginário da obtenção do motor linear a partir do rotativo (OLIVEIRA, 2004).

O motor linear é formado por duas partes: o estator e o linor. O primeiro não se movimenta e possui o enrolamento inserido em um material, que pode ser magnético ou não. O linor é a parte que se movimenta e é o responsável pela geração do campo magnético principal, sendo constituído por ímãs ou por um enrolamento sobre uma estrutura (ferromagnética ou não), (PROFUMO; TENCONI; GIANOLIO, 2001).

O termo "linor" foi proposto por E. R. Laithwaite em 1957 para denominar o secundário dos motores de indução, caracterizando o movimento desta parte (CREPPE et al., 1998).

A interação do estator e do linor gera a força normal $F_{n}$ e a força propulsora $F$ (principal objetivo).

Máquinas em que a força normal levita o linor sobre o estator devem ser utilizadas principalmente para suspensão, denominadas máquinas lineares de levitação, convenientemente construídas. Por outro lado, as máquinas utilizadas para produzir força propulsora são denominadas de motores lineares (BOLDEA; NASAR, 1985). 


\subsection{Características Construtivas}

Analisando-se os aspectos construtivos do estator e do linor, têm-se os seguintes motores lineares: planos, setoriais e tubulares.

\subsubsection{Motores Planos}

Os motores planos são os mais conhecidos e utilizados (CREPPE et al., 1998). Possuem a forma plana, como o próprio nome sugere.

O motor pode ter estator curto e linor longo ou estator longo e linor curto, sendo uma das partes móvel e a outra fixa. Também, pode ter dois estatores, denominado de dupla face (MLDF), ou ter apenas um, que é classificado como de única face (MLUF), (BOLDEA; NASAR, 1985).

\subsubsection{Motores Setoriais}

Os motores setoriais diferenciam-se dos rotativos em relação ao estator, que possui uma saliência, ou seja, o estator não envolve totalmente o rotor, como pode ser observado na figura 24.

Devido às caracterísitcas de assimetria, esta máquina é tratada como linear (OLIVEIRA, 2004).

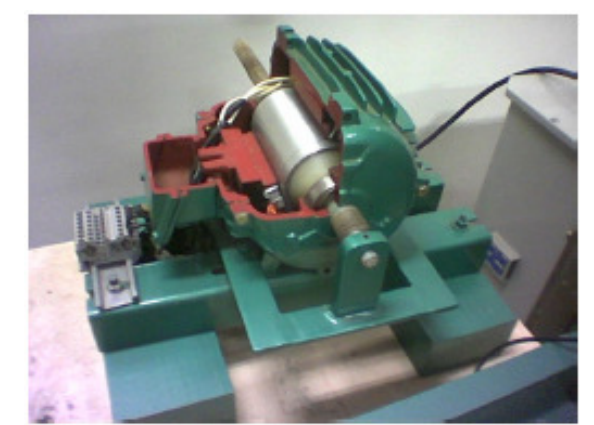

Figura 24 - Motor setorial (OLIVEIRA, 2004). 


\subsubsection{Motores Tubulares}

Os motores tubulares são derivados dos planos (figura 25), porém têm a seção transversal em forma circular, quadrada ou retangular.

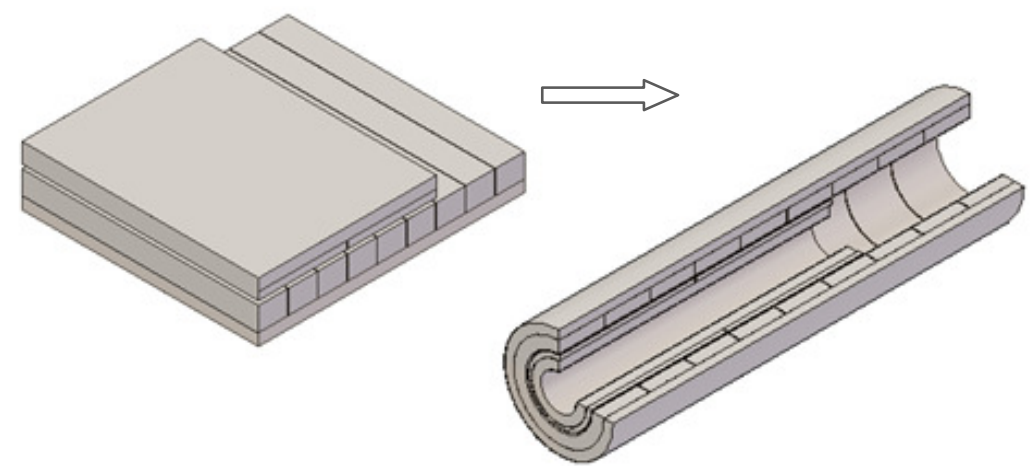

Figura 25 - Obtenção do motor linear tubular, com seção transversal em forma circular, a partir do motor linear plano (JULIANI, 2010).

Normalmente, os motores são projetados com a seção transversal em forma circular para facilitar a construção da parte que contém o enrolamento.

\subsection{Classificação}

Conforme o funcionamento e a geometria, os motores elétricos lineares mais comuns são classificados em:

- Motores de indução;

- Motores de corrente contínua;

- Motores síncronos. 


\subsubsection{Motores de Indução}

Os motores lineares, mais utilizados pelas indústrias, são os de indução. Podem ser monofásicos, bifásicos ou trifásicos. O enrolamento do estator (primário) é similar ao da máquina rotativa (BOLDEA; NASAR, 1985).

O linor (secundário) consiste em uma placa, às vezes apoiada em um material ferromagnético ou em gaiola. Raramente é utilizado enrolamento em sua constituição, como no motor rotativo de rotor bobinado (BOLDEA; NASAR, 1985).

De acordo com a construção, os motores de indução lineares possuem dois tipos de fluxo magnético: longitudinal, em que as linhas de fluxo são paralelas à direção do movimento do campo magnético, ou transversal, em que as linhas são perpendiculares à direção de movimento do campo magnético.

A principal vantagem do fluxo magnético transversal, comparado com o longitudinal, é a baixa corrente de magnetização, por causa do menor caminho do fluxo magnético, porém tem a desvantagem de possuir uma menor força propulsora.

Além do motor linear de indução plano com fluxo magnético transversal produzir força propulsora, ele pode gerar suspensão eletrodinâmica.

\subsubsection{Motores de Corrente Contínua}

Motores de corrente contínua, embora teoricamente plausíveis, são de pouco interesse prático (BOLDEA; NASAR, 1985). As justificativas, para o seu baixo emprego, são as desvantagens também apresentadas por esse tipo de máquina rotativa: menor desempenho do que os motores síncronos, problemas relacionados às escovas e outros.

\subsubsection{Motores Síncronos}

Os motores síncronos possuem a velocidade mecânica $\left(v_{m}\right)$ igual à velocidade do campo deslizante (equação 9). 


$$
v_{m}=\frac{2 \cdot f \cdot \tau}{P P}
$$

Onde:

$f$ é a freqüência da alimentação $[\mathrm{Hz}]$;

$P P$ é o número de pares de pólo.

A força propulsora pode ser gerada como a interação entre:

- O campo magnético deslizante produzido por um enrolamento polifásico e o campo de ímãs permanentes (alimentação de corrente alternada);

- O campo magnético produzido pelo chaveamento eletrônico de uma alimentação contínua e o campo de ímãs permanentes (GIERAS; PIECH, 2000).

A parte que produz o campo magnético deslizante é denominada de armadura e a que é responsável pelo fluxo magnético CC ou variação de relutância é chamada de sistema de excitação de campo, ou de linor. Os termos primário e secundário devem ser evitados, pois são empregados apenas para motores lineares de indução ou transformadores. A operação de um motor linear síncrono não depende de qual parte é móvel ou de qual é estacionária (GIERAS; PIECH, 2000).

\subsubsection{Motores com Ímãs Permanentes}

Os motores lineares síncronos, com ímãs permanentes (MLSIP), têm alta força propulsora, quando comparados com as máquinas lineares assíncronas e as de corrente contínua. Permitem, também, uma fácil construção de topologias modulares (PROFUMO; TENCONI; GIANOLIO, 2001). Podem ser divididos em dois grupos, de acordo com a força contraeletromotriz produzida pelo fluxo magnético incidindo no enrolamento do estator: brushless $A C$ e brushless DC.

O termo brushless refere-se à ausência de escovas e de comutadores mecânicos nesse tipo de máquina.

Segundo (NASAR; BOLDEA; UNNEWEHR, 1993), a nomenclatura brushless DC deve-se à máquina síncrona com ímã permanente no linor, com forma de onda não senoidal, ser comercializada juntamente com o seu conversor de potência. Este conjunto comporta-se como uma máquina $\mathrm{CC}$, mas com um comutador eletrônico. 
De acordo com (HENDERSHOT; MILLER, 1994), os motores brushless $A C$ implicam em excitação senoidal e a tensão induzida, ideal, tem a mesma forma de onda da alimentação. Fisicamente o motor e o seu controle são similares ao brushless $D C$.

\subsubsection{Motores de Passo}

Um motor linear de passo possui pólos salientes, com enrolamento concentrado de armadura, e ímãs permanentes no linor ou relutância variável (material ferromagnético). Não possui sensores de posição e são utilizados em sistemas de posicionamento, que requerem uma alta precisão e rápida aceleração (GIERAS; PIECH, 2000).

\subsubsection{Motores de Relutância Chaveada}

Os motores de relutância chaveada possuem a topologia semelhante ao motor de passo. Para o correto chaveamento da corrente de alimentação são utilizados sensores de posição, sendo a força propulsora sensível a esse chaveamento (GIERAS; PIECH, 2000).

\subsection{Efeitos de Extremidades}

Os motores lineares não possuem a força contraeletromotriz com uma amplitude constante e também, as correntes por fase não são balanceadas como ocorre nas máquinas rotativas. Estas características são consequências dos efeitos de extremidades que são divididos em dois tipos: efeito longitudinal de extremidade e efeito transversal de borda. 


\subsubsection{Efeito Longitudinal de Extremidade}

O efeito longitudinal pode ser divido em dois tipos: estático, que é causado pela assimetria da impedância por fase da máquina trifásica, e dinâmico que é devido à descontinuidade do circuito magnético de entrada e de saída do motor (LI et al., 2010).

A figura 26.a mostra um motor linear de indução e as correntes parasitas geradas, na entrada e na saída do entreferro, com o movimento do primário. O comportamento destas correntes é ilustrado na figura $26 . b$ e a variação do fluxo magnético em função do comprimento do motor é apresentada na figura 26.c.

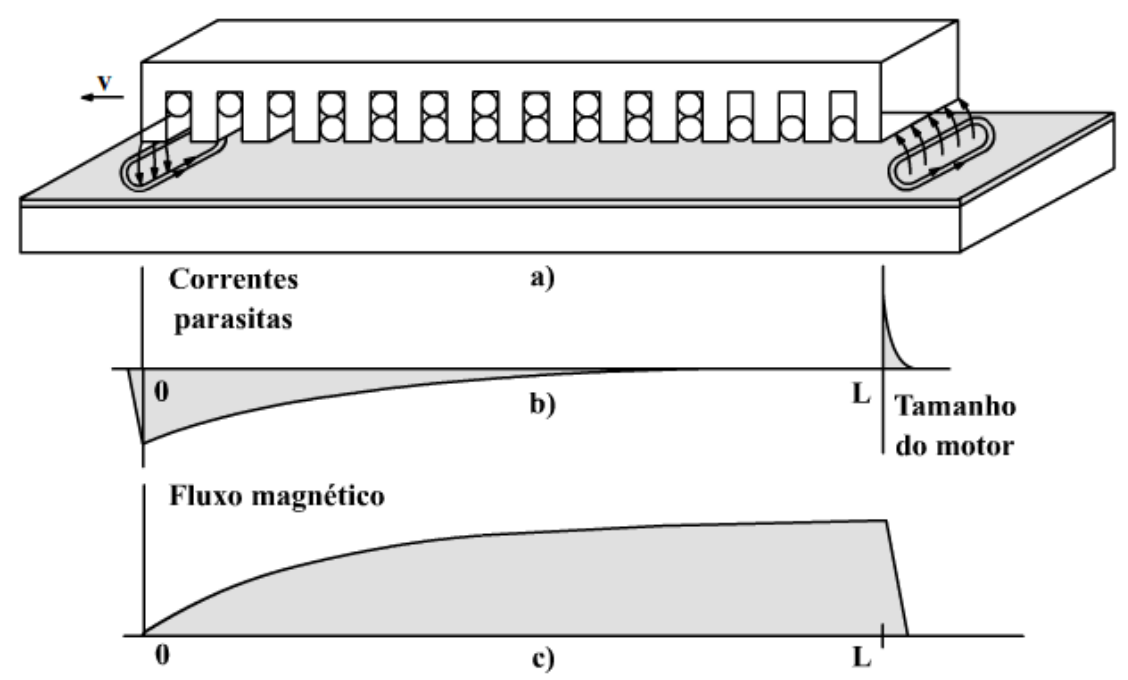

Figura 26 - a) Motor linear de indução e as correntes parasitas nas extremidades;

b) Comportamento das correntes parasitas; c) Variação do fluxo magnético (SUNG; NAM, 1999).

\subsubsection{Efeito Transversal de Borda}

Apenas os motores planos apresentam o efeito transversal de borda, sendo consequência das características geométricas da máquina.

Ocorre quando a largura do linor é maior do que a do estator, causando uma distribuição não uniforme da corrente circulante no linor (CREPPE et al., 1998). 


\subsection{Comparações entre os Principais Motores Lineares}

Por meio das principais características de cada máquina, pode-se fazer uma análise de qual é a melhor opção para aplicá-la em uma prótese de membro superior.

O motor linear de corrente contínua possui as seguintes desvantagens, quando comparado com os demais apresentados: baixa densidade de força propulsora, baixa eficiência, baixa confiabilidade e a necessidade de manutenção periódica decorrente da presença das escovas.

O motor de indução, quando comparado com as máquinas síncronas de ímãs permanentes, possui a desvantagem de necessitar, para baixas velocidades, de um complexo controle elétrico.

Os motores de passo e as máquinas de relutância chaveada apresentam a desvantagem de produzirem uma força propulsora com oscilações.

Além disso, os motores de relutância apresentam uma força propulsora menor do que as máquinas síncronas com ímãs permanentes. Segundo (BIANCHI; BOLOGNANI; CORDA, 2002), em uma mesma temperatura $\left(125^{\circ} \mathrm{C}\right)$, a densidade de força de um motor tubular de relutância chaveada é aproximadamente $70 \%$ da mesma relação de um motor tubular síncrono, com ímãs de $\mathrm{NdFeB}$ e com ranhuras.

Comparando-se o motor brushless $D C$ com o brushless $A C$, tem-se que o segundo possui um maior grau de complexidade de construção do que o primeiro.

Com as observações realizadas anteriormente, conclui-se que o motor síncrono com ímã permanente no linor (brushless DC) é o que melhor se enquadra na aplicação de prótese de membro superior. 


\section{Metodologia de Projeto do Motor}

\section{Linear}

Neste capítulo, é apresentada uma metodologia de projeto do motor linear síncrono com ímãs permanentes. As topologias existentes de estator e de linor são detalhadas e comparadas. Este procedimento é realizado com o objetivo de facilitar a escolha de cada uma das partes constituintes do motor a ser construído, e quando feita é justificada de acordo com a aplicação.

Conforme (HENDERSHOT, 1994), os principais passos de um projeto de uma máquina brushless $D C$ são detalhados a seguir.

\subsection{Determinação das Necessidades da Aplicação}

O projeto de um motor elétrico deve basear-se nas necessidades da aplicação, que são as primeiras a serem estabelecidas, como: velocidade, força, alimentação, volume e outras.

De acordo com (ZOLLO et al., 2007) e (CARROZZA et al., 2002), o motor elétrico linear, que será projetado para ser aplicado em próteses de membro superior, deve possuir a velocidade máxima e a força indicadas na tabela 5. As demais exigências também são mostradas, sendo o deslocamento mínimo do linor determinado na subseção 2.2.2, o comprimento e o diâmetro máximos do motor linear referem-se ao tamanho do antebraço de um indivíduo adulto do sexo masculino, conforme as especificações da subseção 2.2.3. 
Tabela 5 - Características do motor elétrico linear deste trabalho.

\begin{tabular}{cc}
\hline Características & Valores \\
\hline Velocidade Máxima $[\mathrm{m} / \mathrm{s}]$ & 0,02 \\
Deslocamento Mínimo do Linor [cm] & 1,91 \\
Força $[\mathrm{N}]$ & 12 \\
Comprimento Máximo [cm] & 25 \\
Diâmetro Máximo [cm] & 3 \\
Massa [Kg] & a menor possível \\
Alimentação [V] & a menor possível \\
\hline
\end{tabular}

\subsubsection{Ciclo Ativo}

O ciclo ativo $\left(D_{c}-\right.$ Duty Cycle $)$ de um motor é definido como a relação entre o tempo da máquina ligada $\left(t_{o n}\right)$ pela soma deste mesmo tempo com a máquina desligada $\left(t_{o f f}\right)$, (equação 10). Em alguns casos, esta característica pode influenciar no comportamento térmico do motor (CHEVAILLER, 2006).

$$
D_{c}=\frac{t_{o n}}{t_{o n}+t_{o f f}}
$$

\subsection{Escolha do Tipo de Máquina}

Como os motores rotativos, as máquinas lineares síncronas com ímã permanente possuem diversas configurações. A seguir são apresentadas as topologias de estator, de enrolamento e de linor. 


\subsubsection{Estator}

O comprimento do estator depende das exigências da aplicação. A armadura pode ser constituída de material ferromagnético ou não. (BASAK, 1996).

\subsubsection{Longo e Curto}

As diferenças entre o estator longo e o curto interferem no cálculo da eficiência do motor, do comportamento térmico, do custo e da conexão elétrica. No entanto, não influencia no modelo magnético (CHEVAILLER, 2006).

O estator curto possui maior eficiência do que o longo, porque as perdas no cobre são menores. No entanto, as linhas de campo magnético não se concentram totalmente no interior do motor.

A densidade de corrente, nos motores com estator longo, é geralmente maior quando comparada aos que possuem estator curto, desde que o ciclo ativo seja menor do que a unidade (CHEVAILLER, 2006).

O motor linear pode ser constituído por vários módulos, que são conectados em paralelo ou em série, no caso de um motor com estator curto. Isto é possível porque cada setor do motor possui a mesma tensão induzida por fase, para cada instante de tempo. No caso das máquinas com estator longo, elas só podem ser conectadas em série (CHEVAILLER, 2006).

Os motores com estator curto são projetados para possuírem um ciclo ativo igual a $100 \%$, enquanto os de estator longo podem ter esse valor inferior a $50 \%$.

Para máquinas com um estator superior a $30 \mathrm{~cm}$, suportes e guias são necessários (BASAK, 1996). 


\subsubsection{Face Única e Dupla}

A terminologia face única (figura 27) e dupla (figura 28) significa a quantidade de estatores que uma máquina possui, sendo válida para os motores planos e tubulares (GIERAS; PIECH, 2000).

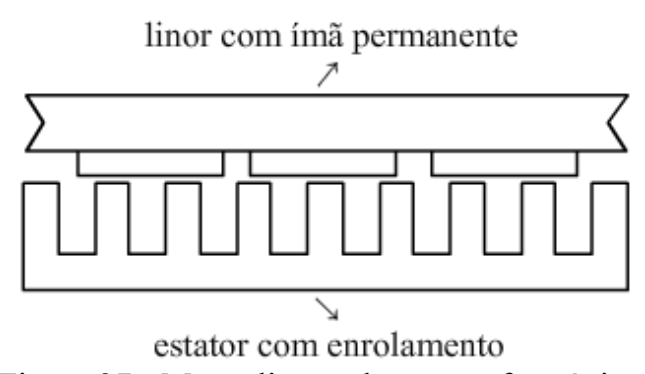

Figura 27 - Motor linear plano com face única.

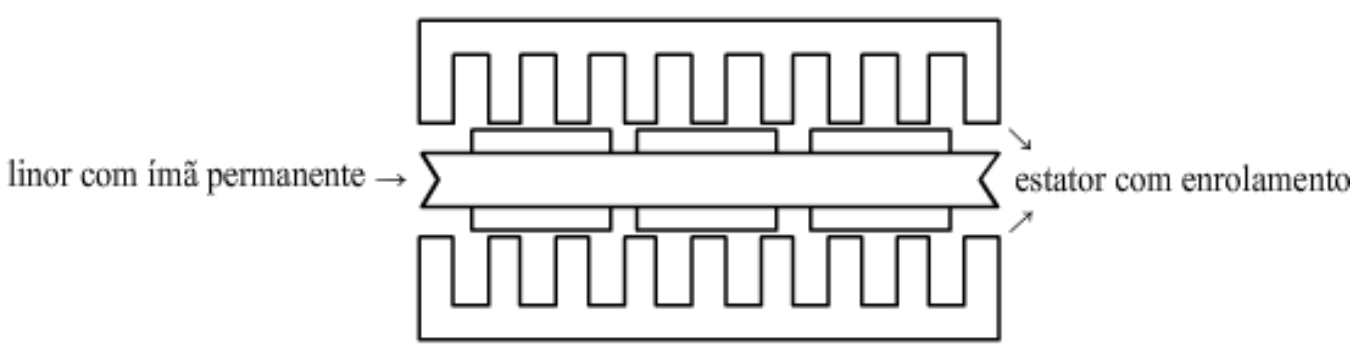

Figura 28 - Motor linear plano com dupla face.

A escolha entre face única ou dupla deve ser feita de acordo com as características mecânicas. As principais razões para a escolha do motor com dupla face são: um motor mais compacto e a redução da força atrativa entre o estator e o linor (CHEVAILLER, 2006).

\subsubsection{Tubular e Plano}

Em (ZYL et al., 1999), comparações são feitas entre motores síncronos planos e um tubular. Para a máquina plana com face única e de ímãs no interior do linor, obteve-se uma força máxima de $717 \mathrm{~N}$. Com a massa do linor de 19,2 Kg, a taxa de força por massa é 4:1. Com as mesmas características da máquina anterior, mas com os ímãs dispostos na superfície do linor, foi obtida uma força máxima de $1681 \mathrm{~N}$, com a massa de $22 \mathrm{Kg}$ da parte móvel, resultando uma taxa de força por massa igual a 7:1. 
Já no motor tubular, com ímãs no interior da parte móvel, a força máxima é de $2972 \mathrm{~N}$ e a massa do linor é igual a $20,8 \mathrm{Kg}$, sendo a taxa de $14: 1$. Os valores de força foram obtidos por meio de análises utilizando-se o método dos elementos finitos, sendo usada a mesma alimentação para todos os casos.

Há justificativas para o motor tubular apresentar uma taxa de força por massa maior do que a dos motores planos: uma delas é devido à natureza tubular, em que o fluxo magnético concentra-se em seu interior; outra é consequência da diferença geométrica da parte móvel, em que a área do entreferro do motor tubular é aproximadamente duas vezes a do plano (ZYL et al., 1999).

Apesar das comparações apresentadas anteriormente serem feitas para máquinas grandes (considerando-se a aplicação do motor em uma prótese de membro superior), os conceitos discutidos são válidos também para máquinas menores.

\subsubsection{Com Ranhuras e Sem Ranhuras}

O estator de um motor pode possuir ranhuras (slotted) ou não (slotless).

A configuração sem ranhuras elimina as oscilações na força causada pela variação períódica da relutância devido à presença de dentes $(\mathrm{Fe})$ e ranhuras (ar), e melhora o desempenho dinâmico (WANG; JEWELL; HOWE, 2001).

Em (BIANCHI et al., 2003), comparações entre essas duas configurações (figuras 30 e 31) são realizadas abrangendo-se dois tipos de máquinas: motor tubular com ímãs permanentes no interior do linor (figura 29.a) e motor tubular com ímãs na superfície do linor (figura 29.b). Também são considerados os ímãs de NdFeB e de ferrita nessas comparações. 


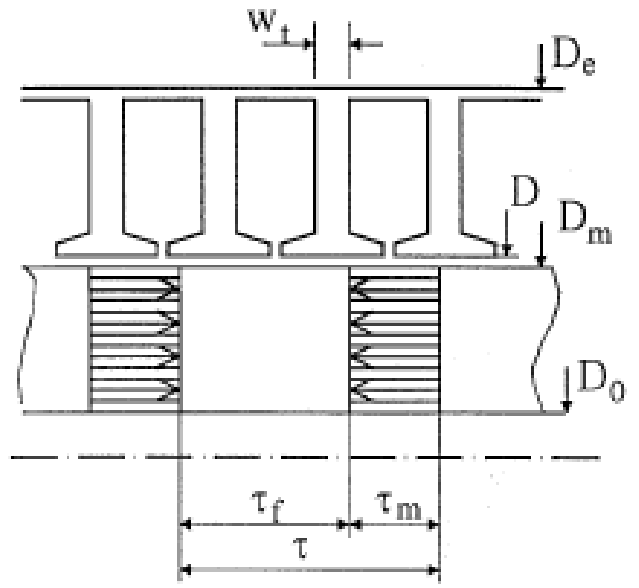

(a)

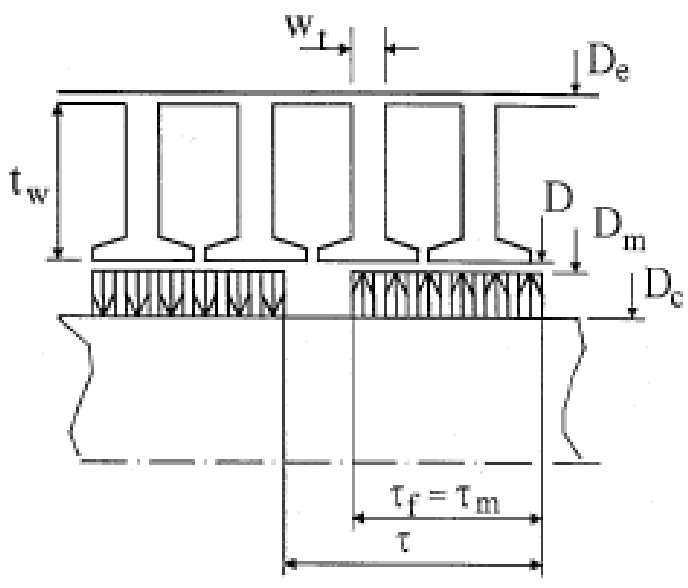

(b)

Figura 29 - Motor tubular: a) com ímãs no interior; b) com ímãs na superfície (BIANCHI et al., 2003).

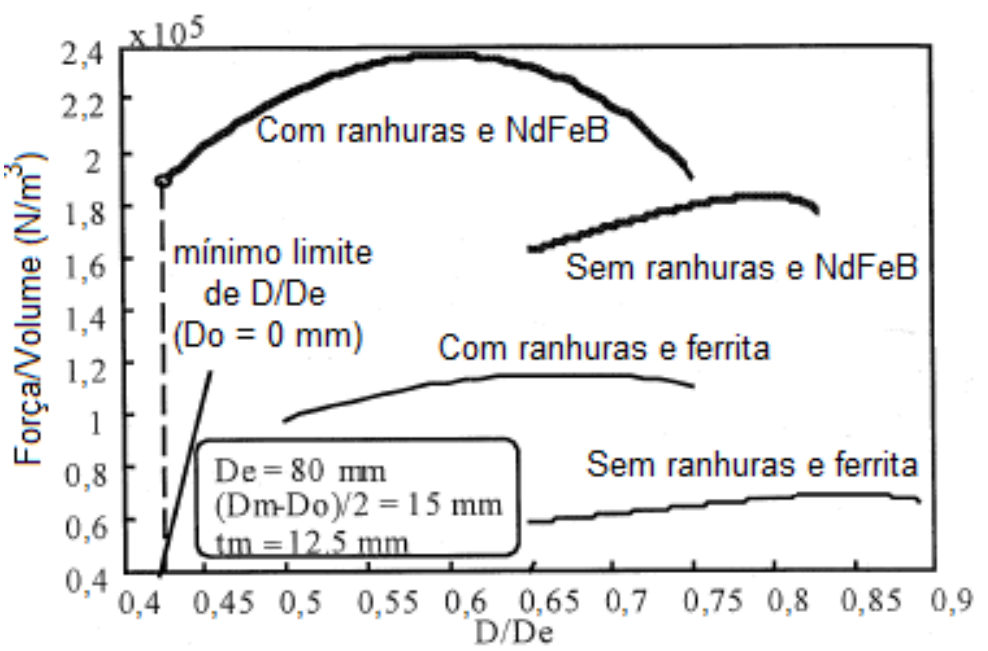

Figura 30 - Taxa de força por volume comparando-se motores tubulares com e sem ranhuras e ímãs no interior do linor. Adaptado de (BIANCHI et al., 2003).

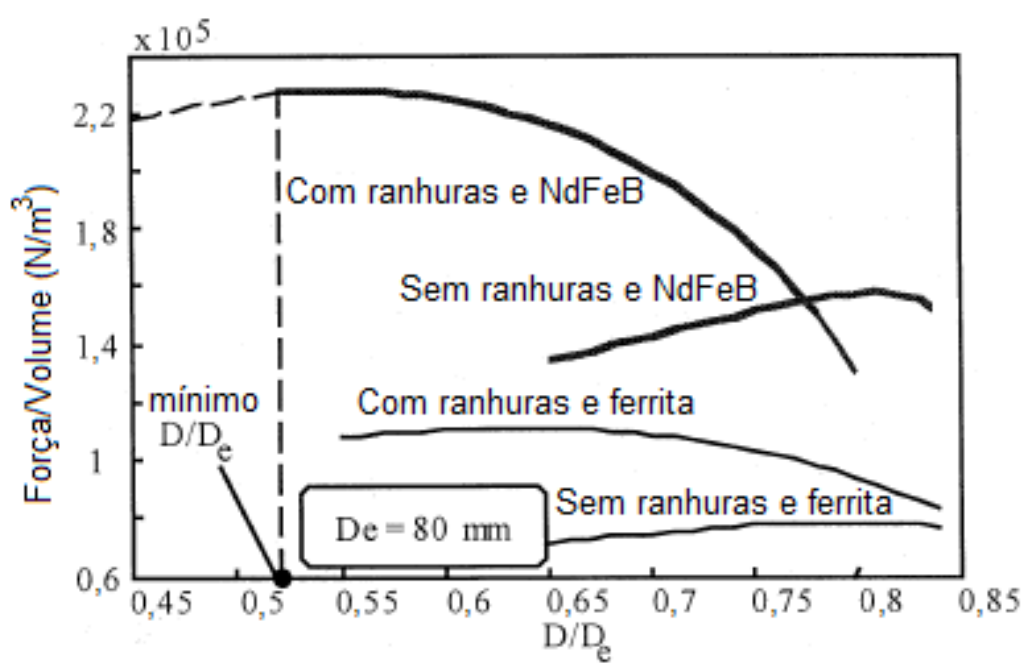

Figura 31 - Taxa de força por volume comparando-se motores tubulares com e sem ranhuras e ímãs na superfície do linor. Adaptado de (BIANCHI et al., 2003). 
As figuras 30 e 31 referem-se a motores com o diâmetro externo $\left(D_{e}\right)$ igual a $80 \mathrm{~mm}$. Para esta dimensão, o valor máximo da taxa de força por volume é atingido com $\mathrm{D} / \mathrm{De} \approx 0,80-0,85$ para a configuração sem ranhuras $\mathrm{e} \mathrm{D} / \mathrm{De} \approx 0,60-0,65$ para os motores com ranhuras (BIANCHI et al., 2003).

Conforme esperado, a taxa de força por volume é maior para as máquinas com ímãs de NdFeB quando comparada com a dos motores de ímãs de ferrita.

Em (BIANCHI; BOLOGNANI; TONEL, 2001), as configurações com ranhuras e sem ranhuras são comparadas apenas para o motor tubular de ímãs no interior do linor para as seguintes dimensões de raio externo: 50, 60 e $80 \mathrm{~mm}$. Concluiu-se que se aumentando $\mathrm{D}_{\mathrm{e}}$, tem-se uma maior densidade de força para os motores com ranhuras. Enquanto diminuindo-o, especificamente para valores iguais ou menores do que $50 \mathrm{~mm}$, tem-se a melhor configuração sem ranhuras, que pode ser observada na figura 32.

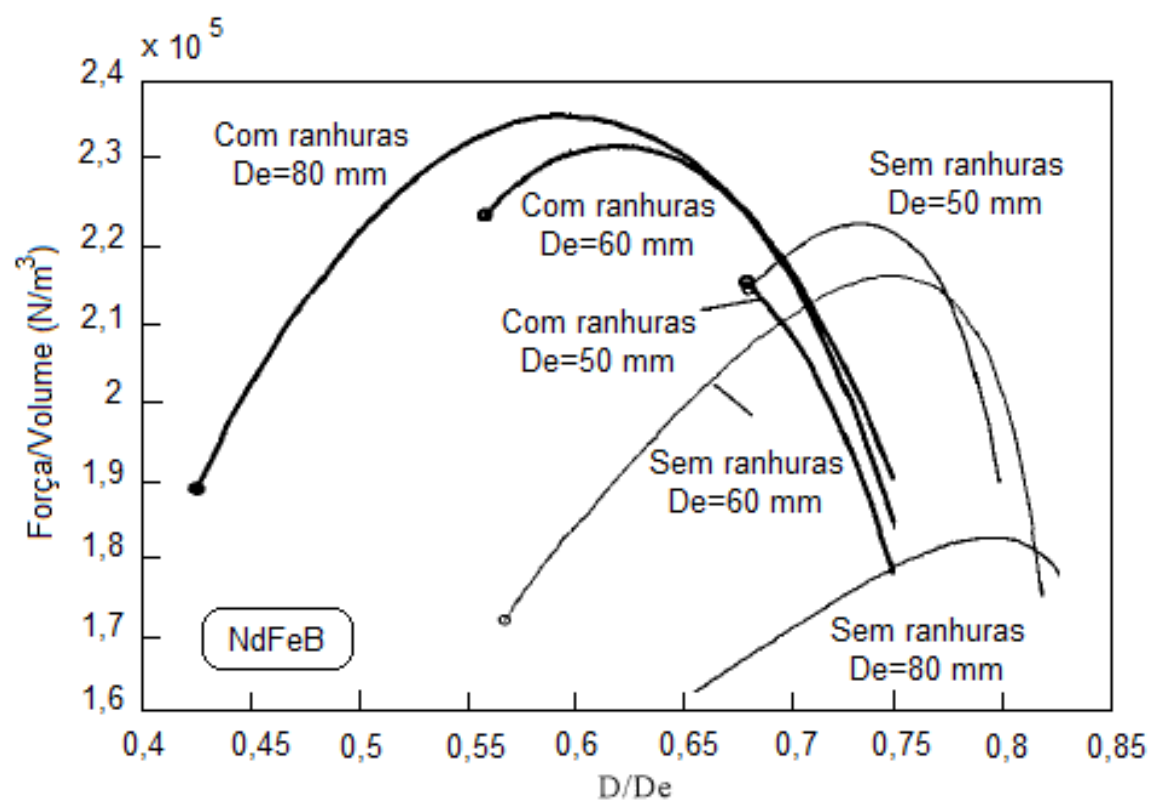

Figura 32 - Taxa de força por volume comparando-se motores tubulares com e sem ranhuras, e ímãs no interior do linor, para diferentes tamanhos de raio externo. Adaptado de (BIANCHI; BOLOGNANI; TONEL, 2001).

\subsubsection{Escolha do Tipo de Estator}

O estator do protótipo a ser construído possui as seguintes características:

- Longo para que as linhas de campo magnético se concentrem no interior do motor, evitando que elas excedam o seu exterior e interfiram no ambiente em que o paciente se encontre; 
- Tubular por fornecer uma força propulsora maior do que a do motor plano por unidade de massa;

- Face única pela facilidade construtiva;

Em relação à presença e à ausência de ranhuras, é feito um estudo comparativo na subseção 4.14.1 para a verificação das vantagens e das desvantagens de cada uma na aplicação de prótese.

\subsubsection{Enrolamento}

São apresentados, no apêndice B, os conceitos essenciais sobre os enrolamentos das máquinas elétricas, especificamente sobre os motores lineares.

\subsubsection{Linor}

Existem três configurações possíveis da parte móvel do motor: linor com ímãs, linor com enrolamento e linor de enrolamento.

\subsubsection{Linor com Î́mãs}

O linor com ímãs é a topologia mais comum, que consiste em um suporte, com a função de caminho para o retorno do fluxo magnético, e ímãs que podem estar dispostos em sua superfície ou em seu interior.

Este tipo de configuração é utilizado quando se deseja um alto valor da força propulsora ou/e quando a simplicidade mecânica é requerida (BASAK, 1996).

Em motores planos, com ímãs no interior do linor, a profundidade do material ferromagnético é a mesma que a dos ímãs. Isto também ocorre nos motores tubulares, o diâmetro do passo polar é o mesmo que o dos ímãs (ZYL et al., 1999). 
O fluxo magnético é mais bem distribuído, nos passos polares, na configuração do linor com ímãs no interior com magnetização axial (figura 33), quando comparado com os ímãs na superfície com magnetização radial (figura 34), o que possibilita a concentração do fluxo em um volume menor de ferro. Em consequência, a redução do material ferromagnético do linor causa uma redução da massa, havendo uma melhora na taxa de força por massa. Porém, a configuração com ímãs na superfície propicia uma força propulsora maior do que aquela com os ímãs no interior, devido à maior densidade de fluxo magnético no entreferro (ZYL et al., 1999).

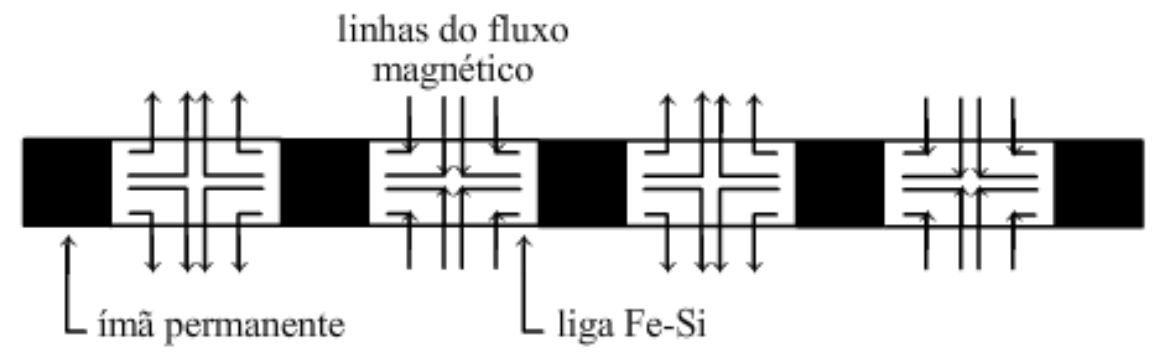

Figura 33 - Linor com ímãs no interior. Adaptado de (ZYL et al., 1999).

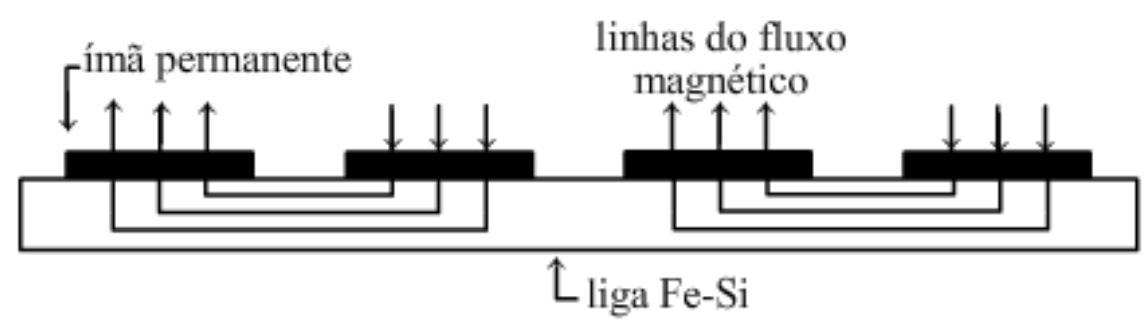

Figura 34 - Linor com ímãs na superfície. Adaptado (ZYL et al., 1999).

Outro tipo de magnetização dos ímãs do linor é a chamada de Halbach, mostrada na figura 35.

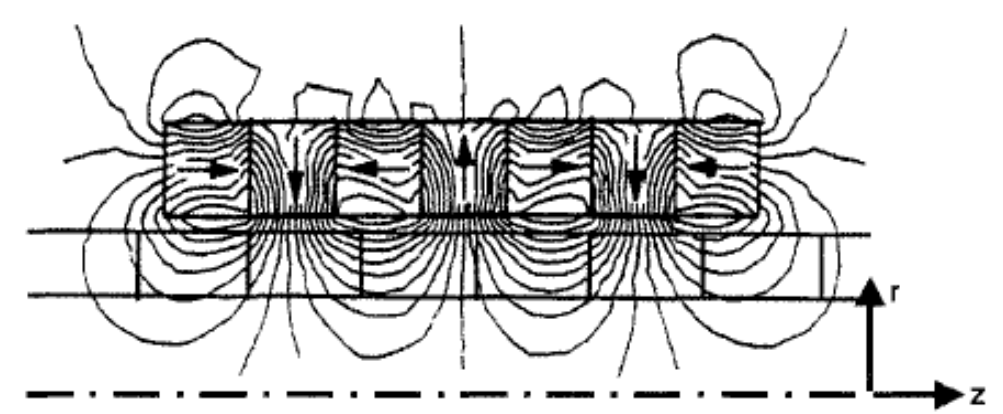

Figura 35 - Linhas de fluxo magnético de um motor tubular com a configuração Halbach (ZHU; HOWE, 2001). 
Esse tipo de magnetização possui o próprio isolamento como propriedade natural e, com isto, não necessita de um material ferromagnético para fazer o caminho de retorno do fluxo magnético (ZHU; HOWE, 2001).

Também, possui algumas vantagens para as máquinas síncronas de corrente alternada (brushless AC): a magnetização Halbach produz uma distribuição senoidal do campo magnético no entreferro e o ponto de operação do ímã é maior do que os que possuem magnetização radial e axial (ZHU; HOWE, 2001).

\subsubsection{Linor com Enrolamento}

O estator consiste em uma superfície ferromagnética com ímãs e o linor, menor do que ele, é formado por chapas laminadas com enrolamento (figura 36).

Esta configuração possui características similares ao linor com ímãs (BASAK, 1996).

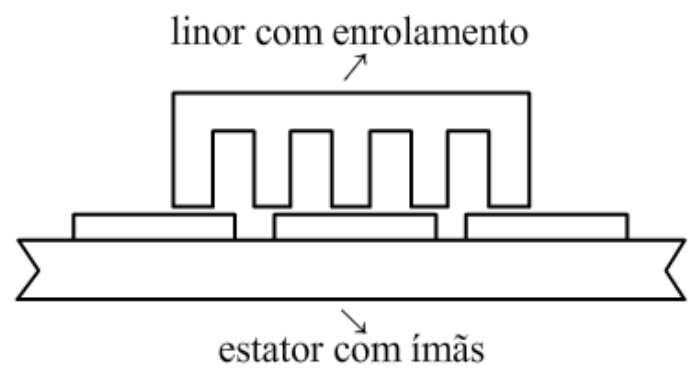

Figura 36 - Linor com enrolamento.

\subsubsection{Linor de Enrolamento}

Linor de enrolamento, como mostrado na figura 37, é similar ao linor com enrolamento, exceto que a estrutura ferromagnética é retirada da parte móvel e somente os condutores e o suporte de sua estrutura permanecem (BASAK, 1996).

Este tipo de configuração é o que oferece a maior taxa de força/inércia. Pode ser projetado para atingir níveis de força com oscilações extremamente baixas, devido à ausência da força de relutância. $\mathrm{O}$ momento de inércia baixo permite um movimento incremental com altas taxas de aceleração e desaceleração. 
A resistência térmica entre o linor e o ambiente (ar) é maior do que a dos outros modelos, necessitando-se de refrigeração do enrolamento em altas velocidades (BASAK, 1996).

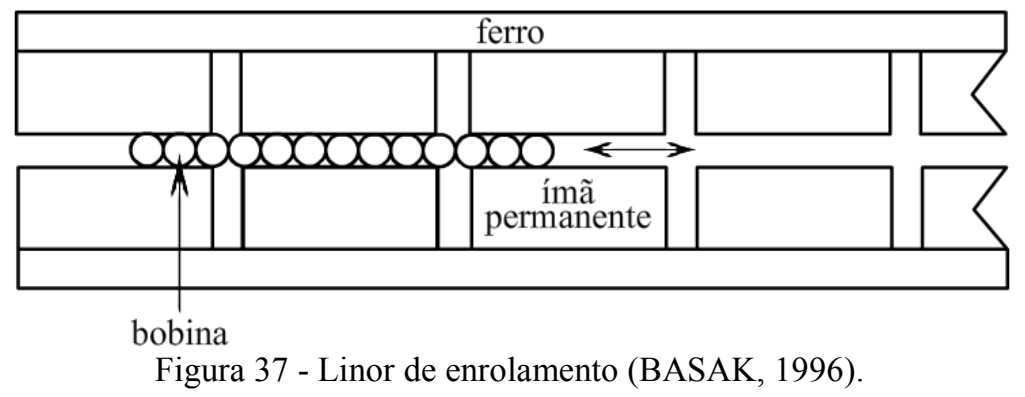

\subsubsection{Escolha do Tipo de Linor}

Todos os tipos de configurações do linor, mostrados anteriormente, necessitam de uma comutação eletrônica. As principais características de cada uma delas são comparadas na tabela 6 (BASAK, 1996).

Tabela 6 - Topologias do linor (BASAK, 1996).

\begin{tabular}{cccc}
\hline Motor Linear & Linor com Ímãs & Linor com Enrolamento & Linor de Enrolamento \\
\hline Peso do Linor & Médio & Elevado & Leve \\
Efeito de Extremidades & Presente & Presente & Ausente \\
Perda & Alta & Média & Baixa \\
Volume dos Ímãs & Pequeno & Médio & Grande \\
Custo & Moderado & Baixo & Alto \\
\hline
\end{tabular}

Analisando-se as topologias mostradas nesta subseção e de acordo com a aplicação deste projeto, selecionou-se o linor com ímãs, pois possui o menor volume e a maior simplicidade mecânica quando comparado com os demais.

A configuração do linor com ímãs na superfície foi escolhida porque fornece uma força propulsora maior do que a com ímãs no interior. Também, ela é mais simples construtivamente, quando comparada com a Halbach. 


\subsection{Seleção do Ímã Permanente}

Para a construção do protótipo deste trabalho, foram selecionados os ímãs à base de terras-raras NdFeB (Neodímio-Ferro-Boro) e SmCo (Samário-Cobalto), pois possuem o produto de energia máximo ( $\left.\mathrm{BH}_{\text {máx }}\right)$ maior do que os demais ímãs (Alnico, ferrita).

Ambos são utilizados (separadamente) no projeto do motor tubular para que uma análise comparativa entre eles possa ser feita, analisando-se os seguintes fatores, para as mesmas dimensões da máquina: efeito de saturação do material ferromagnético e força eletromagnética.

As principais características e propriedades dos materiais magnéticos são apresentadas em (JULIANI, 2007).

\subsection{Escolha do Número de Pólos}

A escolha do número de pólos depende de vários fatores, tais como: material e categoria do ímã, configuração do linor, montagem mecânica do linor e dos ímãs, velocidade, força e inércia requerida.

\subsection{Determinação do Número de Fases do Estator}

Comparando-se máquinas bifásicas e trifásicas, com as mesmas características geométricas, elétricas e magnéticas, tem-se que a segunda oferece uma força cerca de $6 \%$ maior do que a primeira (WANG; JEWELL; HOWE, 2001).

Também, os motores trifásicos, em geral, possuem o desempenho melhor do que os bifásicos. Além disso, os módulos integrados de eletrônica de potência são disponíveis para motores síncronos trifásicos (WANG; JEWELL; HOWE, 2001).

Portanto, o motor linear que será construído possuirá três fases. 


\subsection{Determinação do Tamanho do Entreferro}

O tamanho do entreferro deve ser o menor possível, sendo esta característica não muito significante para as máquinas com o estator sem ranhuras, quando comparadas com as que as possuem (WANG; JEWELL; HOWE, 2001).

\subsection{Determinações das Dimensões Geométricas}

Nesta subseção, são apresentadas as dimensões que devem ser especificadas do motor linear síncrono tubular com ímãs permanentes na superfície para o estator sem e com ranhuras, figuras 38 e 39 , respectivamente.

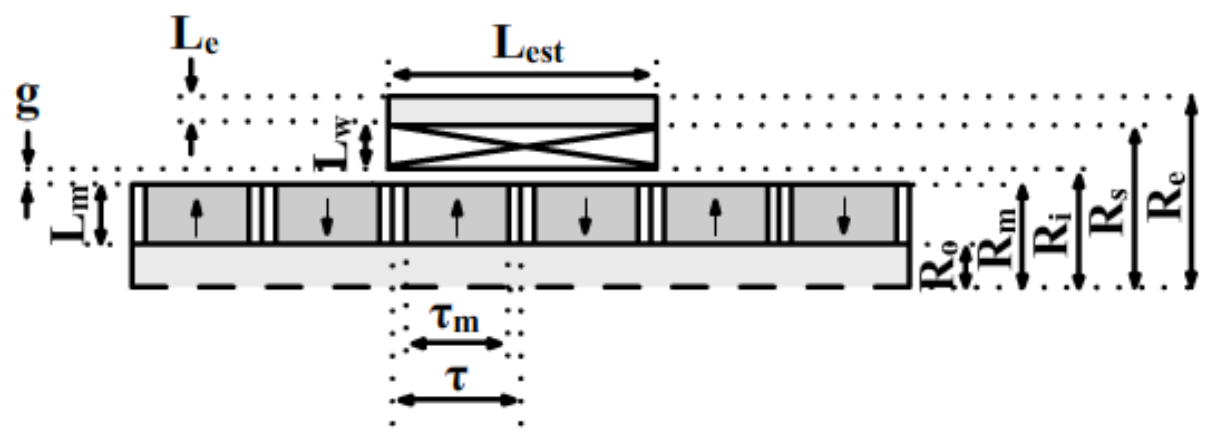

Figura 38 - Dimensões que devem ser especificadas para o projeto do motor linear sem ranhuras.

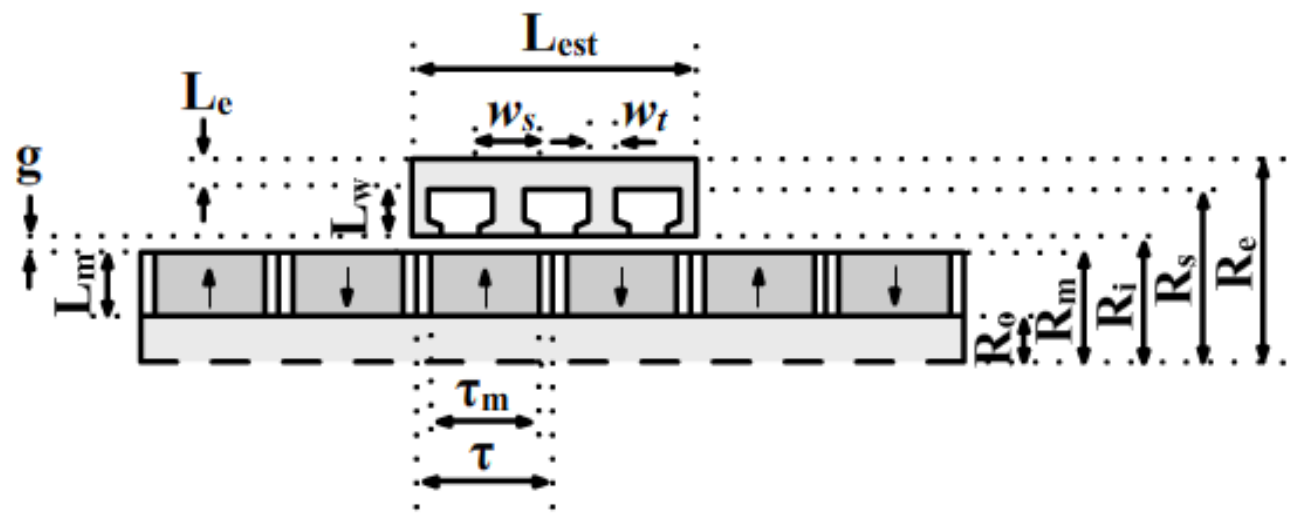

Figura 39 - Dimensões que devem ser especificadas para o projeto do motor linear com ranhuras. 
Conforme descrito na subseção 4.1, o diâmetro máximo do motor deve ser $3 \mathrm{~cm}$. Portanto, $\mathrm{R}_{\mathrm{e}}$ deve ter o valor máximo de $1,5 \mathrm{~cm}$.

A influência de $\tau_{\mathrm{m}} / \tau$ na força e em suas oscilações é independente de outras dimensões. Com o intuito de maximizar a força, essa relação é igual à unidade e quando o objetivo é minimizar as oscilações da força o seu valor ótimo é igual a 0,8 (WANG; JEWELL; HOWE, 2001).

Um valor ótimo de $\tau / R_{\mathrm{s}}$ resulta em uma máxima força. Quando esta relação fica abaixo deste valor ótimo, o campo magnético produzido pelos ímãs decai rapidamente e então a força é reduzida. Se esta taxa é muito grande, o fluxo magnético por pólo torna-se excessivo e ocorrem saturações no material ferromagnético. As oscilações na força também aumentam, conforme esta relação é elevada. Portanto, um valor menor de $\tau / R_{\mathrm{s}}$ é requerido se as oscilações na força são indesejadas (WANG; JEWELL; HOWE, 2001).

A relação de $R_{m} / R_{s}$ representa um balanço ótimo entre a carga elétrica e magnética da máquina, para um dado desempenho térmico (WANG; JEWELL; HOWE, 2001).

A taxa $R_{o} / R_{m}$ determina a espessura dos ímãs e o valor máximo de desmagnetização (WANG; JEWELL; HOWE, 2001).

A espessura dos ímãs $\left(L_{m}\right)$ é determinada por meio do tamanho e do coeficiente de permeância $(P C)$, que caracteriza a operação do ímã permanente no circuito magnético formado pela geometria do motor, sendo expresso pela equação 11 (HENDERSHOT; MILLER, 1994).

$$
P C=\frac{B_{M}}{\mu_{0} \cdot H_{M}}=\frac{L_{m}}{g}
$$

Onde:

$B_{M}$ é a densidade de fluxo magnético no ponto de operação em circuito aberto [T];

$H_{M}$ é a intensidade de campo magnético no ponto de operação em circuito aberto [ $\mathrm{A} \mathrm{m}^{-1}$ ]. 


\subsubsection{Força Eletromagnética}

A força eletromagnética ( $\vec{F}$ ) produzida pela interação do estator com o linor pode ser calculada por meio da equação 12 , sendo $(\vec{J} \times \vec{B})$ a força de Lorentz, que é produzida pela interação de um campo magnético com uma corrente.

$$
\vec{F}=\int(\vec{J} \times \vec{B}) d V
$$

Onde:

$\vec{B}$ é o vetor densidade de fluxo magnético [T];

$d V$ é um elemento infinitesimal de volume;

$\vec{J}$ é o vetor densidade de corrente elétrica $\left[\mathrm{A} \mathrm{m}^{-2}\right]$.

O fluxo magnético ( $\phi[\mathrm{Wb}])$ através de uma superfície é definido como:

$$
\phi=\int_{S} \vec{B} \cdot d \vec{S}
$$

Onde:

$d \vec{S}$ é um elemento infinitesimal de superfície.

Para o cálculo da força eletromagnética em um pólo do motor linear, tem-se a interação do campo magnético produzido pelos ímãs do linor com a corrente que circula no enrolamento do estator. Com isso, substituindo-se a equação 13, que neste caso é o fluxo magnético no entreferro, na equação 12, que calcula a força de Lorentz no volume que abrange o entreferro e o enrolamento do estator, tem-se:

$$
F=J \cdot k_{w} \cdot \phi_{g} \cdot\left(R_{s}-R_{m}\right)
$$

Onde:

$J$ é a densidade de corrente $\left[\mathrm{A} \mathrm{m}^{-2}\right]$;

$k_{w}$ é o fator de enrolamento. 


\subsubsection{Força Eletromagnética Ótima do Motor Sem Ranhuras}

O fluxo magnético no entreferro (figura 40a) pode ser obtido por meio da solução do circuito magnético análogo mostrado na figura $40 \mathrm{~b}$.

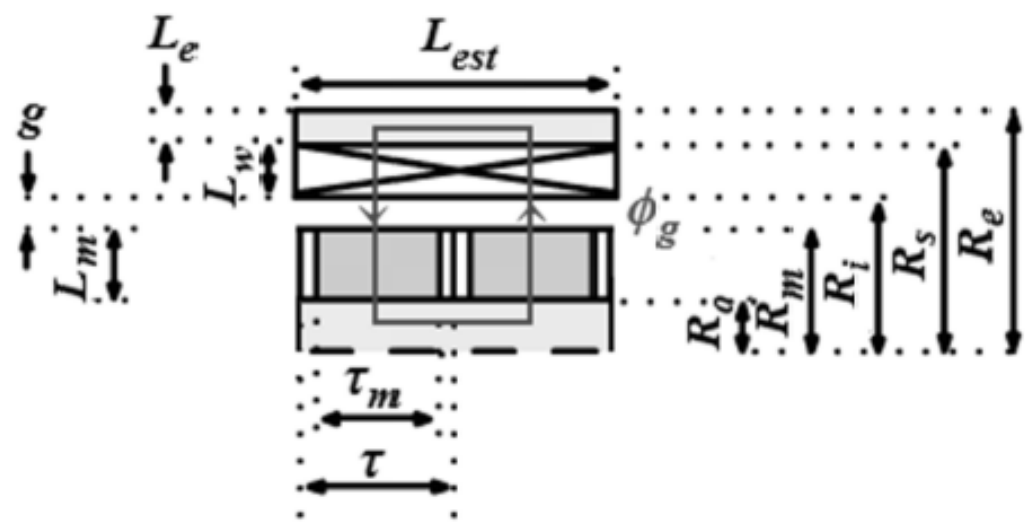

a)

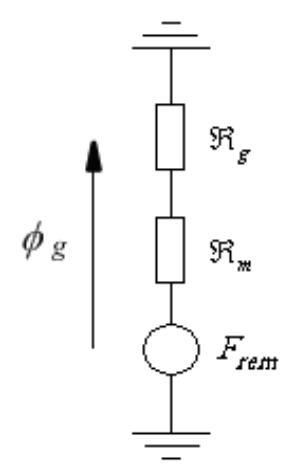

b)

Figura 40 - a) Fluxo magnético em um par de pólo; b) Circuito magnético análogo (JULIANI et al., 2010).

Algumas considerações são feitas para o equacionamento do circuito magnético: permeabilidade magnética infinita do ferro e fluxo magnético produzido apenas pelos ímãs, sendo desprezível o do enrolamento quando comparado a este.

A obtenção do fluxo magnético em um pólo $\left(\phi_{g}\right)$ é detalhada no apêndice $\mathrm{C}$ e é expresso por:

$$
\phi_{g}=\frac{\mathfrak{I}_{r e m}}{\mathfrak{R}_{g}+\mathfrak{R}_{m}}=H_{m} \cdot \mu_{0} \cdot \mu_{r} \cdot 2 \cdot \pi \frac{\tau_{m} \cdot L_{m} \cdot R_{s} \cdot R_{m}}{\left(R_{s}-R_{m}\right) \cdot \mu_{r} \cdot R_{m}+L_{m} \cdot R_{s}}
$$

Onde:

$\mathfrak{I}_{r e m}$ é a força magnetomotriz equivalente dos ímãs [Ae];

$\mathfrak{R}_{g}$ é a relutância do entreferro $\left[\mathrm{Ae} \mathrm{Wb}^{-1}\right]$;

$\mathfrak{R}_{m}$ é a relutância do ímã $\left[\mathrm{Ae} \mathrm{Wb}^{-1}\right]$;

$\mu_{r}$ é a permeabilidade relativa do ímã.

Substituindo-se a equação 15 na 14, tem-se:

$$
F=H_{m} \cdot \mu_{0} \cdot \mu_{r} \cdot 2 \cdot \pi \frac{\tau_{m} \cdot L_{m} \cdot R_{s} \cdot R_{m}}{\left(R_{s}-R_{m}\right) \cdot \mu_{r} \cdot R_{m}+L_{m} \cdot R_{s}} \cdot J \cdot{ }^{v} k_{w} \cdot\left(R_{s}-R_{m}\right)
$$


Rearranjando-se a equação 16 , pode-se estudar o valor ótimo da relação $R_{m} / R_{s}$ :

$$
F=H_{m} \cdot \mu_{0} \cdot \mu_{r} \cdot 2 \cdot \pi \cdot J \cdot{ }^{v} k_{w} \cdot \frac{\tau_{m} \cdot L_{m} \cdot R_{s} \cdot\left(\frac{R_{m}}{R_{s}}-\left(\frac{R_{m}}{R_{s}}\right)^{2}\right) \cdot R_{s}^{2}}{\mu_{r} \cdot\left(\frac{R_{m}}{R_{s}}-\left(\frac{R_{m}}{R_{s}}\right)^{2}\right) \cdot R_{s}{ }^{2}+L_{m} \cdot R_{s}}
$$

A figura 41 mostra a variação da força eletromagnética em função de $R_{m} / R_{S}$, considerando-se todas as constantes iguais a um e variando-se o valor de $R_{s}$.

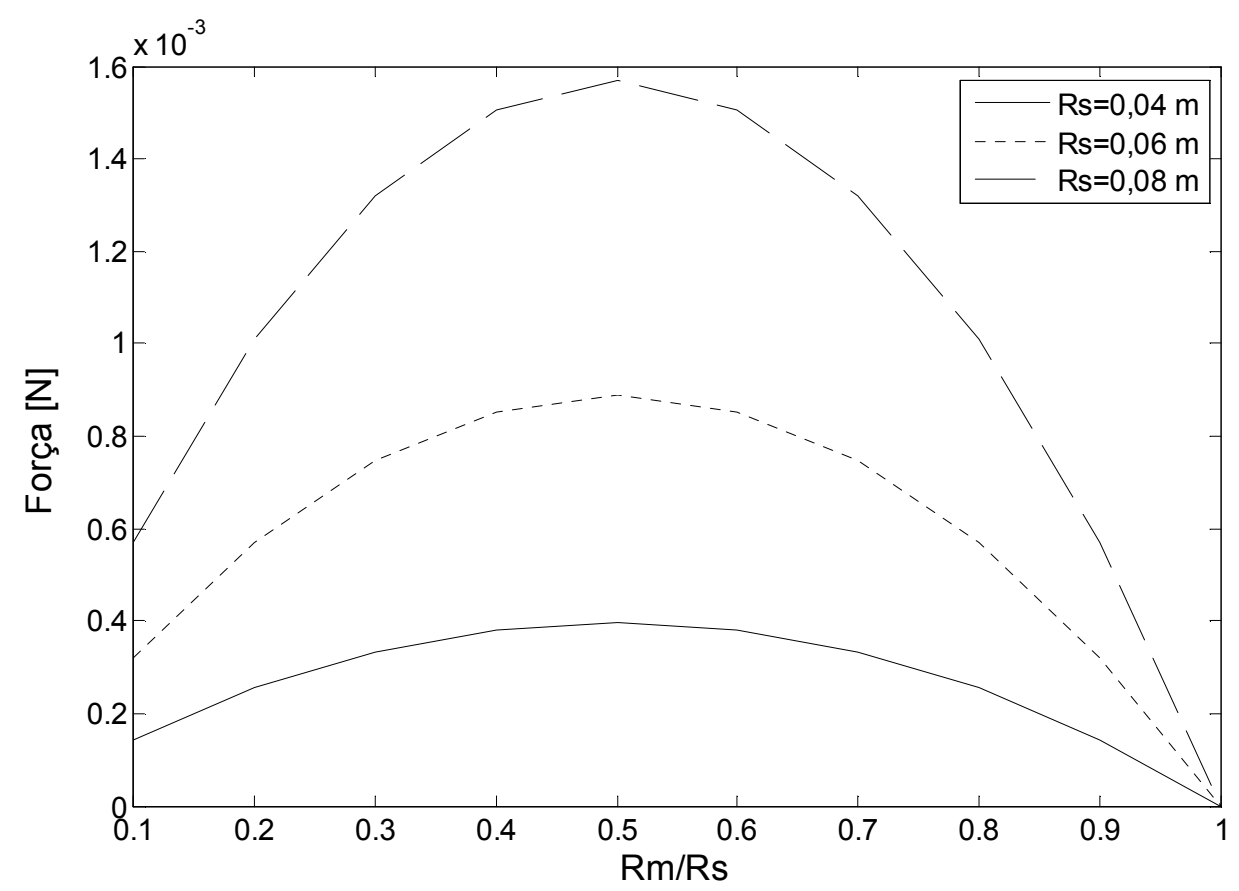

Figura 41 - Força eletromagnética por pólo versus $R_{m} / R_{s}$ (JULIANI et al., 2010).

Analisando-se a figura 41, tem-se que a força eletromagnética é máxima quando $R_{m} / R_{S}$ é igual a 0,5. Esse tipo de análise é muito importante, pois estabelece uma relação ótima para o início do projeto do motor. 


\subsubsection{Força Eletromagnética Ótima do Motor Com Ranhuras}

Em (BIANCHI et al., 2003), é calculado o valor ótimo da força eletromagnética em função de $R_{s} / R_{e}$, por meio da derivada da função da força média, em relação à $R_{s}$, igualada a zero. A máxima força resulta em $R_{s} / R_{e}$ igual a 0,618 .

Como o valor ótimo é calculado por meio de algumas suposições, é aceitável que ele possa ser um pouco diferente do apresentado no parágrafo anterior. No entanto, este valor pode ser considerado o ponto de partida no projeto do motor tubular com ranhuras (BIANCHI, et al., 2003).

\subsubsection{Cálculo das Estruturas Ferromagnéticas}

O diâmetro do núcleo de ferro do linor $\left(R_{0}\right)$ e a dimensão da estrutura ferromagnética do estator $\left(L_{e}\right)$ são calculados por meio das equações 18 e 19, respectivamente. Elas representam a relação da densidade de fluxo magnético no entreferro, em um passo polar, com a densidade de fluxo magnético na parte ferromagnética (EASTHAM; AKMESE; LAI, 1990).

$$
\begin{gathered}
B_{c} \frac{\pi}{4}\left(2 \cdot R_{0}\right)^{2}=\beta \cdot \tau \cdot\left(2 \cdot R_{0}+2 \cdot L_{m}+2 \cdot g\right) \cdot \pi \cdot B_{g} \\
L_{e}=\frac{B_{g}}{B_{t}} \cdot \beta \cdot \tau
\end{gathered}
$$

Os valores obtidos de $R_{0}$ e $L_{e}$ devem ser conferidos, em um programa baseado no método dos elementos finitos, se possuem o tamanho suficiente para que não haja a saturação do material ferromagnético. Caso este último fenômeno ocorra, deve-se analisar, de acordo com a aplicação, o aumento destas medidas ou a troca do ímã existente por um de menor energia. 


\subsubsection{Material Ferromagnético}

As principais características do material ferromagnético, utilizado no projeto do motor elétrico, devem ser conhecidas, principalmente a máxima indução magnética.

A tabela 7 mostra alguns aços elétricos e as suas aplicações mais comuns.

Tabela 7 - Categorias de aço elétrico e algumas aplicações (AKsteel, 2008).

\begin{tabular}{|c|c|c|c|}
\hline Aplicações & $\mathrm{M}-15, \mathrm{M}-19, \mathrm{M}-22$ & M-27, M-36, M-43 & M-45, M-47 \\
\hline $\begin{array}{l}\text { Motores e geradores } \\
\text { grandes }(>100 \mathrm{HP})\end{array}$ & & & \\
\hline $\begin{array}{l}\text { Motores e geradores } \\
\text { pequenos }(<100 \mathrm{HP})\end{array}$ & & & \\
\hline $\begin{array}{c}\text { Transformadores } \\
\text { grandes }(>10 \mathrm{kVA})\end{array}$ & & & \\
\hline $\begin{array}{c}\text { Transformadores } \\
\text { pequenos }(<10 \mathrm{kVA})\end{array}$ & & & \\
\hline
\end{tabular}

A tabela 8 apresenta as principais categorias de aço utilizadas em motores síncronos nos Estados Unidos e a tabela 9 mostra os mais comuns na Europa.

Tabela 8 - Categorias de aço elétrico utilizadas nos Estados Unidos (HENDERSHOT; MILLER, 1994).

$$
\text { Indução Perda Magnética [W/kg] }
$$

Categoria Magnética de $\quad 1,5 \mathrm{~T}$ e $60 \mathrm{~Hz}$

Saturação [T] $\quad 0,356 \mathrm{~mm} \quad 0,470 \mathrm{~mm} \quad 0,635 \mathrm{~mm}$

\begin{tabular}{lllll}
\hline M-15 & 1,99 & 3,19 & 3,70 & NA \\
M-19 & 1,99 & 3,48 & 3,83 & 4,58 \\
M-36 & 2,02 & 4,18 & 4,51 & 5,29 \\
M-43 & 2,04 & 4,40 & 5,07 & 5,95 \\
\hline
\end{tabular}


Tabela 9 - Categorias de aço elétrico utilizadas na Europa (HENDERSHOT; MILLER, 1994).

\begin{tabular}{ccccc}
\hline \multirow{2}{*}{ Categoria } & Indução & \multicolumn{3}{c}{ Perda Magnética [W/kg] } \\
& Magnética de & & $1,5 \mathrm{~T}$ e $50 \mathrm{~Hz}$ & \\
& Saturação [T] & & & \\
& $\mathrm{H}=5 \mathrm{kA} / \mathrm{m}, 50$ & $0,35 \mathrm{~mm}$ & $0,50 \mathrm{~mm}$ & $0,65 \mathrm{~mm}$ \\
& $\mathrm{~Hz}$ & & & $\mathrm{NA}$ \\
\hline Transil 330 & 1,66 & 2,9 & 3,15 & 5,50 \\
Losil 600 & 1,70 & NA & 5,10 & 7,40 \\
Newcor 800 & 1,72 & NA & 6,20 & \\
\hline
\end{tabular}

\subsubsection{Cálculo das Ranhuras}

Para evitar a saturação magnética no dente do estator, pode-se calcular um valor mínimo da sua dimensão $\left(w_{\text {tmin }}\right)$, que depende da máxima densidade de fluxo magnético permitida. A equação 20 expressa este valor (BHAMIDI, 2005).

$$
w_{t \min }=\frac{\pi}{2} B_{g m} \frac{\lambda}{B_{t \max }}
$$

Sendo:

$$
\lambda=\frac{\tau}{m \cdot N R}
$$

Onde:

$B_{g m}$ é a densidade de fluxo magnético média no entreferro [T];

$N R$ é o número de ranhuras por fase em cada pólo.

Em alguns motores, o dente do estator possui um chanfro com o objetivo de reduzir a força de borda e de permitir uma melhor distribuição do fluxo magnético entre os ímãs e o enrolamento do estator, acarretando os seguintes impactos no projeto da máquina (CHEVAILLER, 2006):

1) Em muitos casos, há o aumento da força normal;

2) Redução da tensão induzida devido à diminuição do fator de preenchimento $\left(k_{c u}\right)$; 
3) Dificuldade na construção.

A equação 22 mostra a relação entre o tamanho do dente e do chanfro, que ocorre quando $w_{s}$ é maior do que $w_{t}$ (figura 42 ), ocasionando um aumento de $25 \%$ da densidade de fluxo magnético produzida pelos ímãs. Também, resulta um aumento de $56 \%$ da força normal, implicando em maiores limitações para o mancal de apoio do linor (CHEVAILLER, 2006).

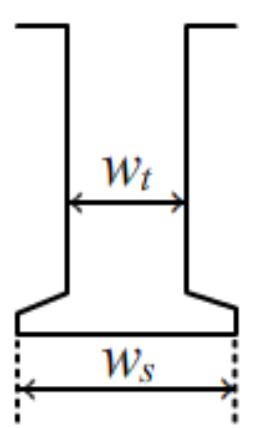

Figura 42 - Dimensões do dente.

$$
w_{s}=1,6 \cdot w_{t}
$$

\subsection{Cálculo do Fluxo Magnético por Pólo}

O fluxo magnético por pólo $\left(\phi_{\text {Pólo }}[\mathrm{Wb}]\right)$ é calculado por meio da multiplicação da área magnética do pólo $\left(A_{m}\left[\mathrm{~m}^{2}\right]\right)$ pela densidade de fluxo magnético do ponto de operação $\left(B_{M}[\mathrm{~T}]\right)$.

$$
\phi_{\text {Pólo }}=A_{m} \cdot B_{M}
$$

Sendo:

$$
A_{m}=2 \cdot \pi \cdot R_{o} \cdot \tau
$$




\subsection{Cálculo do Número de Condutores, de Espiras e do Diâmetro do Enrolamento}

Considerando a velocidade máxima de operação $\left(v_{\text {máx }}[\mathrm{m} / \mathrm{s}]\right)$, a velocidade sem carga é 20\% maior para os ímãs de ferrita e 10\% maior para os ímãs de terras-raras (HENDERSHOT; MILLER, 1994). Com isso, a constante da tensão induzida $\left(k_{e}\left[\mathrm{Vs} \cdot \mathrm{m}^{-1}\right]\right)$ pode ser calculada pela equação (25).

$$
k_{e}=\frac{V_{c c}}{n \cdot v_{\max }}
$$

Onde:

$n$ é igual a 1,250 se os ímãs do linor forem de ferrita ou 1,111 se forem de terras-raras;

$V c c$ é a tensão de barramento [V].

O número total de condutores $(Z)$ é determinado pela equação (26).

$$
Z=1,5 \frac{1}{C} \frac{\pi \cdot k_{e}}{\phi_{\text {Pólo }} \cdot 2 \cdot P P}
$$

Onde $C$ é fator da distribuição do fluxo no enrolamento do estator, podendo ser estimado em torno de 90\% na região de comutação (HENDERSHOT; MILLER, 1994).

O número de espiras de cada bobina $(N)$ é determinado pela equação (27).

$$
N=\frac{Z}{N_{\text {BobinasFase }} \cdot N_{a}}
$$

Onde:

$N_{a}$ é igual a 1, 2 ou 3, dependendo se o motor é monofásico, bifásico ou trifásico, respectivamente;

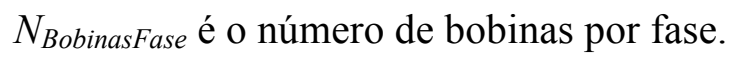

O diâmetro do fio $\left(d_{c u}[\mathrm{~mm}]\right)$ é calculado por meio da equação (28), sendo o seu valor consultado em uma tabela para selecionar a bitola correspondente. Neste trabalho, é utilizado o sistema AWG (American Wire Gauge). 


$$
d_{c u}=\sqrt{\frac{A_{\text {Ranhura }} \cdot k_{c u}}{N_{\text {Espiras }}}}
$$

Onde:

$A_{\text {ranhura }}$ é a área da ranhura, ou a área ocupada pelo enrolamento no caso dos motores sem ranhuras;

$k_{c u}$ é o fator de preenchimento, assumindo o valor em torno de $0,3-0,35$, no caso de camada dupla, e 0,65-0,7, no caso de camada simples (HENDERSHOT; MILLER, 1994).

\subsection{Determinação dos Parâmetros do Motor}

A resistência elétrica e a indutância do enrolamento do estator são calculadas utilizando-se o software FEMM (Finite Element Method Magnetics), (MEEKER, 2007).

\subsection{Acionamento Elétrico}

O acionamento elétrico do motor linear é representado pela figura 43 e é composto por quatro blocos: alimentação do sistema (bateria), inversor trifásico, sistema de detecção da posição do linor e acionamento do inversor trifásico.

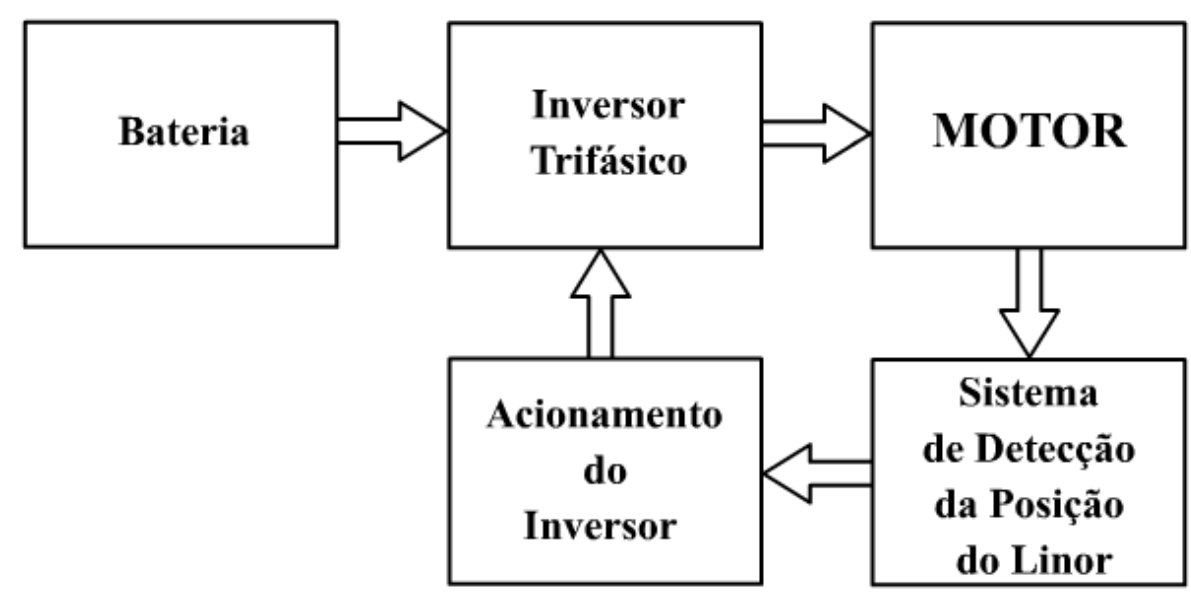

Figura 43 - Diagrama de blocos do acionamento do motor linear. 
Nas subseções seguintes são detalhados o inversor trifásico, incluindo a sua lógica de acionamento, e a bateria a ser utilizada na alimentação.

\subsubsection{Inversores Trifásicos}

Os inversores transformam uma tensão de entrada contínua em uma tensão de saída alternada, simétrica em amplitude e de freqüência e de magnitude ajustáveis (RASHID, 1999).

De acordo com a aplicação, os inversores podem utilizar dispositivos com disparo ou bloqueio controlados, (MOSFETs e IGBTs), ou tiristores em comutação forçada.

O inversor trifásico é composto por três inversores monofásicos conectados em paralelo, como mostra a figura 44 .

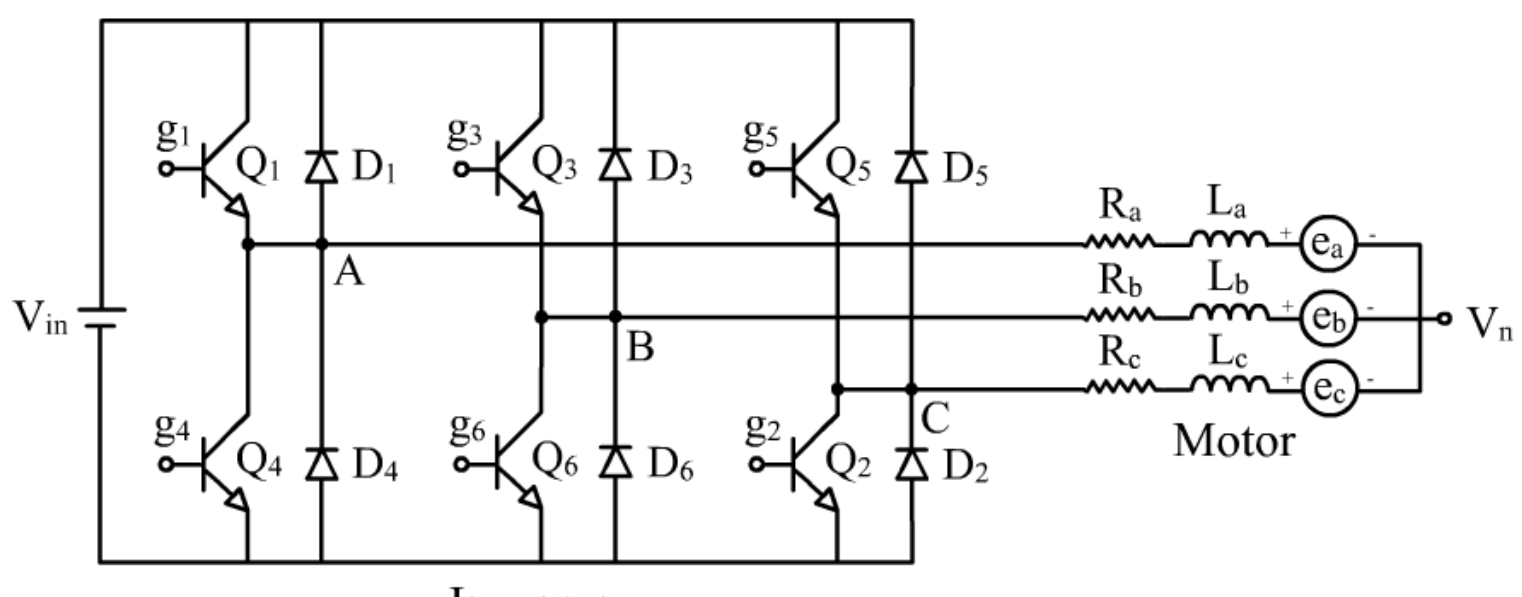

Inversor

Figura 44 - Circuito de acionamento do MLSIP (JULIANI, 2007).

Os transistores de potência do inversor devem receber comandos de condução de um sistema de controle, que é sincronizado com a posição do linor $(x[\mathrm{~m}])$.

Cada transistor conduz por $120^{\circ}$ elétricos. Apenas dois transistores estão conduzindo em qualquer instante de tempo, na seqüência (6-1), (1-2), (2-3), (3-4), (4-5) e (5-6), a partir de $30^{\circ}$. Os sinais de comando são mostrados na figura 45 . 
De acordo com o controle de cada transistor, obtém-se a tensão de alimentação da fase $a\left(v_{a}\right)$, da fase $b\left(v_{b}\right)$ e da fase $c\left(v_{c}\right)$ do motor, figura 46. Quando as duas chaves da fase correspondente estão desligadas ou abertas são as regiões de alta impedância.
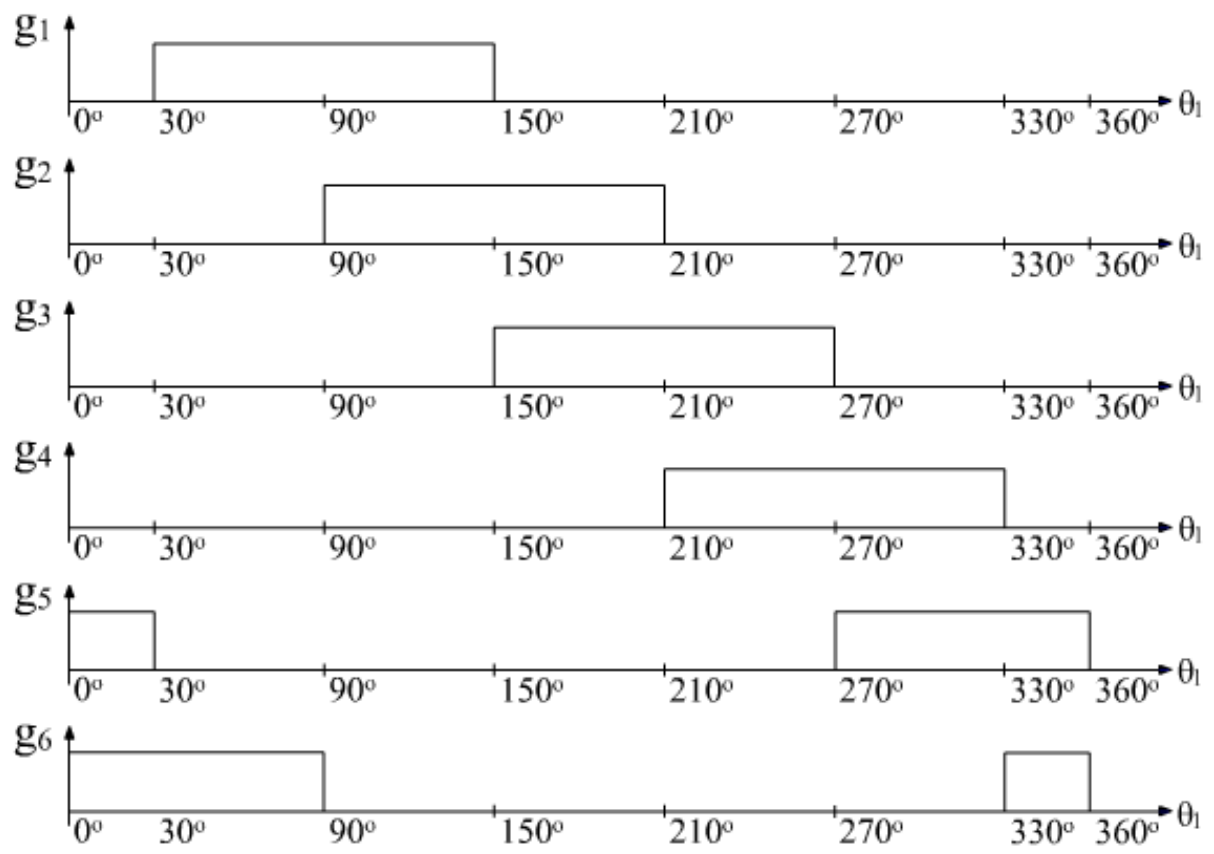

Figura 45 - Sinais de comando dos transistores do circuito de acionamento do MLSIP (JULIANI, 2007).
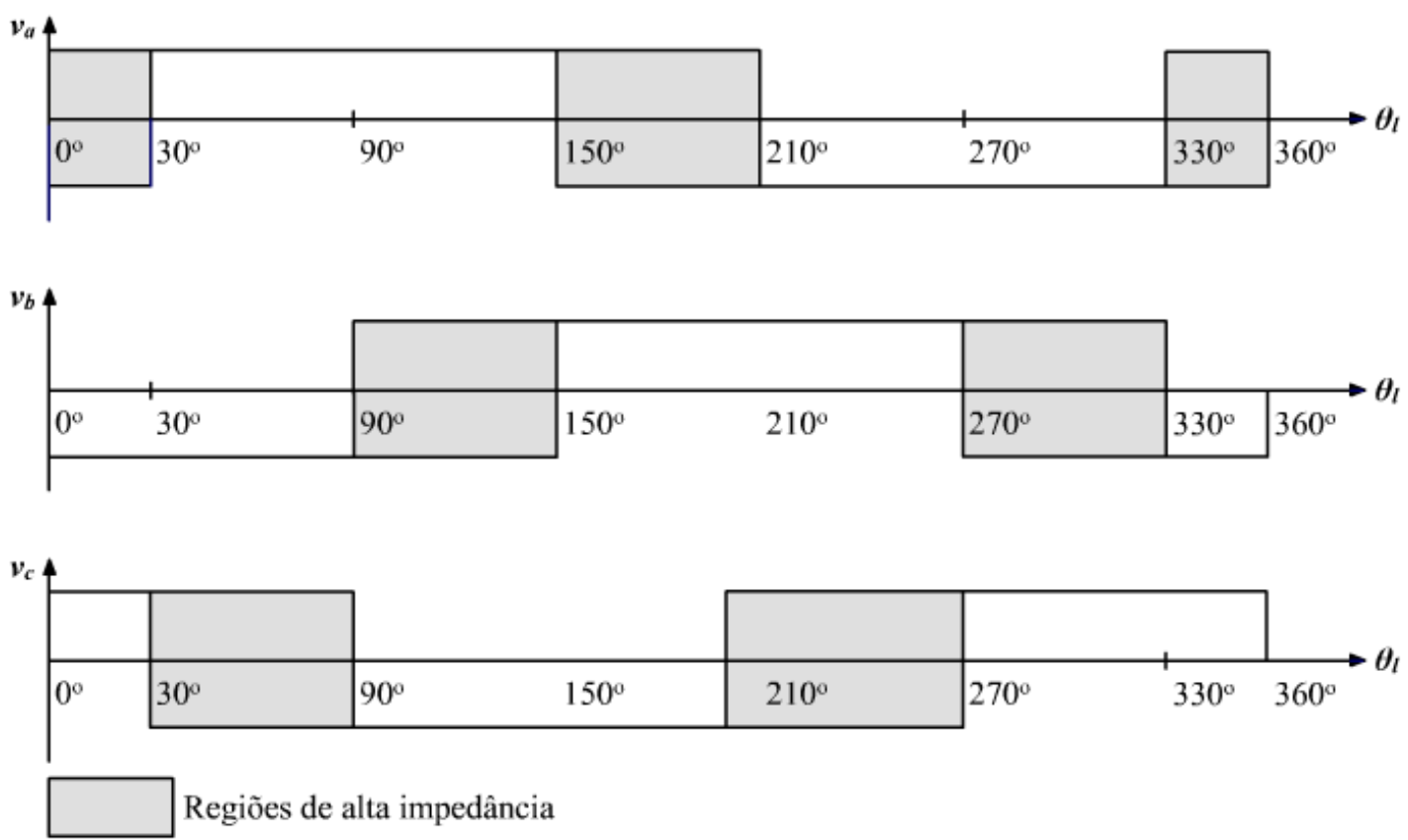

Figura 46 - Tensão de saída do inversor trifásico do MLSIP (JULIANI, 2007). 


\subsubsection{Baterias}

As principais baterias existentes são: Chumbo-Ácido (Pb-Ac), Níquel-Cádmio (NiCd), Níquel-Metal-Hidreto (NiMH) e Lítio-íon (Li-íon). A tabela 10 mostra algumas das características de cada uma delas.

Para a aplicação em uma prótese de membro superior, deve-se utilizar uma bateria que tenha alta eficiência, alta energia específica, não possua efeito memória, não necessite de manutenção, baixa massa e tamanho pequeno.

A bateria de Li-íon possui as características descritas no parágrafo anterior, embora o seu custo seja elevado.

Tabela 10 - Características das principais baterias (ABVE, 2009).

\begin{tabular}{ccccccc}
\hline Bateria & $\begin{array}{c}\text { Energia } \\
\text { Específica } \\
{[\mathbf{W h} / \mathbf{K g}]}\end{array}$ & $\begin{array}{c}\text { Potência } \\
\text { Específica } \\
{[\mathbf{W} / \mathbf{K g}]}\end{array}$ & $\begin{array}{c}\text { Eficiência } \\
{[\mathbf{W h}]}\end{array}$ & $\begin{array}{c}\text { Auto- } \\
\text {-descarga }\end{array}$ & Manutenção & $\begin{array}{c}\text { Custo } \\
{[\boldsymbol{E} / \mathbf{k W h}]}\end{array}$ \\
\hline Pb-Ac & 40 & 250 & $80-85 \%$ & Baixa & Não & $116-151$ \\
NiCd & 60 & 200 & $70-75 \%$ & Baixa & Sim & $490-720$ \\
NiMH & 70 & 350 & $70 \%$ & Alta & Não & $559-666$ \\
Li-íon & 125 & 400 & $90 \%$ & Baixa & Não & $700-860$ \\
\hline
\end{tabular}

\subsection{Modelagem Matemática do Motor Linear Síncrono Tubular com Ímãs na Superfície}

O modelo por fase da máquina é utilizado para a realização da modelagem matemática do motor linear síncrono tubular (MLST), que é representado por um circuito série contendo um resistor, um indutor e uma fonte de tensão representando a tensão induzida (figura 47), conectados em "Y". 


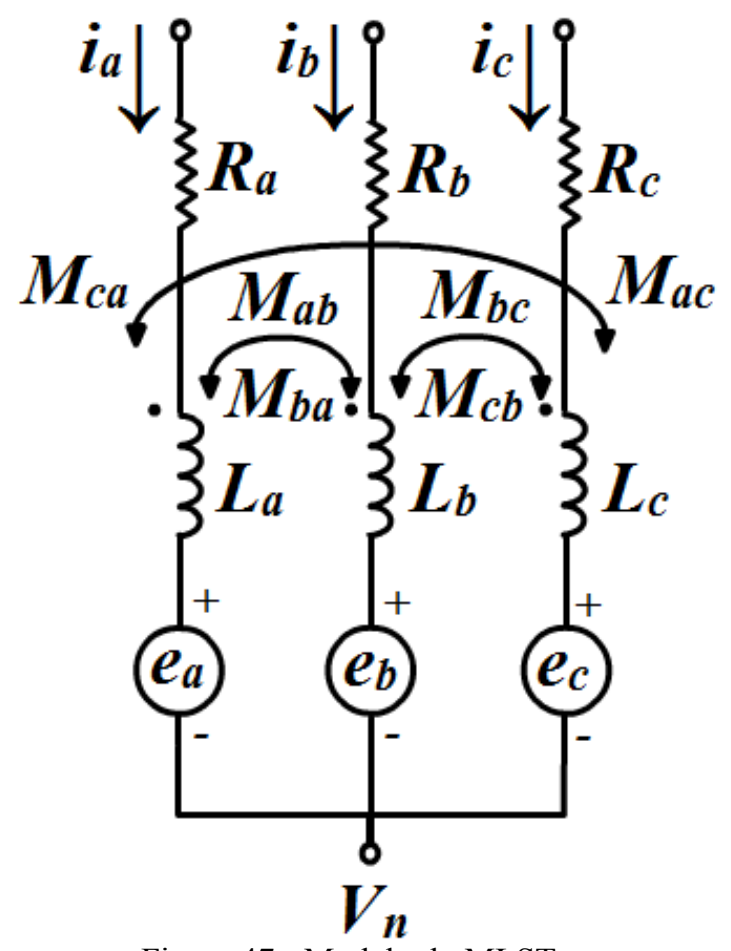

Figura 47 - Modelo do MLST.

O equacionamento do circuito representado pela figura 47 é (KRISHNAN, 2001):

$$
\left[\begin{array}{l}
v_{a} \\
v_{b} \\
v_{c}
\end{array}\right]=\left[\begin{array}{ccc}
R_{a} & 0 & 0 \\
0 & R_{b} & 0 \\
0 & 0 & R_{c}
\end{array}\right] \cdot\left[\begin{array}{c}
i_{a} \\
i_{b} \\
i_{c}
\end{array}\right]+\frac{d}{d t}\left[\begin{array}{ccc}
L_{a} & M_{a b} & M_{a c} \\
M_{b a} & L_{b} & M_{b c} \\
M_{c a} & M_{c b} & L_{c}
\end{array}\right] \cdot\left[\begin{array}{c}
i_{a} \\
i_{b} \\
i_{c}
\end{array}\right]+\left[\begin{array}{c}
e_{a} \\
e_{b} \\
e_{c}
\end{array}\right]
$$

Onde:

$L_{a}, L_{b}$ e $L_{c}$ são as indutâncias do estator por fase [H];

$M_{a b}, M_{a c}, M_{b a}, M_{b c}, M_{c a}$ e $M_{c b}$ são as indutâncias mútuas [H];

$R_{a}, R_{b}$ e $R_{c}$ são as resistências do estator por fase [ $\Omega$ ].

Assumindo-se que as três fases são simétricas e equilibradas, e o linor de pólos lisos, tem-se:

$$
\begin{gathered}
M_{a b}=M_{a c}=M_{b a}=M_{b c}=M_{c a}=M_{c b}=M \\
L_{a}=L_{b}=L_{c}=L
\end{gathered}
$$

Substituindo-se as equações 30 e 31 em 29: 


$$
\left[\begin{array}{l}
v_{a} \\
v_{b} \\
v_{c}
\end{array}\right]=\left[\begin{array}{ccc}
R_{a} & 0 & 0 \\
0 & R_{b} & 0 \\
0 & 0 & R_{c}
\end{array}\right] \cdot\left[\begin{array}{l}
i_{a} \\
i_{b} \\
i_{c}
\end{array}\right]+\frac{d}{d t}\left[\begin{array}{ccc}
L & M & M \\
M & L & M \\
M & M & L
\end{array}\right] \cdot\left[\begin{array}{c}
i_{a} \\
i_{b} \\
i_{c}
\end{array}\right]+\left[\begin{array}{c}
e_{a} \\
e_{b} \\
e_{c}
\end{array}\right]
$$

A soma das correntes por fase é nula e considerando-se o terminal neutro isolado, a equação 32 torna-se:

$$
\left[\begin{array}{l}
v_{a} \\
v_{b} \\
v_{c}
\end{array}\right]=\left[\begin{array}{ccc}
R_{a} & 0 & 0 \\
0 & R_{b} & 0 \\
0 & 0 & R_{c}
\end{array}\right] \cdot\left[\begin{array}{c}
i_{a} \\
i_{b} \\
i_{c}
\end{array}\right]+\frac{d}{d t}\left[\begin{array}{ccc}
L-M & 0 & 0 \\
0 & L-M & 0 \\
0 & 0 & L-M
\end{array}\right] \cdot\left[\begin{array}{c}
i_{a} \\
i_{b} \\
i_{c}
\end{array}\right]+\left[\begin{array}{c}
e_{a} \\
e_{b} \\
e_{c}
\end{array}\right]
$$

As tensões induzidas de cada fase são expressas pela equação 34 (KRISHNAN, 2001).

$$
e_{f}=f_{f}(x) \cdot k_{e} \cdot v_{m}
$$

Onde:

$f_{f}(x)$ é uma função normalizada que representa a forma de onda da força contraeletromotriz de cada fase em função da posição do linor;

A velocidade angular elétrica é dada pela equação 35 , podendo ser reescrita conforme a equação 36 .

$$
\begin{gathered}
\omega_{e}=P P \cdot \omega_{m} \\
\omega_{m}=\frac{\pi \cdot v_{m}}{\tau}
\end{gathered}
$$

Onde:

$\omega_{e}$ é a velocidade angular elétrica $[\mathrm{rad}$ elétricos/s];

$\omega_{m}$ é a velocidade angular mecânica $[\mathrm{rad} / \mathrm{s}]$.

A equação dinâmica de um sistema linear, considerando-se o seu funcionamento na posição horizontal, é:

$$
F_{e l}-F_{c}=M_{L} \frac{d v_{m}}{d t}+D \cdot v_{m}
$$


Sendo:

$$
F_{e l}=\frac{e_{a} \cdot i_{a}+e_{b} \cdot i_{b}+e_{c} \cdot i_{c}}{v_{m}}
$$

Onde:

$D$ é o coeficiente de atrito viscoso $\left[\mathrm{Kg} \mathrm{s}^{-1}\right]$;

$F_{c}$ é a força de carga $[\mathrm{N}]$;

$F_{e l}$ é a força eletromagnética $[\mathrm{N}]$;

$M_{L}$ é a massa da parte móvel $[\mathrm{Kg}]$.

A força é produzida em 6 ciclos, com duas fases conduzindo ao mesmo tempo. Com isso, a equação 38 pode ser reescrita como:

$$
F_{e l}=\frac{2 \cdot e \cdot i}{v_{m}}=\frac{2 \cdot k_{e} \cdot v_{m} \cdot i}{v_{m}}=2 \cdot k_{e} \cdot i=K_{f} \cdot i
$$

\subsection{Controle Elétrico do Motor}

O controle do MLST é de posicionamento devido à aplicação em prótese de membro superior, sendo as funções cinemáticas do dedo relacionadas ao deslocamento da parte móvel do motor.

A figura 48 mostra a lógica resumida do controle, em que a posição linear do linor é comparada com a referência desejada e o erro entre estas duas grandezas é corrigido pelo controle de posição. Consequentemente, a velocidade de referência é obtida, que é comparada com a do motor, sendo a diferença entre elas corrigida pelo controle de velocidade, que pode ser aplicado ao controle de tensão (por PWM - Pulse Width Modulation) ou pode ser enviado a uma malha de controle da corrente. A saída do controle de tensão ou de corrente é a responsável por enviar os comandos de condução dos transistores ao inversor trifásico.

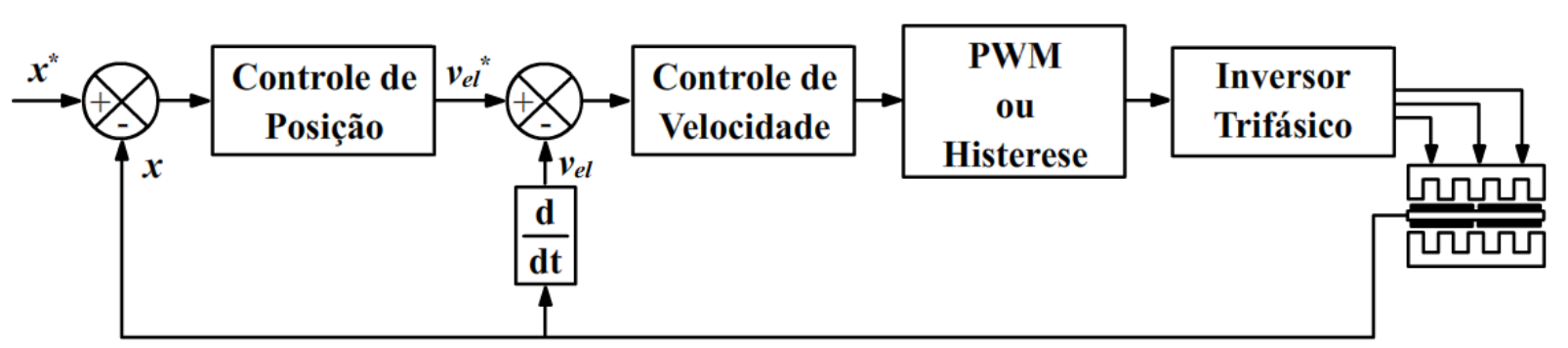

Figura 48 - Controle do MLST. 
As funções de transferência relacionadas ao controle elétrico são mostradas no apêndice D.

\subsection{Motores Projetados}

Foram projetados diversos motores para se avaliarem as vantagens e as desvantagens de cada um, e se estavam de acordo com as necessidades da aplicação.

Foram considerados importantes os seguintes fatores, ao projetar-se a máquina:

1) Força eletromagnética em torno de $12 \mathrm{~N}$;

2) Distância mínima de deslocamento igual a 0,0191 m (para realizar a garra de força);

3) Diâmetro do motor inferior a $3 \mathrm{~cm}$;

4) Tamanho mínimo do estator;

5) Menor perda resistiva;

6) Menor potência.

Um dedo humano tem a capacidade aproximada de produzir um aperto de até $100 \mathrm{~N}$ (BARROS, 1993 apud Cunha, 2002). No entanto, as próteses que imitam os movimentos naturais do ser humano são projetadas visando-se a precisão da garra, por meio do aumento da área de contato com o objeto, e com isso, necessitam de forças menores (CARROZZA et al., 2002).

Em (CARROZZA et al., 2002), é utilizado o mecanismo de transmissão manivela deslizante (slider crank), que é conectado ao atuador linear (conjunto do motor rotativo e redutor), que proporciona uma força nominal de $12 \mathrm{~N}$.

Já em (ZOLLO et al., 2007), o mecanismo é o soft gripper e as características do conjunto do motor com o redutor e com a rosca não são especificadas. No entanto, há a informação do valor da força máxima da mão, ao realizar a garra de precisão anelar (movimento do polegar em oposição a outro dedo), que é 15 N. Com isso, pode-se concluir que a força aplicada ao cabo pelo motor é próxima a este valor, pois o dedo foi projetado para possuir uma distribuição uniforme da força.

As figuras apresentadas nesse capítulo, referentes aos gráficos de cores da densidade de fluxo magnético, possuem simetria axial e mostram os dois primeiros pares de pólo do motor, conforme destacado pelo retângulo vermelho na figura 49. Essa localização foi escolhida porque é a que apresenta os maiores valores de indução magnética. 


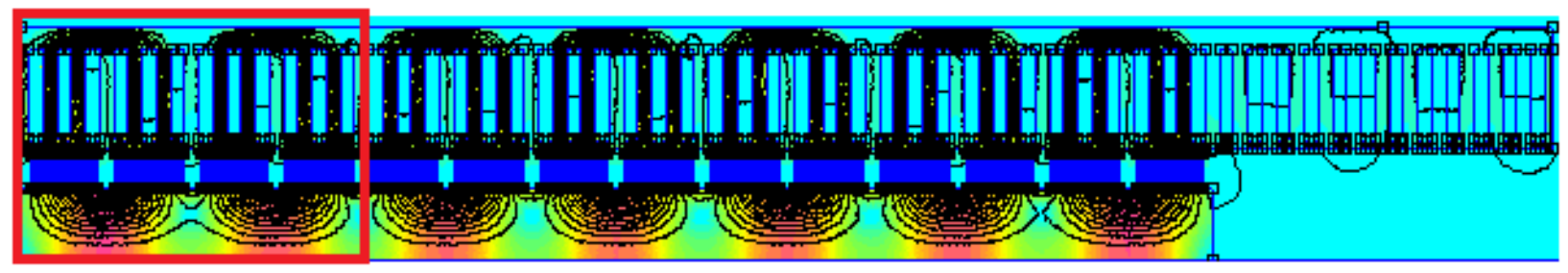

Figura 49 - Localização dos dois primeiros pares de pólo do motor.

\subsubsection{Comparação do Estator Com e Sem Ranhuras}

Foi projetado um motor sem ranhuras, com ímãs permanentes na superfície do linor de $\mathrm{NdFeB}$ (32 MGOe ou 254,66 $\mathrm{kJm}^{-3}$ ), e utilizando-se do mesmo projeto inseriram-se ranhuras com e sem chanfros (de acordo com a figura 42), sendo as características construtivas especificadas na tabela 11, onde: $N_{p}$ é o número de pólos, $g$ é o tamanho do entreferro, $T_{L}$ é o tamanho do linor, $T_{E}$ é o tamanho do estator, $D_{e}$ é o diâmetro externo do motor, $\tau$ é o tamanho do passo polar, $N$ é o número de espiras e $B_{e}$ é a bitola do enrolamento.

Tabela 11 - Características construtivas dos motores projetados com e sem ranhuras.

\begin{tabular}{lcccccccc}
\hline & $\boldsymbol{N}_{\boldsymbol{p}}$ & $\boldsymbol{g}$ & $\boldsymbol{T}_{\boldsymbol{L}}$ & $\boldsymbol{T}_{\boldsymbol{E}}$ & $\boldsymbol{D}_{\boldsymbol{e}}$ & $\boldsymbol{\tau}$ & $\boldsymbol{N}$ & $\boldsymbol{B}_{\boldsymbol{e}}$ \\
& & {$[\mathbf{m m}]$} & {$[\mathbf{c m}]$} & {$[\mathbf{c m}]$} & {$[\mathbf{c m}]$} & {$[\mathbf{c m}]$} & & $(\mathbf{A W G )}$ \\
\hline Sem ranhuras & 36 & 0,4 & 18,36 & 20,40 & 2,77 & 0,51 & 24 & 25 \\
Com ranhuras & 36 & 0,4 & 18,36 & 20,40 & 2,77 & 0,51 & 24 & 28 \\
\hline
\end{tabular}

A figura 50 mostra os fluxos magnéticos da fase $A$ para os três tipos de motores. A partir deles, as tensões induzidas (figura 51) foram calculadas para a velocidade mecânica igual a $0,01 \mathrm{~ms}^{-1}$ (valor aproximado para a aplicação em próteses de membro superior). Os resultados da fase $B$ e $C$ são iguais aos apresentados da fase $A$, no entanto, defasados entre si em $120^{\circ}$. 


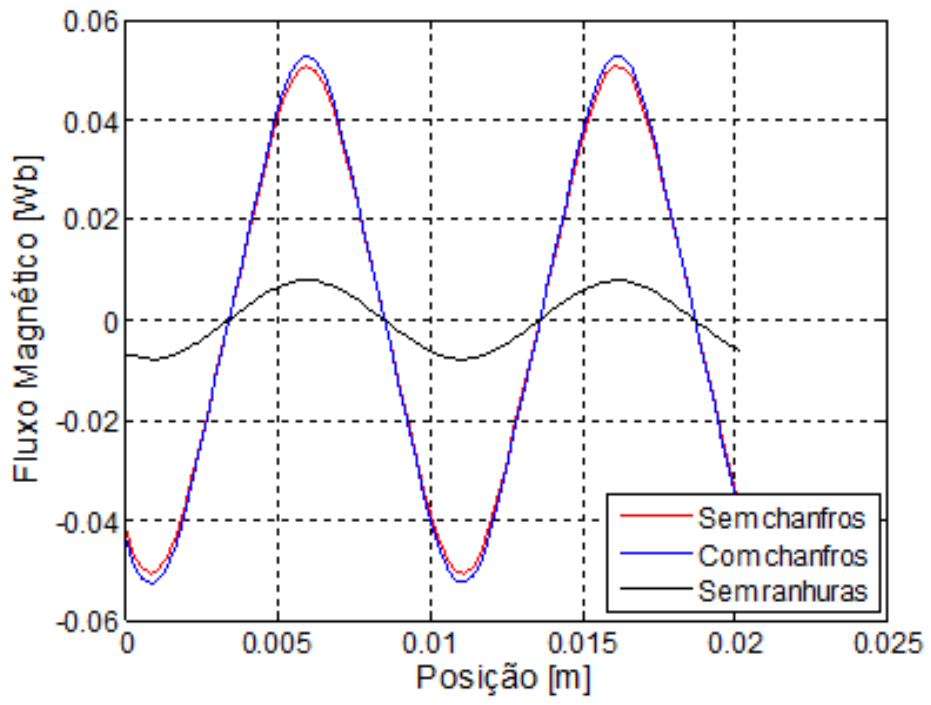

Figura 50 - Comparação dos fluxos magnéticos da fase $A$ referentes aos motores com e sem ranhuras.

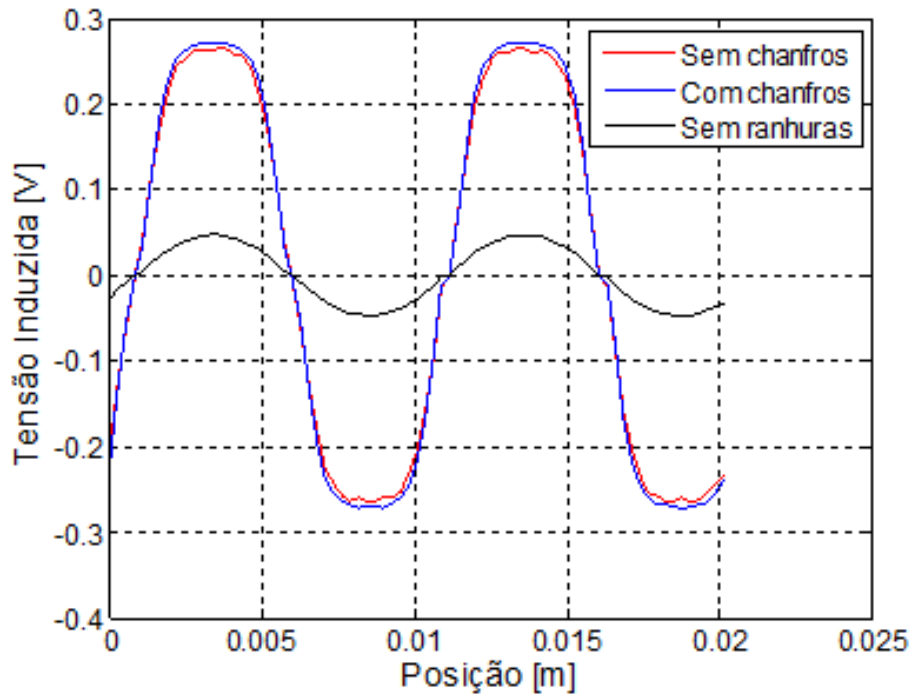

Figura 51 - Comparação das tensões induzidas da fase $A$ referentes aos motores com e sem ranhuras.

A figura 52 apresenta a forças eletromagnéticas para os motores com e sem ranhuras. Pode-se observar que as oscilações são maiores para a configuração com ranhuras e sem chanfros, já a máquina sem ranhuras possui a menor magnitude. 


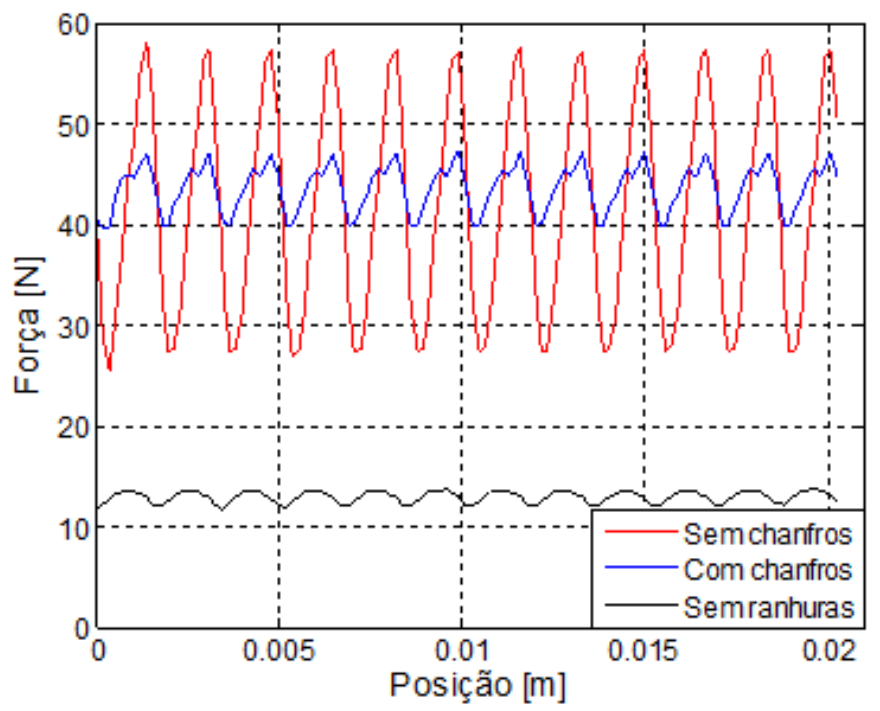

Figura 52 - Comparação das forças eletromagnéticas referentes aos motores com e sem ranhuras.

A tabela 12 mostra os parâmetros do motor projetado, onde: $i_{m a ́ x}$ é a corrente máxima por fase, $F_{e f}$ é o valor eficaz da força eletromagnética, $R_{\text {fase }}$ é a resistência elétrica por fase, $P_{r}$ é a perda resistiva por fase considerando-se a corrente máxima, $V_{\min }$ é a tensão mínima necessária para a alimentação do motor (considerando-se apenas a parcela resistiva), $M_{L}$ é a massa da parte móvel, $M_{e}$ é a massa do estator, $M_{T}$ é a massa total, $V_{o l}$ é o volume total e $D_{F}$ é a densidade de força.

Tabela 12 - Parâmetros dos motores projetados com e sem ranhuras.

\begin{tabular}{|c|c|c|c|c|c|c|c|c|c|c|}
\hline & $\begin{array}{l}i_{\max } \\
{[\mathrm{A}]}\end{array}$ & $\begin{array}{l}F_{e f} \\
{[\mathbf{N}]}\end{array}$ & $\begin{array}{l}R_{\text {fase }} \\
{[\mathbf{\Omega}]}\end{array}$ & $\begin{array}{c}\boldsymbol{P}_{r} \\
{[\mathbf{W}]}\end{array}$ & $\begin{array}{l}V_{\min } \\
{[\mathbf{V}]}\end{array}$ & $\begin{array}{c}M_{L} \\
{[\mathrm{Kg}]}\end{array}$ & $\begin{array}{c}M_{e} \\
{[\mathbf{K g}]}\end{array}$ & $\begin{array}{c}M_{T} \\
{[\mathbf{K g}]}\end{array}$ & $\begin{array}{c}V_{o l} \\
X 10^{-5} \\
{\left[\mathrm{~m}^{3}\right]} \\
\end{array}$ & $\begin{array}{c}D_{F} \\
X 10^{5} \\
{\left[\mathbf{N} / \mathbf{m}^{3}\right]} \\
\end{array}$ \\
\hline $\begin{array}{c}\text { Sem } \\
\text { ranhuras }\end{array}$ & 1,62 & 12,9 & 6,15 & 16,14 & 38,6 & 0,171 & 0,564 & 0,735 & 9,72 & 1,33 \\
\hline $\begin{array}{l}\text { Ranhuras } \\
\text { sem } \\
\text { Chanfros }\end{array}$ & 0,84 & 43,1 & 12,32 & 8,69 & 20,70 & 0,171 & 0,652 & 0,823 & 11,2 & 3,85 \\
\hline $\begin{array}{l}\text { Ranhuras } \\
\text { com } \\
\text { Chanfros } \\
\end{array}$ & 0,84 & 43,7 & 12,53 & 8,84 & 21,04 & 0,171 & 0,655 & 0,826 & 11,3 & 3,87 \\
\hline
\end{tabular}

Por meio dos resultados apresentados anteriormente, pode-se concluir que o estator com ranhuras, comparado com a configuração sem ranhuras, possui as seguintes características: maior densidade de força, maior resistência elétrica por fase, menor perda resistiva, maior massa e maiores oscilações na força eletromagnética devido à força de borda.

A presença das ranhuras aumenta a densidade de fluxo magnético nas estruturas com material ferromagnético, como pode ser observado nas figuras 53 e 54. 

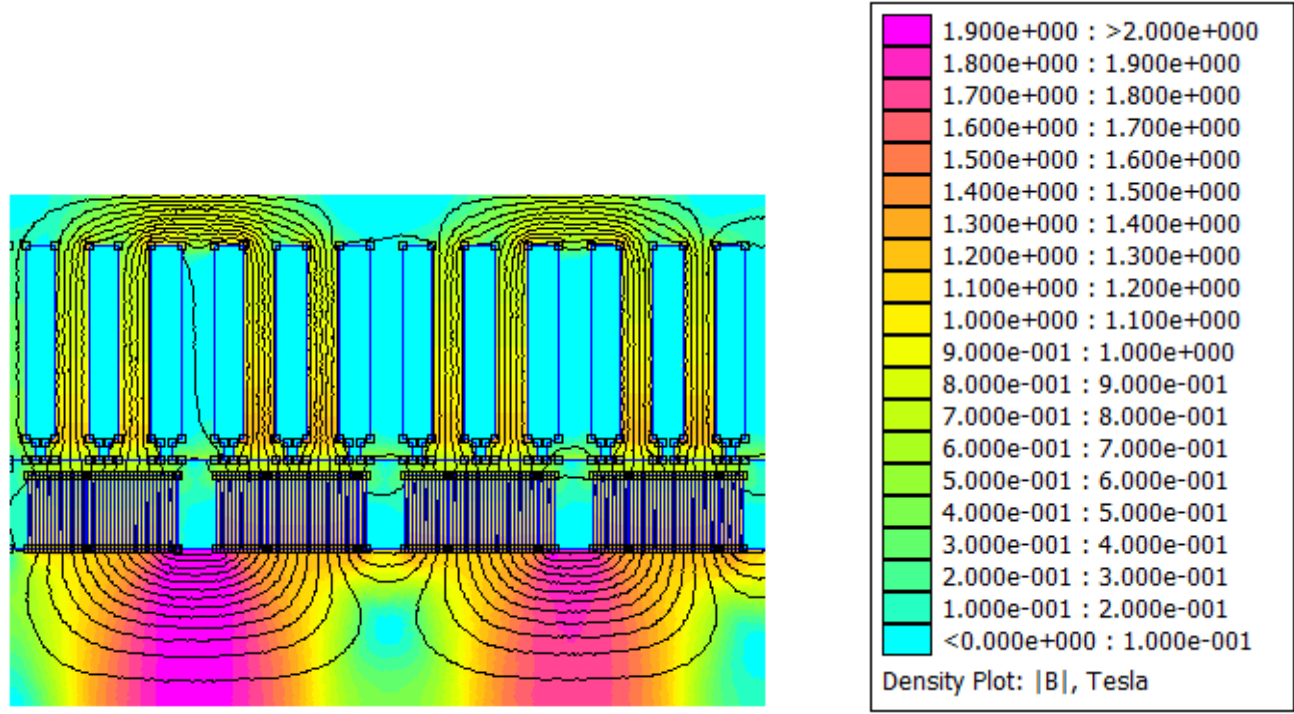

Figura 53 - Densidade de fluxo magnético do motor com ranhuras e chanfros.
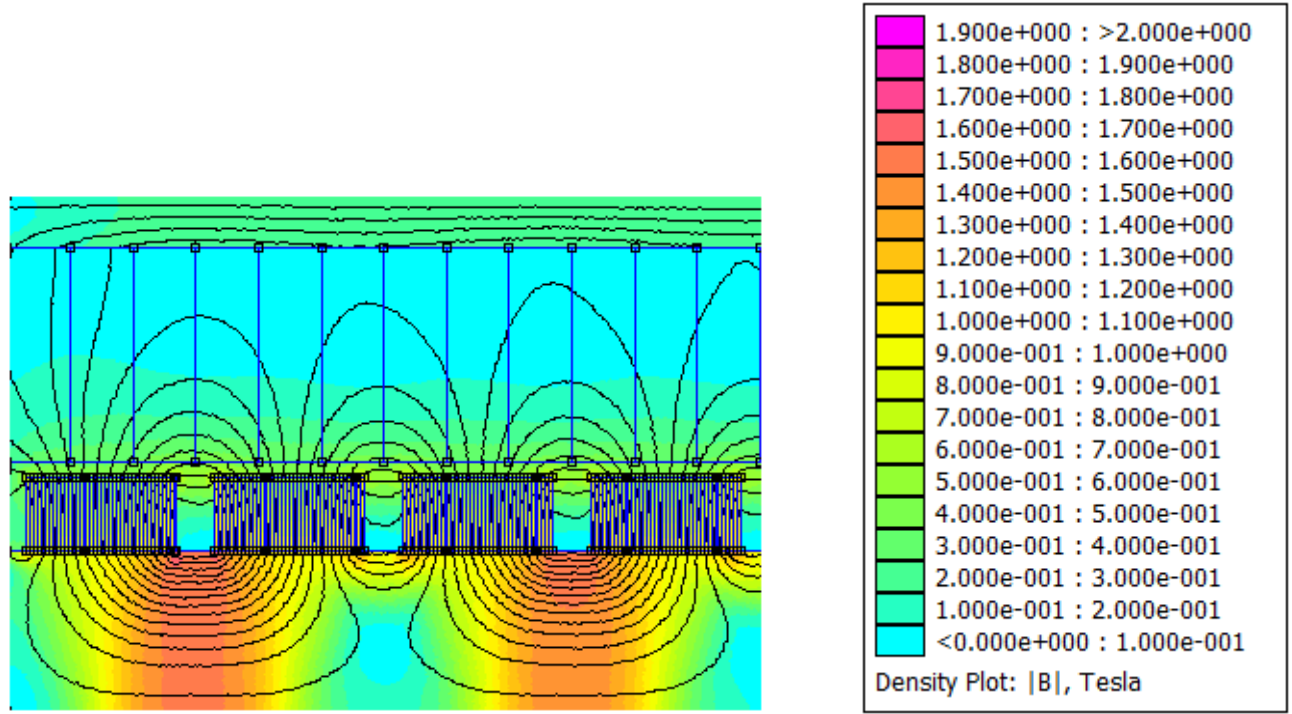

Figura 54 - Densidade de fluxo magnético do motor sem ranhuras.

No motor sem ranhuras, o maior valor da indução magnética é igual a 1,62 T, enquanto na máquina com ranhuras é 2,02 T.

A inserção dos chanfros na ranhura proporciona uma maior concentração do fluxo magnético, tornando a forma de onda da tensão induzida mais próxima da trapezoidal, e também, causa uma redução na oscilação da força.

Portanto, o estator com ranhuras e chanfros apresenta as melhores características para a aplicação do motor em uma prótese de membro superior. 


\subsubsection{Análise da Influência da Geometria e dos Ímãs}

Foram projetados quatro motores, com valores eficazes próximos da força eletromagnética, para que comparações relacionadas à influência da geometria e dos ímãs fossem feitas.

O primeiro projeto refere-se ao motor com ranhuras e chanfros apresentado na subseção anterior, mas com um número menor de pólos.

O segundo motor é igual ao primeiro, mas com ímãs de SmCo (20 MGOe ou 159,16 $\mathrm{kJm}^{-3}$ ). A substituição dos ímãs de $\mathrm{NdFeB}$ foi feita com o intuito de diminuir-se a densidade de fluxo magnético no aço elétrico, para evitar-se a saturação.

O motor do terceiro projeto é constituído por ímãs de NdFeB e possui o tamanho do passo polar menor do que o dos dois primeiros.

A quarta máquina foi projetada com um entreferro menor, com ímãs de $\mathrm{NdFeB}$ (32 MGOe ou 254,66 $\mathrm{kJm}^{-3}$ ) e com o mesmo tamanho do passo polar da primeira máquina.

As características descritas nos parágrafos anteriores podem ser observadas na tabela 13.

Tabela 13 - Características construtivas dos motores projetados.

\begin{tabular}{ccccccccccc}
\hline Motor & $\boldsymbol{N}_{\text {bob }}$ & $\boldsymbol{N}_{\boldsymbol{p}}$ & $\begin{array}{c}\boldsymbol{g} \\
{[\mathbf{m m}]}\end{array}$ & $\begin{array}{c}\boldsymbol{T}_{\boldsymbol{L}} \\
{[\mathbf{c m}]}\end{array}$ & $\begin{array}{c}\boldsymbol{T}_{\boldsymbol{E}} \\
{[\mathbf{c m}]}\end{array}$ & $\begin{array}{c}\boldsymbol{D}_{\boldsymbol{e}} \\
{[\mathbf{c m}]}\end{array}$ & $\begin{array}{c}\boldsymbol{\tau} \\
{[\mathbf{c m}]}\end{array}$ & $\boldsymbol{N}$ & $\begin{array}{c}\boldsymbol{B}_{\boldsymbol{e}} \\
(\mathbf{A W G})\end{array}$ & $\boldsymbol{B}_{\boldsymbol{g}}[\mathbf{T}]$ \\
\hline $\mathbf{1}$ & 18 & 14 & 4 & 7,14 & 9,18 & 2,78 & 0,51 & 24 & 28 & 0,80 \\
$\mathbf{2}$ & 18 & 14 & 4 & 7,14 & 9,18 & 2,78 & 0,51 & 24 & 28 & 0,60 \\
$\mathbf{3}$ & 28 & 23 & 4 & 9,66 & 11,76 & 2,97 & 0,42 & 12 & 28 & 0,75 \\
$\mathbf{4}$ & 22 & 18 & 3 & 9,18 & 11,22 & 2,89 & 0,51 & 13 & 28 & 0,80 \\
\hline
\end{tabular}

As figuras 55, 56, 57 e 58 mostram a densidade de fluxo magnético normal no centro do entreferro, para os dois primeiros pares de pólo, dos quatro projetos. 


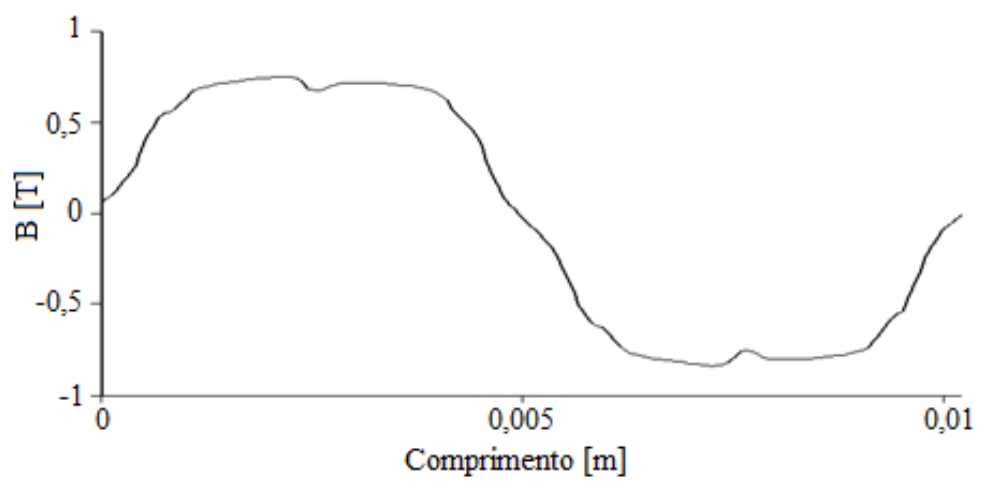

Figura 55 - Densidade de fluxo magnético normal no entreferro do primeiro projeto.

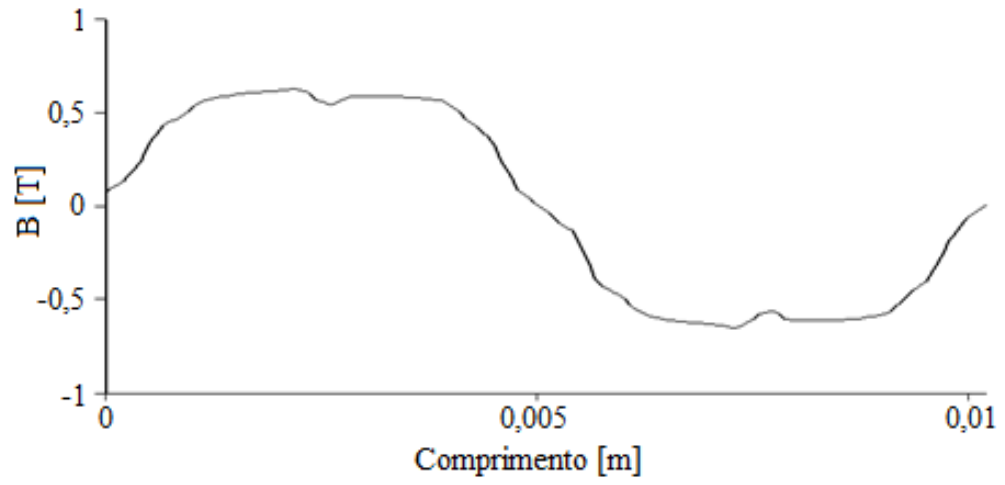

Figura 56 - Densidade de fluxo magnético normal no entreferro do segundo projeto.

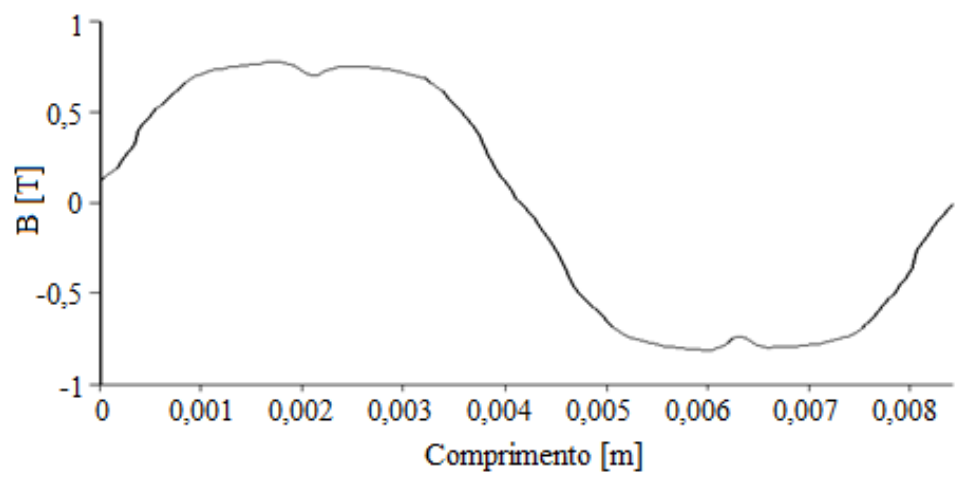

Figura 57 - Densidade de fluxo magnético normal no entreferro do terceiro projeto.

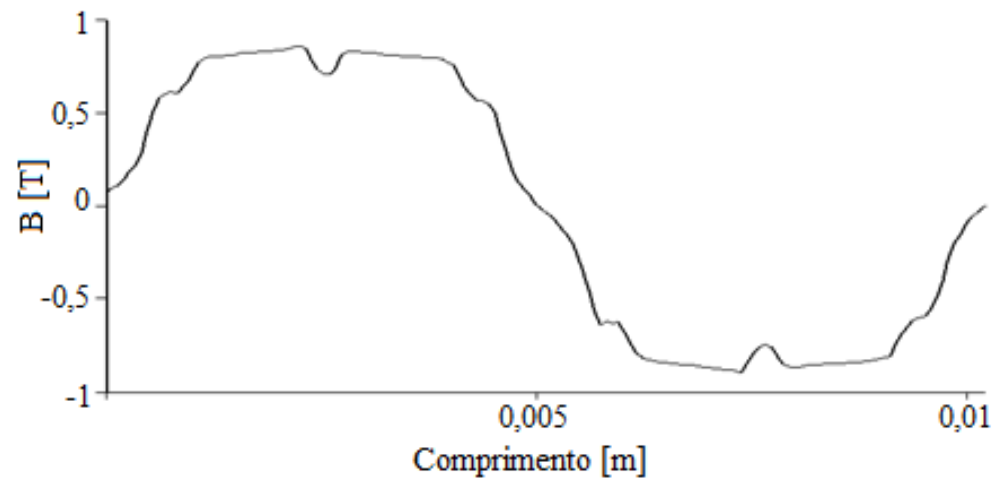

Figura 58 - Densidade de fluxo magnético normal no entreferro do quarto projeto. 
As figuras 59, 60, 61 e 62 apresentam a força eletromagnética em cada posição do linor, para os quatro projetos.

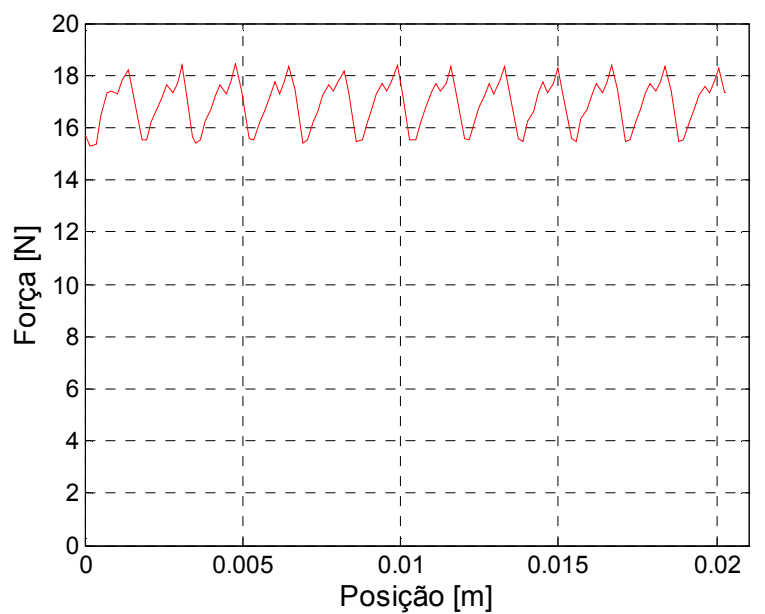

Figura 59 - Força eletromagnética do primeiro projeto.

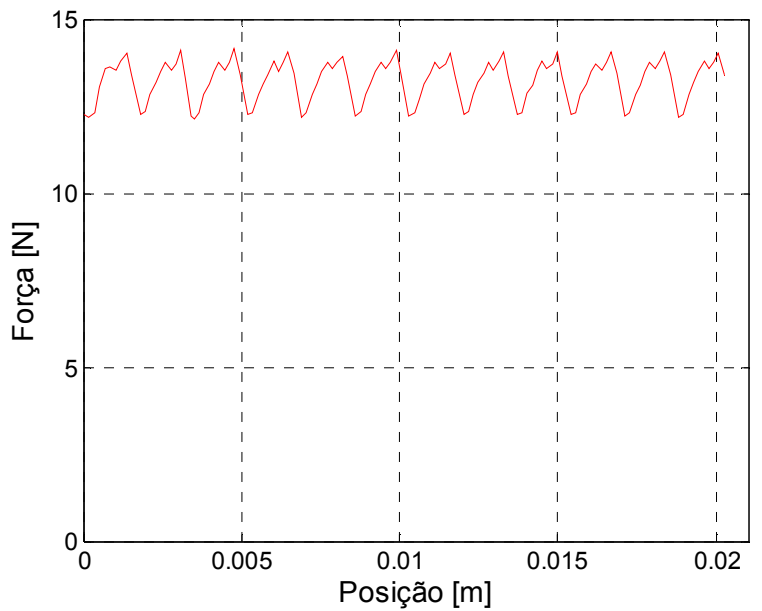

Figura 60 - Força eletromagnética do segundo projeto.

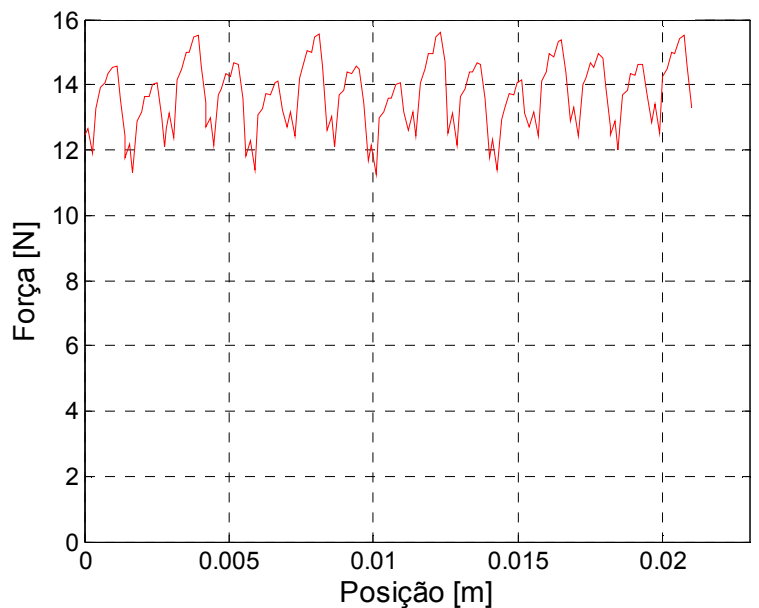

Figura 61 - Força eletromagnética do terceiro projeto. 


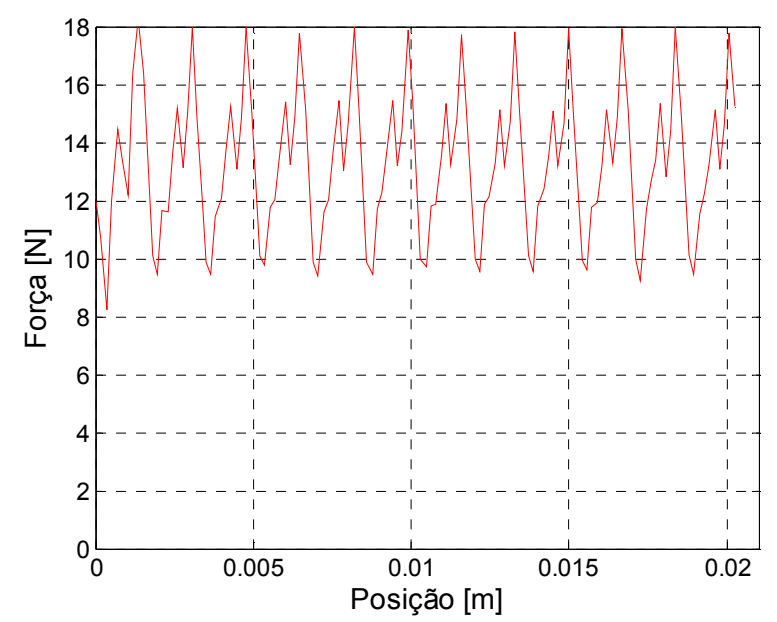

Figura 62 - Força eletromagnética do quarto projeto.

As figuras 63, 64, 65 e 66 mostram a densidade de fluxo magnético, sendo os seguintes valores máximos encontrados para cada projeto (do primeiro ao quarto, respectivamente): $2,06 \mathrm{~T}, 1,75 \mathrm{~T}, 1,70 \mathrm{~T}$ e $1,80 \mathrm{~T}$.

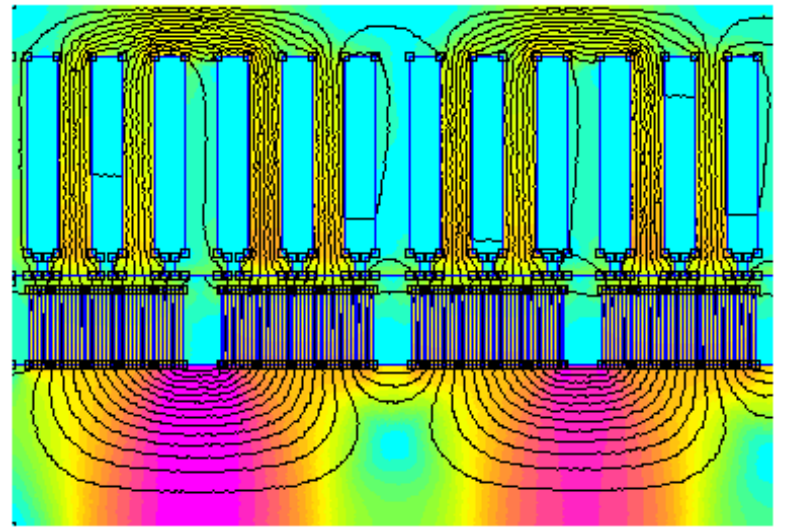

$1.900 \mathrm{e}+000:>2.000 \mathrm{e}+000$ $1.800 \mathrm{e}+000: 1.900 \mathrm{e}+000$

$1.700 \mathrm{e}+000: 1.800 \mathrm{e}+000$

$1.600 \mathrm{e}+000: 1.700 \mathrm{e}+000$

$1.500 \mathrm{e}+000: 1.600 \mathrm{e}+000$

$1.400 \mathrm{e}+000: 1.500 \mathrm{e}+000$

$1.300 \mathrm{e}+000: 1.400 \mathrm{e}+000$

$1.200 \mathrm{e}+000: 1.300 \mathrm{e}+000$

$1.100 \mathrm{e}+000: 1.200 \mathrm{e}+000$

$1.000 \mathrm{e}+000: 1.100 \mathrm{e}+000$

$9.000 \mathrm{e}-001: 1.000 \mathrm{e}+000$

$8.000 \mathrm{e}-001: 9.000 \mathrm{e}-001$

$7.000 \mathrm{e}-001: 8.000 \mathrm{e}-001$

$6.000 \mathrm{e}-001: 7.000 \mathrm{e}-001$

$5.000 \mathrm{e}-001: 6.000 \mathrm{e}-001$

$4.000 \mathrm{e}-001: 5.000 \mathrm{e}-001$

$3.000 \mathrm{e}-001: 4.000 \mathrm{e}-001$

$2.000 \mathrm{e}-001: 3.000 \mathrm{e}-001$

$1.000 \mathrm{e}-001: 2.000 \mathrm{e}-001$

$<0.000 \mathrm{e}+000: 1.000 \mathrm{e}-001$

Density Plot: |B|, Tesla

Figura 63 - Densidade de fluxo magnético do primeiro projeto. 

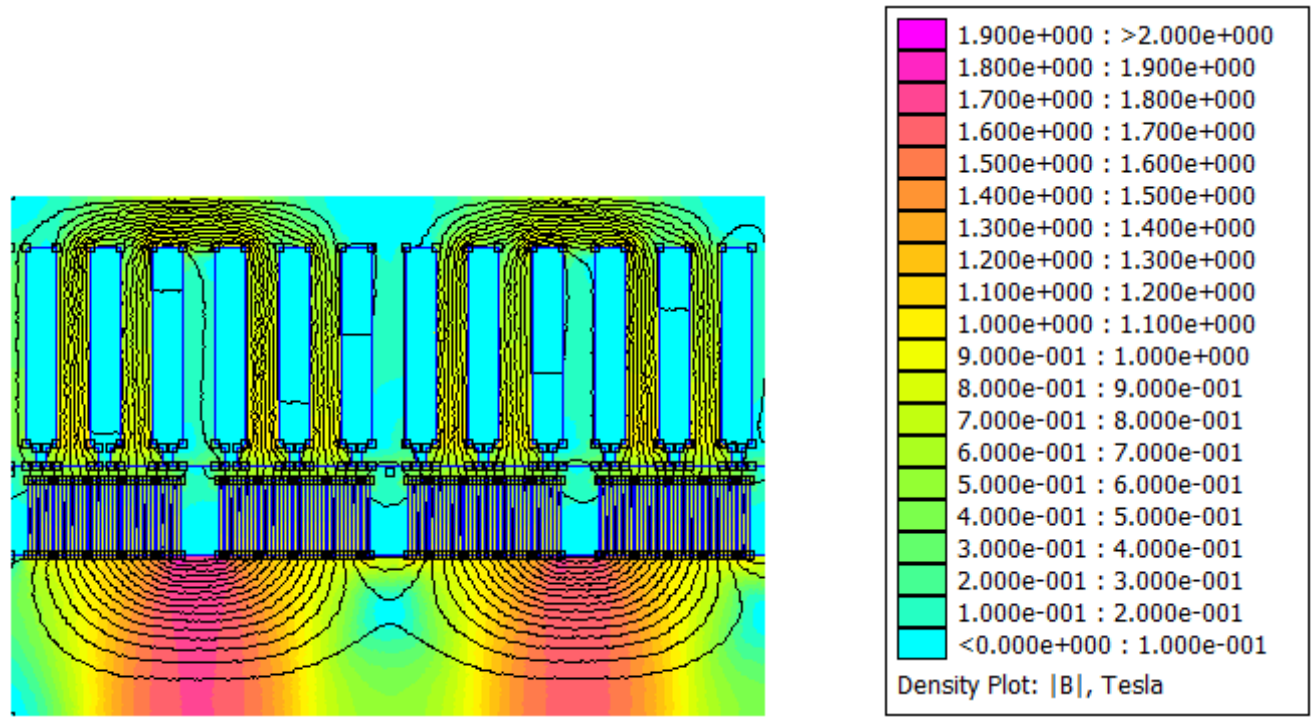

Figura 64 - Densidade de fluxo magnético do segundo projeto.
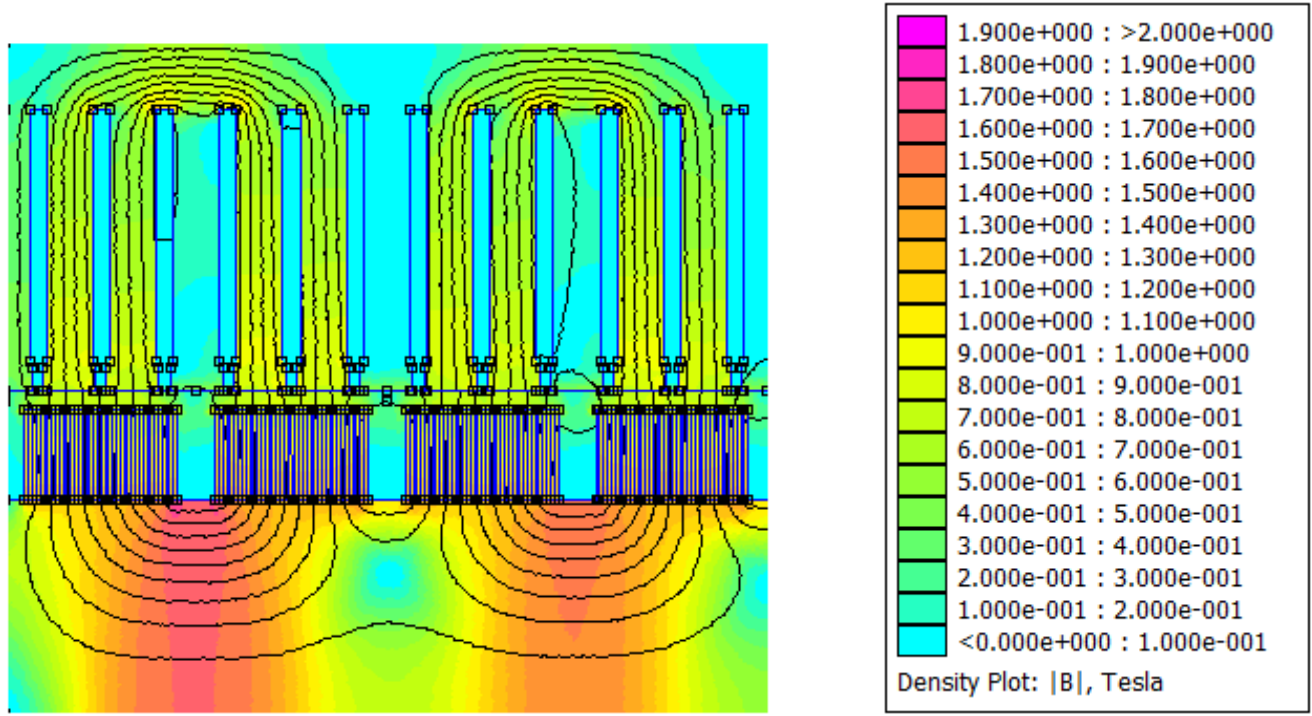

Figura 65 - Densidade de fluxo magnético do terceiro projeto.

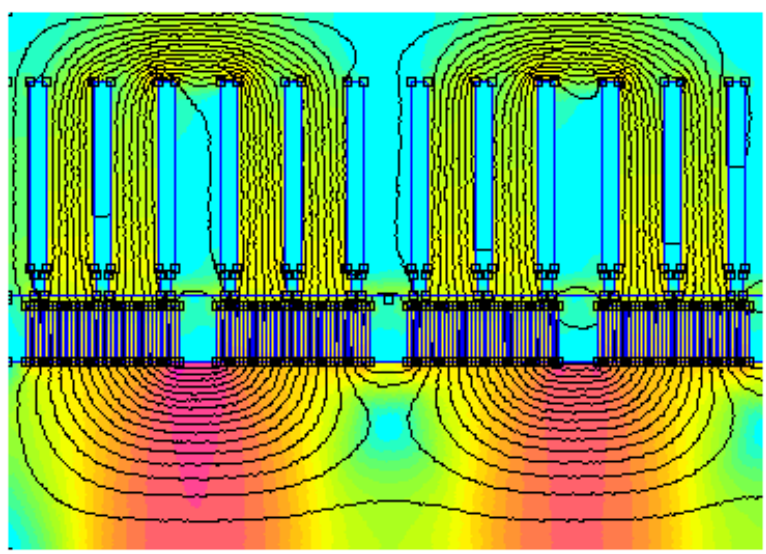

\begin{tabular}{|l|l|}
\hline & $1.900 \mathrm{e}+000:>2.000 \mathrm{e}+000$ \\
$1.800 \mathrm{e}+000: 1.900 \mathrm{e}+000$ \\
$1.700 \mathrm{e}+000: 1.800 \mathrm{e}+000$ \\
$1.600 \mathrm{e}+000: 1.700 \mathrm{e}+000$ \\
$1.500 \mathrm{e}+000: 1.600 \mathrm{e}+000$ \\
$1.400 \mathrm{e}+000: 1.500 \mathrm{e}+000$ \\
$1.300 \mathrm{e}+000: 1.400 \mathrm{e}+000$ \\
$1.200 \mathrm{e}+000: 1.300 \mathrm{e}+000$ \\
$1.100 \mathrm{e}+000: 1.200 \mathrm{e}+000$ \\
$1.000 \mathrm{e}+000: 1.100 \mathrm{e}+000$ \\
$9.000 \mathrm{e}-001: 1.000 \mathrm{e}+000$ \\
$8.000 \mathrm{e}-001: 9.000 \mathrm{e}-001$ \\
$7.000 \mathrm{e}-001: 8.000 \mathrm{e}-001$ \\
$6.000 \mathrm{e}-001: 7.000 \mathrm{e}-001$ \\
$5.000 \mathrm{e}-001: 6.000 \mathrm{e}-001$ \\
$4.000 \mathrm{e}-001: 5.000 \mathrm{e}-001$ \\
$3.000 \mathrm{e}-001: 4.000 \mathrm{e}-001$ \\
$2.000 \mathrm{e}-001: 3.000 \mathrm{e}-001$ \\
$1.000 \mathrm{e}-001: 2.000 \mathrm{e}-001$ \\
$<0.000 \mathrm{e}+000: 1.000 \mathrm{e}-001$ \\
\hline Density Plot: |B|, Tesla \\
\hline
\end{tabular}

Figura 66 - Densidade de fluxo magnético do quarto projeto. 
A tabela 14 mostra os parâmetros dos motores projetados, que auxiliam na escolha da máquina de acordo com as limitações da aplicação.

Tabela 14 - Parâmetros dos motores projetados.

\begin{tabular}{|c|c|c|c|c|c|c|c|c|c|c|}
\hline Motor & $\begin{array}{l}i_{m a ́ x} \\
{[\mathrm{~A}]}\end{array}$ & $\begin{array}{c}F_{e f} \\
{[\mathbf{N}]}\end{array}$ & $\begin{array}{c}R_{\text {fase }} \\
{[\Omega]}\end{array}$ & $\begin{array}{c}\boldsymbol{P}_{\boldsymbol{r}} \\
{[\mathbf{W}]}\end{array}$ & $\begin{array}{l}V_{\min } \\
{[\mathrm{V}]}\end{array}$ & $\begin{array}{c}M_{L} \\
{[\mathrm{Kg}]}\end{array}$ & $\begin{array}{c}M_{e} \\
{[\mathbf{K g}]}\end{array}$ & $\begin{array}{c}M_{T} \\
{[\mathrm{Kg}]}\end{array}$ & $\begin{array}{c}V_{o l} \\
\times 10^{-5} \\
{\left[\mathrm{~m}^{3}\right]}\end{array}$ & $\begin{array}{c}D_{F} \\
\times 10^{5} \\
{\left[\mathbf{N} / \mathbf{m}^{3}\right]}\end{array}$ \\
\hline 1 & 0,84 & 16,7 & 5,64 & 3,98 & 9,48 & 0,062 & 0,295 & 0,357 & 4,95 & 3,37 \\
\hline 2 & 0,84 & 13,2 & 5,64 & 3,98 & 9,48 & 0,064 & 0,295 & 0,359 & 4,95 & 2,67 \\
\hline 3 & 0,84 & 13,7 & 4,30 & 3,03 & 7,22 & 0,104 & 0,495 & 0,599 & 7,56 & 1,81 \\
\hline 4 & 0,84 & 13,5 & 3,77 & 3,14 & 6,33 & 0,089 & 0,417 & 0,507 & 6,80 & 1,98 \\
\hline
\end{tabular}

\subsubsection{Seleção do Motor a Ser Construído}

Os projetos número 1 e 2 da subseção 4.14 .2 são os que apresentam as melhores características para a aplicação em uma prótese de membro superior, quando comparados aos demais mostrados, tais como: maior densidade de força eletromagnética, menor massa e menores dimensões de estator, diâmetro e linor. Entretanto, é a máquina que apresenta maior perda resistiva e maior tensão mínima de alimentação.

A substituição do ímã de $\mathrm{NdFeB}$ pelo de $\mathrm{SmCo}$ (projetos 1 e 2) acarretou diminuições de $20,8 \%$ da densidade de força e de $15,05 \%$ do valor máximo da densidade de fluxo magnético no material ferromagnético do linor. No entanto, mesmo o primeiro projeto apresentando um elevado valor de indução magnética no linor, pode-se considerá-lo a melhor opção para a aplicação de prótese.

A seleção do projeto número 1, em relação aos 3 e 4, baseou-se principalmente nas dimensões e na massa do motor, pois em uma prótese, que utiliza o mecanismo soft gripper, são necessários três motores elétricos para o acionamento desta mesma quantidade de dedos. Em relação ao projeto 2, o fator determinante é a alta densidade de força e o menor custo do ímã de NdFeB comparado com o de SmCo.

A tabela 15 mostra as dimensões do motor selecionado para ser construído (Projeto 1) e os valores da indutância própria e mútua obtidas no software FEMM. 
Tabela 15 - Dimensões do projeto inicial do motor.

\begin{tabular}{|c|c|c|c|c|c|c|c|c|c|c|}
\hline $\begin{array}{c}R_{0} \\
{[\mathrm{~cm}]}\end{array}$ & $\begin{array}{c}R_{m} \\
{[\mathrm{~cm}]}\end{array}$ & $\begin{array}{c}R_{i} \\
{[\mathrm{~cm}]}\end{array}$ & $\begin{array}{c}R_{S} \\
{[\mathrm{~cm}]}\end{array}$ & $\begin{array}{c}R_{e} \\
{[\mathrm{~cm}]}\end{array}$ & $\begin{array}{c}w_{s} \\
\times 10^{-2} \\
{[\mathrm{~cm}]}\end{array}$ & $\begin{array}{c}w_{t} \\
\times 10^{-2} \\
{[\mathrm{~cm}]}\end{array}$ & $\begin{array}{c}\tau \\
{[\mathrm{cm}]}\end{array}$ & $\begin{array}{c}\tau_{m} \\
{[\mathrm{~cm}]}\end{array}$ & $\begin{array}{c}L \\
{[\mathrm{mH}]}\end{array}$ & $\begin{array}{c}M \\
{[\mathrm{mH}]}\end{array}$ \\
\hline 0,43 & 0,63 & 0,67 & 1,25 & 1,39 & 8,0988 & 8,9012 & 0,51 & 0,41 & 3,1 & 0,1 \\
\hline
\end{tabular}

A figura 67 apresenta o fluxo magnético da fase $A$ do motor a ser construído e a partir dele foi calculada a tensão induzida para a mesma fase, considerando-se a velocidade igual a $0,01 \mathrm{~m} \mathrm{~s}^{-1}$, figura 68 .

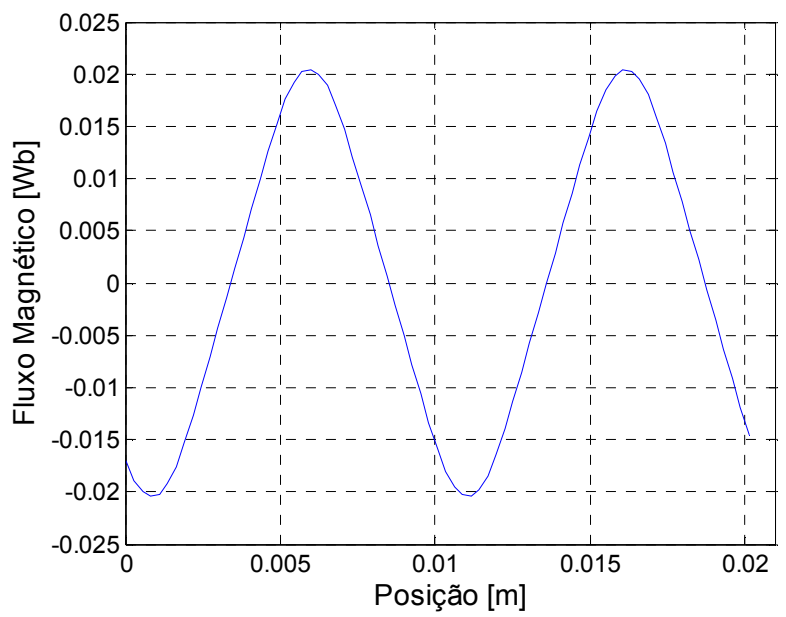

Figura 67 - Fluxo magnético da fase $A$ do motor selecionado para ser construído.

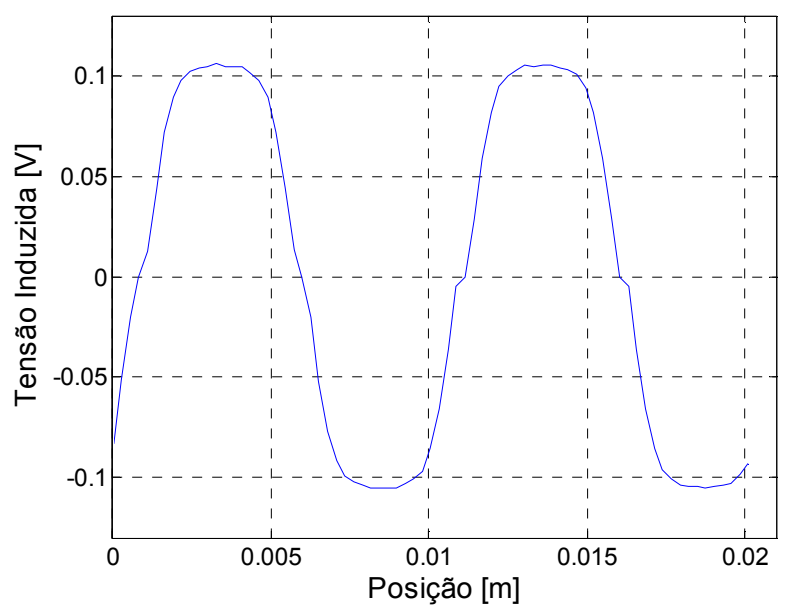

Figura 68 - Tensão induzida da fase $A$ do motor selecionado para ser construído. 


\subsubsection{Comparação dos Resultados Obtidos por Meio do Software FEMM com o Software iMOOSE}

Nesta subseção são apresentados os resultados obtidos com o software iMOOSE (Modern Object-Oriented Solving Environment), que está sendo desenvolvido pelo Instituto de Máquinas Elétricas, da Universidade RWTH Aachen. Ele é um ambiente, com o código fonte aberto, para cálculos por meio do Método dos Elementos Finitos (RIESEN et al., 2004).

Inicialmente, utilizou-se o iMOOSE.stat2d, que é uma extensão do solver iMOOSE e faz análises estáticas em três dimensões, para obterem-se a força eletromagnética do motor projetado e os mapas com a densidade de fluxo magnético.

O desenho da geometria a ser analisada e a discretização da mesma, em elementos triangulares de primeira ordem, foi feita no software Ansys ${ }^{\circledR}$. Devido ao motor tubular ser simétrico, pode-se dividi-lo em várias partes iguais e realizar os cálculos em apenas uma delas, com o objetivo de reduzir-se o tempo computacional. A figura 69a mostra o motor em duas dimensões e a $69 \mathrm{~b}$ apresenta a parte do motor $\left(10^{\circ}\right)$ que foi utilizada para obterem-se os resultados.

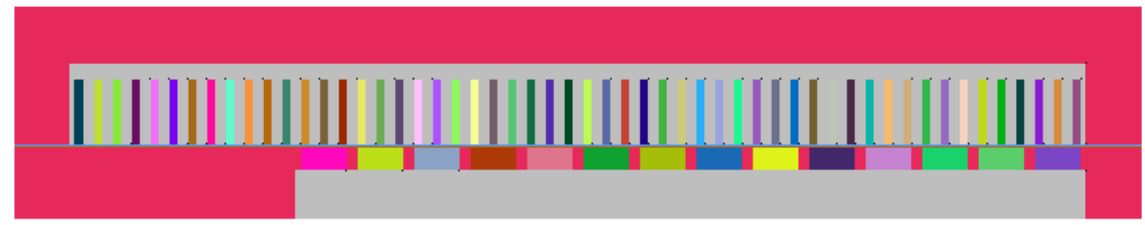

a)

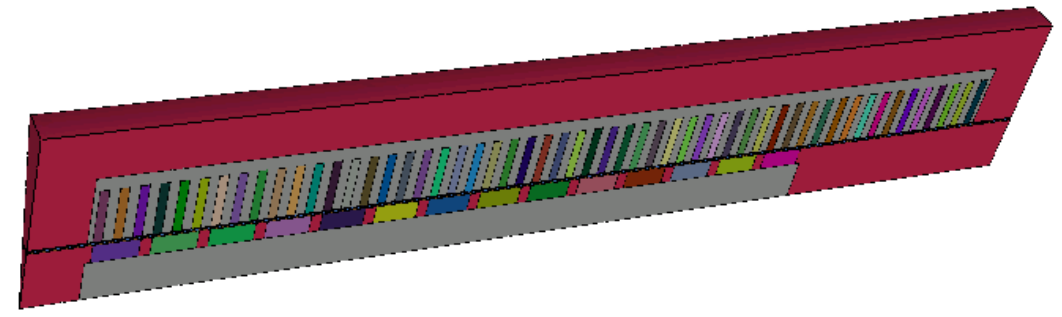

b)

Figura 69 - Desenho do motor linear tubular no software Ansys ${ }^{\circledR}$ : a) Vista em duas dimensões, b) Vista de uma parte do motor tubular $\left(10^{\circ}\right)$.

A figura 70 mostra a densidade de fluxo magnético, em duas dimensões, do motor e a 71 apresenta os vetores da densidade de fluxo magnético na região abrangida pelo retângulo vermelho da figura 70 . 


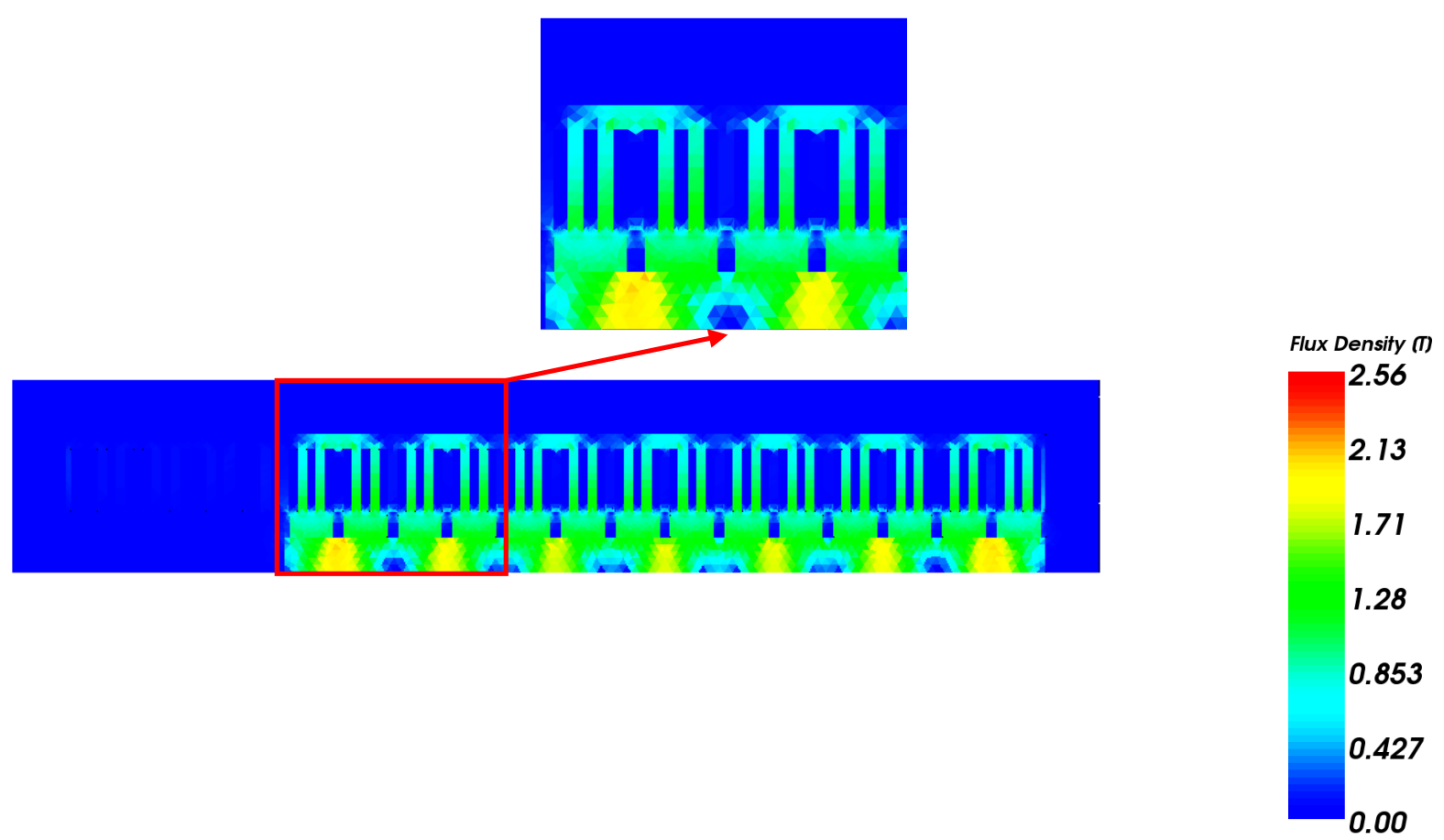

Figura 70 - Densidade de fluxo magnético obtida no programa iMOOSE.
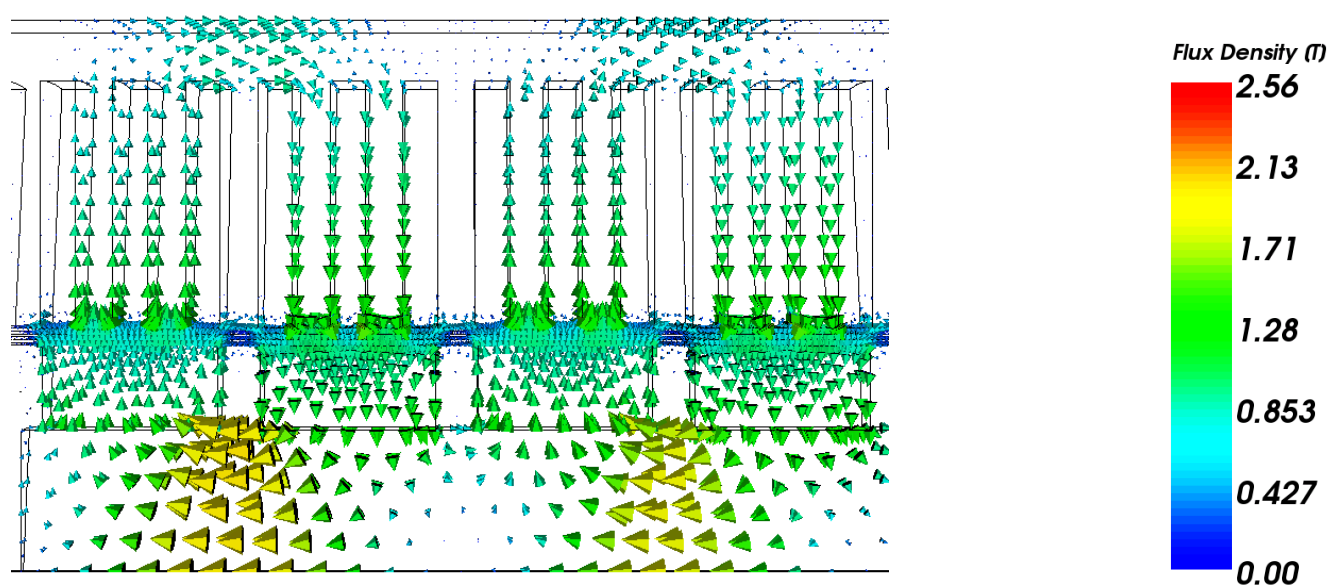

Figura 71 - Vetores da densidade de fluxo magnético na região abrangida pelo retângulo vermelho da figura 70.

A densidade de corrente é mostrada na figura 72 e os vetores da mesma são apresentados na figura 73 . 


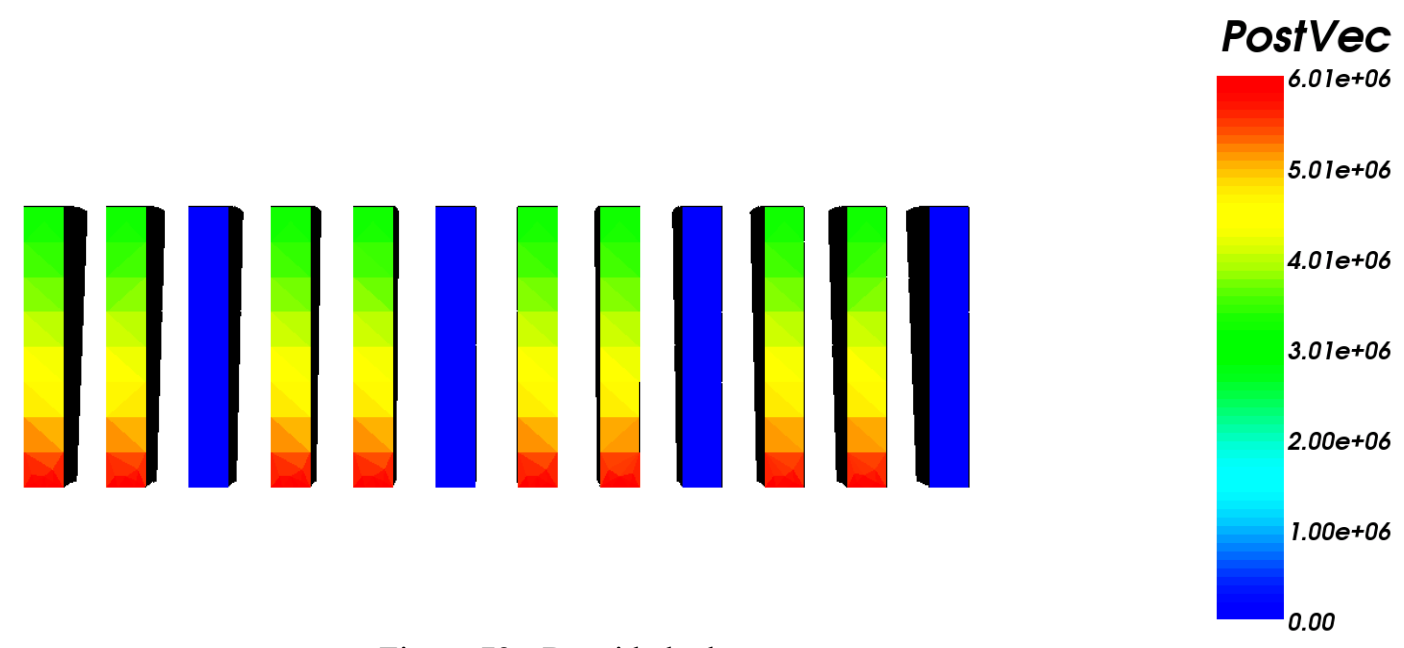

Figura 72 - Densidade de corrente.

PostVec

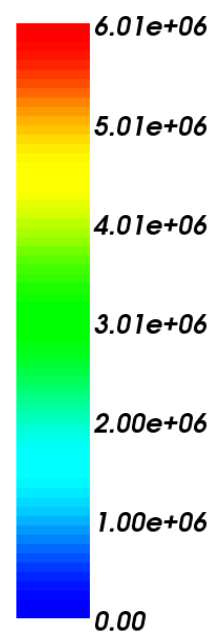

Figura 73 - Vetores da densidade de corrente.

A comparação da força eletromagnética obtida por meio do software FEMM com o iMOOSE é mostrada na figura 74. A diferença do valor eficaz entre ambas é em torno de 3\%, que pode ser causada pelas características não idênticas dos materiais utilizados nos cálculos. No software FEMM, a principal propriedade do material magnético é a coercividade intrínsica, enquanto no iMOOSE é a densidade de fluxo residual. Outro fator que pode ocasionar essa diferença é a precisão considerada no método numérico. 


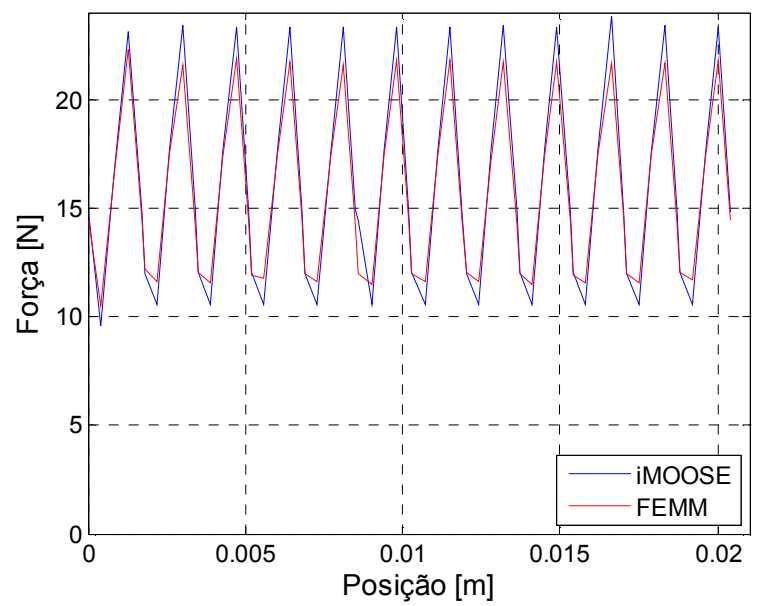

Figura 74 - Comparação da força eletromagnética obtida por meio do software FEMM com o iMOOSE.

\subsubsection{Otimização do Projeto do Motor Tubular Considerando-se Dois Métodos do Efeito da Inclinação (Skew) dos Ímãs}

A atração entre os ímãs e as ranhuras causa o efeito de borda, que produz a força de borda, que é uma das responsáveis pela oscilação da força. Para minimizar essa consequência indesejada, são investigadas duas aproximações do efeito da inclinação (skew) dos ímãs na superfície do linor, que são comparadas com o motor sem esta alteração.

A figura 75 mostra um par de ímãs sem o efeito da inclinação, a 76 ilustra esse efeito que foi obtido com pedaços de ímãs, com dimensões iguais em forma de arco, alocados de maneira diferente. A figura 77 apresenta a inclinação dos ímãs atingida por meio de cortes planos e paralelos, no material em forma de anel, na parte superior e inferior.

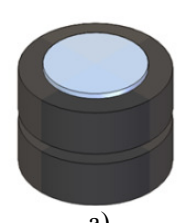

a)

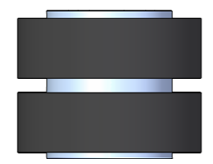

b)

Figura 75 - Ímãs sem o efeito da inclinação: a) Vista dimetric; b) Vista frontal (JULIANI et al., 2010).

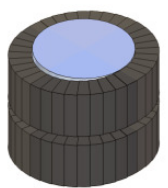

a)

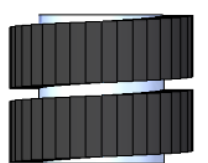

b)

Figura 76 - Ímãs com o efeito da inclinação: a) Vista dimetric; b) Vista frontal (JULIANI et al., 2010). 


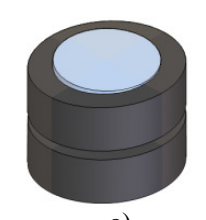

a)

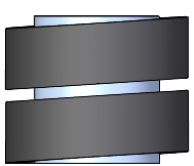

b)

Figura 77 - Ímãs com o efeito da inclinação plana: a) Vista dimetric; b) Vista frontal (JULIANI et al., 2010).

Utilizando-se o iMOOSE.tsa3d, também uma extensão do iMOOSE, pode-se realizar análises dinâmicas, em três dimensões, do motor projetado.

O método multi-slice divide o modelo de $180^{\circ}$ do motor em vários pedaços para compô-lo em sua totalidade, minimizando o tempo computacional (SCHMÜLLING et al., 2008). O resultado final é obtido pela superposição dos passos computacionais. Neste trabalho, este método é utilizado e as partes são iguais a $10^{\circ}$.

A figura 78 compara a força eletromagnética do motor considerando-se os ímãs com e sem o efeito da inclinação. Pode-se observar que a oscilação da força para os casos, sem a inclinação, com o efeito e com a inclinação plana é, respectivamente: $41,6 \mathrm{~N}, 2,0 \mathrm{~N}$ e 8,32 N. Portanto, a taxa da oscilação pelo valor médio da força, quando comparado com o motor sem efeito, foi melhorada de 2,14 para 0,11 , no primeiro caso, e de 2,14 para 0,45 , na segunda situação.

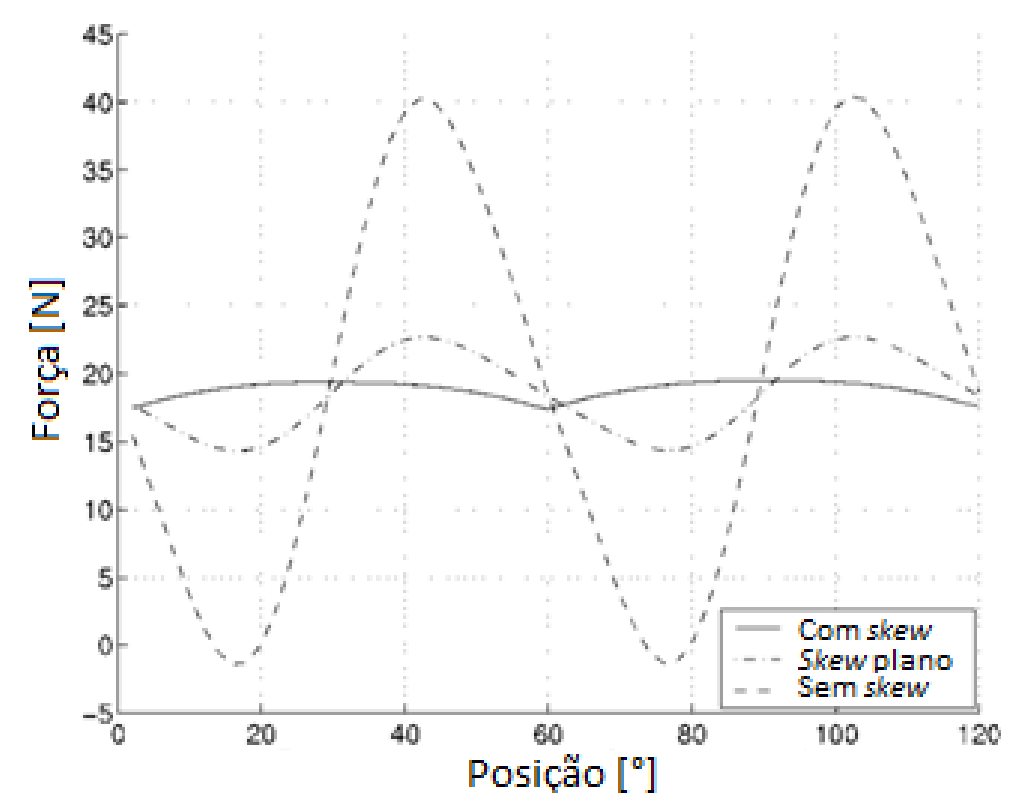

Figura 78 - Comparação da força eletromagnética do motor considerando-se os ímãs com e sem o efeito da inclinação (JULIANI et al., 2010). 


\subsubsection{Simulação Dinâmica}

Por meio da modelagem do motor linear tubular, realizada na subseção 4.12, e dos parâmetros apresentados nas tabelas 14 e 15, criou-se no programa Simulink ${ }^{\circledR}$ (MathWorks, 2010), um modelo matemático da máquina, juntamente com o acionamento e o controle de tensão por PWM, sendo o diagrama de blocos utilizado na simulação mostrado na figura 79.

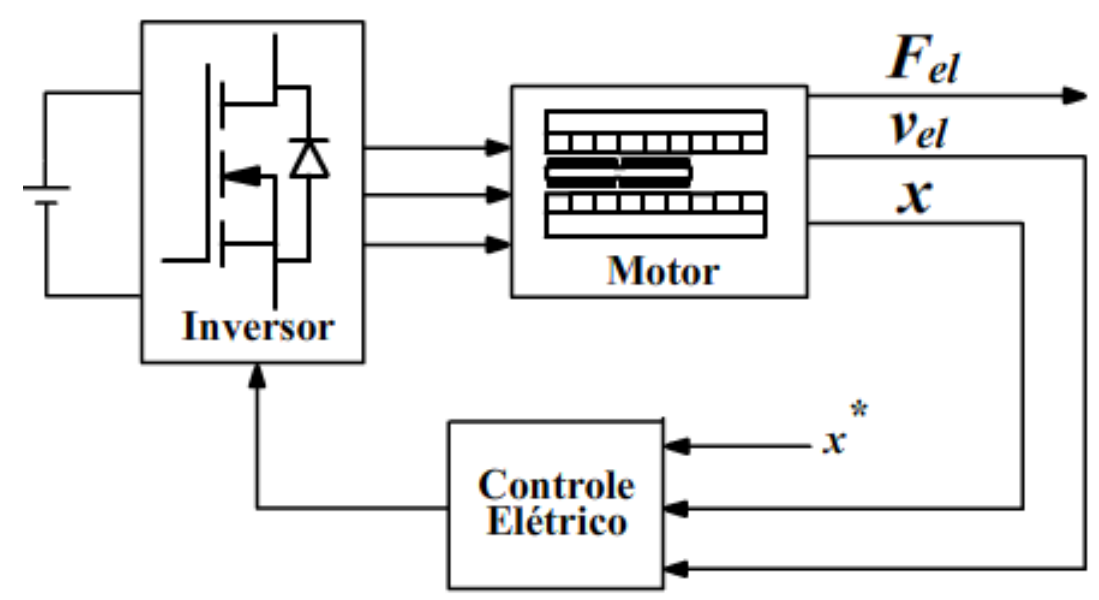

Figura 79 - Diagrama de blocos da simulação dinâmica.

As constantes dos compensadores do bloco de controle foram calculadas por meio das malhas de velocidade e de posição mostradas no apêndice D.

A figura 80 mostra a referência de posição, para realizar o movimento de fechamento do dedo indicador, e a posição real do motor, que está operando com uma carga igual a $5 \mathrm{~N}$.

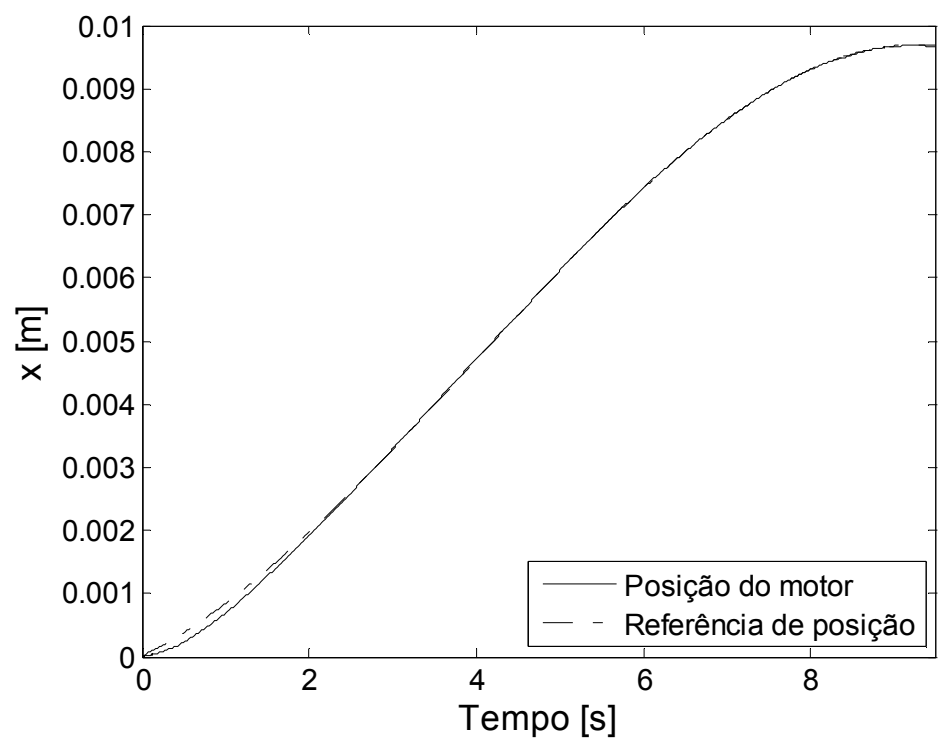

Figura 80 - Deslocamento da parte móvel do motor com controle de tensão por PWM. 
A velocidade mecânica e a sua referência são apresentadas na figura 81 .

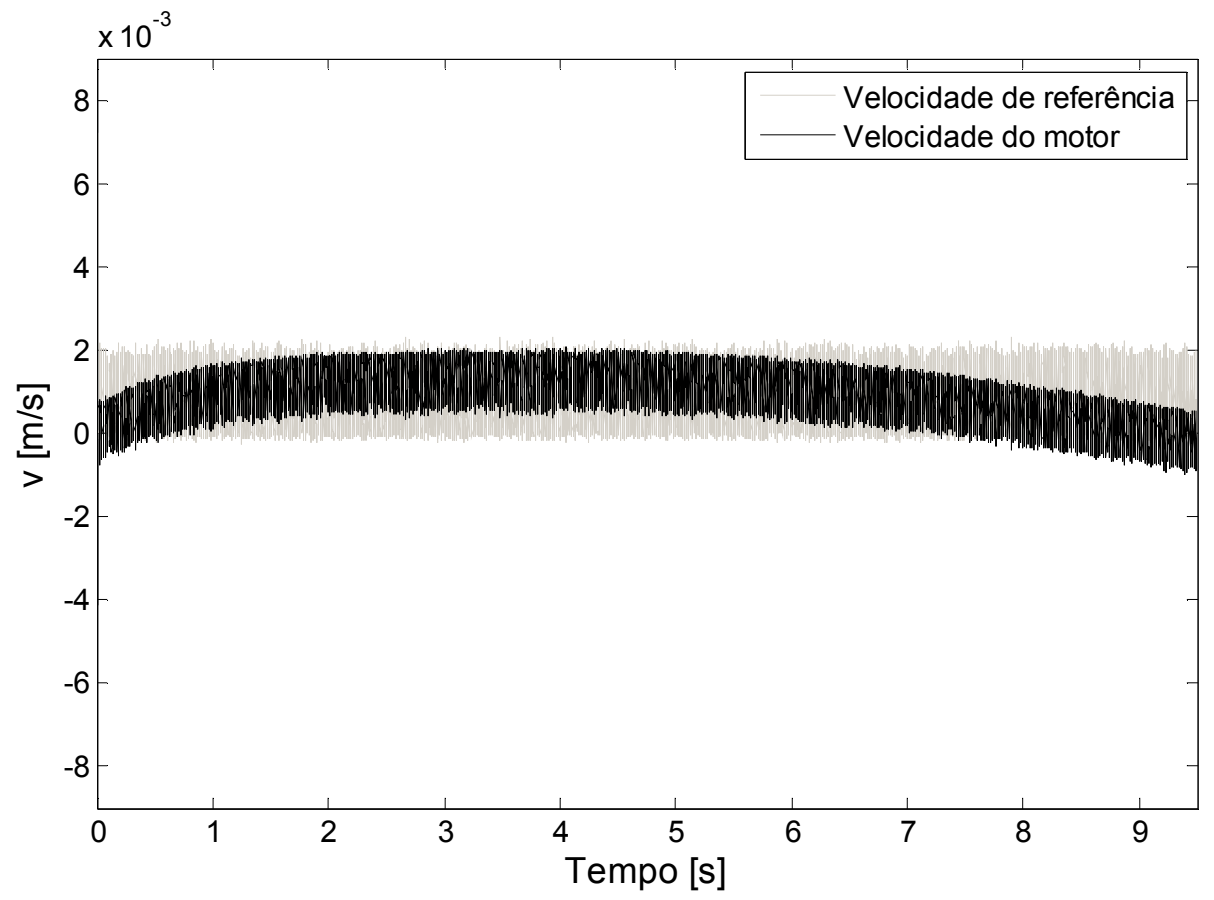

Figura 81 - Velocidade mecânica e referência com controle de tensão por PWM.

A figura 82 mostra a força eletromagnética instantânea do motor e o seu valor filtrado. $\mathrm{Na}$ prática, a ação do filtro é feita pela inércia do linor e pelo atrito viscoso.

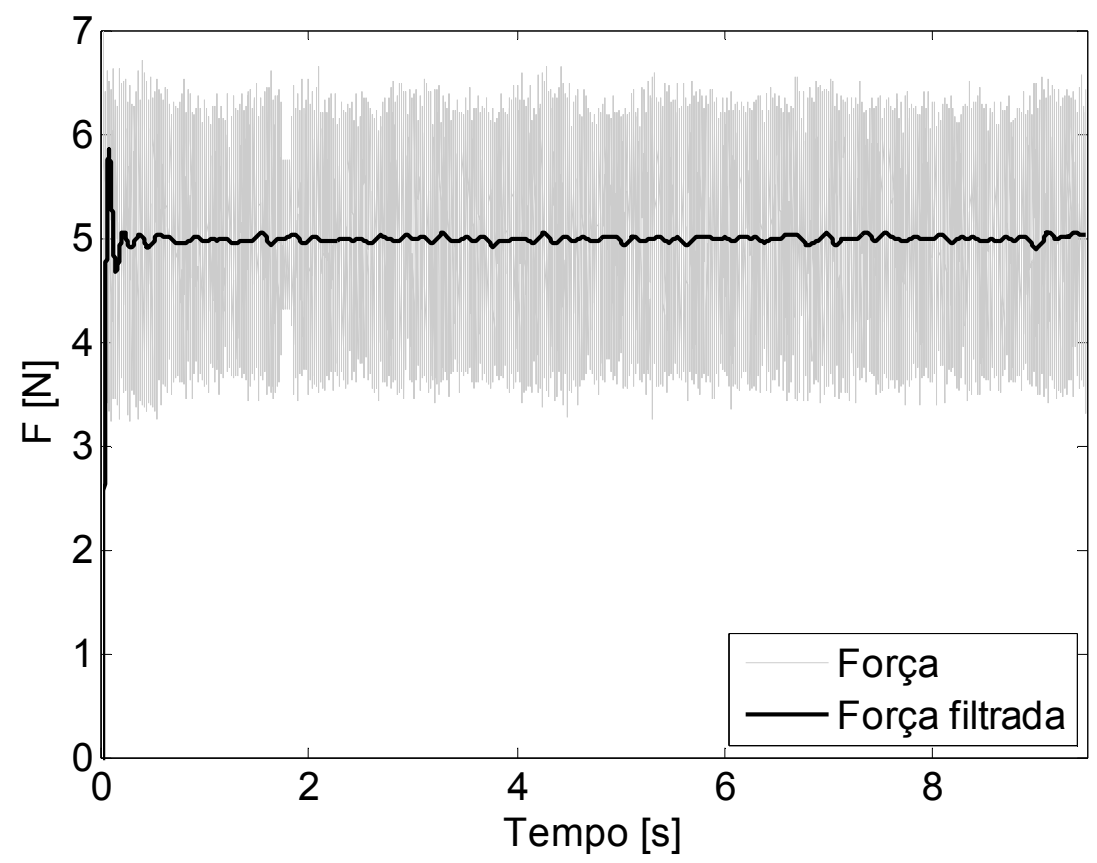

Figura 82 - Força eletromagnética com controle de tensão.

As correntes elétricas e as tensões induzidas por fase são mostradas na figura 83 . 

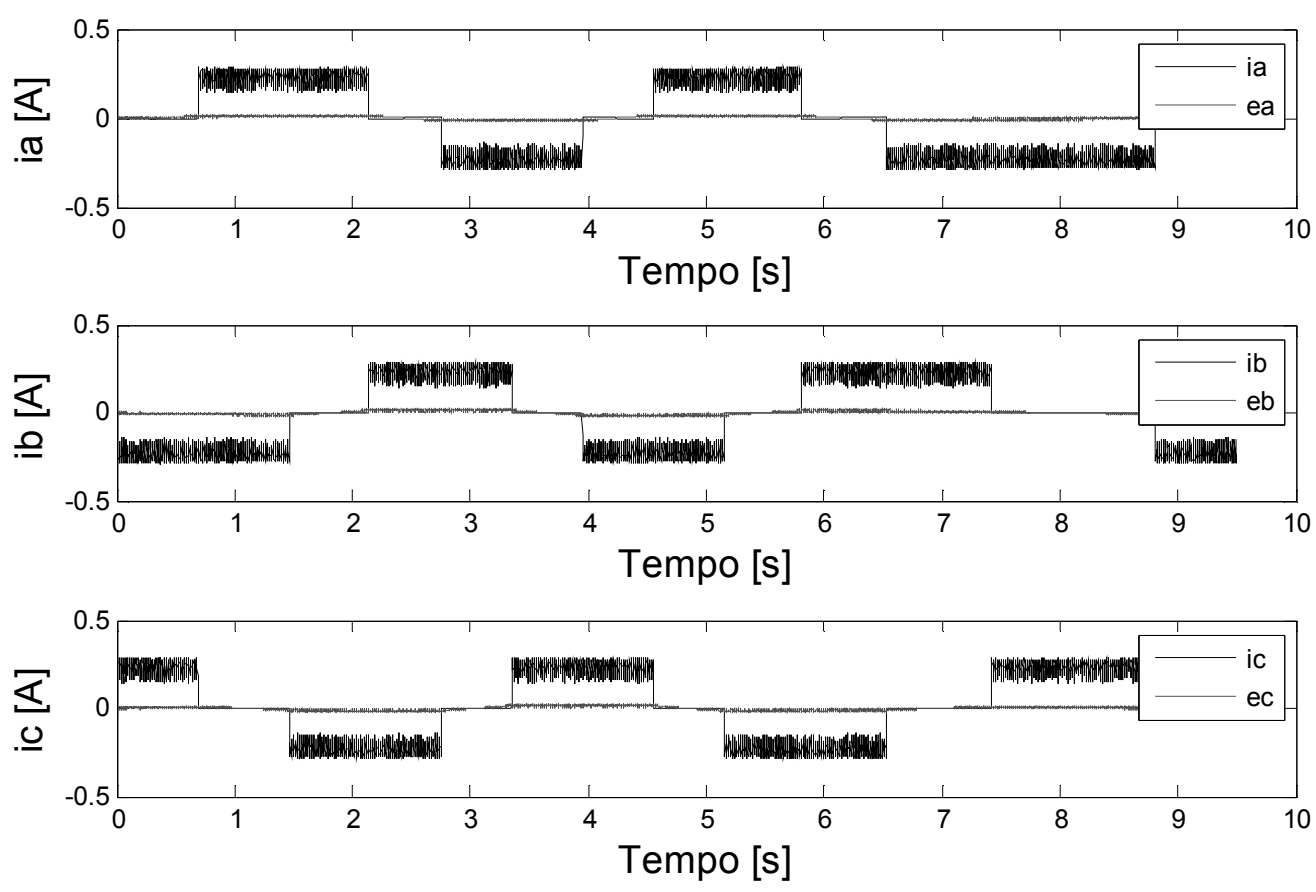

Figura 83 - Corrente elétrica e tensão induzida por fase com controle de tensão.

Os resultados da simulação dinâmica, com o controle feito por tensão, estão coerentes com o funcionamento de um motor síncrono com ímãs permanentes na superfície e alimentação trapezoidal.

O tempo de resposta, dos dispositivos de potência, considerado na simulação $(15 \mathrm{kHz})$ é plausível de ser reproduzido na prática. 


\section{Construção do Motor Linear Tubular}

Neste capítulo, é apresentado um estudo da viabilidade da construção do motor linear tubular, de acordo com os materiais existentes e da disponibilidade financeira.

Cada etapa da construção da máquina é detalhada e as metodologias utilizadas na sua execução são descritas.

Deve-se ressaltar que o motor implementado é para fins experimentais das propriedades elétricas, magnéticas e mecânicas exigidas pela aplicação. Ele foi feito artesanalmente e diversas adaptações foram realizadas para viabilizar a sua confecção. Portanto, alguns fatores como massa e dimensões foram alterados. Essas mudanças não interferem no funcionamento da máquina, mas para a aplicação em uma prótese de membro superior, esses fatores não devem ser modificados, no caso do motor ser fabricado industrialmente.

\subsection{Estudo da Viabilidade da Construção do Motor}

Para a construção do motor linear tubular, materiais foram pesquisados de acordo com as dimensões apresentadas na tabela 15.

Primeiramente, verificaram-se as espessuras das chapas do material ferromagnético para o estator, existentes comercialmente. De acordo com o projeto inicial, seria necessária a produção deste material sob encomenda. No entanto, não foi encontrado nenhum fornecedor que pudesse produzir, em pequena quantidade, o material desejado. Então, decidiu-se utilizar chapas de 0,5 mm para a confecção do estator. Com isso, houve a alteração do tamanho do passo polar.

Apesar do aumento da área das ranhuras, manteve-se o diâmetro do fío de cobre e o número de espiras do projeto inicial, para facilitar a montagem. 
O tamanho dos ímãs foi adaptado à nova dimensão do passo polar e à espessura mínima do fabricante, que é de $2 \mathrm{~mm}$. A magnetização radial oferecida pelos fornecedores de ímãs é feita de uma maneira paralela, ou seja, para a obtenção de um anel magnetizado radialmente, é necessária a sua divisão em pequenos arcos de mesmo tamanho, para que seja feita a orientação desejada. No apêndice E é ilustrado esse tipo de magnetização e o número de divisões do anel solicitado ao fabricante.

Para a montagem do linor, utilizou-se o aço carbono 1020, ao invés do aço Fe-Si, pois não foi encontrado nenhum fornecedor deste tipo de material na forma maciça, apenas no formato de chapas. A dimensão também foi alterada, pois foi necessário o aumento da área do material ferromagnético para receber os ímãs permanentes, em sua superfície, com as espessuras maiores.

Um resumo das principais dimensões do motor que foi construído é mostrado na tabela 16 e os seus parâmetros são apresentados na tabela 17.

Tabela 16 - Dimensões do motor construído.

\begin{tabular}{ccccccccc}
\hline $\boldsymbol{R}_{\boldsymbol{0}}$ & $\boldsymbol{R}_{\boldsymbol{m}}$ & $\boldsymbol{R}_{\boldsymbol{i}}$ & $\boldsymbol{R}_{\boldsymbol{s}}$ & $\boldsymbol{R}_{\boldsymbol{e}}$ & $\boldsymbol{w}_{\boldsymbol{s}}$ & $\boldsymbol{w}_{\boldsymbol{t}}$ & $\boldsymbol{\tau}$ & $\boldsymbol{\tau}_{\boldsymbol{m}}$ \\
{$[\mathbf{c m}]$} & {$[\mathbf{c m}]$} & {$[\mathbf{c m}]$} & {$[\mathbf{c m}]$} & {$[\mathbf{c m}]$} & {$[\mathbf{c m}]$} & {$[\mathbf{c m}]$} & {$[\mathbf{c m}]$} & {$[\mathbf{c m}]$} \\
\hline 0,53 & 0,73 & 0,77 & 1,35 & 1,49 & 0,1 & 0,1 & 0,6 & 0,48 \\
\hline
\end{tabular}

\begin{tabular}{lllll} 
Tabela & 17 & - Parâmetros do motor construído. \\
\hline $\boldsymbol{i}_{\boldsymbol{m} \boldsymbol{m} \boldsymbol{x}}$ & $\boldsymbol{F}_{\boldsymbol{e f}}$ & $\boldsymbol{P}_{\boldsymbol{r}}$ & $\boldsymbol{V}_{\boldsymbol{m i n}}$ & $\boldsymbol{M}_{\boldsymbol{L}}$
\end{tabular}

\begin{tabular}{ccccc}
{$[\mathbf{A}]$} & {$[\mathbf{N}]$} & {$[\mathbf{W}]$} & {$[\mathbf{V}]$} & {$[\mathbf{K g}]$} \\
\hline 0,84 & 19,4 & 3,98 & 9,48 & 0,182 \\
\hline
\end{tabular}

As dimensões da máquina projetada inicialmente podem ser comparadas com as da máquina construída no Apêndice E.

Para a montagem do linor, verificou-se a influência da presença de um material ferromagnético entre os ímãs (anéis), que facilitaria a colagem dos mesmos, pois o aço (na forma cilíndrica) poderia ser usinado, no tamanho apresentado na tabela 16, juntamente com anéis (inicialmente inexistentes), que delimitariam a posição inicial e final dos ímãs.

A figura 84 compara a força eletromagnética com a ausência e a presença de anéis, sendo o valor eficaz para esses casos, respectivamente: 19,3661 N e 17,4435 N. 


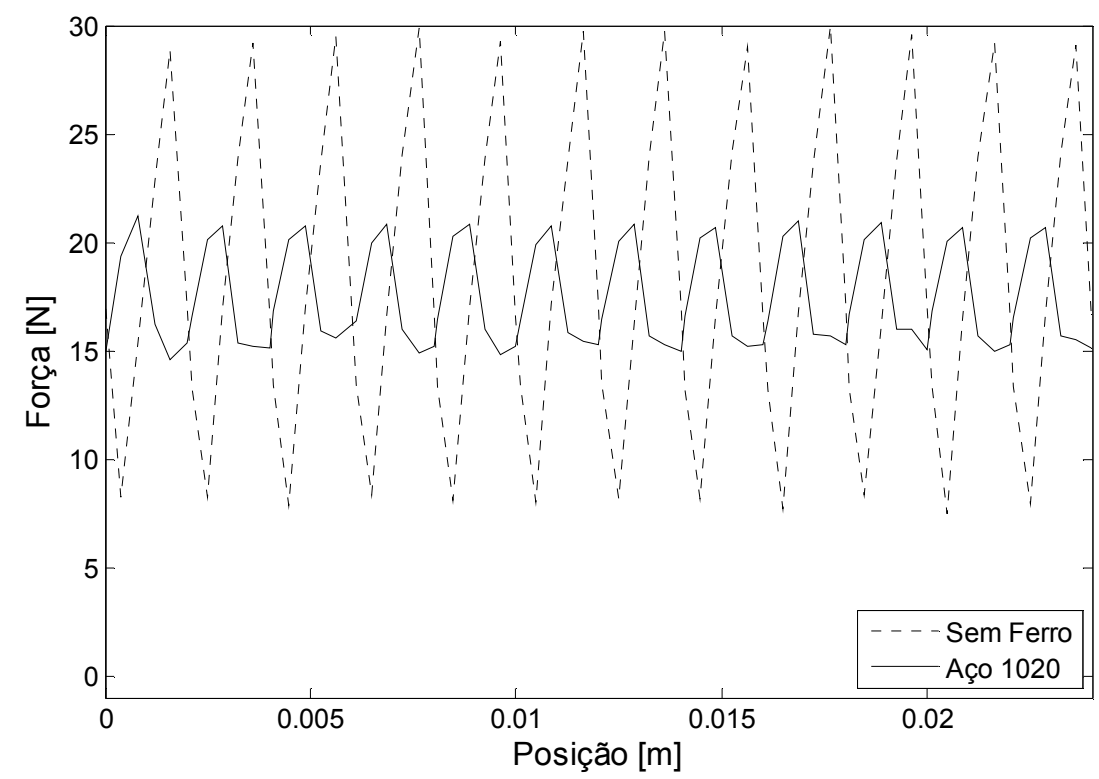

Figura 84 - Força eletromagnética com a ausência e a presença de anéis feitos de aço entre os ímãs.

O fluxo magnético é mostrado na figura 85 , a ampliação da região abrangida pelo retângulo cinza é mostrada na 86 . A tensão induzida para a velocidade mecânica igual a 0,01 $\mathrm{m} / \mathrm{s}$ é apresentada na 87.

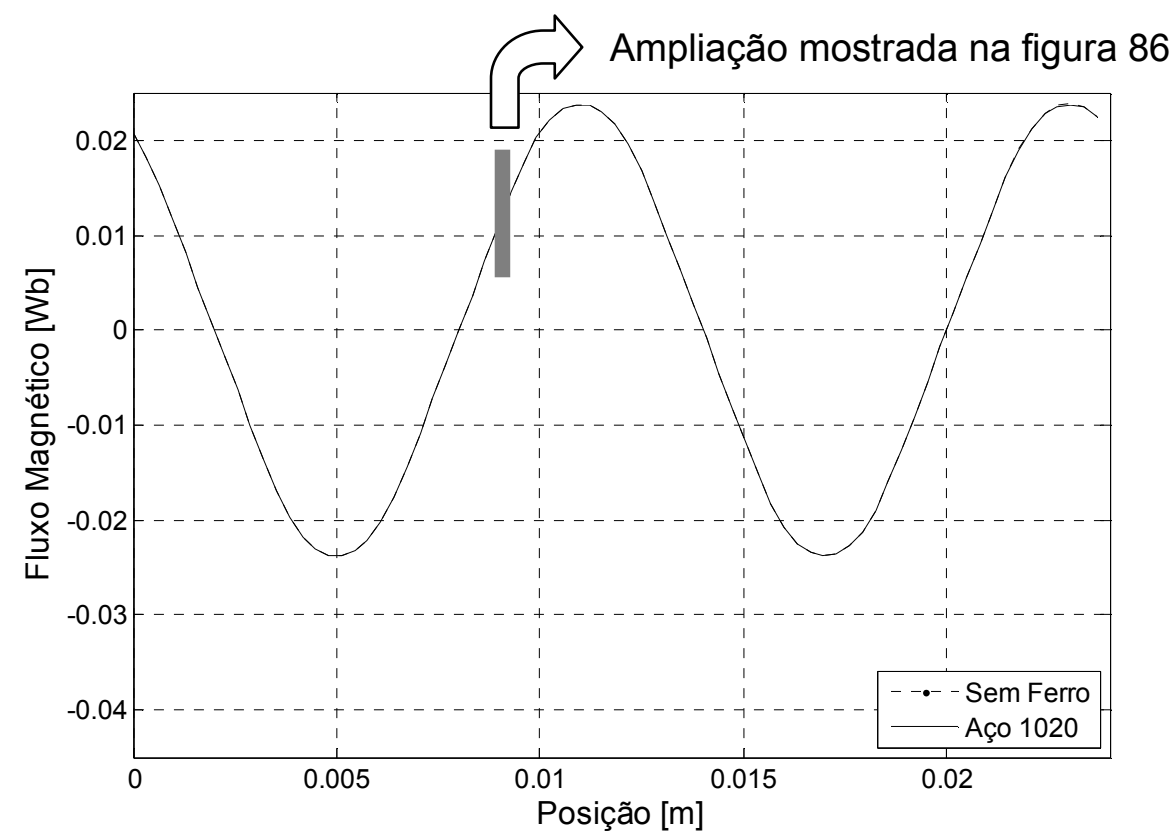

Figura 85 - Fluxo magnético com a ausência e a presença de anéis feitos de aço entre os ímãs. 


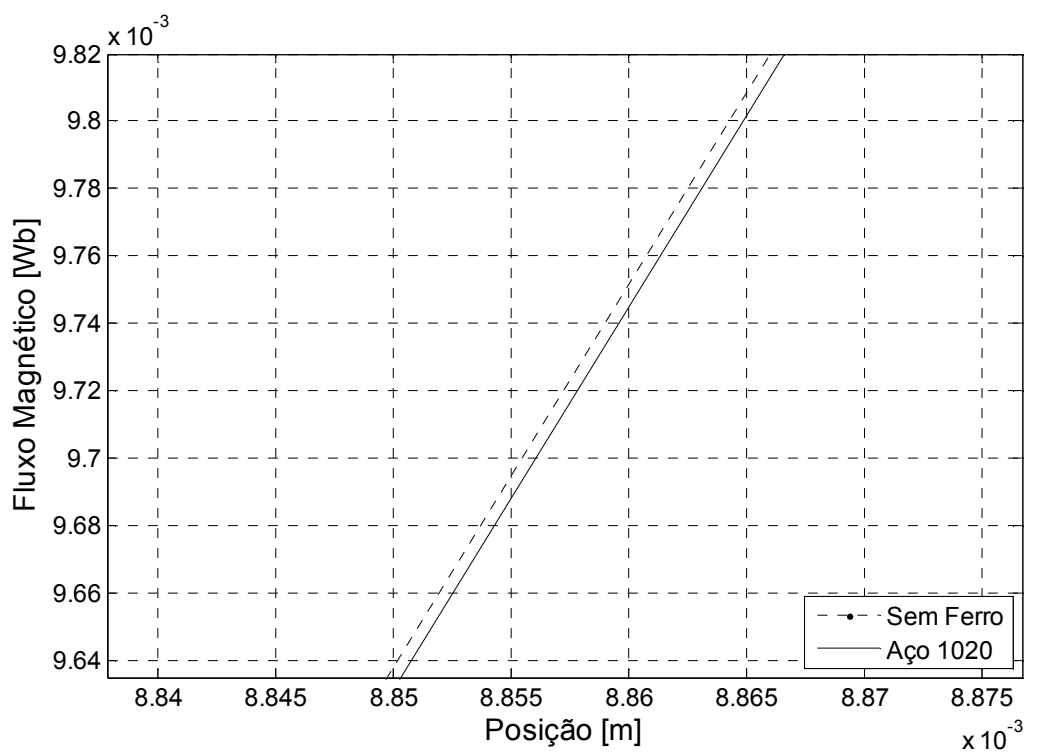

Figura 86 - Ampliação da área abrangida pelo retângulo cinza da figura 85.

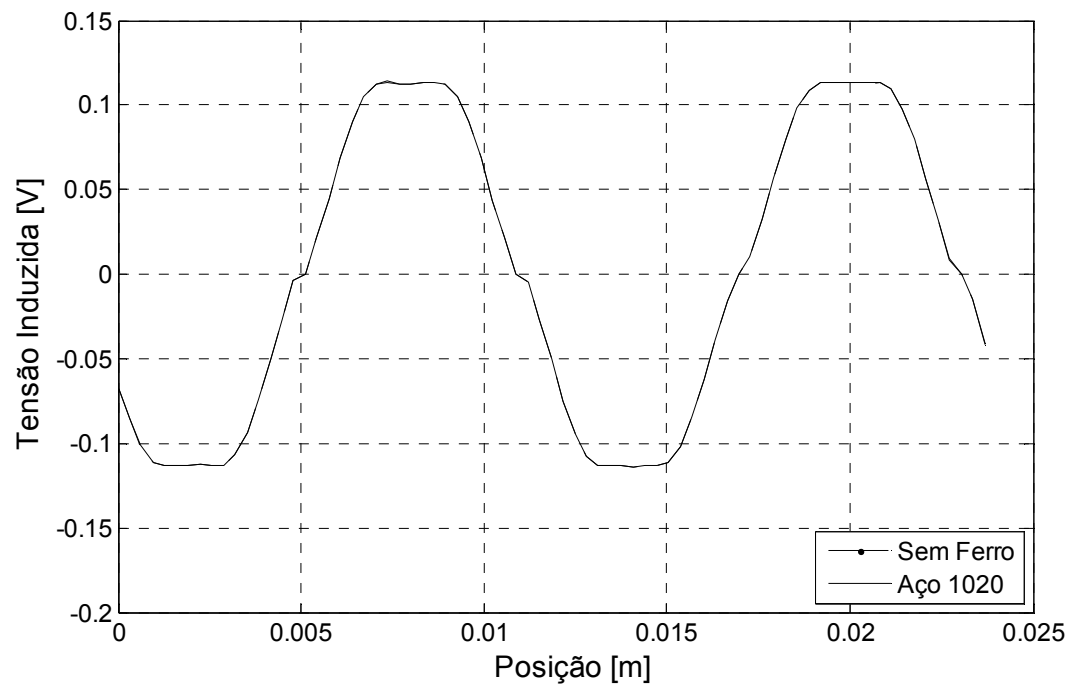

Figura 87 - Tensão induzida com a ausência e a presença de anéis feitos de aço entre os ímãs.

Apesar do valor eficaz com a presença de anéis entre os ímãs ser menor do que com a ausência, a forma de onda da tensão induzida não foi alterada. A inserção deles possui as seguintes vantagens: facilitar a colagem dos ímãs no material ferromagnético e diminuir as oscilações na força. Portanto, essa configuração foi a selecionada para ser executada. 


\subsection{Detalhes da Construção}

O detalhamento da construção do motor é feito em função das suas partes constituintes: linor e estator.

\subsubsection{Linor}

O linor é formado por um material ferromagnético e por ímãs incrustados em sua superfície, que foram fabricados no formato de arco (figura 88) para a obtenção da magnetização radial.

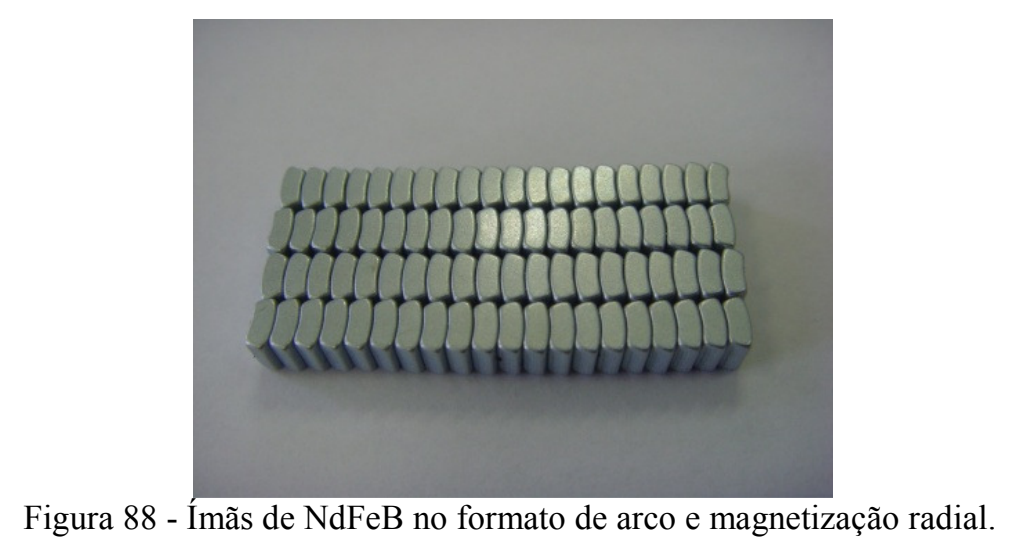

O material ferromagnético foi usinado com o raio interno $\left(R_{0}\right)$ apresentado na tabela 16, e anéis foram feitos entre os espaços reservados à alocação dos ímãs, com o intuito de delimitar precisamente o início e o fim de suas ocupações.

Para se obter um ímã na forma de anel, os arcos são colados entre si e na superfície do material ferromagnético.

A figura 89 mostra o dispositivo, em madeira, que foi construído para auxiliar na colagem dos ímãs no material ferromagnético, sendo este último mostrado em detalhe na ampliação da região abrangida pelo retângulo vermelho. 


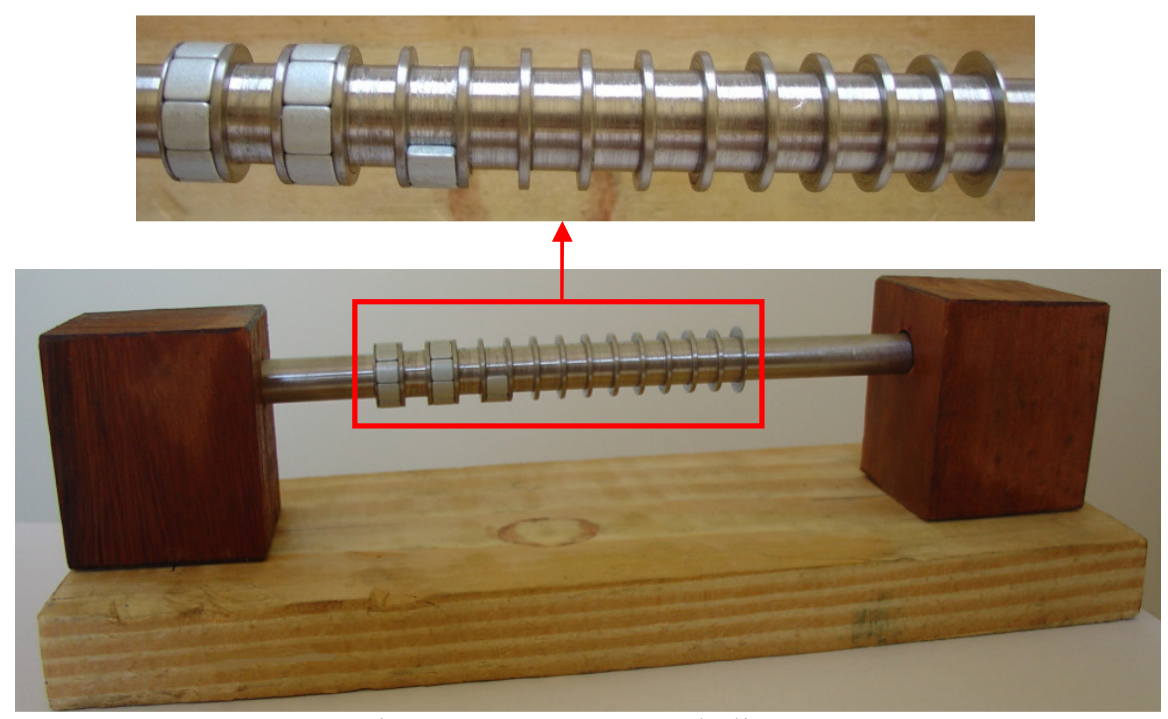

Figura 89 - Construção do linor.

Decidiu-se prolongar o comprimento do material ferromagnético, para que rolamentos fossem adaptados em suas partes externas, sendo mostrados na figura 90.

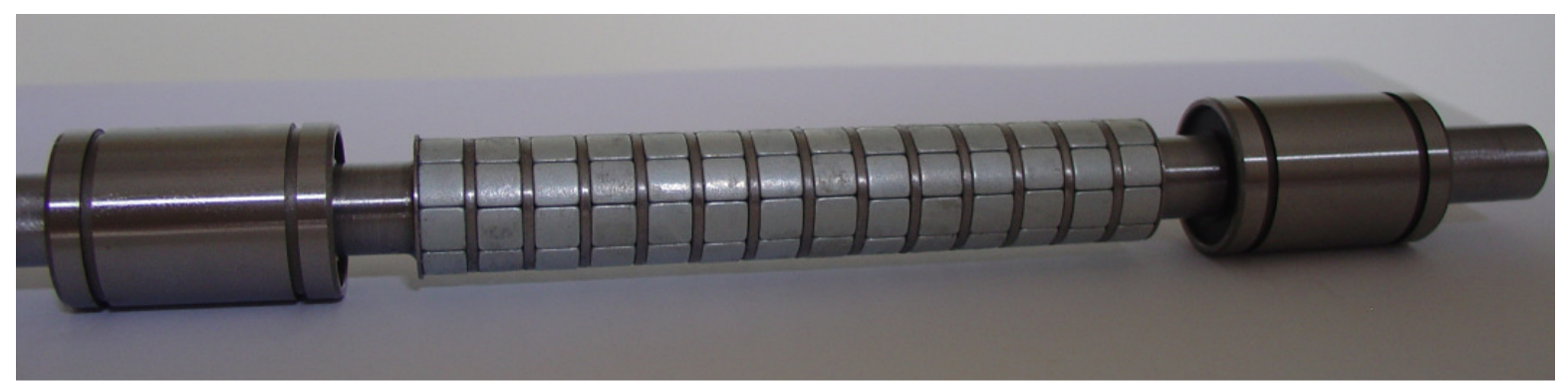

Figura 90 - Linor construído com os rolamentos.

\subsubsection{Estator}

Para a construção do estator, utilizaram-se chapas de aço elétrico de grãos não-orientados, existentes na oficina mecânica do departamento de engenharia elétrica, oriundas de um transformador.

Devido ao formato tubular, o estator deve ser montado em partes, ou seja, são utilizadas duas chapas de $0,5 \mathrm{~mm}$ com o raio igual a $R_{i}$ para formar o dente, e sobre elas são posicionadas duas chapas de mesma espessura, mas com o raio igual a $R_{S}$, onde é colocada uma bobina em seu interior. Esse processo é repetido diversas vezes até a obtenção de 54 ranhuras. 
A figura 91 mostra uma chapa com o furo de raio maior $\left(R_{s}\right)$. Deve-se esclarecer que o formato externo quadrado foi escolhido para ser construído, ao invés do circular, devido à facilidade de manuseá-lo nas máquinas ferramentas existentes na oficina. Além disso, nessa região incrementada de material ferromagnético, serão inseridos pinos para fazer a junção das partes do estator.

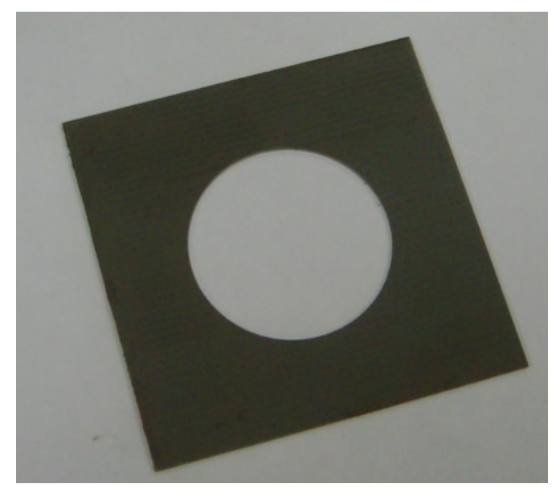

Figura 91 - Chapa com furo central e raio igual a $R_{s}$.

A figura 92 apresenta os dois tipos de chapas que formam o estator, sendo unidas por pinos nos furos exteriores.

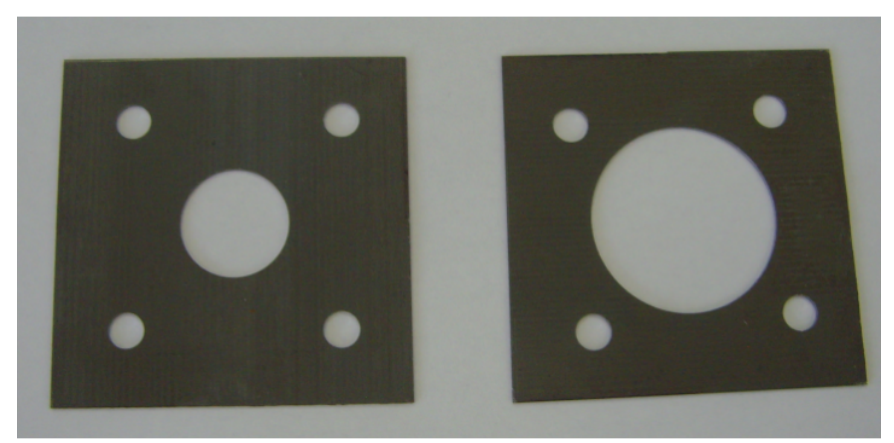

Figura 92 - Os dois tipos de chapas que compõem o estator.

Para enrolar as bobinas, foram criados três tipos de carretéis com as dimensões da ranhura. O primeiro possui apenas uma base (figura 93a), mas não foi utilizado porque não viabilizou a fixação de duas camadas de fio de cobre. No processo de confecção das bobinas, utiliza-se cola para que elas mantenham o seu formato quando são retiradas do carretel. Foram testados dois tipos de materiais que não aderem à cola: o nylon e o Teflon ${ }^{\circledR}$. Na figura 93b e 93c, podem-se observar os carretéis que foram construídos com uma tampa, para ajustar a espessura desejada, utilizando-se os dois materiais citados anteriormente. $\mathrm{O}$ dispositivo que melhor facilitou a construção das bobinas foi o que foi feito com o Teflon ${ }^{\circledR}$. 


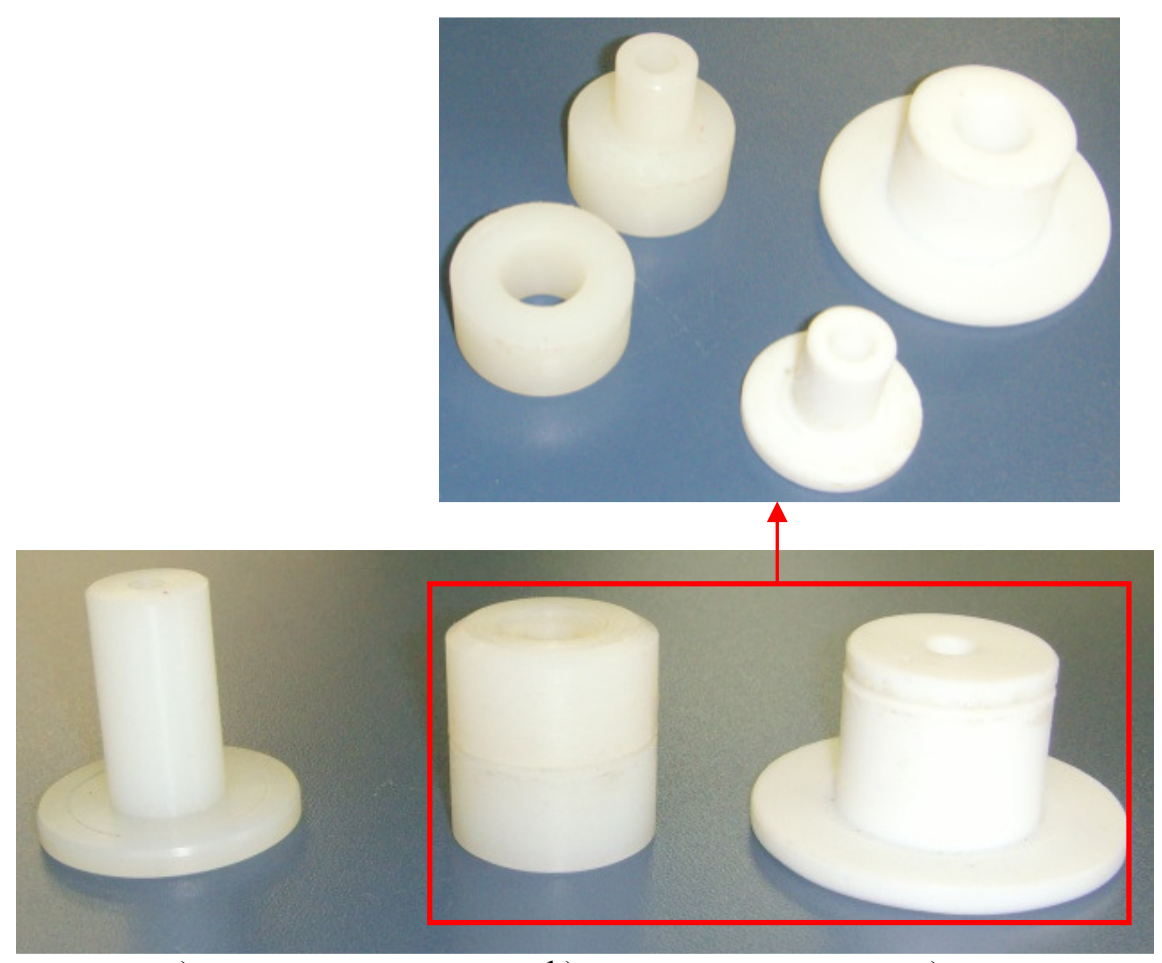

a)

b)

c)

Figura 93 - Carretéis para enrolar as bobinas.

A figura 94 mostra o dispositivo que foi criado para auxiliar no enrolamento das bobinas.

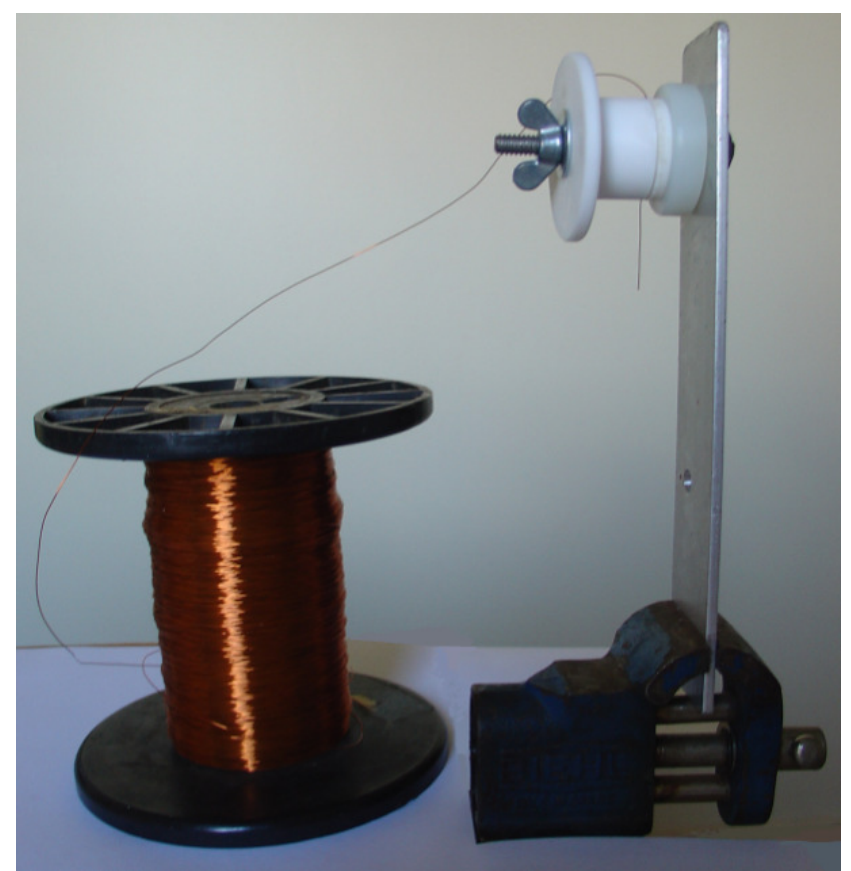

Figura 94 - Dispositivo para auxiliar o enrolamento das bobinas.

As bobinas feitas e separadas por fase podem ser vistas na figura 95. 


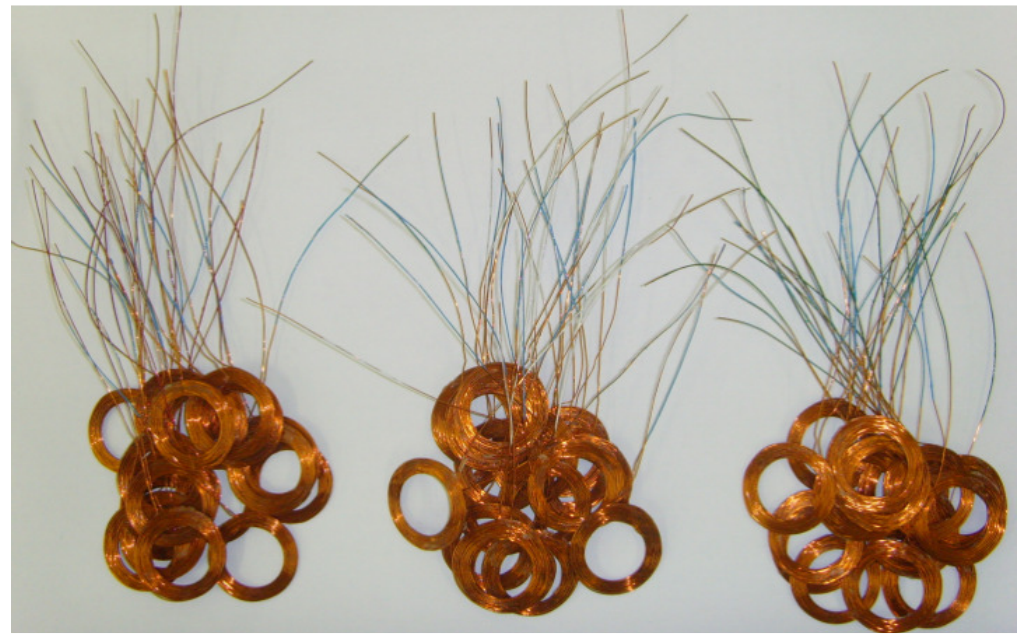

Figura 95 - Bobinas feitas e separadas por fase.

A figura 96 mostra os componentes do estator e o aparato utilizado durante a montagem, que é apresentada na figura 97.

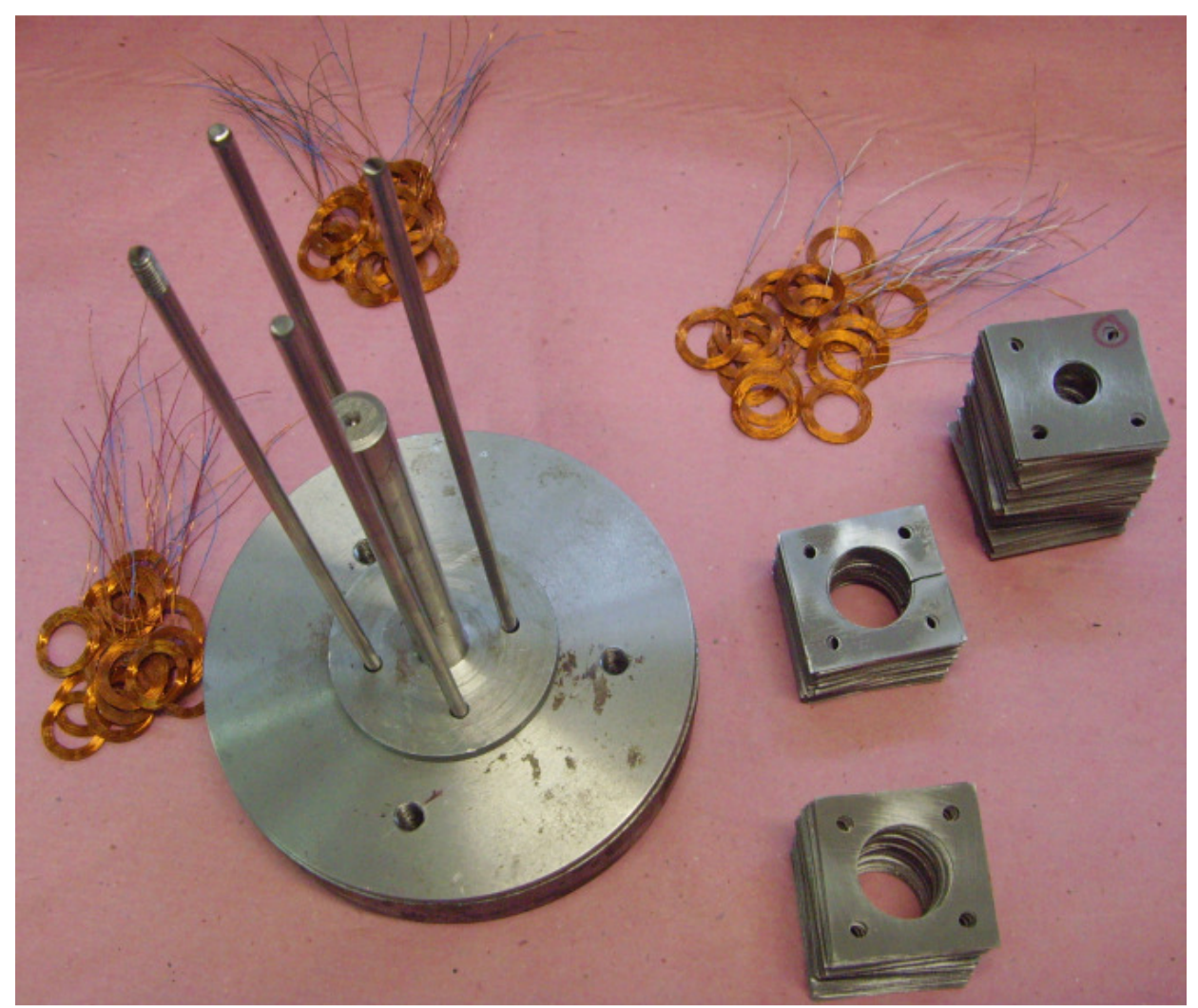

Figura 96 - Componentes do estator. 

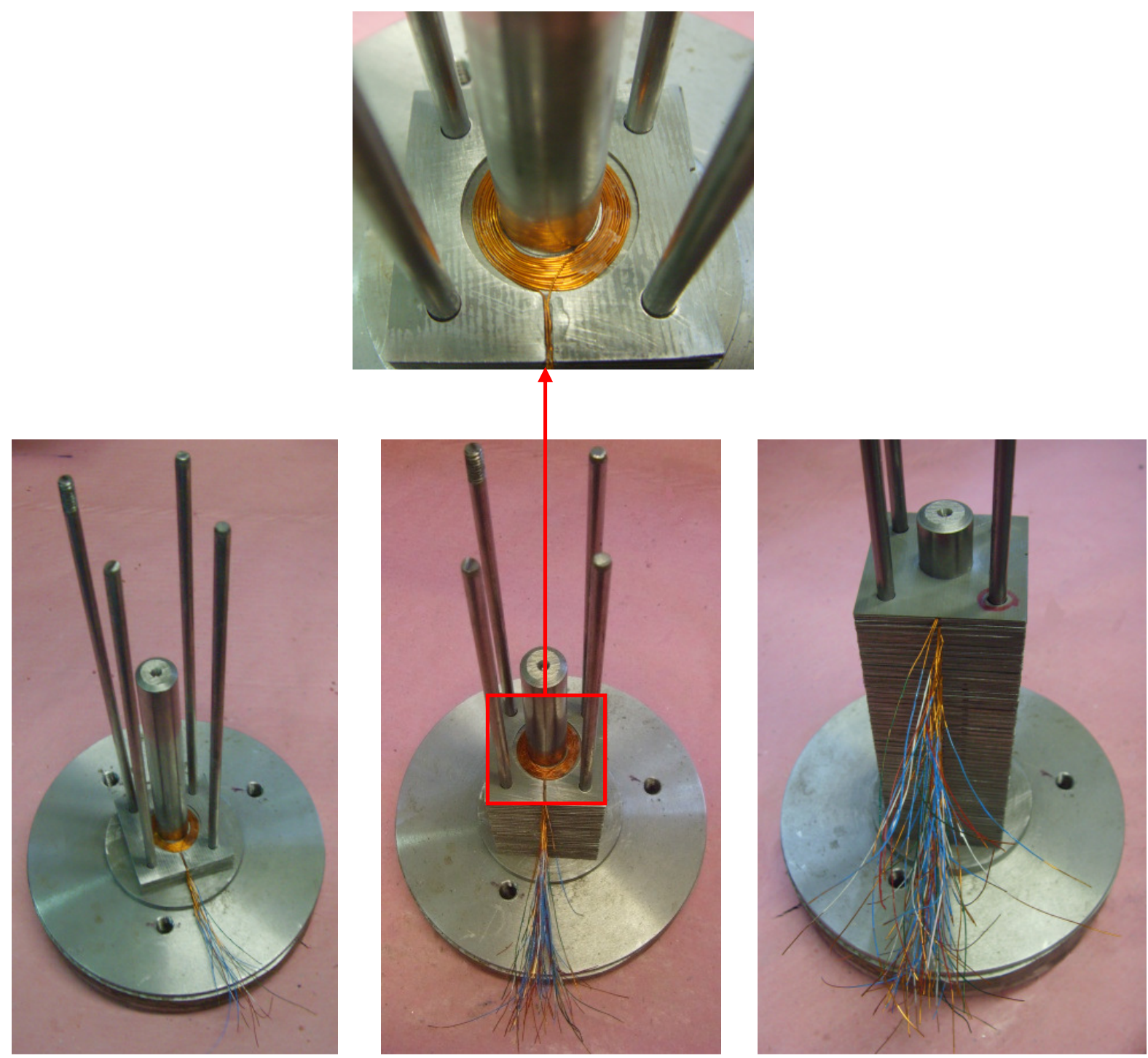

Figura 97 - Montagem do estator.

O motor construído é apresentado na figura 98. Uma placa de circuito impresso foi utilizada para conectar as bobinas, em série, sem o uso da solda, para facilitar a abertura do estator, caso fosse necessária. 


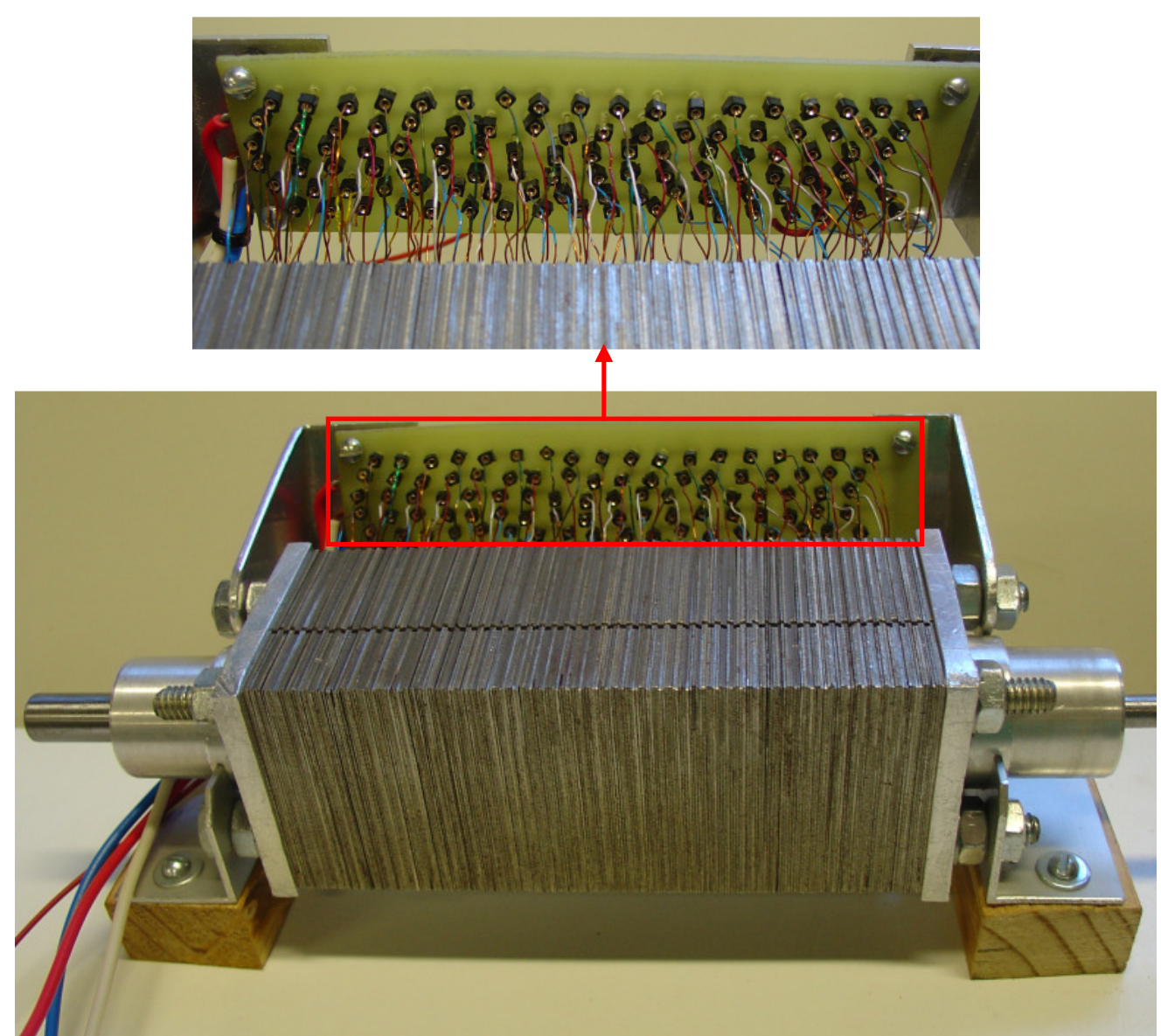

Figura 98 - Motor construído.

\subsubsection{Acionamento Elétrico}

Para a detecção da posição do linor, foram utilizadas três chaves optoeletrônicas posicionadas a cada $240^{\circ}$ elétricos (figura 99).

Esses sensores enviam os sinais lógicos (figura 100) para o circuito de acionamento, que detecta a posição linear a cada $60^{\circ}$ elétricos (tabela 18), com o intuito de chavear os transistores do inversor trifásico. 


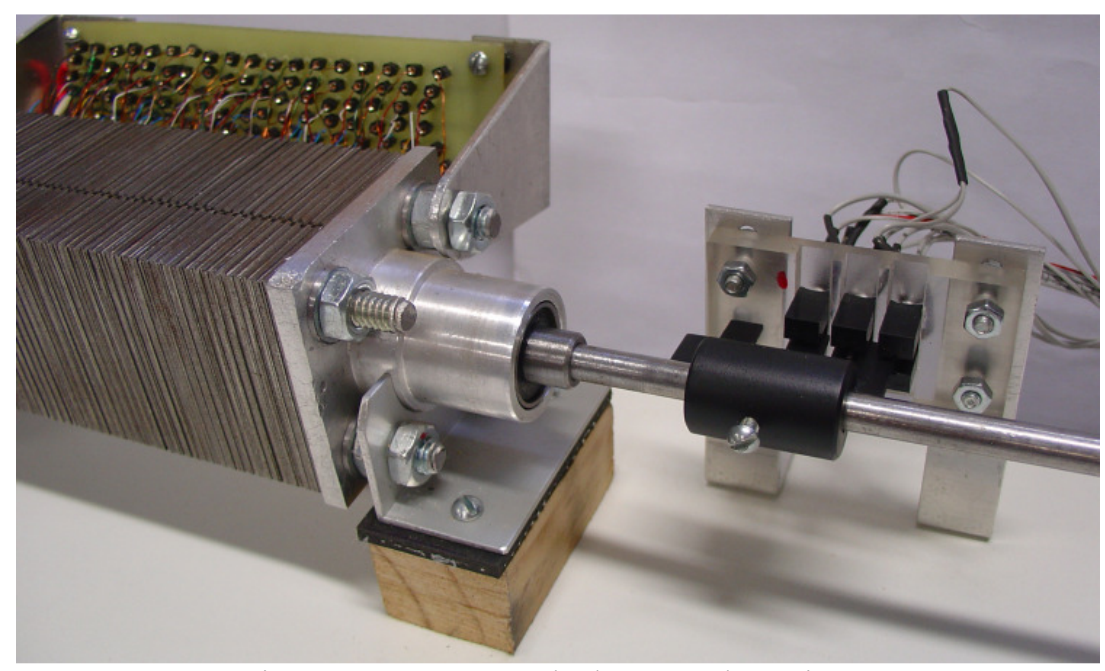

Figura 99 - Sensores de detecção da posição.

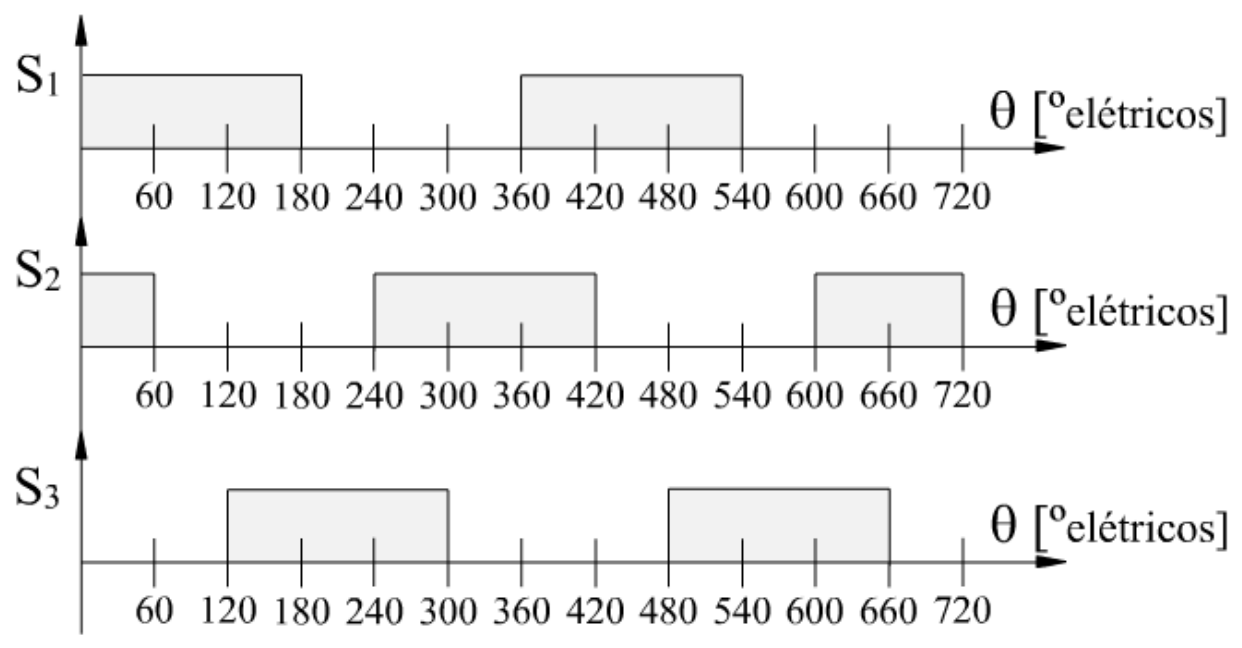

Figura 100 - Sinais lógicos das chaves optoeletrônicas.

Tabela 18 - Detecção dos sensores de acordo com a posição angular.

\begin{tabular}{ccccccc}
\hline Sensores & $\mathbf{0}^{\circ}-\mathbf{6 0}^{\circ}$ & $\mathbf{6 0}^{\circ}-\mathbf{1 2 0}^{\circ}$ & $\mathbf{1 2 0}^{\circ}-\mathbf{1 8 0}^{\circ}$ & $\mathbf{1 8 0}^{\circ}-\mathbf{2 4 0}^{\circ}$ & $\mathbf{2 4 0}^{\circ}-\mathbf{3 0 0}^{\circ}$ & $\mathbf{3 0 0}^{\circ}-\mathbf{3 6 0}^{\circ}$ \\
\hline S1 & 1 & 1 & 1 & 0 & 0 & 0 \\
S2 & 1 & 0 & 0 & 0 & 1 & 1 \\
S3 & 0 & 0 & 1 & 1 & 1 & 0 \\
\hline
\end{tabular}




\section{Ensaios Experimentais}

Neste capítulo são apresentados os resultados dos ensaios experimentais do protótipo construído. Primeiramente, foram feitas as medições para a obtenção dos parâmetros do motor. Após isso, o desempenho dinâmico da máquina (em malha aberta), juntamente com o dedo artificial, foi analisado.

\subsection{Parâmetros do Motor}

Na tabela 19, as propriedades elétricas calculadas no programa FEMM e as obtidas experimentalmente são mostradas.

Tabela 19 - Características elétricas por fase do protótipo.

\begin{tabular}{|c|c|c|}
\hline Características & Calculado & Experimental \\
\hline 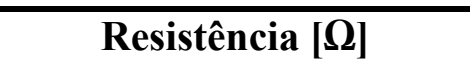 & 6,12 & 10,80 \\
\hline Indutância Própria [mH] & 2,30 & 3,50 \\
\hline Indutância Mútua [mH] & 0,30 & 0,70 \\
\hline
\end{tabular}

A resistência elétrica e a indutância própria, por fase, foram medidas com o uso de uma ponte digital na frequência igual a $1 \mathrm{kHz}$. A indutância mútua foi obtida por meio das equações 40 e 41, onde $I_{m}$ é a corrente CA aplicada em uma das fases e $V_{m}$ é a tensão induzida em outra fase, o circuito para essas medições é exemplificado na figura 101. 


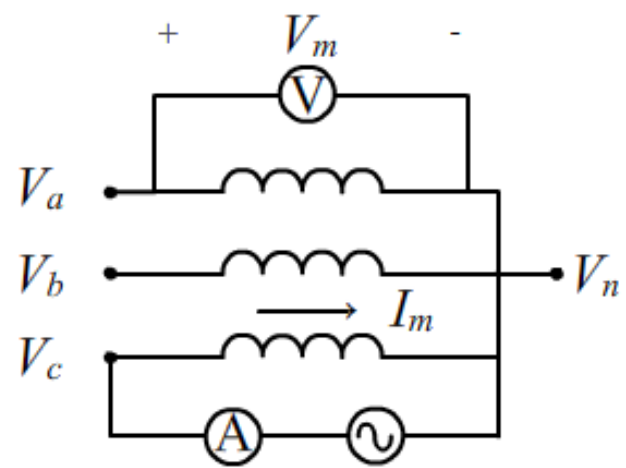

Figura 101 - Circuito de medição da indutância mútua.

$$
\begin{gathered}
X_{m}=\frac{V_{m}}{I_{m}} \\
M=\frac{X_{m}}{2 \cdot \pi \cdot f}
\end{gathered}
$$

Onde $f$ é a frequência da tensão CA.

As diferenças entre os valores experimentais e os calculados no programa FEMM, mostrados na tabela 19, são relacionadas aos fios conectados em cada fase e no neutro para facilitar o acesso a elas (aumento aproximado de $2 \Omega$ em cada fase) e à placa de circuito impresso que realiza as conexões em série das bobinas.

A tensão induzida do motor construído foi obtida com o auxílio de um motor rotativo e de um dispositivo mecânico, que converte o seu movimento em linear, para movimentar a máquina analisada com a velocidade nominal de operação $(0,01 \mathrm{~m} / \mathrm{s})$.

A montagem do experimento pode ser observada na figura 102 e as tensões na 103 , juntamente com os valores calculados no programa FEMM. 


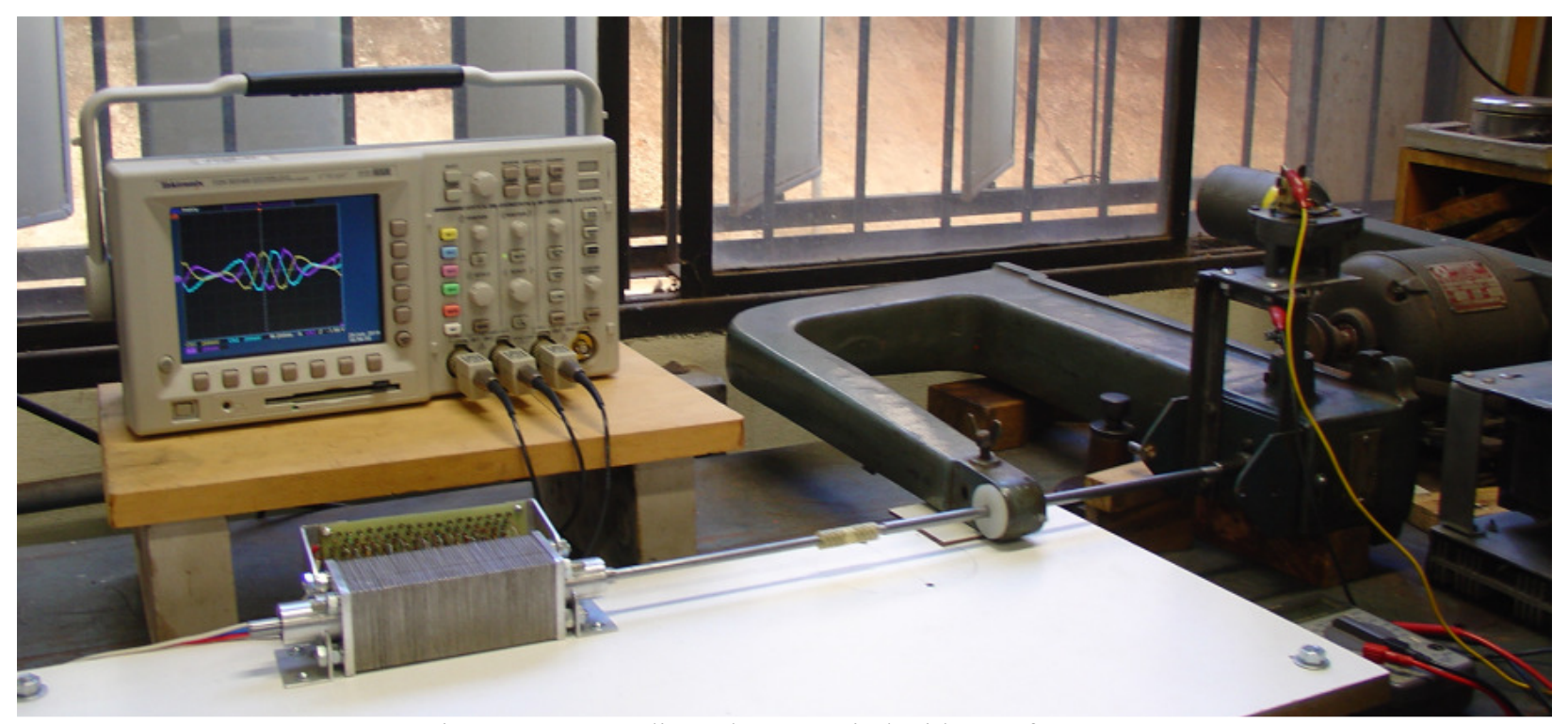

Figura 102 - Medição da tensão induzida por fase.

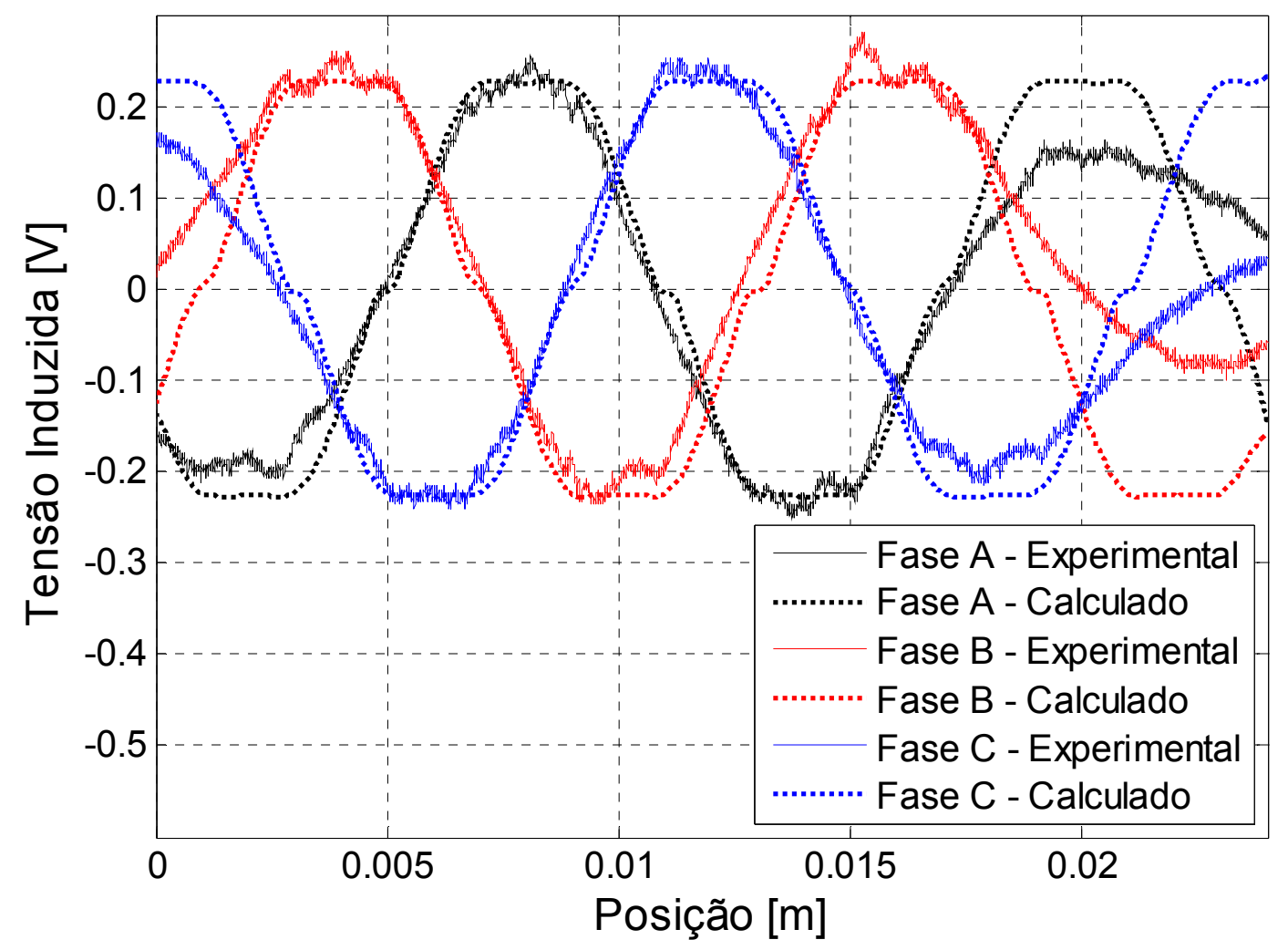

Figura 103 - Comparação da tensão induzida experimental e calculada no programa FEMM.

Observando-se a figura 103, nota-se que na região central os valores experimentais são similares aos calculados. No entanto, nas extremidades existe uma significativa diferença entre ambos, que se justifica pelo efeito longitudinal dinâmico. O programa FEMM realiza os cálculos estaticamente, por isso o efeito extremidade não é notado em seus resultados. 
A força eletromagnética foi mensurada com o sistema $E L F^{T M}$, que consiste em um pacote formado por um software, pelo hardware de aquisição de dados e por um sensor piezorresistivo FlexiForce ${ }^{\circledR}$, sendo a força aplicada inversamente proporcional à resistência elétrica (TEKSCAN, 2010).

A mesma montagem utilizada na medição da tensão induzida foi usada para a obtenção da força eletromagnética. Nas extremidades dos eixos (do motor linear e da adaptação mecânica do motor rotativo) foram inseridas peças no formato circular para que a força tivesse uma distribuição uniforme no sensor (figura 104).

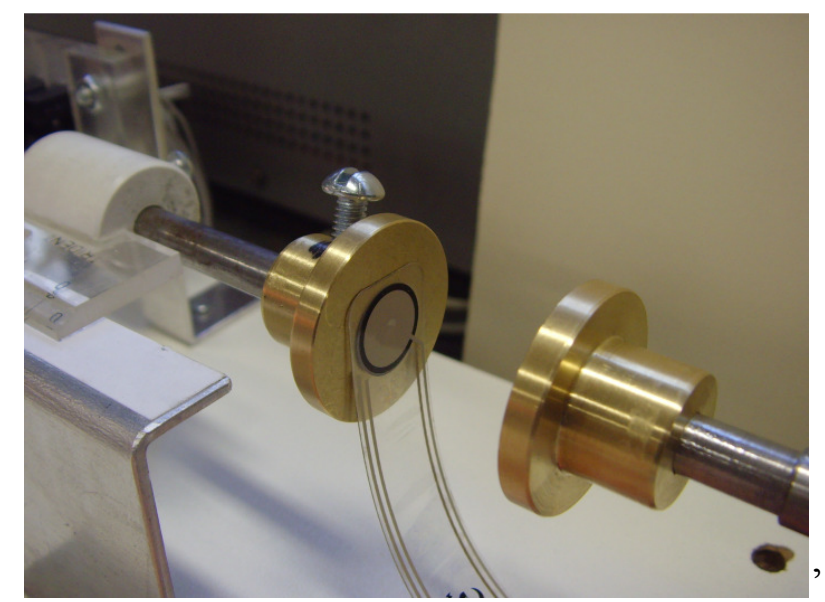

Figura 104 - Sensor piezorresistivo FlexiForce ${ }^{\circledR}$.

Na figura 105, o aparato para a medição da força eletromagnética pode ser observado. O motor linear é acionado pelo inversor trifásico e o motor rotativo, com a adaptação mecânica, faz o movimento contrário ao da máquina analisada, empurrando-a. Essa montagem foi feita para que a força fosse mensurada instantaneamente, por meio do software do sistema $E L F^{T M}$ que registra e armazena os dados (observar o laptop), para toda a extensão do deslocamento do linor. 


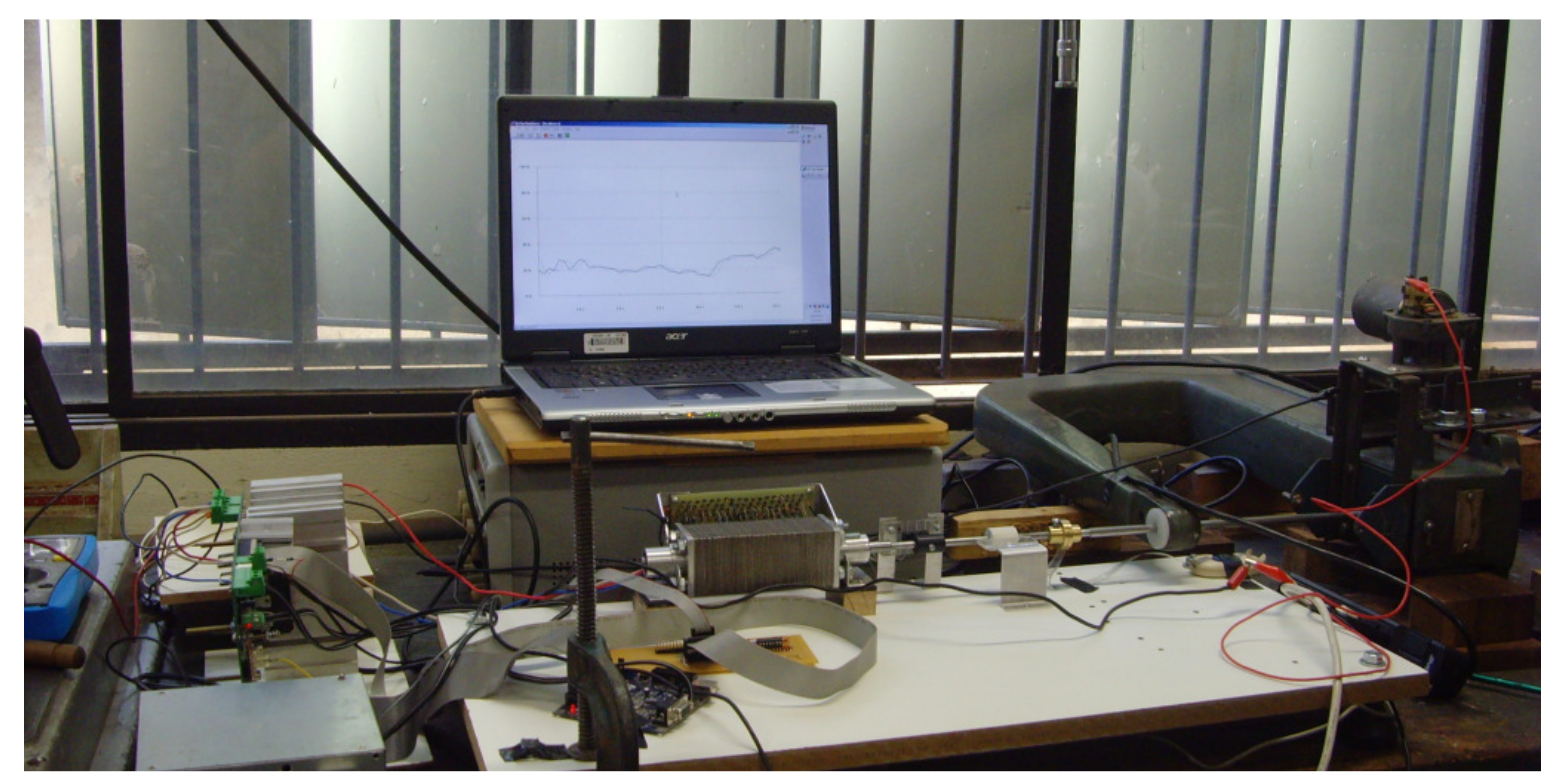

Figura 105 - Medição da força eletromagnética.

A força eletromagnética medida experimentalmente é comparada com a obtida no software FEMM, para uma corrente de fase igual a 0,7 A, sendo apresentada na figura 106.

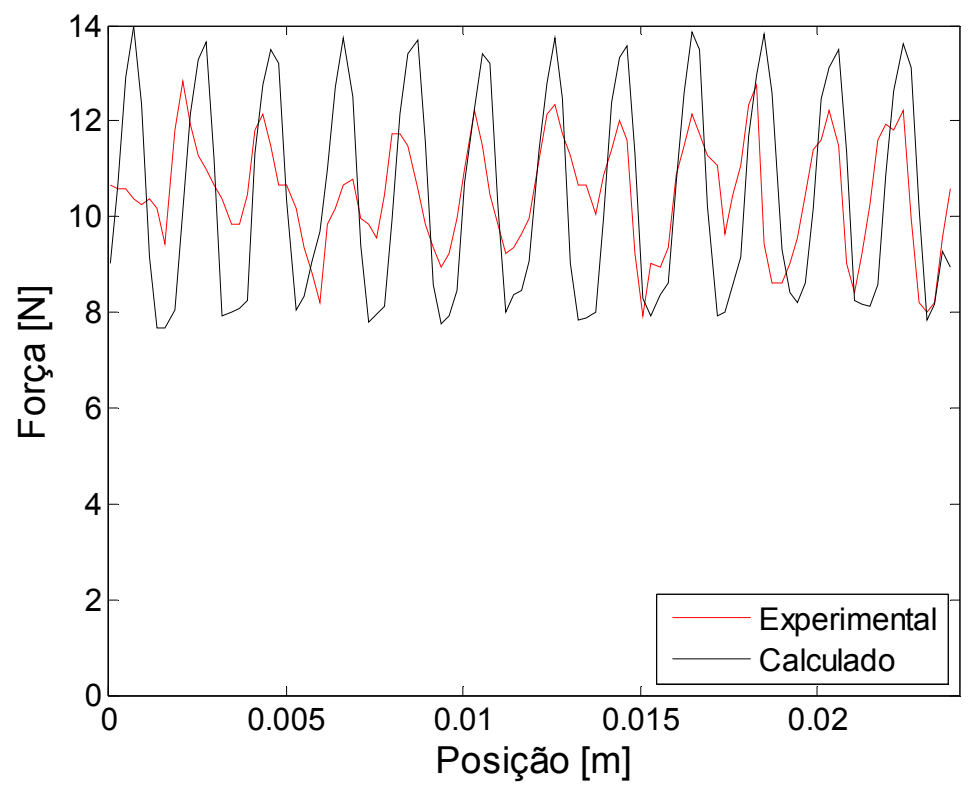

Figura 106 - Força eletromagnética experimental comparada com a calculada no programa FEMM.

O valor eficaz da força calculado é igual a $10,56 \mathrm{~N}$, enquanto o da experimental é $10,54 \mathrm{~N}$. 
Para o motor linear acionar o dedo artificial de uma prótese, uma força aproximada de $12 \mathrm{~N}$ é necessária, podendo ser alcançada com o aumento da corrente no estator. Esse cálculo pode ser observado na figura 107 , com a corrente igual a $0,84 \mathrm{~A}$, sendo $12,6 \mathrm{~N}$ o valor eficaz da força.

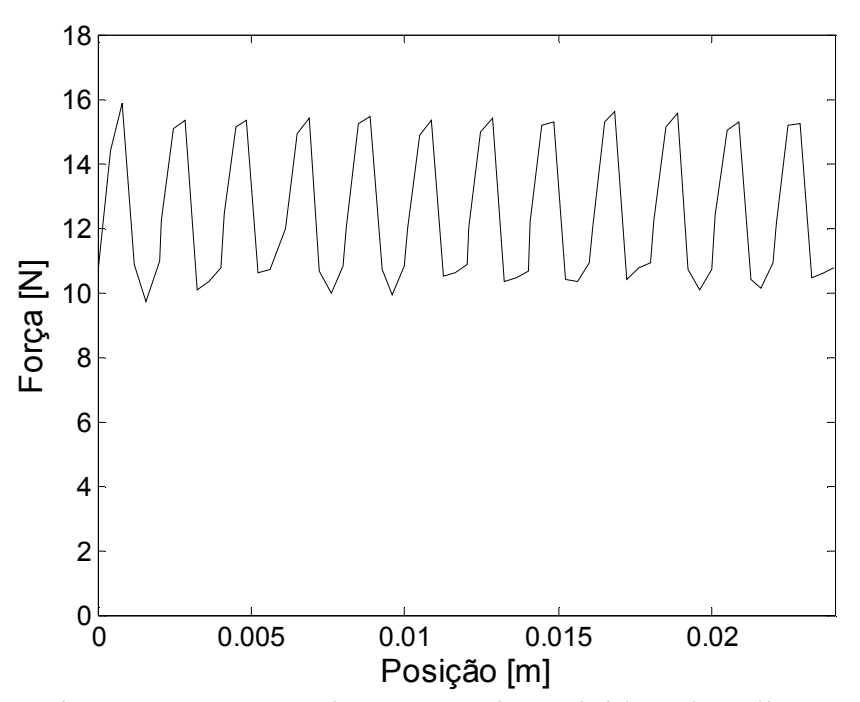

Figura 107 - Força eletromagnética exigida pela aplicação.

No início do capítulo 5, a figura 84 mostra a força eletromagnética referente ao protótipo que seria construído. Comparando-se o valor eficaz desse gráfico com o da figura 107, que foi calculado com as características reais do motor construído, observa-se uma redução de aproximadamente $28 \%$ em relação ao projeto inicial. Essa diferença pode ser justificada pela qualidade dos materiais utilizados na confecção da máquina, que não foram previamente analisados.

Após a obtenção dos parâmetros do protótipo, o motor foi conectado ao dedo artificial para realizar o ensaio em malha aberta, verificando-se a sua capacidade de realiazar corretamente o movimento de fechar o dedo artificial. Na figura 108, pode-se observar três posições do atuador: inicial (a), intermediária (b) e final (c). 


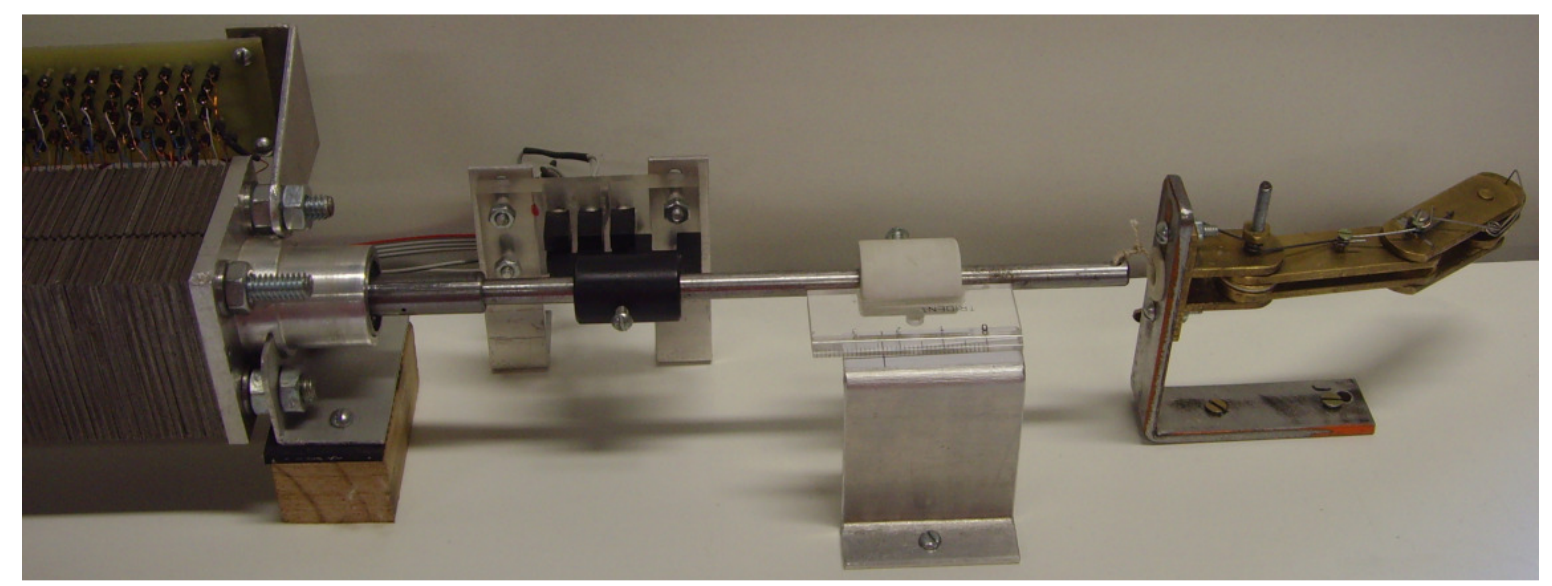

a)

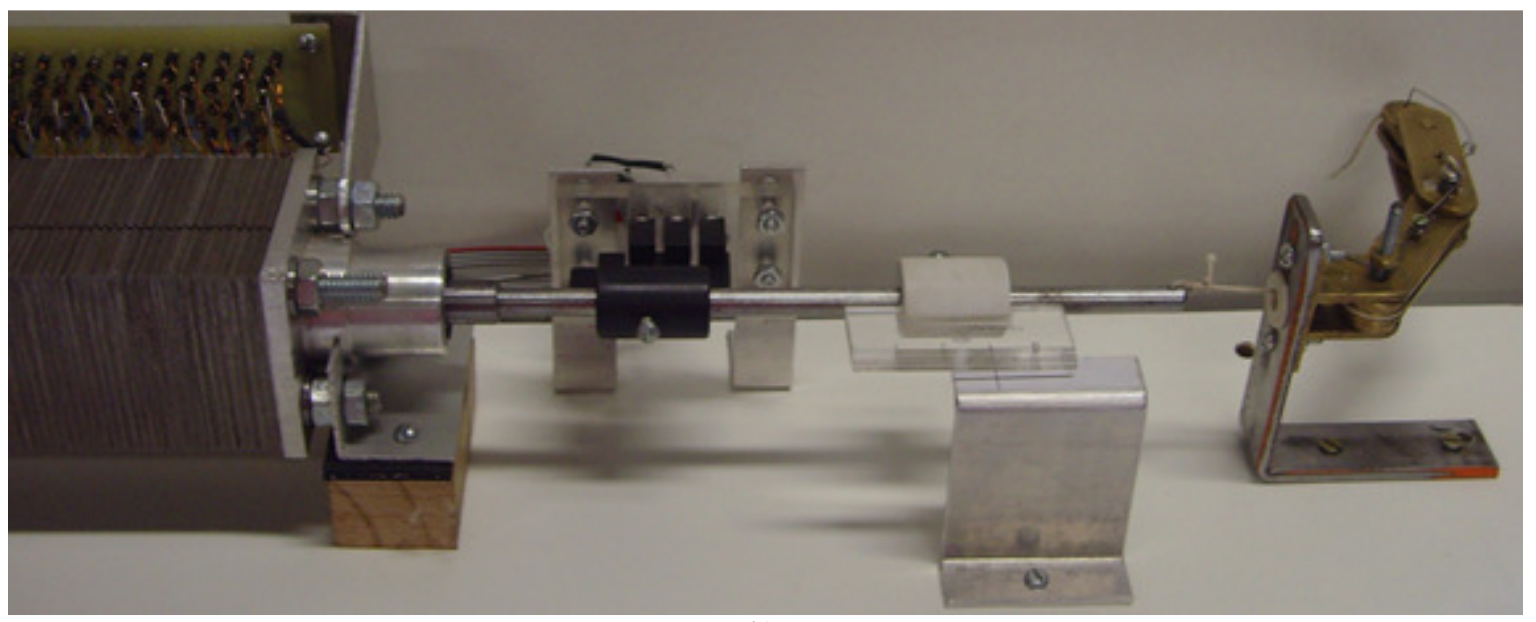

b)

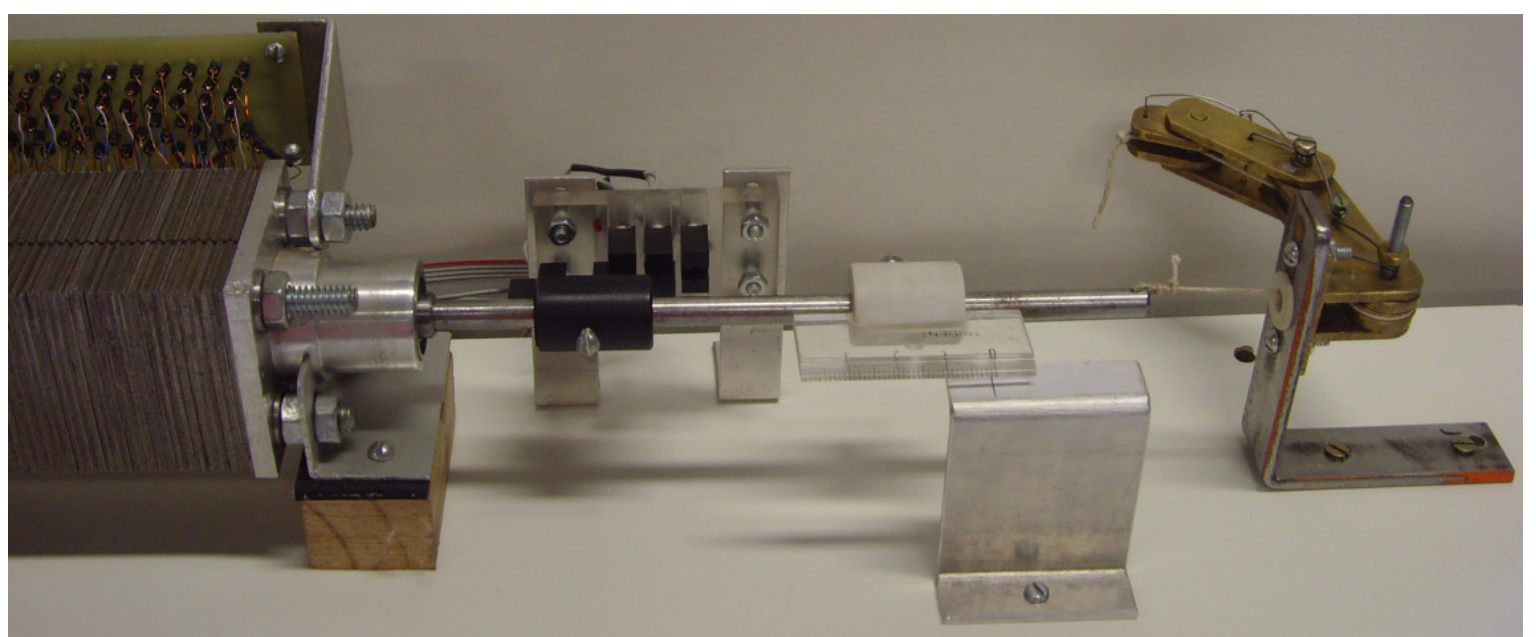

c)

Figura 108 - Posição do atuador: a) inicial; b) intermediária; c) final. 


\section{Conclusões e Continuidade do Projeto}

Este trabalho apresentou os principais conceitos e necessidades na área de bioengenharia, voltados aos motores elétricos lineares aplicados à prótese de membro superior.

Comparações e estudos de valores ótimos dos diversos aspectos construtivos de máquinas foram realizados, com o intuito da obtenção de um tamanho reduzido, com eficiência e força eletromagnética máxima.

Várias exigências da aplicação contrapunham-se ao projeto do motor, como: quanto maior for a dimensão da máquina, maior é a força eletromagnética produzida. Com isso, a obtenção de uma força elevada se opõe à idéia de uma máquina pequena.

Além disso, para um determinado valor de força, quanto menor for o diâmetro do motor, maior é o tamanho do estator, implicando em um aumento nas perdas resistivas.

Também, deve-se observar que se aumentando o tamanho do estator, há uma elevação no número de bobinas, que é proporcional à resistência elétrica do enrolamento. Quanto maior for esta última, maior é a tensão necessária para a alimentação da máquina, para uma determinada corrente.

Considerando-se todos estes conceitos, foram projetados dois tipos de máquinas com a presença e a ausência de ranhuras. Pode-se constatar que o estator com ranhuras, quando comparado com o sem ranhuras, possui maior densidade de força e menor perda resistiva, apesar de ter maiores oscilações na força, que podem ser atenuadas com a inserção de chanfros nos dentes. 
Para analisar a influência da geometria e dos ímãs, foram projetados quatro motores com valores eficazes da força eletromagnética próximos. Dois dos projetos possuem dimensões idênticas, mas com ímãs permanentes diferentes. O motor com ímãs de $\mathrm{NdFeB}$ apresenta a densidade de força 20,8\% maior do que com os ímãs de SmCo, consequentemente possui uma maior indução magnética no material ferromagnético. Nos outros dois projetos, foram realizadas diminuições, separadamente, no tamanho do passo polar e no tamanho do entreferro. Elas causaram uma redução da resistência elétrica por fase, mas ambos os motores têm a densidade de força menor do que a dos dois primeiros projetos, além de possuírem dimensões superiores.

Com isso, a primeira máquina foi selecionada para ser aplicada na prótese de membro superior, sendo que ela está de acordo com as exigências da aplicação, como: força eletromagnética superior a $12 \mathrm{~N}$, deslocamento mínimo da parte móvel de 1,91 cm, diâmetro menor do que $3 \mathrm{~cm}$, tamanho do estator menor do que $20 \mathrm{~cm}$, perda resistiva e tensão de alimentação coerentes com as baterias existentes.

Comparações entre os resultados obtidos com o software iMOOSE e FEMM foram realizadas. A diferença entre o valor eficaz da força eletromagnética de ambos os casos é em torno de $3 \%$, que pode ser justificada pelo uso de materiais não idênticos e pela precisão considerada no método numérico.

Estudos relacionados à viabilidade da construção do motor foram feitos. A partir deles, o projeto ideal do motor foi alterado para adequar-se aos materiais existentes e à disponibilidade financeira.

Após o término da construção da máquina, ensaios experimentais foram realizados para verificar se as suas características estavam de acordo com os valores projetados. Todos os parâmetros estão coerentes com o projeto inicial e de acordo com as alterações que foram feitas tanto para viabilizar a construção do motor quanto para facilitar as montagens realizadas para as medições.

A máquina construída possui a força eletromagnética exigida pela prótese de membro superior, portanto, ela é viável para ser utilizada nessa aplicação. No entanto, o valor eficaz da força, calculado no programa FEMM, no início do projeto e após a sua implementação possui uma redução em torno de $28 \%$. Essa diferença pode ser justificada pela qualidade dos materiais utilizados, que não foi previamente analisada. 
O último teste feito foi conectar o dedo artificial no motor linear, que realizou o movimento desejado de fechar a mão, em malha aberta. Com isso, comprovou-se a sua capacidade de substituir os motores rotativos para a realização do acionamento de uma prótese de mão.

A próxima etapa do projeto consiste na implementação do controle elétrico, utilizando os valores dos compensadores calculados neste trabalho.

Após isso, o motor pode novamente ser construído, por meio de um processo industrial permitindo que as suas dimensões e massa sejam reduzidas. Além disso, a qualidade dos materiais pode ser analisada, antes da construção, para garantir a obtenção da força desejada. Outra sugestão nesta mesma área é a realização da análise térmica da máquina, garantindo o seu correto funcionamento dentro da prótese de membro superior.

Os ímãs na superfície do linor também podem ser substituídos por ímãs com o efeito da inclinação, que podem reduzir a taxa da oscilação pelo valor médio da força aproximadamente em $95 \%$ ou $79 \%$, dependendo do método selecionado. 


\section{Referências Bibliográficas}

ABVE. Evolução e Perspectiva dos Veículos Elétricos Híbridos. Disponível em: $<$ http://www.abve.org.br/downloads.asp>. Acesso em 10 jan. 2009.

AKSteel. Nonoriented Electrical Steels. Disponível em: < http://www.aksteel.com/>. Acesso em: 19 jul. 2007.

BARROS, S. A. Desempenho em Força Máxima no Hand Grip em Relação a 3 Posições na Disposição dos Comandos de Controle da Moto (comunicação). V Congresso Brasileiro de Biomecânica, p. 306, 1993

BASAK, A. Permanent-Magnet DC Linear Motors. Clarendon Press, 1996.

BHAMIDI, S. P. Design of Single Sided Linear Induction Motor (SLIM) Using a User Interactive Computer Program. 90 f. Dissertação - Faculty of the Graduate School, University of Missouri-Columbia, 2005.

BIANCHI, N.; BOLOGNANI, S.; TONEL, F. Design Criteria of a Tubular Linear IPM Motor. IEEE International Electric Machines and Drives Conference, p. 1-7, 2001.

BIANCHI, N.; BOLOGNANI, S.; CORDA, J. Tubular Linear Motors: a Comparison of Brushless PM and SR Motors. IEE International Conference on Power Electronics, Machines and Drives, p. 626-631, April 2002.

BIANCHI, N.; BOLOGNANI, S.; CORTE, D. D.; TONEL, F. Tubular Linear Permanent Magnet Motors: an Overall Comparison. IEEE Transactions on Industry Applications, p. 466-475, v.39, No 2, March-April 2003.

BOLDEA, I.; NASAR, S. A. Linear Motion Electromagnetic Systems. A WileyInterscience Publication, 1985.

CABAS, R.; BALAGUER, C. Design and Development of a Light Weight Embodied Robotic Hand Activated with Only One Actuator. IEEE International Intelligent Robots and Systems Conference, p. 2369-2374, August 2005. 
CARROZZA, M. C.; DARIO, P.; LAZZARINI, R.; MASSA, B.; ZECCA, M.; ROCCELLA, M.; SACCHETTI, R. An Actuator System for a Novel Biomechatronic Prosthetic Hand. $7^{\text {th }}$ International Conference on New Actuators, p. 276-280, June 2000.

CARROZZA, M. C.; MASSA, B.; MICERA, S.; LAZZARINI, R.; ZECCA, M.; DARIO, P. The Development of a Novel Prosthetic Hand - Ongoing Research and Preliminary Results. IEEE/ASME Transactions on Mechatronis, p. 108-114, v. 7, No 2, June 2002.

CHAPPELL, P. H.; KYBERD, P. J. Prehensile Control of a Hand Prosthesis by a Microcontroller. Biomedical Engineering Journal, v. 13, p. 363-369, September 1991.

CHENG, H.; OBERGEFELL, L.; RIZER, A. Generator of Body (GEBOD) manual. Armstrong Laboratory. Dayton, 1994.

CHEVAILLER, S. Comparative Study and Selection Criteria of Linear Motors. $239 \mathrm{f}$. Tese - Faculté Sciences et Techniques de L'Ingénieur, École Polytechnique Fédérale de Lausanne, Lausanne (Suíça), 2006.

CREPPE, R. C.; SIMONE, G. A.; SERNI, P. J. A.; SOUZA, C. R. Motores de Indução Lineares. Revista Ciências Aplicadas e Engenharias, v. 4, p. 65-95, 1998.

CRISMAN, J. D.; KANOJIA, C.; ZEID, I. Graspar: a Flexible, Easily Controllable Robotic Hand. IEEE Robotics \& Automation Magazine, p. 32-38, June 1996.

CUNHA, F. L. Obtenção e Uso dos Acoplamentos Cinemáticos Interfalangianos e Interdigitais no Projeto de Próteses Antropomórficas para Membros Superiores.Vitória. 143 p. Dissertação, Universidade Federal do Espírito Santo, 1999.

CUNHA, F. L. Mão de São Carlos, Uma Prótese Multifunção para Membros Superiores: Um Estudo dos Mecanismos, Atuadores e Sensores. São Carlos. 146 p. Tese, Escola de Engenharia de São Carlos, Universidade de São Paulo, 2002.

DEL CURA, V. O.; CUNHA, F. L.; AGUIAR, M. L.; CLIQUET JÚNIOR, A. Study of the Different Types of Actuators and Mechanisms for Upper Limb Prostheses. Artificial Organs, v. 27, No 6, p. 507-516, 2003.

DENG, Z.; BOLDEA, I.; NASAR, S. A. Fields in Permanent Magnet Linear Synchronous Machines. IEEE Transactions on Magnetics, v. 22, No 2, p. 107-112, March 1986. 
DENG, Z.; BOLDEA, I.; NASAR, S. A. Forces and Parameters of Permanent Magnet Linear Synchronous Machines. IEEE Transactions on Magnetics, v. 23, No 1, p. 305-309, January 1987.

DOLLAR, A. Grasping Overview. Disponível em: $<$ http://pergatory.mit.edu/medical/cathbot/ documents/Background/grasping_overview.pdf $>$. Acesso em: 03 jan. 2008.

DRAGUlESCU, D.; UNGUREANU, L. The Modeling Process of a Human Hand Prosthesis. IEEE International Symposium on Applied Computational Intelligence and Informatics, p. 263-268, 2007.

EASTHAM, J. F. Novel Synchronous Machines: Linear and Disc. IEE Proceedings on Electric Power Applications, v. 137, No 1, p. 49-58, January 1990.

EASTHAM, J. F.; AKMESE, R.; LAI, H. C. Optimum Design of Brushless Tubular Linear Machines. IEEE Transactions on Magnetics, v. 26, No 5, p. 2547-2549, September 1990.

ENDERLE, J., BLANCHARD, S.; BRONZINO, J. Introduction to Biomedical Engineering. $2^{\text {nd }}$ ed. USA: Elsevier Academic Press, 2005.

FAULHABER. Faulhaber Group. Disponível em: <www.faulhaber-group.com>. Acesso em: 11 de outubro de 2007.

GIERAS, J. F. Linear Induction Drives. First Edition. Oxford University Press, 1994.

GIERAS, J. F.; PIECH, Z. J. Linear Synchronous Motors - Transportation and Automation Systems. CRC Press, 2000.

GRUNHOFER, H. J.; KROH G. A Review of Anthropometric Data on German Air Force and United States Air Force Flying Personnel 1967-1968. Advisory Group for Aerospace Research and Development. França, 1975.

HENDERSHOT JÚNIOR, J. R.; MILLER, T. J. E. Design of Brushless Permanent-Magnet Motors. First Edition. New York: Oxford University Press, 1994.

HIROSE, S.; UMETANI, Y. The Development of Soft Gripper for the Versatile Robot Hand. Mechanism and Machine Theory, v. 13, p. 351-359, 1978. 
JACOBSEN, S. C.; WOOD, J. E.; KNUTTI, D. F.; BIGGERS, K. B. The Utah/MIT Hand: Work in Progress. International Journal of Robotics Research, p. 21-50, v. 3, No. 4, 1984.

JANG, S. M.; CHOI, J. Y.; CHO, H. W.; LEE, S. H. Thrust Analysis and Measurements of Tubular Linear Actuator with Cylindrical Halbach Array. IEEE Transactions on Magnetics, v. 41, No 5, p. 2028-2031, May 2005.

JIN, J. The Finite Element Method in Electromagnetics. First Edition. New York: John Wiley \& Sons, Inc., 1993.

JUliAni, A. D. P. Análise do Campo Magnético de um Motor de Ímã Permanente no Rotor Utilizando o Método dos Elementos Finitos. 115 f. Dissertação (Mestrado) - Escola de Engenharia de São Carlos, Universidade de São Paulo, São Carlos, 2007.

JULIANI, A. D. P.; LEßMANN, M.; GONZAGA, D. P.; HAMEYER, K. Development and Optimization of a Tubular Linear Synchronous Motor Considering Various Skewing Methods and Eddy Current Losses. Proceedings of the XIX Internacional Conference on Electrical Machines, 2010, v.1.

JULIANI, A. D. P.; GONZAGA, D. P.; AGUIAR, M.; MONTEIRO, J. R. B. Slotless Tubular Linear Synchronous Motor Model. Proceedings of the XIX Internacional Conference on Electrical Machines, 2010, v.1.

KRAUS, J. D.; FLEISCH, D. A. Electromagnetics with Applications. Fifth Edition. New York: McGRAW-HILL BOOK COMPANY, Inc, 1999.

KRISHNAN, R. Electric Motor Drives - Modeling, Analysis, and Control. First Edition. New Jersey: Prentice Hall, 2001.

LAITHWAITE, E. R. Linear Induction Motors. Electronics and Power, No 10, p. 309-311, 1973.

LAITHWAITE, E. R. Linear Electric Machines - A Personal View. Proceedings of the IEEE, v. 63, p. 250-290, February, 1975.

LEE, B. S.; BAE, H. K.; VIJAYRAGHAVAN, P.; KRISHNAN, R. Design of a Linear Switched Reluctance Machine. IEEE Transactions on Industry Applications, v. 36, No 6, p. 1571-1580, November/December 2000. 
LI, C.; ZHAO, L.; LI, Q.; QI, X.; CUI, J. Wavelet Transform Applied in Analyze the Endeffect of Linear Motor. IEEE International Conference on Logistics Systems and Intelligente Management, v. 3, p. 615-618, January 2010.

LIN, F. J.; SHYU, K. K.; LIN, C. H. Incremental Motion Control of Linear Synchronous Motor. IEEE Transactions on Aerospace and Electronic Systems, v. 38, No 3, p. 10111022, July 2002.

LU, H.; ZHU, J.; GUO, Y. A Permanent Magnet Linear Motor for Micro Robots. IEEE International Conference on Power Electronics and Drives Systems, v. 1, p. 590-595, Jan. 2005.

MA, S.; HIROSE, S.; YOSHINADA, H. Design and Experiments for a Coupled TendonDriven Manipulator. IEEE Control Systems, p. 30-36, v. 13, 1993.

MathWorks, MATLAB 7 - Getting Started Guide. The MathWorks, Inc, 2010.

MathWorks, SIMULINK 7 - Getting Started Guide. The MathWorks, Inc, 2010.

McConville, J. T.; CHURCHILl, T. D.; KAlEPS, I.; ClAUSER, C. E.; CUZZI, J. Anthropometric Relationships of Body and Body Segment Moments of Inertia. Aerospace Medical Research Laboratory, Wright-Patterson Air Force Base. Ohio, 1980.

McLean, G. W. Review of Recent Progress in Linear Motors. IEE Proceedings on Electric Power Applications, v. 135, No 6, p. 380-416, November 1988.

MEEKER, D. Finite Element Method Magnetics - User's Manual. Version 4.2. Walthan (MA): disponível em: <http://femm.foster-miller.net>. Acesso em: 19 jul. 2007.

MILLER, C. E.; ZYL, A. W.; LANDY C. F. Modelling a Permanent Magnet Linear Synchronous Motor for Control Purposes. IEEE 6 ${ }^{\text {th }}$ Africon., v. 2, p. 671-674, October 2002.

NASAR, S. A.; BOLDEA, I.; UNNEWEHER, L. E. Permanent Magnet, Relutance, and Self Synchronous Motors. CRC Press, 1993.

NAVAL BIODYNAMICS LABORATORY. Anthropometry and Mass Distribution for Human Analogues - Volume I: Military Male Aviators. New Orleans, 1988. 
NETTER, F. H.; MACHADO, C. A. G. Atlas of Human Anatomy. Version 3.0. Icon Learning Systems LLC, 2003.

OLIVEIRA, M. A. P. Controle de Velocidade do Motor de Indução Linear Utilizando DSP. 2004. 170f. Dissertação - Escola de Engenharia Elétrica e de Computação, Universidade Federal de Goiás, Goiânia, 2004.

OTTO BOCK. Otto Bock Health Care. Disponível em: <http://www.ottobock.com >. Acesso em: 07 de outubro de 2007.

PORFÍRIO, R. S. Estudo Analítico do Mecanismo Dinâmico de uma Prótese de Mão: Representação pelo Modelo de um Dedo. 105 f. Dissertação (mestrado) - Faculdade de Engenharia Elétrica, Universidade Estadual de Campinas, Campinas, 1992.

PROFUMO, F.; TENCONI, A.; GIANOLIO, G. Design and Realization of a PM Linear Synchronous Motor with a Very High Thrust/Normal Force Ratio. Industry Applications Conference, v. 3, p. 1984-1988, September/October 2001.

RIESEN, D. VAN; MONZEL, C.; KAEHLER, C.; SCHLENSOK, C.; HENNEBERGER, G. iMOOSE - An Open-source Environment for Finite-element Calculations. IEEE Transactions on Magnetics, vol. 40, no. 2, pp. 1390-1393, 2004.

ROBERTSON, D. G. E. Vicon Workstation Quick Reference Guide. Ottawa, 2009.

SALISBURY, J. K.; CRAIG, J. J. Articulated Hands: Force Control and Kinematic Issue, International Journal of Robotics Research, p. 4-17, v. 1, No. 1, 1982.

SCHMÜLLING, B.; LEßMANN, M.; RIEMER, B. and HAMEYER, K. The Multi-slice Method for the Design of a Tubular Linear Motor with a Skewed Reaction Rail, in IEEE International Conference on Electrical Machines, pp. 1-5, 2008.

SHAFFER, E. C.; GROSS, C. A. Methods for Determining Linear Synchronous Machine Parameters. Proceedings of the $26^{\text {th }}$ Southeastern Symposium on System Theory, p. 411 415, March 1994.

SHOURESHI, R. A. Introduction to Bioengineering: Melding of Engineering and Biological Sciences. Otolaryngologic Clinics of North America, vol. 38, April 2005. 
SOBOTTA. Atlas de Anatomia Humana. 22a edição. Nova Guanabara, 2006.

SUNG, J. H.; NAM, K. A New Approach to Vector Control for a Linear Induction Motor Considering End Effects. IEEE Industry Applications Conference, p.2284-2289, 1999.

TEKSCAN. Pressure Mapping, Force Measurement and Tactile Sensors. Disponível em: $<$ http://www.tekscan.com/>. Acesso em 18 nov. 2010.

USP, SIBi. Diretrizes para Apresentação de Dissertações e Teses da USP: Documento Impresso e Eletrônico. São Paulo: disponível em: <http://www.teses.usp.br/info >. Acesso em: 20 jul. 2007.

VAGATI, A.; FRATTA, A.; FRANCESCHINI, G.; ROSSO, P. AC Motors for HighPerformance Drives: a Design-Based Comparison. IEEE Transactions on Industry Applications, v. 32, No 5, p. 1211-1219, September/October 1996.

WANG, J.; JEWELL, G. W.; HOWE, D. Design Optimization and Comparison of Tubular Permanent Magnet Machine Topologies. IEE Proceedings on Electric Power Applications., p. 456-464, v. 148, No 5, September 2001.

WANG, J.; HOWE, D. Design Optimization of Radially Magnetized, Iron-Cored, Tubular Permanent-Magnet Machines and Drive Systems. IEEE Transactions on Magnetics, p. 3262-3277, v. 40, No 5, September 2004.

WEIR, R. F.; GRAHN, E. Development of Externally-Powered Prostheses for Persons with Partial Hand Amputations. Proceedings of the $\mathbf{2 2}^{\text {nd }}$ Annual EMBS International Conference, p. 427-430, July 2000.

ZHU, Z. Q.; HOWE, D. Halbach Permanent Magnet Machines and Applications: a Review. IEE Proceedings on Electric Power Applications, p. 299-308, v. 148, No 4, July 2001.

ZOLlO, L; ROCCELlA, S.; GUGLIELMELli, E.; CARROZZA, M. C.; DARIO, P. Biomechatronic Design and Control of an Anthropomorphic Artificial Hand for Prosthetic and Robotic Applications. IEEE/ASME Transactions on Mechatronics, p.418-429, v. 12, No 4, August 2007.

ZYL, A. W.; JEANS, C. G.; CRUISE, R. J.; LANDY, C. F. Comparison of Force to Weight Ratios between a Single-Sided Linear Synchronous Motor and a Tubular Linear Synchronous Motor. IEEE International Electric Machines and Drives Conference, p. 571-573, May 1999. 
Apêndice A - Projeto do Dedo Artificial

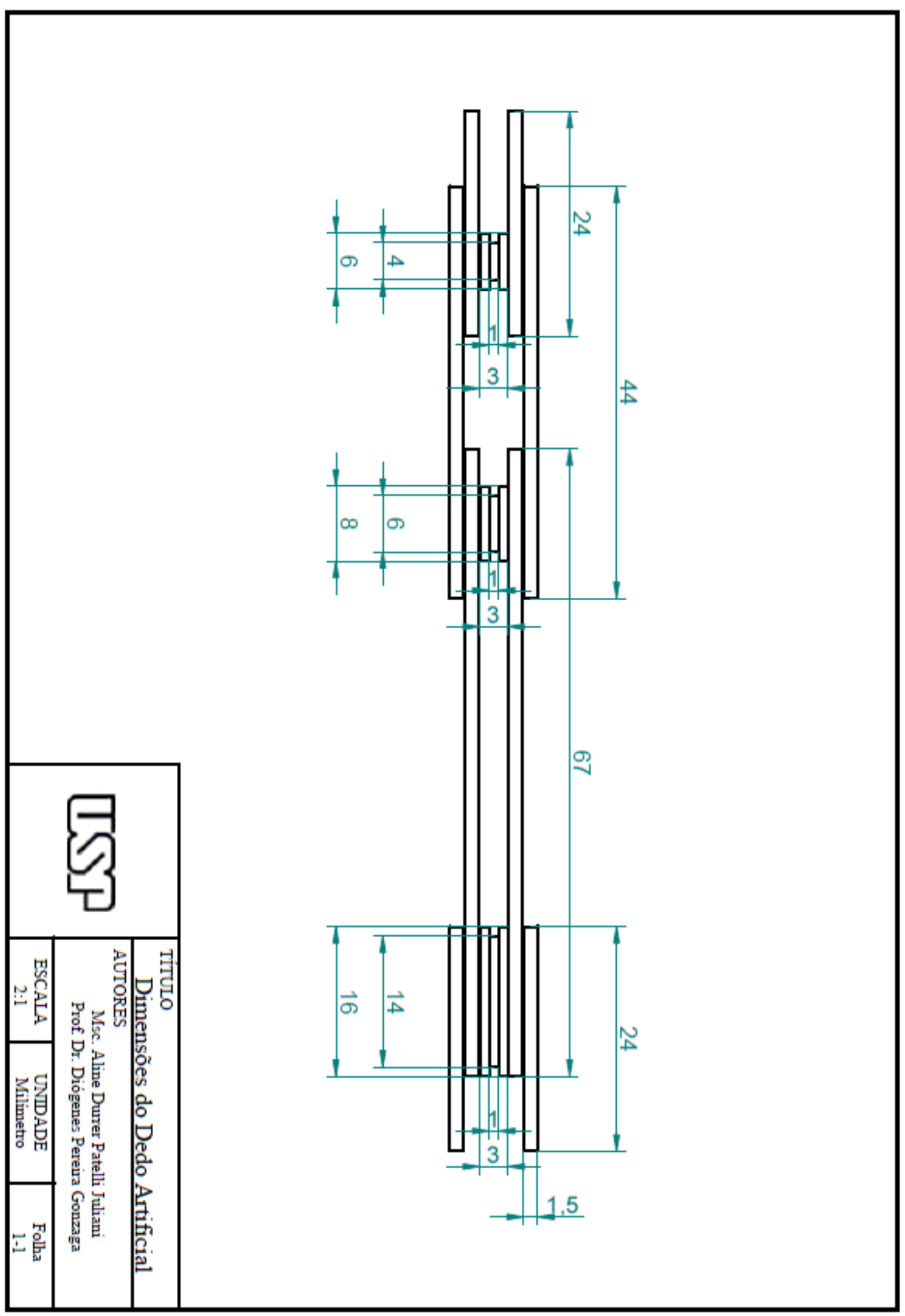




\section{Apêndice B - Enrolamentos}

A literatura sobre os enrolamentos das máquinas elétricas é escassa, mas em (CHEVAILLER, 2006) ela é detalhada, sendo este apêndice inteiro baseado nesta referência bibliográfica.

Os enrolamentos podem ser concentrados ou distribuídos e são classificados de acordo com o fator $q$, que é determinado pela equação (42).

$$
q=\frac{N_{s}}{m \cdot N_{p}}
$$

Onde:

$m$ é o número de fases;

$N_{s}$ é o número total de ranhuras.

Motores com um enrolamento concentrado têm o $q \leq 0,5$, implicando uma distância entre dois dentes consecutivos igual ou maior do que 120 graus elétricos. No entanto, um enrolamento com $q>0,5$ também pode ser com bobinas concentradas, entretanto, o fator de enrolamento não será maior do que 0,866 , gerando uma baixa densidade de força.

Uma boa opção para os motores lineares são os enrolamentos concentrados, desde que nenhum dente adicional seja necessário.

Os enrolamentos distribuídos, caracterizados por $q>0,5$, são usados em motores grandes. Para as máquinas lineares, não é comum a utilização desta configuração.

Este tipo de enrolamento, às vezes, proporciona uma distribuição assimétrica das bobinas, em que as ranhuras não são completamente preenchidas por cobre.

\section{B.1. Fatores de Enrolamento}

Cada enrolamento é caracterizado pelo fator de enrolamento ${ }^{v} k_{w}$, que consiste em três coeficientes relativos: fator de passo $k_{s}$, fator de distribuição ${ }^{v} k_{z}$ e fator de inclinação ${ }^{v} k_{s k}$. Todos estes parâmetros dependem do número de harmônicas relacionadas ao passo polar $(\tau)$. As dimensões geométricas da bobina, utilizadas para definir o enrolamento, são mostradas na figura B.1. 


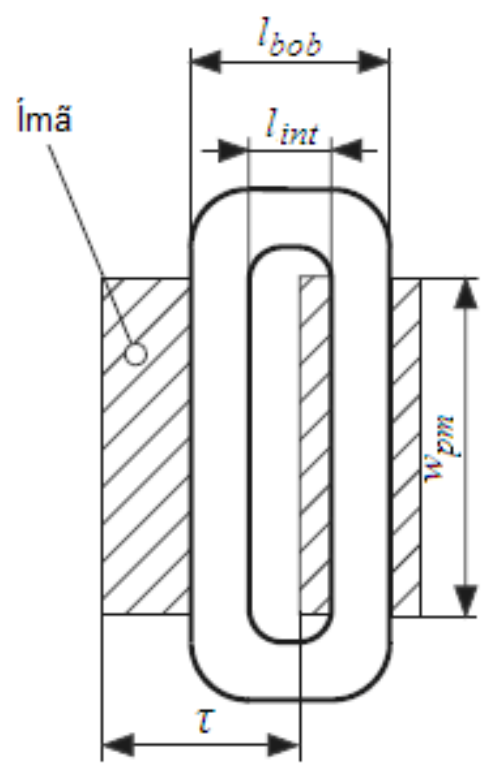

Figura B.1. Dimensões da bobina vistas na parte superior de um motor linear plano (CHEVAILLER, 2006).

Outras características que definem uma bobina são: o tamanho $h_{b o b}$, que não influencia a superfície ativa, o número de espiras $N$, o diâmetro do fio $d_{c u}$ e o fator de preenchimento do cobre $k_{c u}$. Para todos os projetos de motores, assume-se que a parte reta da bobina é igual à largura do ímã.

Estes fatores são relacionados ao fluxo produzido pelo ímã permanente que atravessa o enrolamento. Eles são obtidos pela comparação com uma bobina aberta igual a um passo polar. O primeiro item a ser calculado é a força contraeletromotriz para um condutor $\left({ }^{v} e_{c o n d}\right)$ se movimentando com velocidade $\left(v_{e l}\right)$ dentro de uma distribuição senoidal de densidade de fluxo magnético $(B)$.

$$
{ }^{v} e_{c o n d}={ }^{v} B \cdot w_{p m} \cdot v_{e l}
$$

Onde:

$v$ é o número de harmônicas da série de Fourier.

Portanto, a força contraeletromotriz de dois condutores, conectados em série ( $\left.{ }^{v} e_{\text {espira }}\right)$ e separados por um passo polar, pode ser calculada pela equação (44), desde que cada condutor esteja dentro da mesma magnitude de indução magnética.

$$
{ }^{v} e_{\text {espira }}=2 \cdot{ }^{v} e_{\text {cond }}
$$


Caso os dois condutores estejam separados por uma bobina aberta $S$ menor do que um passo polar (figura B.2), a tensão induzida dada pela equação (44) deve ser corrigida pelo fator de passo ${ }^{v} k_{s}$, calculado pela equação (45).

$$
{ }^{v} k_{s}=\left|\operatorname{sen}\left(v \frac{S}{\tau} \frac{\pi}{2}\right)\right|
$$

Sendo:

$$
S=\left\{\begin{array}{cc}
\frac{l_{b o b}}{2}+\frac{l_{\text {int }}}{2} & \text { Sem ranhuras } \\
w_{t} & \text { Com ranhuras }
\end{array}\right.
$$

Embora todas as bobinas não tenham o mesmo tamanho, assume-se que os dois condutores de uma mesma bobina são separados pelo tamanho $S$, desde que todas elas estejam conectadas em série.

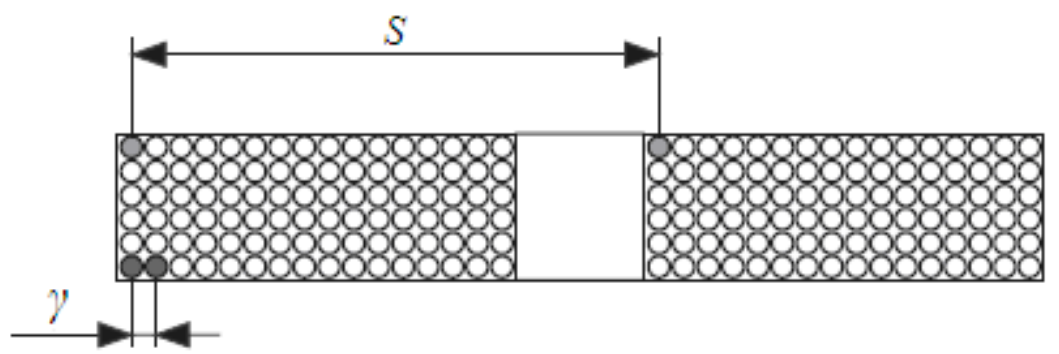

Figura B.2. Distância entre dois condutores e duas bobinas (CHEVAILLER, 2006).

Além disso, se o enrolamento é composto por várias bobinas (figura B.2), a distância entre duas bobinas consecutivas $\gamma$ produz um deslocamento entre as tensões induzidas geradas nos fios, que é representado pelo fator de distribuição das espiras ${ }^{v} k_{z c}$.

$$
{ }^{v} k_{z c}=\frac{\operatorname{sen}\left(\frac{\nu \cdot N_{x} \cdot \gamma \cdot \pi}{2 \cdot \tau}\right)}{N_{x} \cdot \operatorname{sen}\left(\frac{v \cdot \gamma \cdot \pi}{2 \cdot \tau}\right)}
$$


$N_{x}$ é o número de espiras na direção $x\left(N_{x}=16\right.$ na figura 4.8). Em alguns casos, a mesma fase possui diversas bobinas separadas por uma distância $\gamma_{c}$ (figura B.3).

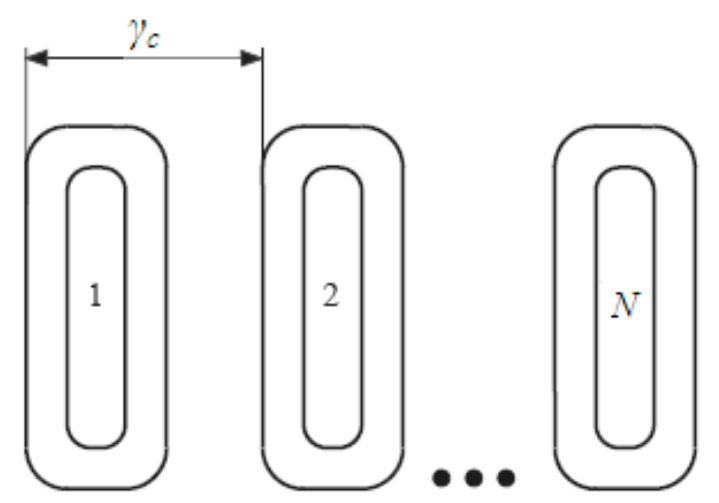

Figura B.3. Distância de separação entre bobinas de uma mesma fase (CHEVAILLER, 2006).

Se $\gamma_{c}$ não é múltiplo de $\tau$, uma diferença aparece entre essas bobinas. Portanto, as tensões induzidas nas bobinas para uma mesma fase devem ser somadas vetorialmente, sendo o fator de distribuição ${ }^{v} k_{z}$ que considera este aspecto (equação 48).

$$
{ }^{v} k_{z}=\frac{\operatorname{sen}\left(\frac{v \cdot N_{b} \cdot \gamma_{c}}{2}\right)}{N_{c s} \cdot \operatorname{sen}\left(\frac{v \cdot \gamma_{c}}{2}\right)}
$$

$N_{b}$ é o número de bobinas em série e $v$ é um número ímpar.

A força de borda pode ser minimizada em algumas aplicações pelo efeito de inclinação (skew) dos ímãs ou dos dentes do estator por um ângulo $\alpha$ (figura B.4), sendo esta considerada pelo fator de inclinação:

$$
{ }^{v} k_{s k}=\frac{\operatorname{sen}\left(\frac{v \cdot \alpha}{2}\right)}{\frac{v \cdot \alpha}{2}}
$$




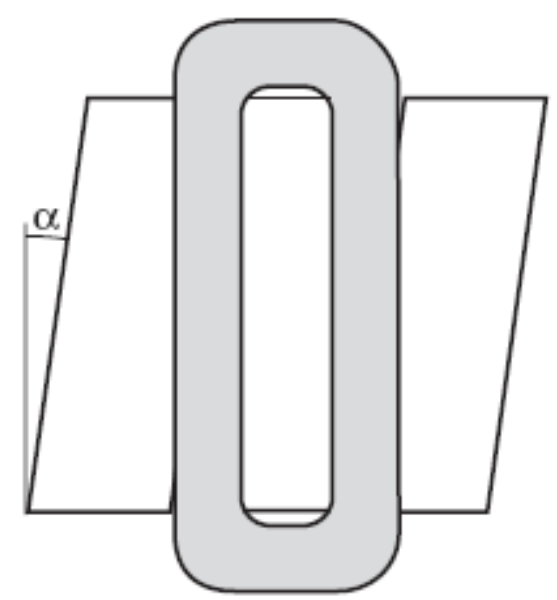

Figura B.4. Inclinação de um ângulo $\alpha$ do dente do estator (CHEVAILLER, 2006).

Portanto, considerando-se as equações 44, 45, 47, 48 e 49, a tensão induzida pelo enrolamento pode ser escrita como:

$$
{ }^{v} e_{\text {bob }}=\sum_{N}{ }^{v} e_{\text {espira }} \cdot{ }^{v} k_{s} \cdot{ }^{v} k_{z c} \cdot{ }^{v} k_{z} \cdot{ }^{v} k_{s k}=\sum_{N}{ }^{v} e_{e s p i r a}{ }^{v} k_{w}
$$

A força contraeletromotriz é proporcional ao fator ${ }^{v} k_{w}$, sendo o seu valor máximo igual à unidade.

\section{B.2. Configuração Sem Ranhuras}

Nesta subseção, é estudado apenas o enrolamento concêntrico, pois apresenta a maior simplicidade construtiva. No entanto, a metodologia de projeto também é válida para outros tipos de enrolamentos, como o de Gramme ou o distribuído sobreposto.

O enrolamento do estator sem ranhuras não tem o efeito de inclinação, sendo o fator ${ }^{v} k_{s k}$ igual à unidade. Se o tamanho da bobina $\left(h_{b o b}\right)$ for maior do que o passo polar, o fator de distribuição das bobinas deve ser levado em consideração $\left({ }^{v} k_{z c}\right)$.

O único fator que não depende do número de espiras e do tamanho do interior da bobina é o fator de distribuição ${ }^{v} k_{z}$, que é dado na tabela 18 , sendo consideradas diferentes combinações do número de bobinas e do número de pólos. 


\begin{tabular}{|c|c|c|c|c|}
\hline$N_{p}{ }^{\mathbf{N}_{\mathbf{b o b}}}$ & 3 & 6 & 9 & 12 \\
\hline 1 & & & & \\
\hline $\begin{array}{l}2 \\
3\end{array}$ & 1 & & & \\
\hline 4 & 1 & 1 & & \\
\hline 5 & 1 & 0,966 & & \\
\hline 6 & & & 1 & \\
\hline 7 & & 0,966 & 0,844 & \\
\hline $\begin{array}{l}8 \\
0\end{array}$ & & 1 & 0,960 & 1 \\
\hline $\begin{array}{l}9 \\
10\end{array}$ & & 1 & 0,960 & 0,966 \\
\hline 11 & & 0,966 & 0,844 & 0,958 \\
\hline 12 & & & 1 & \\
\hline 13 & & & & 0,958 \\
\hline 14 & & & & 0,966 \\
\hline
\end{tabular}

Fonte: Chevailler, 2006.

Conforme mostrado na tabela 20, existem apenas três configurações básicas de enrolamento com o fator de distribuição igual a um. As demais, com o fator igual à unidade são múltiplas destas, que são especificadas a seguir.

1. $\mathrm{N}_{\mathrm{bob}}=3$ e $\mathrm{P}=2: \frac{\tau}{3}\left(60^{\circ} e\right)<l_{b o b} \leq \frac{2 \tau}{3}\left(120^{\circ} e\right)$;

2. $\mathrm{N}_{\mathrm{bob}}=3$ e $\mathrm{P}=4: \frac{2 \tau}{3}\left(120^{\circ} e\right)<l_{b o b} \leq \frac{4 \tau}{3}\left(240^{\circ} e\right)$;

3. $\mathrm{N}_{\mathrm{bob}}=3$ e $\mathrm{P}=5: \frac{4 \tau}{3}\left(240^{\circ} e\right)<l_{b o b} \leq \frac{5 \tau}{3}\left(300^{\circ} e\right)$.

As configurações mostram que a bobina aberta varia entre 60 e 300 graus elétricos. Em geral, a bobina aberta pode variar entre 0 e 360 graus elétricos. Na verdade, o tamanho da bobina maior do que 360 graus elétricos não é uma boa opção, porque uma parte da força produzida pela bobina é cancelada por ela mesma. Para uma bobina variando entre 300 e $360^{\circ}$, algumas áreas sem enrolamento aparecem entre duas bobinas consecutivas com o objetivo de manter um múltiplo de $120^{\circ}$ entre duas fases, produzindo uma menor força por unidade de área. Ao contrário, um tamanho de bobina menor do que $\tau / 3$ gera uma força muito pequena, por isso não é levada em consideração (baixo fator de enrolamento). 
Para evitarem-se áreas sem cobre, o enrolamento dos motores sem ranhuras é projetado para a bobina ter um tamanho igual ou próximo do valor superior dos três limites possíveis, por exemplo, bobinas abertas de $120^{\circ}, 240^{\circ}$ ou $300^{\circ}$, que podem ser observadas na figura B.5.

O fator de passo $k_{s}$ é calculado com a bobina aberta:

$$
k_{s}=\frac{l_{b o b}}{2}+\frac{l_{\text {int }}}{2}
$$

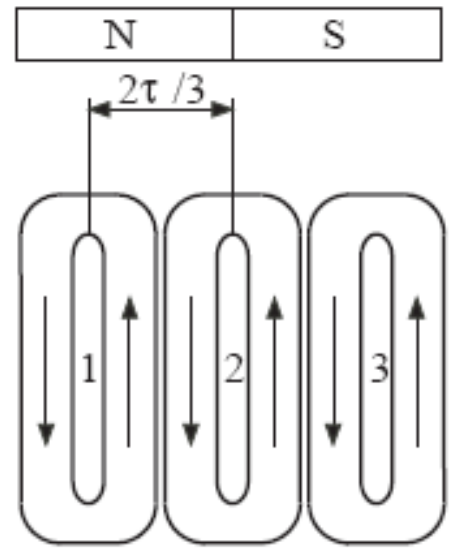

Caso 1:

$60^{\circ}<1_{\text {bob }}<120^{\circ}$

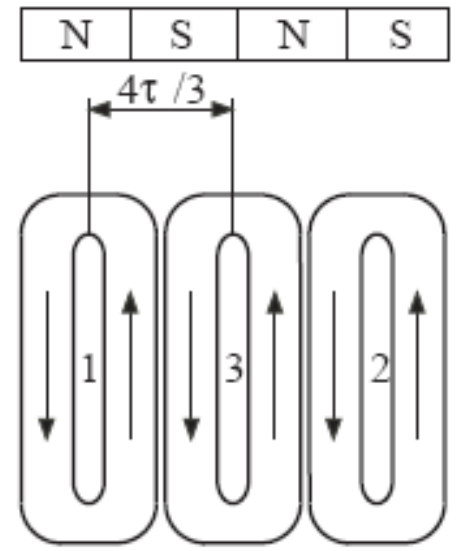

Caso 2 :

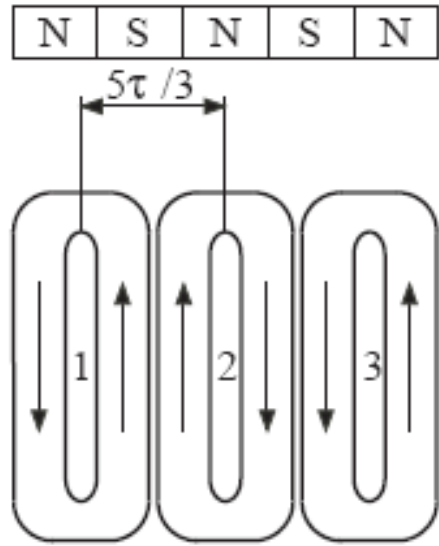

Caso 3:

$120^{\circ}<1_{\text {bob }}<240^{\circ}$

Figura B.5. Configurações possíveis do enrolamento concêntrico no estator sem ranhuras (CHEVAILLER, 2006). 


\section{Apêndice C - Obtenção do Fluxo Magnético no Entreferro do Motor Sem Ranhuras}

A partir das dimensões apresentadas na figura $47 \mathrm{a}$, as seguintes relações podem ser feitas:

$$
\begin{gathered}
R_{m}=R_{0}+L_{m} \\
R_{i}=R_{0}+L_{m}+g \\
R_{s}=R_{0}+L_{m}+g+L_{w} \\
R_{e}=R_{0}+L_{m}+g+L_{w}+L_{e}
\end{gathered}
$$

O fluxo magnético em um pólo é dado por:

$$
\begin{gathered}
\phi_{g}=\frac{F_{r e m}}{R_{g}+R_{m}}=\frac{1}{\frac{1}{\mu_{0} \cdot 2 \cdot \pi}\left(\frac{g+L_{w}}{\tau_{m} \cdot\left(R_{0}+L_{m}+g+L_{w}\right)}+\frac{L_{m}}{\mu_{r} \cdot \tau_{m} \cdot\left(R_{0}+L_{m}\right)}\right)}= \\
\quad=H_{m} \cdot \mu_{0} \cdot 2 \cdot \pi \frac{L_{m}}{\left(\frac{g+L_{w}}{\tau_{m} \cdot\left(R_{0}+L_{m}+g+L_{w}\right)}+\frac{L_{m}}{\mu_{r} \cdot \tau_{m} \cdot\left(R_{0}+L_{m}\right)}\right)}
\end{gathered}
$$

Rearranjando-se a equação 56, tem-se:

$$
\phi_{g}=H_{m} \cdot \mu_{0} \cdot \mu_{r} \cdot 2 \cdot \pi \frac{\tau_{m} \cdot L_{m} \cdot\left(R_{0}+L_{m}+g+L_{w}\right) \cdot\left(R_{0}+L_{m}\right)}{\left(g+L_{w}\right) \cdot \mu_{r} \cdot\left(R_{0}+L_{m}\right)+L_{m} \cdot\left(R_{0}+L_{m}+g+L_{w}\right)}
$$

Substituindo-se as equações 52, 53, 54 e 55 na 57, obtém-se a equação 15 que é mostrada na subseção 4.7.1.1. 


\section{Apêndice D - Funções de Transferência do Controle Elétrico}

As funções de transferência da parte elétrica e mecânica podem ser obtidas aplicando-se a transformada de Laplace nas equações da modelagem dinâmica, 33 e 37 , respectivamente, resultando-se as equações 58 e 59.

$$
\begin{gathered}
G_{e l}(s)=\frac{1}{(L-M) \cdot s+R} \\
G_{\text {mec }}(s)=\frac{1}{M_{L} \cdot s+D}
\end{gathered}
$$

O diagrama de bloco com o controle de tensão por PWM é apresentado a seguir. Este tipo de controle causa uma menor oscilação (para uma dada frequência) na corrente e tem uma resposta mais lenta quando comparado com o controle de tensão por histerese (KRISHNAN, 2001).

\section{D.1. Controle de Tensão por PWM}

Neste tipo de controle, o dispositivo de potência é ligado e desligado em uma frequência fixa $f_{s}$. Durante o tempo ligado $t_{o n}$, a tensão aplicada na carga é $V_{c c}$ e durante o tempo desligado $t_{o f f}$, a tensão é zero. O controle de tensão é feito pelo ajuste do fator de serviço $d$ (duty cycle), que é expresso pela equação 60 .

$$
d=\frac{t_{o n}}{T s}=\frac{t_{o n}}{t_{o n}+t_{o f f}}
$$

Se a tensão for fixa, a tensão média $\left(V_{m}\right)$ aplicada na carga é: 


$$
V_{m}=d \cdot V_{c c}
$$

A figura D.1 mostra o diagrama de blocos para o controle de tensão por PWM, sendo $G_{x}$ o bloco de controle de posição, $G_{v}$ o de velocidade e $H_{c}$ o ganho do sensor de corrente.

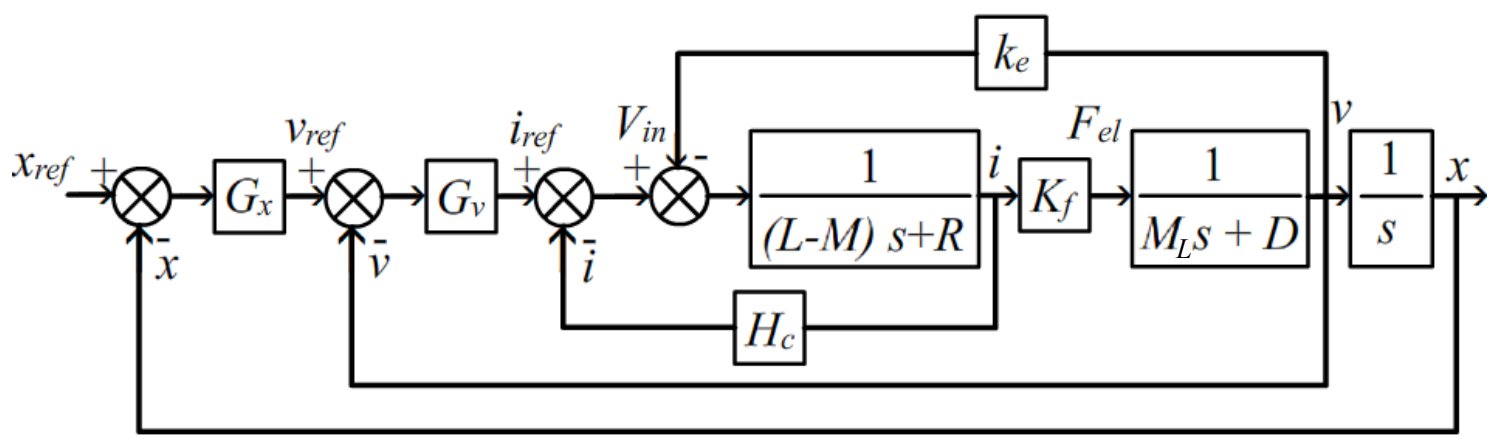

Figura D. 1. Diagrama de blocos do controle de tensão do MLST.

Devido à resistência elétrica ser muito maior do que a indutância, o termo $(R+S(L-M))$ pode ser simplificado a $(R)$, resultando o diagrama mostrado na figura D.2.

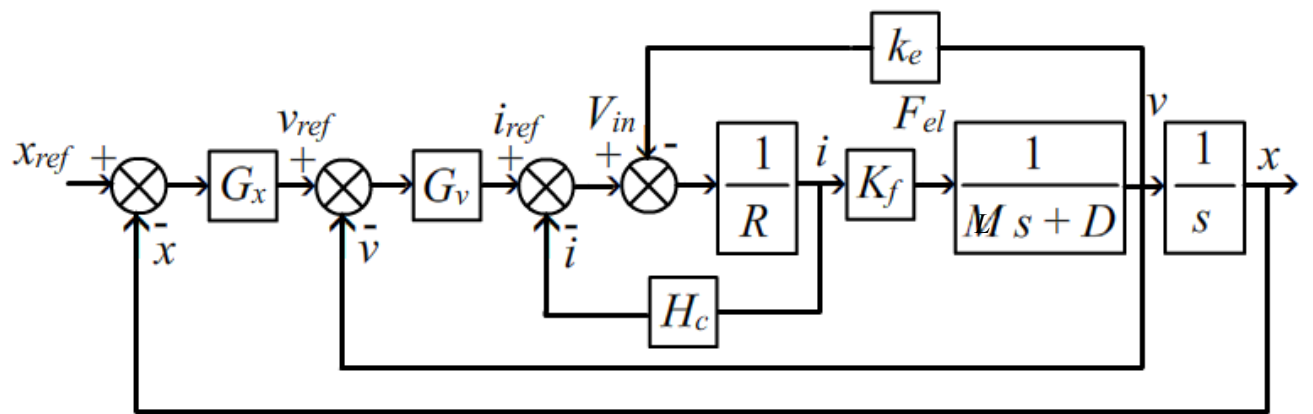

Figura D. 2. Diagrama de blocos do controle de tensão do MLST, simplificando-se a equação elétrica.

Realizando-se as simplificações dos blocos, obtém-se a malha de velocidade.

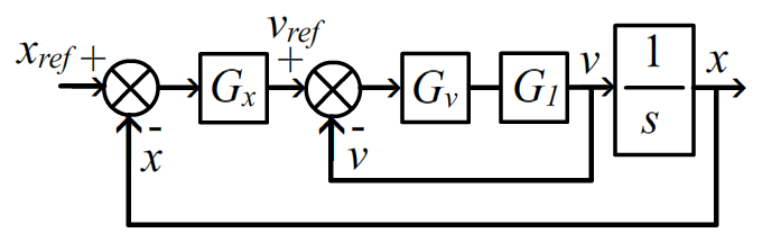

Figura D. 3. Diagrama de blocos simplificado da malha de velocidade.

Onde:

$$
G_{1}(s)=\frac{s \cdot K_{f} \cdot T_{m}+K_{f}}{s^{2} \cdot N_{1}+s \cdot N_{2}+N_{3}}
$$


Sendo:

$$
\begin{gathered}
K_{m}=\frac{1}{D} \\
T_{m}=\frac{M_{L}}{D} \\
N_{1}=T_{m} \cdot R \cdot M_{L}+H_{c} \cdot T_{m} \cdot M_{L} \\
N_{2}=M_{L} \cdot H_{c}+M_{L} \cdot R+M_{L} \cdot K_{f} \cdot K_{m} \cdot k_{e}+D \cdot T_{m} \cdot R+D \cdot H_{c} \cdot T_{m} \\
N_{3}=D \cdot H_{c}+D \cdot R+D \cdot K_{f} \cdot K_{m} \cdot k_{e}
\end{gathered}
$$

Utilizando-se o controlador proporcional e integral para corrigir a velocidade (equação 68), a malha de posição é obtida (figura D.4).

$$
G_{v}(s)=\frac{K_{p v} s+K_{i n t v}}{s}
$$

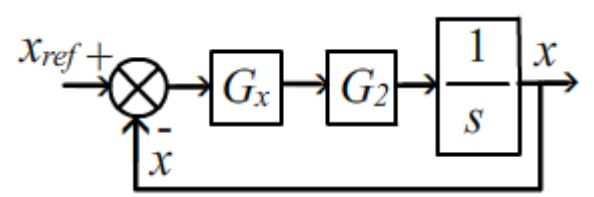

Figura D. 4. Diagrama de blocos simplificado da malha de posição.

Onde:

$G_{2}(s)$

$$
\begin{gathered}
=\frac{\left(K_{f} \cdot T_{m} \cdot K_{p}\right) \cdot s^{2}+\left(K_{f} \cdot K_{p}+K_{i n t} \cdot K_{f} \cdot T_{m}\right) \cdot s+K_{f} \cdot K_{\text {int }}}{s^{3} \cdot N_{1}+s^{2} \cdot\left(N_{2}+K_{f} \cdot T_{m} \cdot K_{p}\right)+s \cdot\left(N_{3}+K_{f} \cdot K_{p}+K_{\text {int }} \cdot K_{f} \cdot T_{m}\right)+K_{f} \cdot K_{\text {int }}} \\
G_{x}(s)=\frac{K_{d x} s^{2}+K_{p x} s+K_{\text {intx }}}{s}
\end{gathered}
$$

Por meio das equações desenvolvidas nesta subseção e de ferramentas computacionais do programa Matlab $^{\circledR}$, como a control system toolbox (MathWorks,2010), obteve-se os seguintes valores dos compensadores para a simulação dinâmica do motor linear: $K_{p v}=1, K_{\text {intv }}=2, K_{d x}=1,5, K_{p x}=3$ e $K_{\text {intx }}=3$. 


\section{Apêndice E - Dimensões do Motor}

As dimensões, em mm, do motor elétrico linear, no modelo de $180^{\circ}$, do projeto inicial e do motor construído são mostradas nas figuras E.1 e E.2, respectivamente.

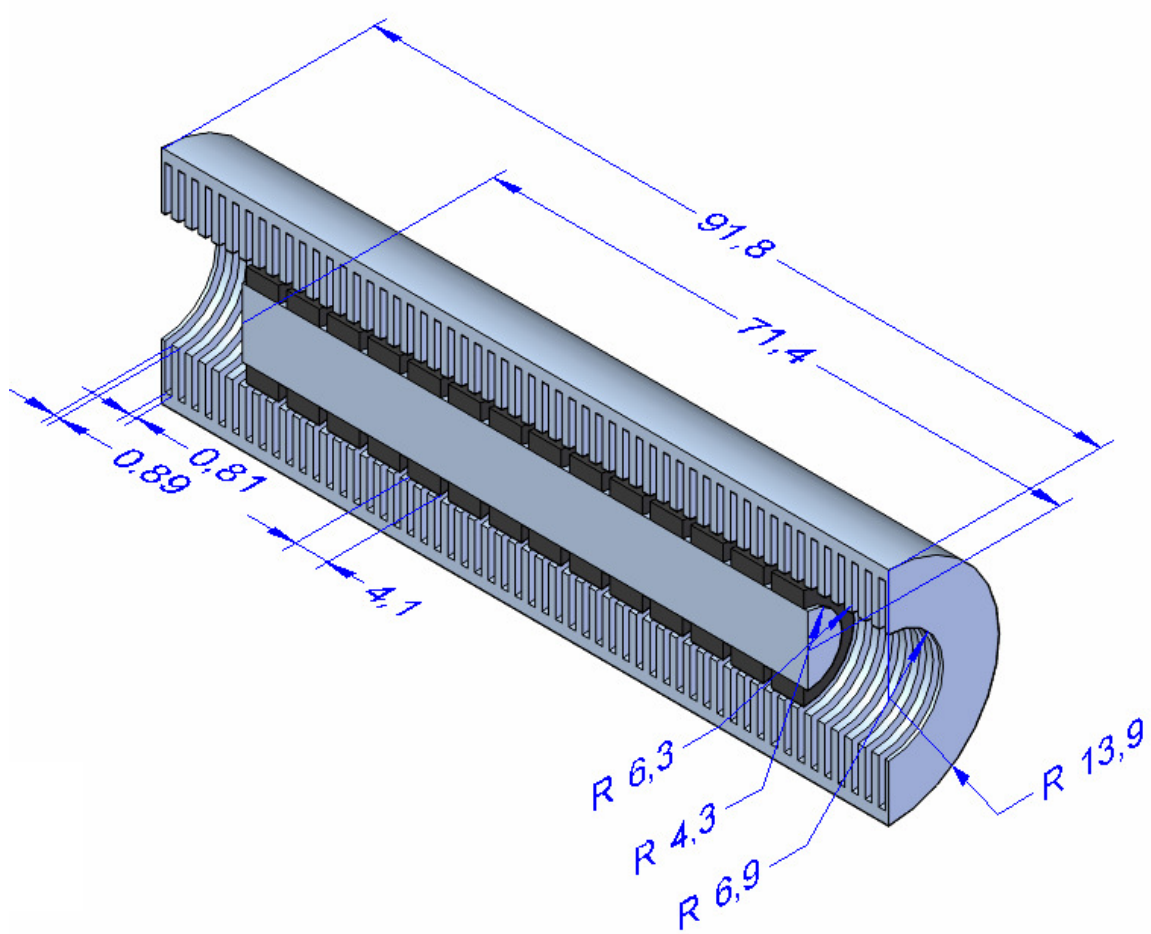

Figura E. 1. Dimensões, em mm, do motor elétrico linear projetado inicialmente, no modelo de $180^{\circ}$.

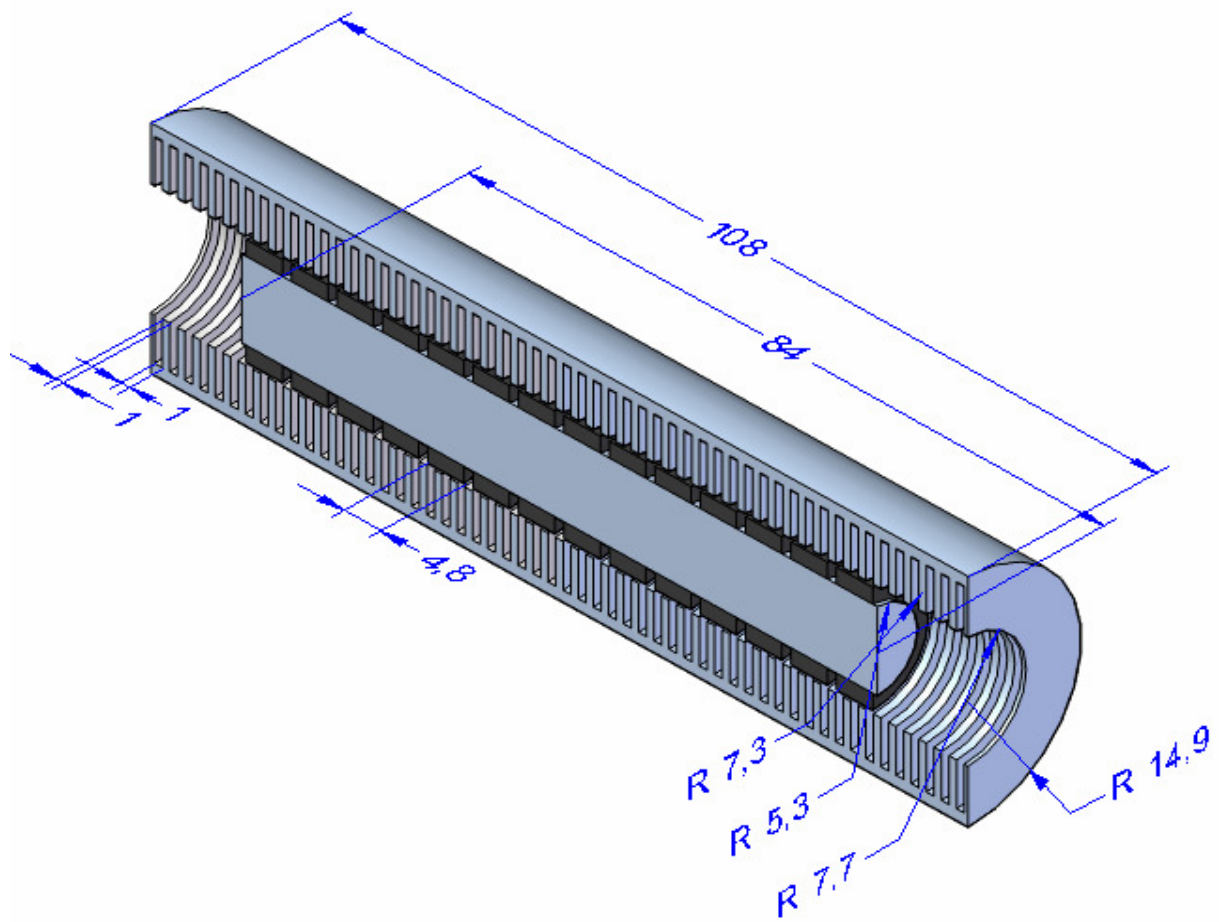

Figura E. 2. Dimensões, em mm, do motor elétrico linear construído, no modelo de $180^{\circ}$.

O projeto final do motor é detalhado a seguir. 


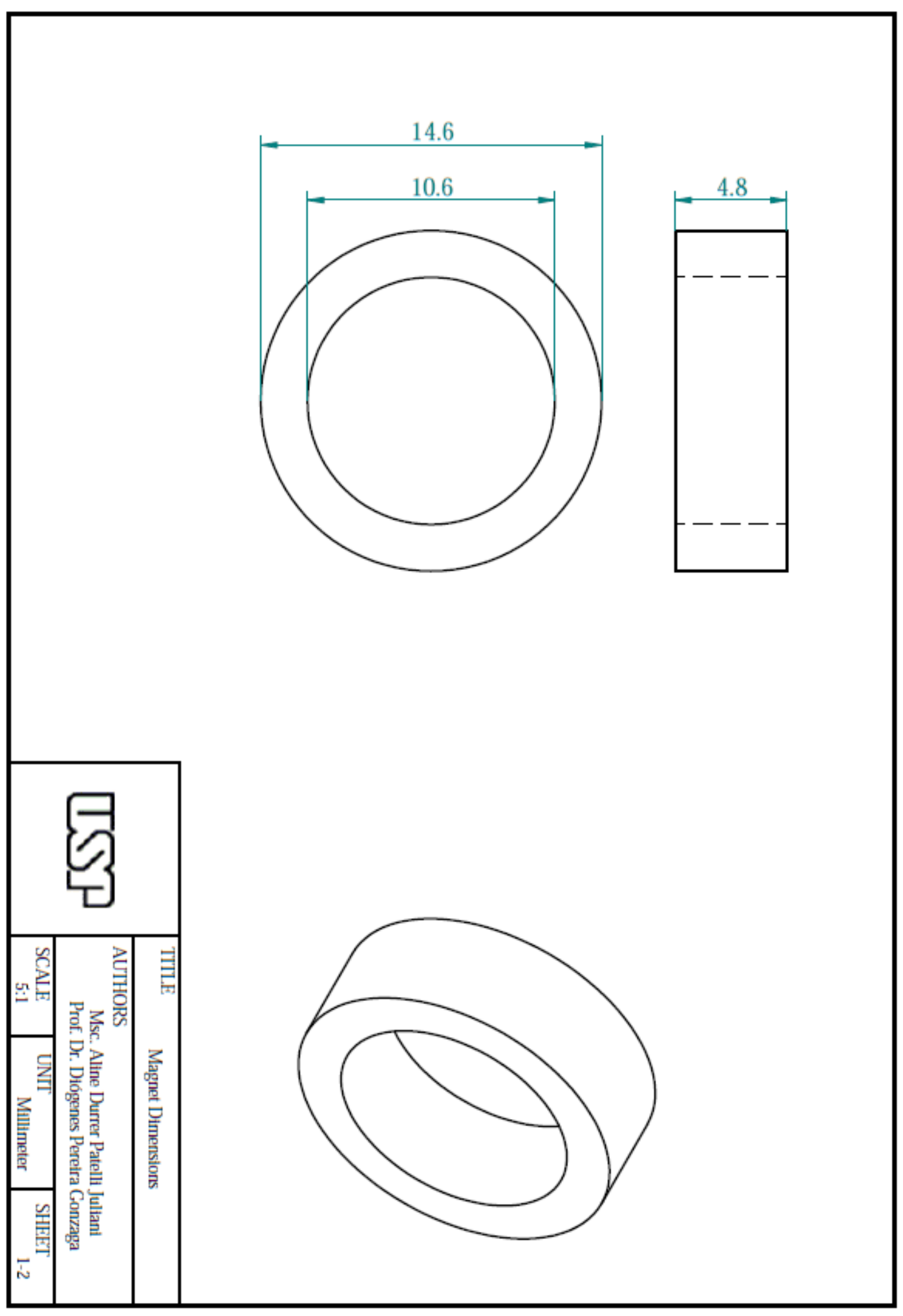



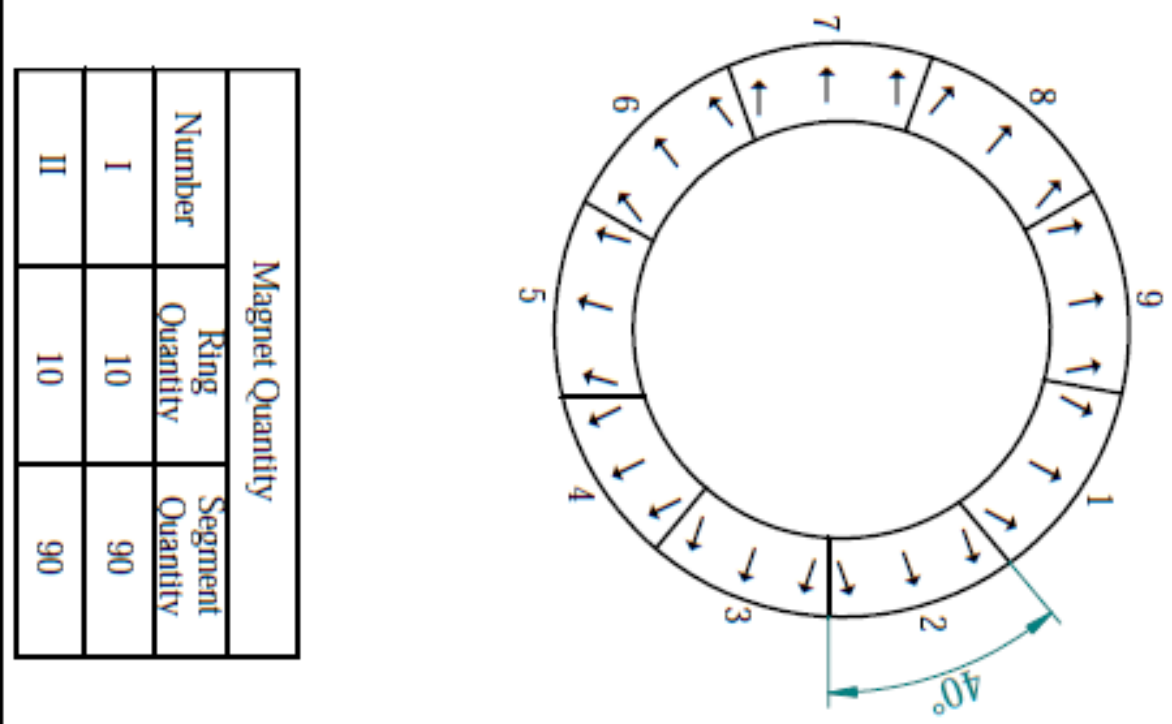

(1)

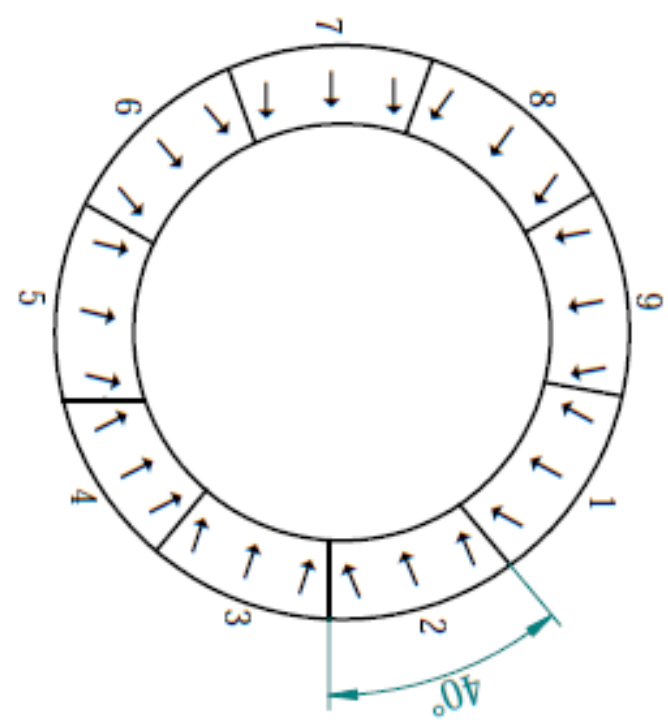

(日)

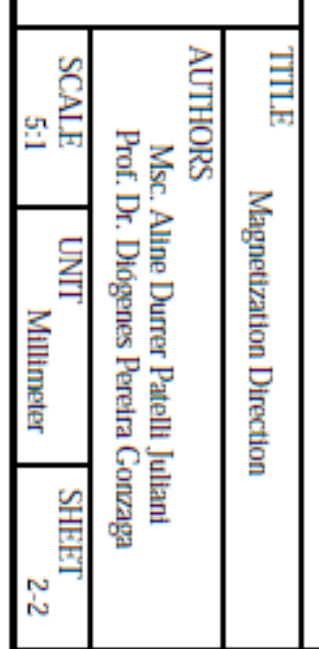




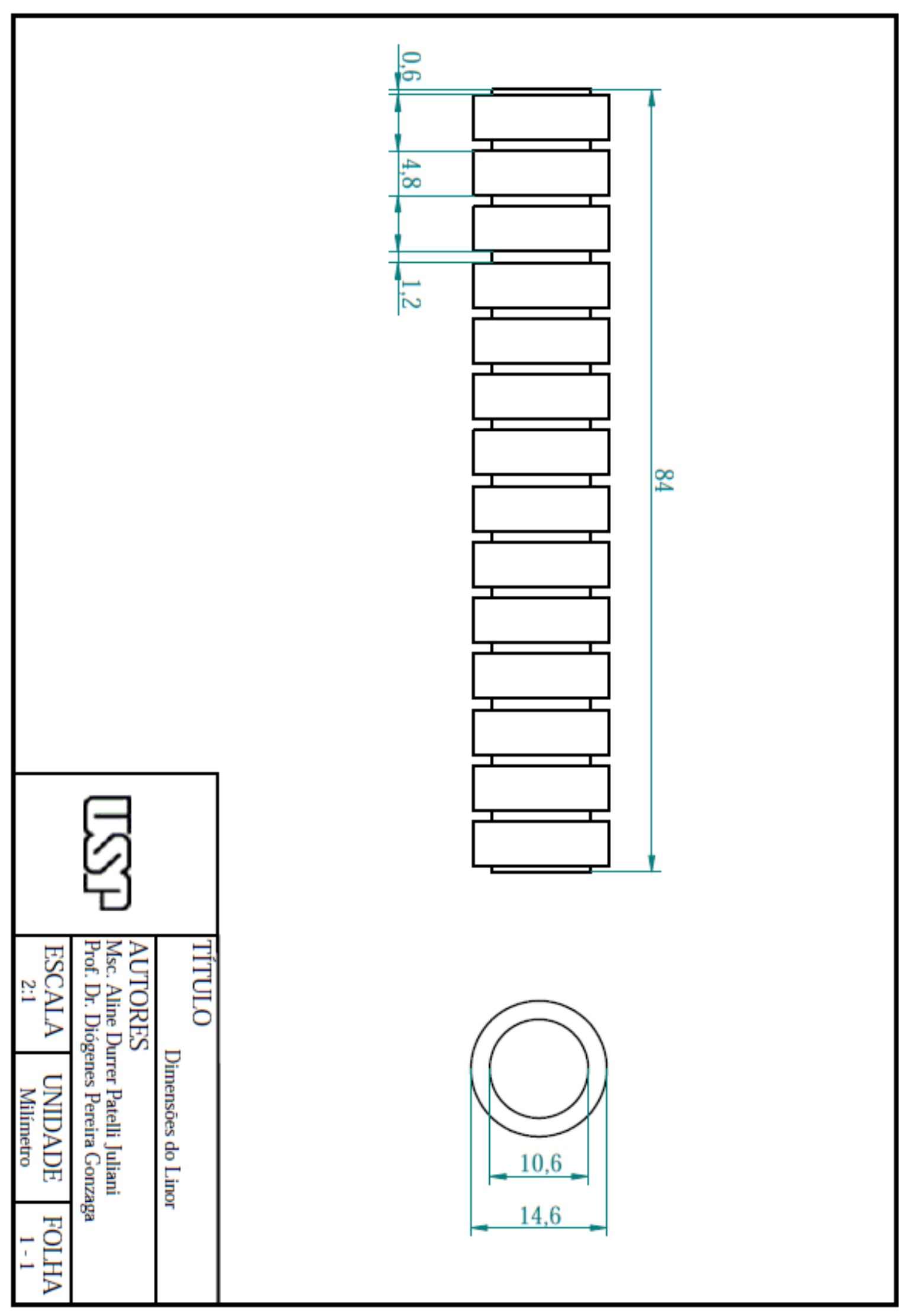




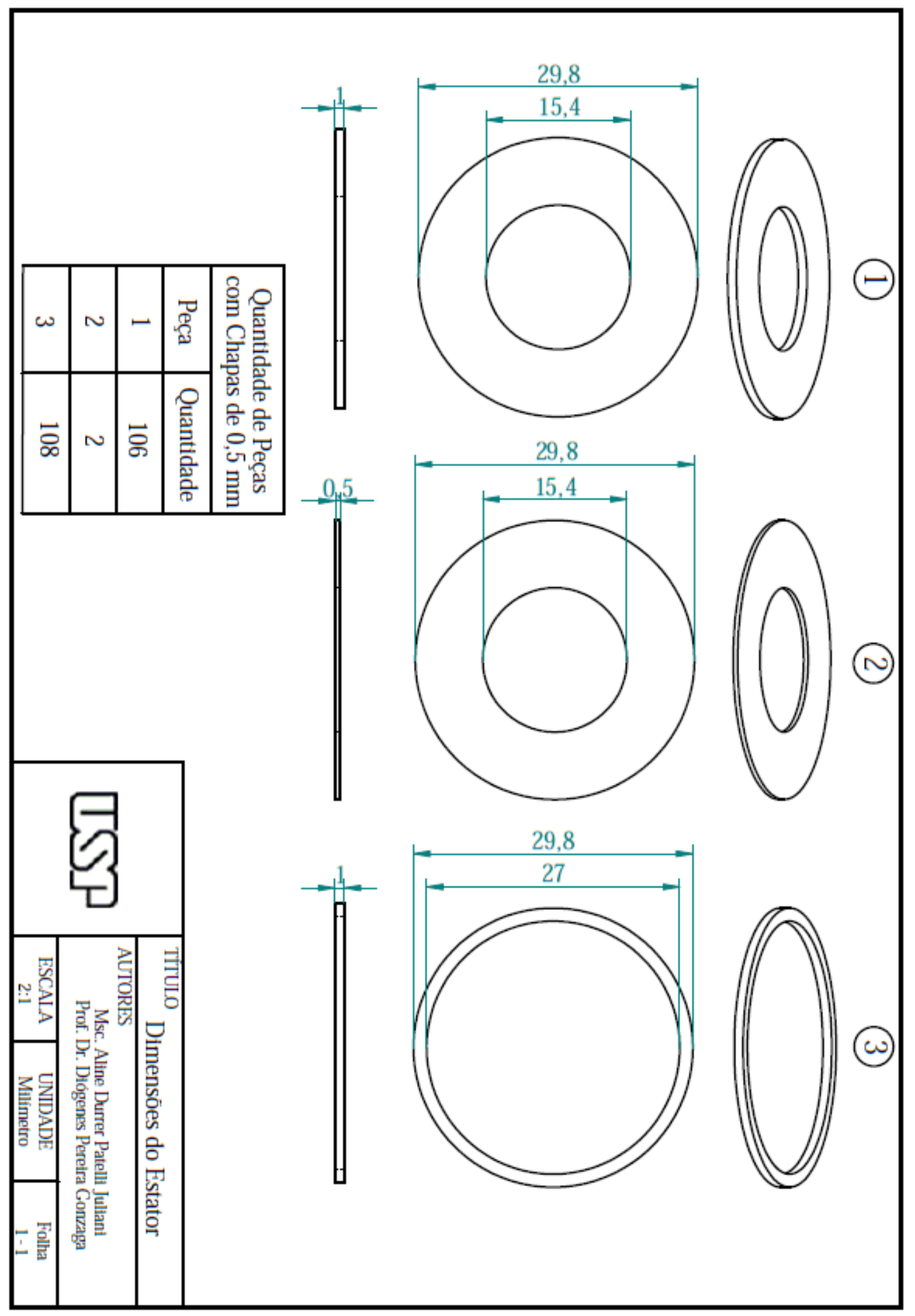

